Response Amplification of Idealized Powerhouse Substructures to Earthquake Ground Motions

Robert M. Ebeling, Elvin J. Pérez-Marcial, June 2006 and Donald E. Yule

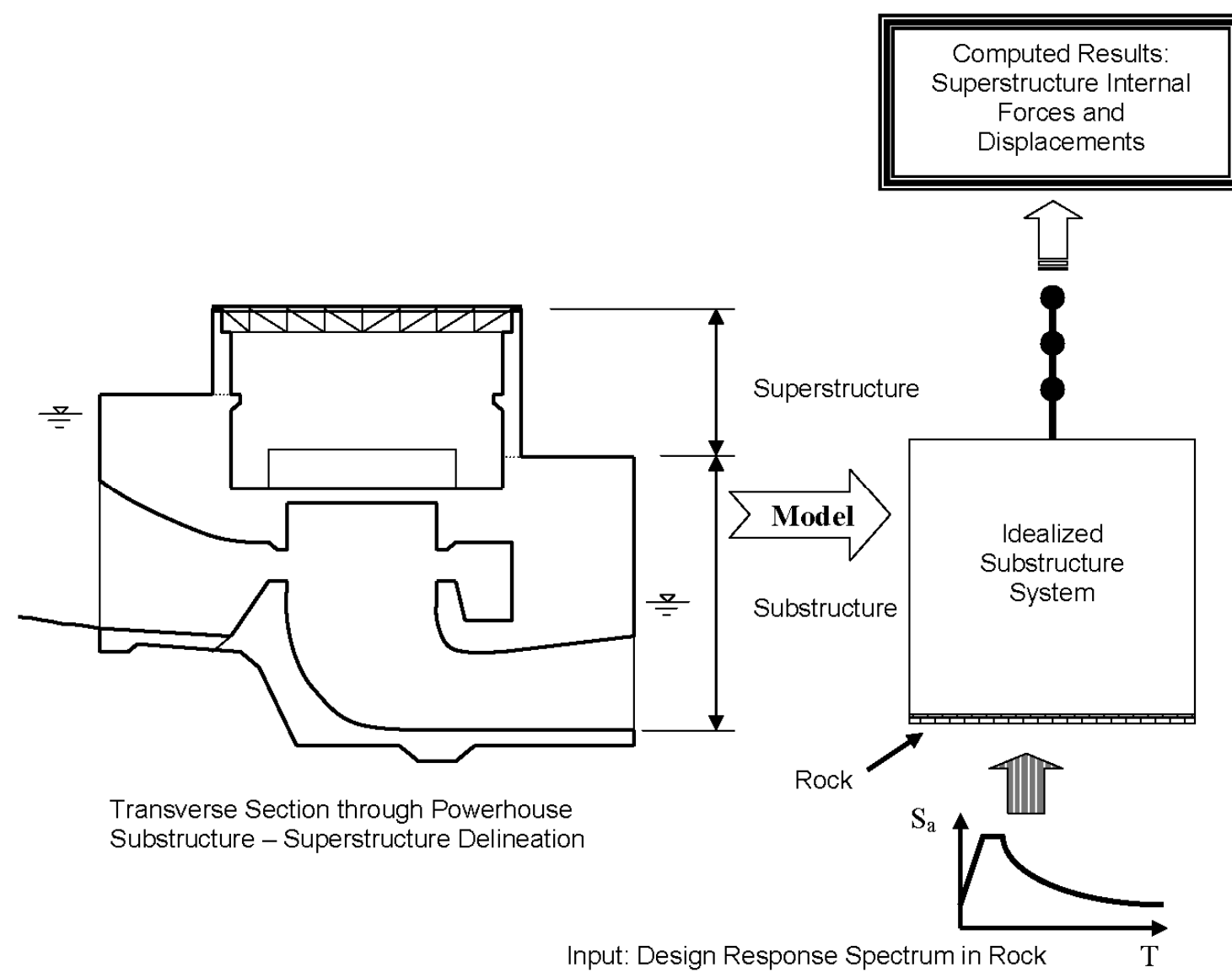


ERDC TR-06-3

June 2006

\title{
Response Amplification of Idealized Powerhouse Substructures to Earthquake Ground Motions
}

\author{
Robert M. Ebeling \\ Information Technology Laboratory \\ U.S. Army Engineer Research and Development Center \\ 3909 Halls Ferry Road \\ Vicksburg, MS 39180-6199 \\ Elvin J. Pérez-Marcial \\ CMA Architects and Engineers, LLP \\ 1509 F.D. Roosevelt Avenue \\ Guaynabo, Puerto Rico 00968 \\ Donald E. Yule \\ Geotechnical and Structures Laboratory \\ U.S. Army Engineer Research and Development Center \\ 3909 Halls Ferry Road \\ Vicksburg, MS 39180-6199
}

Final report

Approved for public release; distribution is unlimited 


\begin{abstract}
This report summarizes an investigation of the seismic response of Corps powerhouse structures. Research results include (1) the characterization and organization of the range in geometry of Corps powerhouse substructures for generator bays and service/erection bays; (2) development of representative, idealized substructure geometries for these types of structures; (3) construction of a series of finite element models of the substructures and subjecting these substructures to earthquake acceleration time-histories representing central/eastern United States ground motions and ground motions of the Pacific Northwest of the United States; (4) development of a database of first-mode periods of the typical powerhouse substructures; (5) computation of top-of-substructure acceleration time-histories and conversion of these time-histories into response spectra; (6) development of amplification factor curves (as a function of frequency) that quantify the magnitude of the amplification of ground shaking by the substructures; (7) development of a methodology for performing a simplified seismic analysis of the superstructure (or of the equipment on top of the substructure) that takes into account, in an approximate sense, the effect of the substructure on the response of the superstructures in the decoupled seismic structural analysis.
\end{abstract}

DISCLAIMER: The contents of this report are not to be used for advertising, publication, or promotional purposes. Citation of trade names does not constitute an official endorsement or approval of the use of such commercial products. All product names and trademarks cited are the property of their respective owners. The findings of this report are not to be construed as an official Department of the Army position unless so designated by other authorized documents. 


\section{Contents}

Conversion Factors, Non-SI to SI Units of Measurement............................... xvii

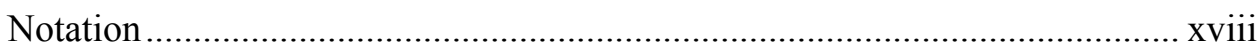

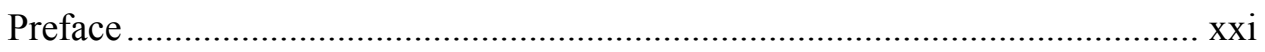

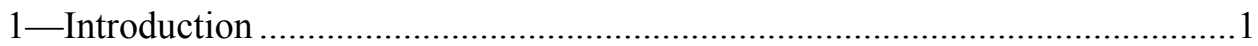

1.1. Background to Powerhouse Substructure Seismic Amplification Study.....

1.1.1 Complete dynamic analysis .................................................... 1

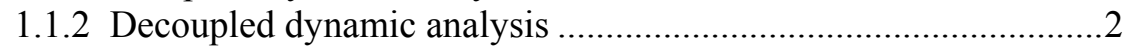

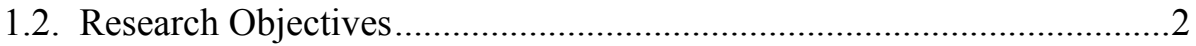

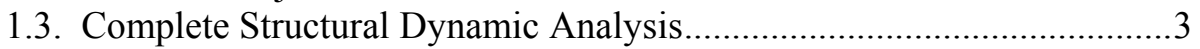

1.4. Decoupled Structural Dynamic Analysis...................................................3

1.5. Evaluating Nonlinear Behavior of Powerhouse Superstructures by Coupled or Decoupled Response Spectrum Analysis............................8

1.6. Time-History Modal Response Analysis ...............................................8

1.7. Monoliths Analyzed (Generator and Erection/Service Bay

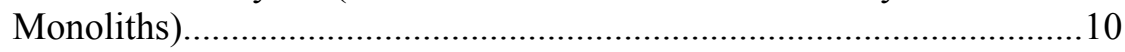

1.8. Idealized Two-Dimensional Finite Element Models ..............................11

1.9. Report Content ................................................................................ 16

2-Development of Earthquake Time-Histories ............................................... 17

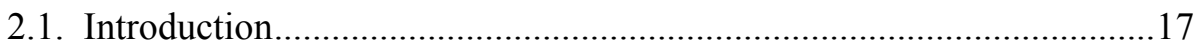

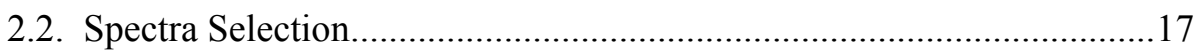

2.2.1 Pacific Northwest site ..................................................... 18

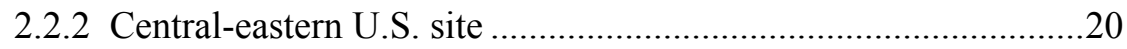

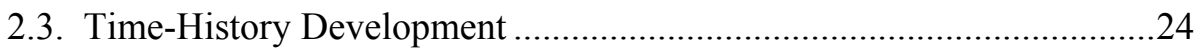

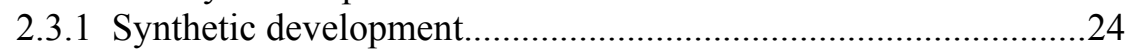

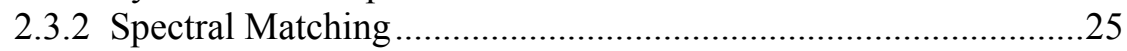

3-Time-History Finite Element Results for the Generator Bay Monoliths.........30

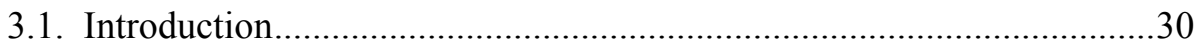

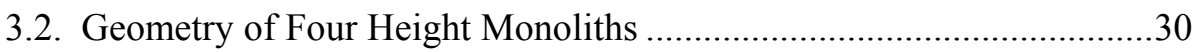

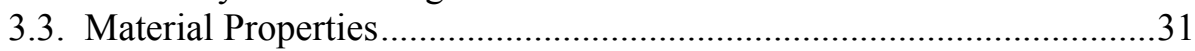

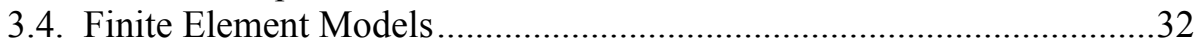

3.5. Undamped Natural Frequencies and Modal Mass Participation

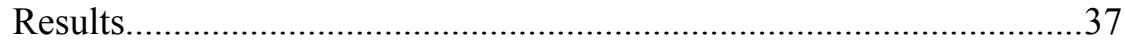

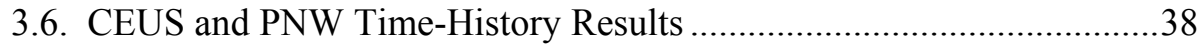


3.7. Response Amplification Sensitivity to Location along the Top of the Substructure for the Generator Bay Composite Model.

3.8. Response Amplification Sensitivity to Shear Wall Thickness for the Generator Bay Composite Finite Element Models

4-Time-History Finite Element Results for the Erection/Service Bay

Monolith .58

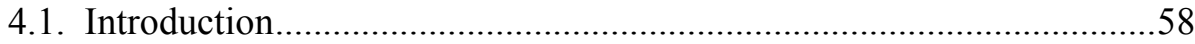

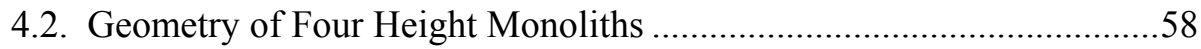

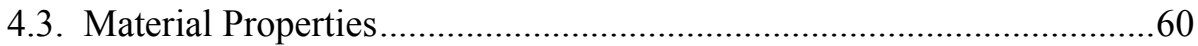

4.4. Finite Elements Models .....................................................................61

4.5. Undamped Natural Frequencies and Modal Mass Participation Results.

4.6. CEUS and PNW Time-History Results for Block Finite Element Models .66

4.6.1 Analysis results .66

4.6.2 Response amplification sensitivity to location at top of the substructure for the erection/service bay block model

4.7. CEUS and PNW Time-History Results for Block-Frame-Shear Wall Finite Element Models ..............................................................82

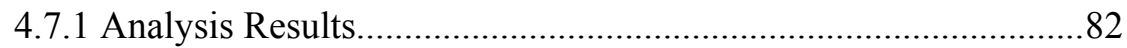

4.7.2 Response amplification sensitivity to shear wall thickness for the erection/service bay block-frame-shear wall finite element models.

4.7.3 Response amplification sensitivity to location at top of the substructure for the erection/service bay block-frame-shear

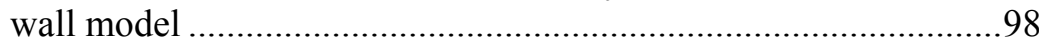

5-Amplification Factors for Response Spectra/Modal Analysis......................102

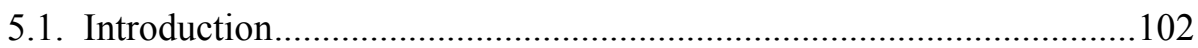

5.2. Computed AF Relationships for Generator Bay Composite Models...103

5.3. Computed AF Relationships for Erection/Service Bay Block Models

5.4. Computed AF Relationships for Erection/Service Bay Block-

Frame-Shear Wall Model. 108

5.5. Comparison Example: Time-History/Modal Response, Response Spectra Analysis, and Decoupled Response Spectra Analysis of an Erection/Service Bay 108

5.6. Demonstration Example: Decoupled Analysis of an Erection/ Service Bay Using NEHRP Maps .......................................................121

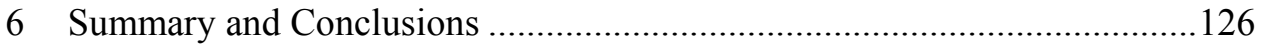

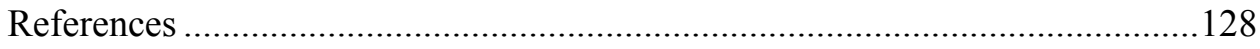

Appendix A: Summary of Generator and Erection/Service Bay Monolith

Geometry

Appendix B: Equivalent Flexural Wall in Generator Bay Idealized

Geometry 
Appendix C: Investigation of Plane Stress and Plane Strain Modal Time-

History Analyses of a Monolith Using SAP2000 Linear Elastic Finite

Elements.

Appendix D: Hydrodynamic Added Mass ……................................................

Appendix E: Absolute Acceleration versus Pseudo-Spectral Acceleration........E1

Appendix F: Amplification Factor Curves for 2 Percent Damping.................... F1

SF 298

\section{List of Figures}

Figure 1-1. Complete dynamic analysis of substructure and superstructure ..................................................................

Figure 1-2. Idealized decoupled dynamic analysis of substructure ................5

Figure 1-3. Development of a response spectrum curve ...............................10

Figure 1-4. Cheatham Powerhouse generator bay cross section ....................12

Figure 1-5. Cheatham Powerhouse plan view at generator area ...................13

Figure 1-6. Cordell Hull Powerhouse erection/service bay cross

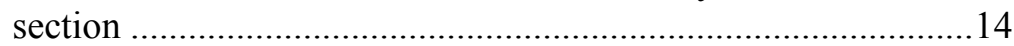

Figure 1-7. The idealized two-dimensional composite finite element model for the generator bay substructure used in this study ......15

Figure 2-1. PNW powerhouse sites and active faults and seismicity

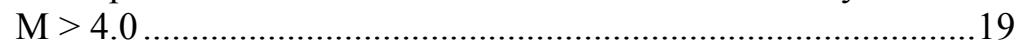

Figure 2-2. CEUS powerhouse sites and seismicity $\mathrm{M}>4.0 \ldots \ldots \ldots \ldots \ldots \ldots \ldots . .20$

Figure 2-3. Northwest powerhouse site equal hazard spectra .......................21

Figure 2-4. Northwest powerhouse site spectral ratios .............................21

Figure 2-5. Bonneville site probabilistic hazard deaggregation for

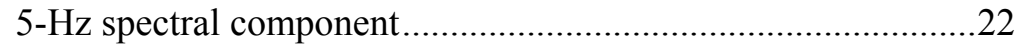

Figure 2-6. CEUS powerhouse site equal hazard spectra ...........................23

Figure 2-7. CEUS powerhouse site spectral ratios.....................................23

Figure 2-8. Greers Ferry site probabilistic hazard deaggregation for 5-Hz spectral component.......................................................24

Figure 2-9. Acceleration time-history for PNW powerhouse Bonneville 1,000-year equal hazard spectra synthetic and spectrally matched.

Figure 2-10. Acceleration time-history for CEUS powerhouse - Greers Ferry 1,000-year equal hazard spectra synthetic and spectrally matched. 
Figure 2-11. Comparison of original, target, and spectral matched spectra for the PNW powerhouse site

Figure 2-12. Comparison of original, target, and spectral matched spectra for CEUS powerhouse site

Figure 3-1. Idealized geometry of generator bay for composite finite element model

Figure 3-2. SAP2000 generator bay composite finite element models 35

Figure 3-3. First mode of vibration for generator bay composite models

Figure 3-4. Response spectra and AF curves, generator bay, composite model, 125-ft height for CEUS ground motion with 5 percent damping

Figure 3-5. Response spectra and AF curves, generator bay, composite model, 100-ft height for CEUS ground motion with 5 percent damping....

Figure 3-6. Response spectra and AF curves, generator bay, composite model, 70-ft height for CEUS ground motion with 5 percent damping

Figure 3-7. Response spectra and AF curves, generator bay, composite model, 40-ft height for CEUS ground motion with 5 percent damping....

Figure 3-8. Response spectra and AF curves, generator bay, composite model, 125-ft height for PNW ground motion with 5 percent damping.

Figure 3-9. Response spectra and AF curves, generator bay, composite model, 100-ft height for PNW ground motion with 5 percent damping.

Figure 3-10. Response spectra and AF curves, generator bay, composite model, 70-ft height for PNW ground motion with 5 percent damping.

Figure 3-11. Response spectra and AF curves, generator bay, composite model, 40-ft height for PNW ground motion with 5 percent damping

Figure 3-12. Location of the three nodes in the 125-ft-height generator bay composite model used to calculate AFs

Figure 3-13. Response spectrum curves for nodes at three different locations along the top-of-substructure of the generator bay 125 -ft-height, composite model, in the wet condition, using 5 percent damping

Figure 3-14. AF curves for nodes at three different locations along the top-of-substructure of the generator bay, 125 -ft-height, composite model in the wet condition, using 5 percent damping 
Figure 3-15. Response spectrum curves at top-of-substructure for three different shear wall thicknesses of the generator bay, 125-ft-height, composite model, in the wet condition, using 5 percent damping

Figure 3-16. AF curves at top-of-substructure for three different shear wall thicknesses of the generator bay, 125-ft-height, composite model, in the wet condition, using 5 percent damping.....

Figure 4-1. Geometry of erection/service bay block finite element model

Figure 4-2. Geometry of an erection/service bay block-frame-shear wall finite element model 59

Figure 4-3. Erection/service bay block finite element models. .62

Figure 4-4. Erection/service bay block-frame-shear wall finite element models

Figure 4-5. First mode of vibration for erection/service bay block models

Figure 4-6. First mode of vibration for erection/service bay blockframe-shear wall models

Figure 4-7. Response spectra and AF curves, erection/service bay, block model, 110-ft height for CEUS ground motion with 5 percent damping.

Figure 4-8. Response spectra and AF curves, erection/service bay, block model, 75-ft height for CEUS ground motion with 5 percent damping.

Figure 4-9. Response spectra and AF curves, erection/service bay, block model, 45-ft height for CEUS ground motion with 5 percent damping.

Figure 4-10. Response spectra and AF curves, erection/service bay, block model, 20-ft height for CEUS ground motion with 5 percent damping

Figure 4-11. Response spectra and AF curves, erection/service bay, block model, 110-ft height for PNW ground motion with 5 percent damping

Figure 4-12. Response spectra and AF curves, erection/service bay, block model, 75-ft height for PNW ground motion with 5 percent damping.

Figure 4-13. Response spectra and AF curves, erection/service bay, block model, 45-ft height for PNW ground motion with 5 percent damping....

Figure 4-14. Response spectra and AF curves, erection/service bay, block model, 20-ft height for PNW ground motion with 5 percent damping. .80 
Figure 4-15. Location of the three nodes in the 110-ft-height erection/ service bay block model used to calculate the AFs

Figure 4-16. Response spectrum curves for nodes at three different locations along the top-of-substructure of the erection bay 110-ft-height block model, in wet condition, using 5 percent damping

Figure 4-17. AF curves for nodes at three different locations along the top-of-substructure of the erection bay, 110-ft-height block model, in wet condition, using 5 percent damping.

Figure 4-18. Response spectra and AF curves, erection/service bay, block-frame-shear wall model, 110-ft height for CEUS ground motion with 5 percent damping ....

Figure 4-19. Response spectra and AF curves, erection/service bay, block-frame-shear wall model, 75-ft height for CEUS ground motion with 5 percent damping ....

Figure 4-20. Response spectra and AF curves, erection/service bay, block-frame-shear wall model, 45-ft height for CEUS ground motion with 5 percent damping ....

Figure 4-21. Response spectra and AF curves, erection/service bay, block-frame-shear wall model, 20-ft height for CEUS ground motion with 5 percent damping ...

Figure 4-22. Response spectra and AF curves, erection/service bay, block-frame-shear wall model, 110-ft height for PNW ground motion with 5 percent damping ....

Figure 4-23. Response spectra and AF curves, erection/service bay, block-frame-shear wall model, 75-ft height for PNW ground motion with 5 percent damping ....

Figure 4-24. Response spectra and AF curves, erection/service bay, block-frame-shear wall model, 45-ft height for PNW ground motion with 5 percent damping

Figure 4-25. Response spectra and AF curves, erection/service bay, block-frame-shear wall model, 20-ft height, for PNW ground motion with 5 percent damping ....

Figure 4-26. Response spectrum curves at top-of-substructure for three different shear wall thicknesses of the erection bay, 110-ft height, block-frame-shear wall model, using 5 percent damping.....

Figure 4-27. AF curves at top-of-substructure for three different shear wall thicknesses of the erection bay, 110-ft height, blockframe-shear wall model, using 5 percent damping

Figure 4-28. Location of nodes in the 110-ft-height erection bay blockframe-shear wall model used in the AF calculations. 99 
Figure 4-29. Response spectrum curves at three different locations along the top-of-substructure of the erection bay, 110-ftheight block-frame-shear wall model, in wet condition, using 5 percent damping

Figure 4-30. AF curves at three different locations along the top-ofsubstructure of the erection bay, 110-ft-height blockframe-shear wall model, in wet condition, using 5 percent damping.....

Figure 5-1. In-rock CEUS and PNW normalized response spectra versus frequency

Figure 5-2. AF versus frequency curves, generator bay, composite model, 125-ft height with 5 percent damping

Figure 5-3. AF versus frequency curves, generator bay, composite model, 100-ft height with 5 percent damping .....

Figure 5-4. AF versus frequency curves, generator bay, composite model, 70-ft height with 5 percent damping 106

Figure 5-5. AF versus frequency curves, generator bay, composite model, 40-ft height with 5 percent damping

Figure 5-6. AF versus frequency curves, erection/service bay, block model, 110-ft height with 5 percent damping ....

Figure 5-7. AF versus frequency curves, erection/service bay, block model, 75-ft height with 5 percent damping

Figure 5-8. AF versus frequency curves, erection/service bay, block model, 45-ft height with 5 percent damping

Figure 5-9. AF versus frequency curves, erection/service bay, block model, 20-ft height with 5 percent damping

Figure 5-10. AF versus frequency curves, erection/service bay, blockframe-shear wall model, 110-ft height with 5 percent damping

Figure 5-11. AF versus frequency curves, erection/service bay, blockframe-shear wall model, 75 -ft height with 5 percent damping

Figure 5-12. AF versus frequency curves, erection/service bay, blockframe-shear wall model, 45 -ft height with 5 percent damping

Figure 5-13. AF versus frequency curves, erection/service bay, blockframe-shear wall model, 20-ft height with 5 percent damping.....

Figure 5-14. SAP2000 complete response spectra and time-history analysis of Cordell Hull erection/service bay cross section for comparison example

Figure 5-15. SAP2000 decoupled analysis of Cordell Hull Powerhouse for comparative example 
Figure 5-16. Frame lumped mass model ..................................................121

Figure 5.17. Frame superstructure for demonstration example ...................122

Figure 5-18. Design rock response spectrum constructed using the NEHRP procedure with PGA anchor from USGS map for demonstration example site

Figure 5-19. Amplified USGS/NEHRP response spectrum at top-ofsubstructure constructed using the 75-ft block model AF curve for the wet condition.

Figure 5-20. SAP2000 frame superstructure lumped mass model

Figure B-1. Three-dimensional view of the idealized composite structural model for generator bay substructure idealization .... B2

Figure B-2. Plan view of the real generator bay channel walls and its conversion to equivalent inertia flexural wall....

Figure D-1. Hydrodynamic added mass distribution on the idealized powerhouse substructure model

Figure D-2. Finite element block model for 110-ft-height erection/ service bay idealization.

Figure E-1. SA and PSA response spectrum curves at top-ofsubstructure for the 110-ft-height block model using the CEUS ground motion for 5 percent damping..... E2

Figure E-2. AF using SA and PSA at top-of-substructure for the 110$\mathrm{ft}$-height block model using the CEUS ground motion E2

Figure F-1. AF curve development for 2 percent damping and its application to equipment analysis

Figure F-2. Response spectra and AF curves, generator bay, composite model, 125-ft height for CEUS ground motion with 2 percent damping....

Figure F-3. Response spectra and AF curves, generator bay, composite model, 100-ft height for CEUS ground motion with 2 percent damping

Figure F-4. Response spectra and AF curves, generator bay, composite model, 70-ft height for CEUS ground motion with 2 percent damping.

Figure F-5. Response spectra and AF curves, generator bay, composite model, 40-ft height for CEUS ground motion with 2 percent damping.

Figure F-6. Response spectra and AF curves, generator bay, composite model, 125-ft height for PNW ground motion with 2 percent damping

Figure F-7. Response spectra and AF curves, generator bay, composite model, 100-ft height for PNW ground motion with 2 percent damping. 
Figure F-8. Response spectra and AF curves, generator bay, composite model, 70-ft height for PNW ground motion with 2 percent damping

Figure F-9. Response spectra and AF curves, generator bay, composite model, 40-ft height for PNW ground motion with 2 percent damping

Figure F-10. Response spectra and AF curves, erection/service bay, block model, 110-ft height for CEUS ground motion with 2 percent damping

Figure F-11. Response spectra and AF curves, erection/service bay, block model, 75-ft height for CEUS ground motion with 2 percent damping

Figure F-12. Response spectra and AF curves, erection/service bay, block model, 45-ft height for CEUS ground motion with 2 percent damping

Figure F-13. Response spectra and AF curves, erection/service bay, block model, 20-ft height for CEUS ground motion with 2 percent damping

Figure F-14. Response spectra and AF curves, erection/service bay, block model, 110-ft height for PNW ground motion with 2 percent damping...

Figure F-15. Response spectra and AF curves, erection/service bay, block model, 75-ft height for PNW ground motion with 2 percent damping

Figure F-16. Response spectra and AF curves, erection/service bay, block model, 45-ft height for PNW ground motion with 2 percent damping.

Figure F-17. Response spectra and AF curves, erection/service bay, block model, 20-ft height for PNW ground motion with 2 percent damping....

Figure F-18. Response spectra and AF curves, erection/service bay, block-frame-shear wall model, 110-ft height for CEUS ground motion with 2 percent damping

Figure F-19. Response spectra and AF curves, erection/service bay, block-frame-shear wall model, 75-ft height for CEUS ground motion with 2 percent damping ....

Figure F-20. Response spectra and AF curves, erection/service bay, block-frame-shear wall model, 45 -ft height for CEUS ground motion with 2 percent damping

Figure F-21. Response spectra and AF curves, erection/service bay, block-frame-shear wall model, 20-ft height for CEUS ground motion with 2 percent damping ..... F25 
Figure F-22. Response spectra and AF curves, erection/service bay, block-frame-shear wall model, 110-ft height for PNW ground motion with 2 percent damping ....

Figure F-23. Response spectra and AF curves, erection/service bay, block-frame-shear wall model, 75-ft height for PNW ground motion with 2 percent damping ....

Figure F-24. Response spectra and AF curves, erection/service bay, block-frame-shear wall model, 45-ft height for PNW ground motion with 2 percent damping ....

Figure F-25. Response spectra and AF curves, erection/service bay, block-frame-shear wall model, 20-ft height for PNW ground motion with 2 percent damping ....

\section{List of Tables}

Table 1-1. Definitions of Earthquake Response Spectrum Terms

Table 2-1. Powerhouse Sites and Probabilistic PGA for Return Periods $500,1,000$, and 2,475 Years

Table 3-1. Dimensions of Generator Bay Section

Table 3-2. Material Properties Used in the Generator Bay Mass

Concrete Substructure

Table 3-3. Geometry of Composite Finite Element Model

Table 3-4. Undamped Natural Frequencies and Modal Mass Participa-

tion Ratio for Generator Bay Composite Models, Dry

Condition

Table 3-5. Undamped Natural Frequencies and Modal Mass Participation Ratio for Generator Bay Composite Models, Wet Condition

Table 3-6. Absolute Acceleration (SA) at Frequency of $50 \mathrm{~Hz}$ for Generator Bay Composite Models, Dry Condition

Table 3-7. Absolute Acceleration (SA) at Frequency of $50 \mathrm{~Hz}$ for Generator Bay Composite Models, Wet Condition

Table 3-8. Maximum AF and Its Corresponding SA for Generator Bay Composite Models, Dry Condition

Table 3-9. Maximum AF and Its Corresponding SA for Generator Bay Composite Models, Wet Condition. .42

Table 3-10. Figure Numbers of Generator Bay Composite Model Results for 5 Percent Damping. 
Table 3-11. SA at $50 \mathrm{~Hz}$ at Three Different Locations along the Top of the 125-ft-Height Composite Substructure Model for the Wet Condition

Table 3-12. Maximum AF and Its Corresponding Frequency at Three Different Locations along the Top of the 125-ft-Height Composite Substructure Model for the Wet Condition 52

Table 3-13. First Mode of Vibration and PMR for Three 125-ft-Height Generator Bay Composite Models .55

Table 3-14. $\quad$ SA at $50 \mathrm{~Hz}$ for the Three Finite Element Models Using the CEUS and PNW Ground Motions .55

Table 3-15. Maximum AF and Its Corresponding Frequency for the Three 125-ft-Height Generator Bay Models 55

Table 4-1. Geometry of Block and Block-Frame-Shear Wall Finite Element Models .60

Table 4-2. Material Properties Used in the Powerhouse Plane-Stress Continua Finite Elements 60

Table 4-3. Material Properties Used in the Frame Elements 60

Table 4-4. Undamped Natural Frequencies and Modal Mass Participation Ratio for Erection/Service Bay Block Models, Dry Condition. 66

Table 4-5. Undamped Natural Frequencies and Modal Mass Participation Ratio for Erection/Service Bay Block Models, Wet Condition.

Table 4-6. Undamped Natural Frequencies and Modal Mass Participation Ratio for Erection/Service Bay Block-Frame-ShearWall Models, Dry Condition.

Table 4-7. Undamped Natural Frequencies and Modal Mass Participation Ratio for Erection/Service Bay Block-FrameShear Wall Models, Wet Condition

Table 4-8. $\quad$ SA at Frequency of $50 \mathrm{~Hz}$ for Erection/Service Bay Block Models, Dry Condition.

Table 4-9. A at Frequency of $50 \mathrm{~Hz}$ for Erection/Service Bay Block Models, Wet Condition ....

Table 4-10. Maximum Amplification Factor $(\mathrm{AF})_{\mathrm{SA}}$ and Its Corresponding SA for Erection/Service Bay Block Models, Dry Condition

Table 4-11. Maximum Amplification Factor (AF) $)_{\mathrm{SA}}$ and Its Corresponding SA for Erection/Service Bay Block Models, Wet Condition

Table 4-12. Figure Numbers of Erection/Service Bay Block Model Results for 5 percent damping. 
Table 4-13. SA at $50 \mathrm{~Hz}$ at Three Different Locations along the Top of the 110-ft-Height Block Substructure Model for the Wet Condition.....

Table 4-14. Maximum AF and Its Corresponding Frequency at Three Different Locations along the Top of the 110-ft-Height Block Substructure Model for the Wet Condition .82

Table 4-15. SA at Frequency of $50 \mathrm{~Hz}$ for Erection/Service Bay BlockFrame-Shear Wall Models, Dry Condition .85

Table 4-16. SA at Frequency of $50 \mathrm{~Hz}$ for Erection/Service Bay BlockFrame-Shear Wall Models, Wet Condition .85

Table 4-17. Maximum AF and Its Corresponding SA for Erection/ Service Bay Block-Frame-Shear Wall Models, Dry Condition .85

Table 4-18. Maximum AF and Its Corresponding SA for Erection/ Service Bay Block-Frame-Shear Wall Models, Wet Condition..... .86

Table 4-19. Figure Numbers of Erection/Service Bay Block-FrameShear Wall Model Results for 5 Percent Damping .86

Table 4-20. First Mode of Vibration and PMR for the 110-ft-Height Erection/ Service Bay Block-Frame-Shear Wall Models .95

Table 4-21. SA at $50 \mathrm{~Hz}$ of the Three Finite Element Models Using the CEUS and PNW Ground Motions

Table 4-22. Maximum AF and Its Corresponding Frequency for the Three 110-ft-Height Erection/Service Bay Models....

Table 4-23. $\quad$ SA at $50 \mathrm{~Hz}$ at Three Different Locations along the Top of the 110-ft-Height Block-Frame-Shear Wall Substructure for the Wet Condition

Table 4-24. Maximum AF and Its Corresponding Frequency at Three Different Locations along the Top of the 110-ft-Height Block-Frame-Shear Wall Substructure for the Wet Condition.

Table 5-1. Material Properties Used in the Comparative Example for the Plane Finite Elements

Table 5-2. Material Properties Used in the Frame Elements 117

Table 5-3. Geometry of Comparative Example SAP2000 Model .............117

Table 5-4. Maximum Displacement at Top of Frame Superstructure .......120

Table 5-5. Shear Forces Within Frame Superstructure for CEUS Earthquake

Table 5-6. Moment Forces Within Frame Superstructure for CEUS Earthquake

Table 5-7. Geometry of the Frame Structural Elements for Demonstration Example. 
Table 5-8. Shear Forces and Moments within Frame from an NEHRP-

Based, Amplified Design Response Spectrum 125

Table A-1. Summary of Heights Considered for Each Generator and Erection/Service Bay Group................................................A1

Table A-2. Powerhouses Sorted by Generator Bay Heights.......................A2

Table A-3. Powerhouses Sorted by Erection/Service Bay Heights .............A3

Table B-1. Summary of Structural Features Dimensions for Generator Bay Substructure Model........................................................ B4

Table C-1. Periods and Frequencies Found for Different Types of Elements for 110-ft-Height Erection/Service Substructure Model $\mathrm{C} 3$

Table C-2. Absolute and Relative Peak Acceleration at Top-ofsubstructure for 110-ft-Height Erection/Service Bay Block Model Using Different Types of Finite Elements for CEUS Ground Motion $\mathrm{C} 4$

Table C-3. Absolute and Relative Peak Acceleration at Top-ofsubstructure for 110-ft-Height Erection/Service Bay Block Model Using Different Types of Finite Elements for PNW Ground Motion

Table D-1. Calculated Hydrodynamic Mass Added to Each Node along the Upstream Pool Face.

Table D-2. Calculated Hydrodynamic Mass Added to Each Node along the Downstream Tailrace Face. .D5

Table D-3. Summary of Hydrodynamic Mass Added to the Idealized Model .D5

Table F-1. List of Figures for Generator Bay Substructure Amplification Factor Curves.

Table F-2. $\quad$ SA at Frequency of $50 \mathrm{~Hz}$ for Generator Bay Composite Models for 2 Percent Damping, Dry Condition F12

Table F-3. $\quad$ SA at Frequency of $50 \mathrm{~Hz}$ for Generator Bay Composite Models for 2 Percent Damping, Wet Condition. F12

Table F-4. List of Figures for Substructure Block Model Amplification Factor Curves

Table F-5. SA at Frequency of $50 \mathrm{~Hz}$ for Generator Bay Composite Models for 2 Percent Damping, Dry Condition

Table F-6. $\quad$ SA at Frequency of $50 \mathrm{~Hz}$ for Generator Bay Composite Models for 2 Percent Damping, Wet Condition

Table F-7. List of Figures for Substructure Block Model Amplification Factor Curves

Table F-8. $\quad$ SA at Frequency of $50 \mathrm{~Hz}$ for Generator Bay Composite Models for 2 Percent Damping, Dry Condition F30 
Table F-9. $\quad$ SA at Frequency of $50 \mathrm{~Hz}$ for Generator Bay Composite Models for 2 Percent Damping, Wet Condition... F30 


\section{Conversion Factors, Non-SI to SI Units of Measure}

Non-SI units of measure used in this report can be converted to SI units as follows:

\begin{tabular}{|l|c|l||}
\hline Multiply & By & To Obtain \\
\hline \hline feet & 0.3048 & meters \\
\hline kips (1,000 lbf) & 4.448222 & kilonewtons \\
\hline kip-feet & $1,355.8180656$ & newton-meters \\
\hline pounds (force) per square inch & 6.894757 & kilopascals \\
\hline pounds (force) -second ${ }^{2}$ foot & 14.593904 & newtons-seconds per meter \\
\hline pounds (mass) & 0.45359237 & kilograms \\
\hline pounds (mass) per cubic foot & 16.01846 & kilograms per cubic meter \\
\hline \hline
\end{tabular}




\title{
Notation
}

\author{
$\mathrm{a}_{\text {ground }}$ Ground acceleration due to an earthquake \\ AF Amplification factor \\ B Plan width; out of plane \\ CEHRP Corps Earthquake Hazards Reduction Program \\ CEUS Powerhouse site in the central-eastern United States \\ StS St. Steven \\ CMD Carters Main Dam \\ RBR Richard B. Russell \\ Brk Barkley \\ GrF Greers Ferry \\ BuS Bull Shoals \\ CSI Computers and Structures, Inc. \\ DCR Displacement to capacity ratio \\ E Elastic modulus \\ $E_{c} \quad$ Modulus of elasticity \\ EHPSA Equal hazard, pseudo-spectral acceleration response spectra \\ $f \quad$ Frequency \\ $f_{c}^{\prime} \quad$ Compressive strength \\ $f_{c a}^{\prime} \quad$ Actual strength of concrete
}


$f_{1} \quad$ Frequency for mode 1

FEMA Federal Emergency Management Agency

H Height

HQUSACE Headquarters, U.S. Army Corps of Engineers

$i \quad$ Mode number

$k \quad$ Stiffness of structure

LDP Linear Dynamic Procedure

$m, m_{c} \quad$ Mass

MDOF Multi-degree-of-freedom

NEHRP National Earthquake Hazards Reduction Program

PE Probability of exceedance

PGA Peak ground acceleration

PMR Participating mass ratio

PNW Powerhouse site in the Pacific Northwest of the United States

BnV Bonneville

JDay John Day

Dal The Dalles

CJ Chief Joseph

McN McNary Dam

PSA Pseudo-spectral acceleration, also called $\mathrm{S}_{\mathrm{A}}$

PSHA Probabilistic seismic hazard analysis

SA Total acceleration (sometimes referred as absolute acceleration and spectral acceleration)

$\mathrm{SA}_{50 \mathrm{~Hz}} \quad$ Total acceleration at a frequency of $50 \mathrm{~Hz}$

SDOF Single-degree-of-freedom

t Thickness 
$T_{1} \quad$ Period for mode 1

2-D Two-dimensional

3-D Three-dimensional

USGS U.S. Geological Survey

$w \quad$ Unit weight of concrete, $\mathrm{pcf}$

W Upstream/downstream width

$\gamma_{c} \quad$ Unit weight

$v$ Poisson's ratio

$\omega \quad$ Natural frequency 


\section{Preface}

The research described in this report was authorized by Headquarters, U.S. Army Corps of Engineers (HQUSACE). This study was conducted under the Corps of Engineers Hazard Reduction Program (CEHRP). Dr. Robert M. Ebeling of the Information Technology Laboratory (ITL), Vicksburg, MS, U.S. Army Engineer Research and Development Center (ERDC), is the Principal Investigator of this research effort.

Research was initiated under the direction of and monitored by Ms. Helen Peterson, U.S. Army Engineer Division, Northwestern, Directorate of Regional Business, Business Technical Division (RBT), former CEHRP Program Manager, and concluded under the direction of Mr. Bruce McCracken, RBT, current CEHRP Program Manager. Headquarters Monitor was Ms. Anjana Chudgar, HQUSACE. This research was jointly conducted and the report prepared by Dr. Robert M. Ebeling, Engineering and Informatic Systems Division, ITL; Elvin J. Pérez-Marcial, CMA Architects and Engineers, LLP, Guaynabo, Puerto Rico (a graduate student at the University of Puerto Rico, Mayaguez, at the time of this study); and Donald E. Yule, Geotechnical and Earthquake Engineering Branch, Geosciences and Structures Division, Geotechnical and Structures Laboratory, ERDC. Dr. Ebeling authored the scope of work for the research effort discussed in this report.

The research was monitored by Dr. Ebeling, under the supervision of Dr. Cary D. Butler, Chief of Engineering and Informatics Systems Division, ITL; David R. Richards, Technical Director, ITL; Dr. Deborah F. Dent, Assistant Director, ITL; and Dr. Jeffery P. Holland, Director, ITL.

COL Richard B. Jenkins was Commander and Executive Director of ERDC. Dr. James R. Houston was Director. 


\section{Introduction}

\subsection{Background to Powerhouse Substructure Seismic Amplification Study}

Powerhouses are hydraulic structures used to generate power. A powerhouse contains numerous types of electrical and mechanical equipment as well as a single bay building system (referred to as the superstructure in this report) used to protect this equipment. The performance of both the equipment resting on top of the substructure and the superstructure during and after seismic shaking is of concern to the U.S. Army Corps of Engineers.

In recent decades technology in the fields of earthquake engineering and structural dynamics has matured into viable methodologies that can be applied in a practical fashion to the seismic evaluation of powerhouse superstructures and their equipment. Regrettably, most of the 79 powerhouses for which the Corps is responsible across the United States were designed and constructed prior to this point in time. Concern regarding the performance of powerhouse superstructures and its contents during earthquakes led the U.S. Army Corps of Engineers under the Corps Earthquake Hazards Reduction Program (CEHRP) ${ }^{1}$ to initiate research leading to the development of simplified procedures for conducting seismic response evaluations of powerhouses and their contents.

\subsubsection{Complete dynamic analysis}

A standard structural dynamics approach to the seismic response evaluation of a structure such as a powerhouse is to (a) develop a detailed finite element model of the powerhouse substructure (i.e., the mass concrete portion identified as the substructure in this report), (b) include in the finite element model the superstructure, and (c) subject this complete model to earthquake shaking. Earthquake shaking is typically represented by either an acceleration time-history or by a response spectrum in the dynamic finite element analysis. An example of a seismic evaluation of a Corps powerhouse substructure and superstructure in a single finite element model (referred to as a complete analysis in this report) is described in Ebeling et al. (2002) for St. Steven Powerhouse. A modification could easily be made to the dynamic finite element model by including key

\footnotetext{
1 Symbols and unusual abbreviations used in this report are listed and defined in the Notation,
} page xviii. 
equipment on top of the substructure in the finite element model in order to predict and evaluate its response to earthquake shaking.

\subsubsection{Decoupled dynamic analysis}

A decoupled seismic analysis may be undertaken if the mass and stiffness of the superstructure and/or equipment are insignificant compared with the mass and stiffness of the substructure; and the presence or absence of the superstructure (and/or equipment) does not alter the dynamic response of the substructure. Experience with the seismic analysis of Corps powerhouses by the senior author of this report indicates that a decoupled structural analysis approach is a viable method of analysis for the Corps powerhouses provided that the response of the substructure is properly taken into account in the simplified analysis. The advantage of a decoupled analysis is that modeling efforts are concentrated on the superstructure with the influence of substructure response accounted for in an approximate manner.

\subsection{Research Objectives}

The purposes of this research are to investigate and characterize the seismic response of a range in idealized Corps powerhouse substructures to earthquake shaking and to develop a simplified method for accounting for the effect of the substructure in a decoupled seismic analysis of the superstructure and/or equipment resting on top of the powerhouse substructure. The following were specific objectives:

- Characterize and organize the range in geometry of Corps powerhouse substructures for generator bays and service/erection bays.

- Develop representative, idealized substructure geometries for each of the two general categories.

- Construct a series of finite element models of the substructures and subject these substructures to earthquake acceleration time-histories representing central/eastern United States ground motions and United States Pacific Northwest ground motions.

- Develop a database of first-mode periods of the typical powerhouse substructures.

- Compute top-of-substructure acceleration time-histories and convert these time-histories into response spectra.

- Develop amplification factor curves (as a function of frequency) that quantify the magnitude of the amplification of ground shaking by the substructures.

- Develop a methodology for performing a simplified seismic analysis of the superstructure (or of the equipment on top of the substructure) that takes into account, in an approximate sense, the effect of the substructure 
on the response of the superstructure in the decoupled seismic structural analysis.

\subsection{Complete Structural Dynamic Analysis}

In order to understand what constitutes a decoupled seismic analysis of the superstructure, a complete dynamic analysis of the substructure and superstructure in a single finite element model will be discussed first. A schematic drawing of a complete dynamic analysis is shown in Figure 1-1. A key feature of this type of analysis is that the substructure and superstructure (and/or equipment) are idealized in a single model. This figure shows a rock response spectrum used as input at the base of the substructure, and the internal forces and displacements are calculated within the superstructure and/or the equipment. The substructure is usually modeled using continua elements and the superstructure (and/or equipment) as multi-degree-of-freedom (MDOF) beam elements and lumped masses. Note that an acceleration time-history may also be used to characterize earthquake shaking in a seismic analysis.

\subsection{Decoupled Structural Dynamic Analysis}

An alternative approach for the dynamic analysis of Corps powerhouse superstructures and/or equipment resting on top of the substructure is a decoupled analysis. A decoupled dynamic analysis of a structural system consists of decoupling the superstructure and/or equipment from the substructure and analyzing each separately. First, the rock ground motion (or response spectra) is transferred using a dynamic analysis from the base of the model to the top of the substructure using a dynamic response model of the substructure (or the results from a dynamic analysis of such a substructure model). In this research a timehistory/modal response analysis is performed on each substructure model and a time-history is calculated at the top of each substructure. The calculated timehistory is converted to a top-of-substructure response spectrum, which is in turn used to analyze the superstructure and/or equipment model. In most analyses the acceleration time-history (or response spectrum) at the top of the substructure is not the same as the rock acceleration time-history (or response spectrum) due to dynamic response effects of the substructure. This top-of-substructure response spectrum is then used as input to the simplified finite element model of the superstructure (or equipment), from which internal structural forces and displacements are computed.

In this research study, a series of time-history/modal analyses of idealized powerhouse substructures was conducted to compute the top-of-substructure acceleration time-history responses. For each top-of-substructure analysis, a corresponding acceleration time-history was computed, as shown in Figure 1-2a. Using the Figure 1-2a top-of-substructure response spectra and the response spectra for rock, an amplification factor curve versus frequency was developed at the top of the substructure, as shown in Figure 1-2b. Using the amplification factor curve times a user-defined rock response spectrum, an "amplified" (top-ofsubstructure) response spectrum would be constructed, as shown in Figure 1-2c. 


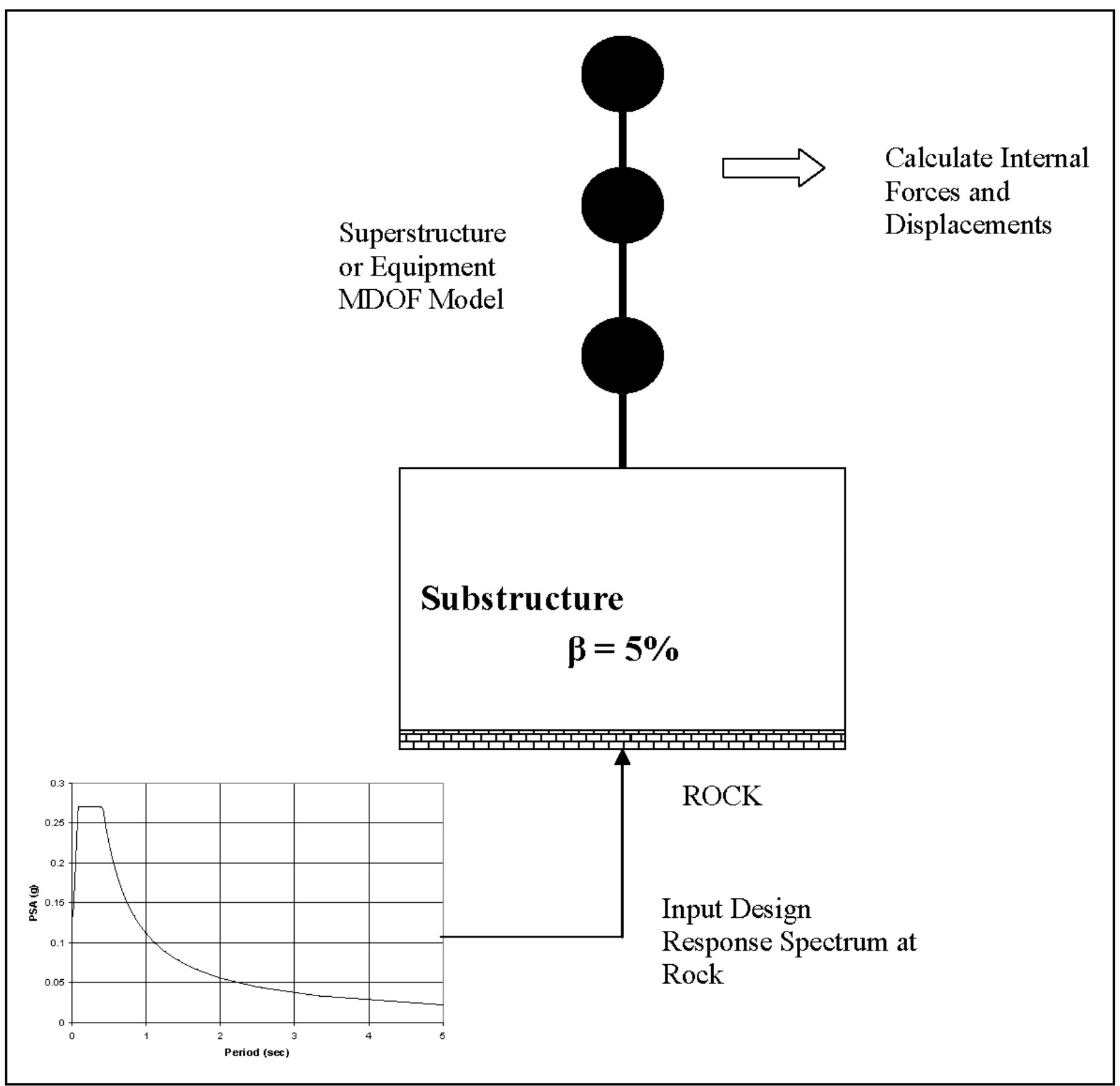

Figure 1-1. Complete dynamic analysis of substructure and superstructure 


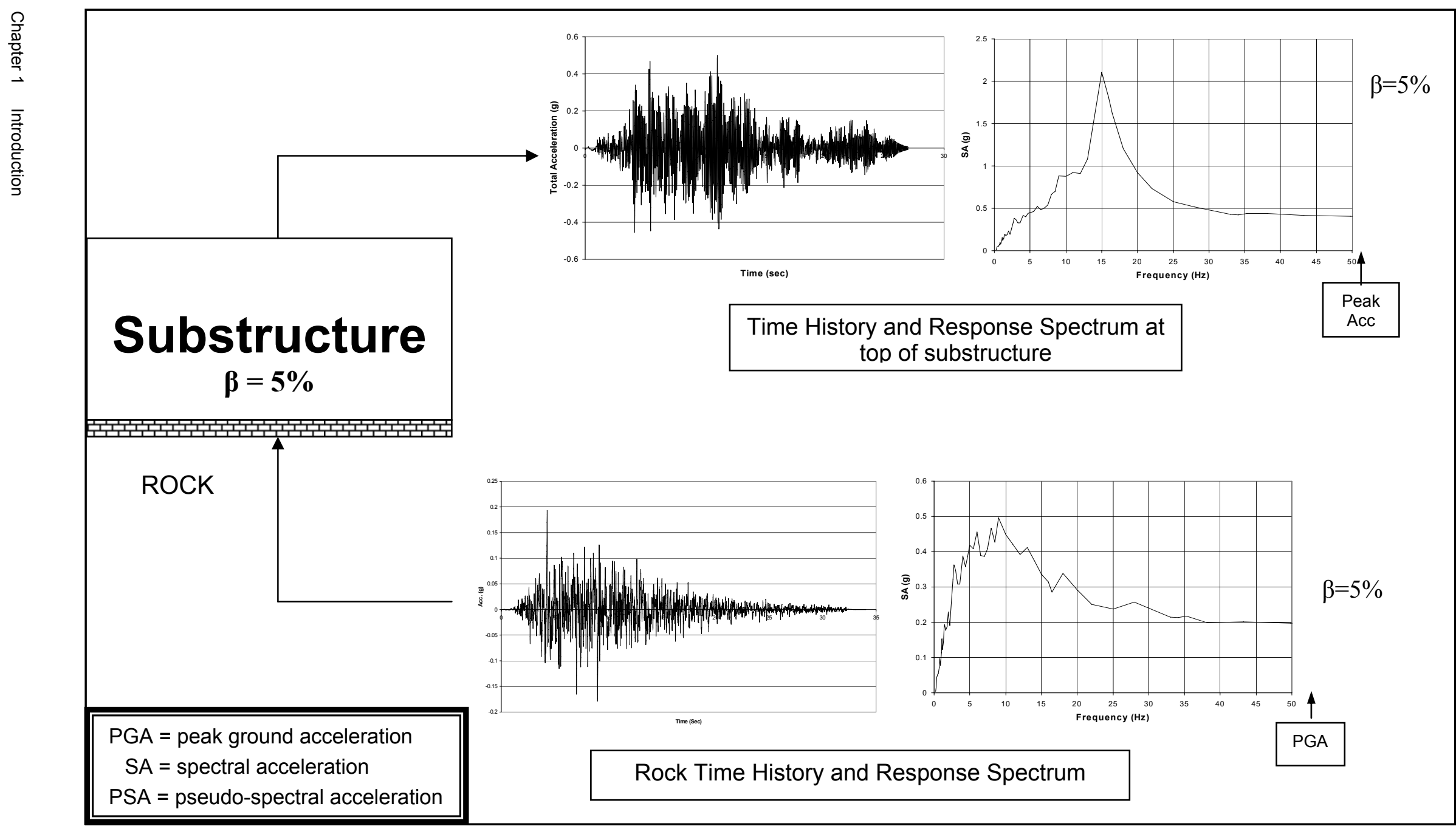

a. Computed top-of-substructure response spectrum

Figure 1-2. Idealized decoupled dynamic analysis of substructure (Sheet 1 of 3 ) 


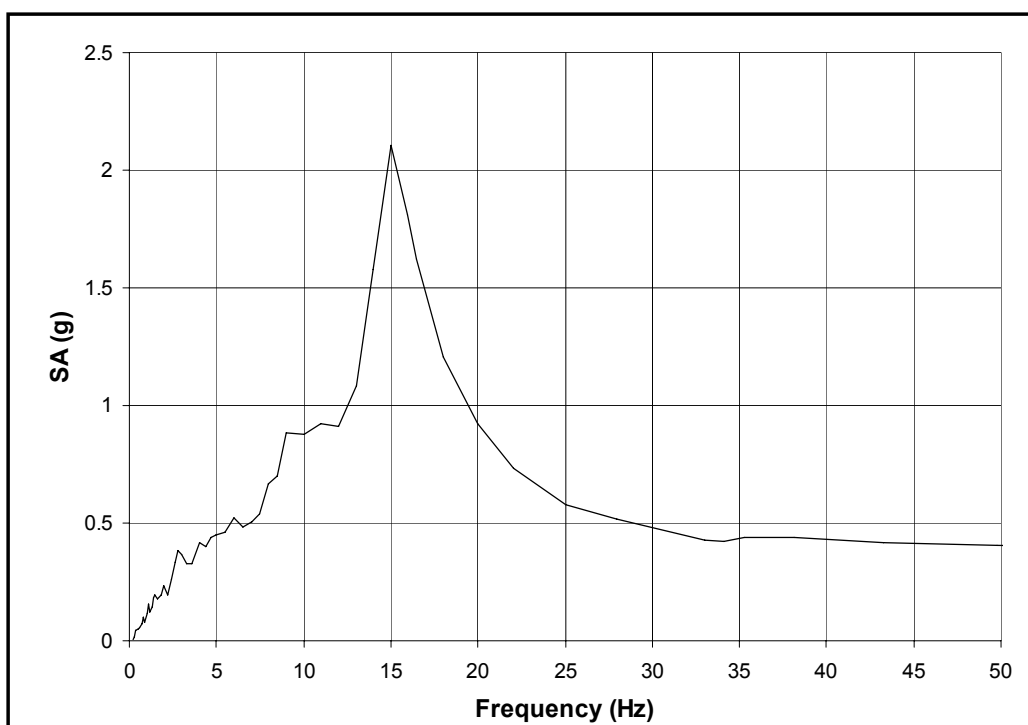

\section{Response Spectrum at top of substructure $\beta=5 \%$}
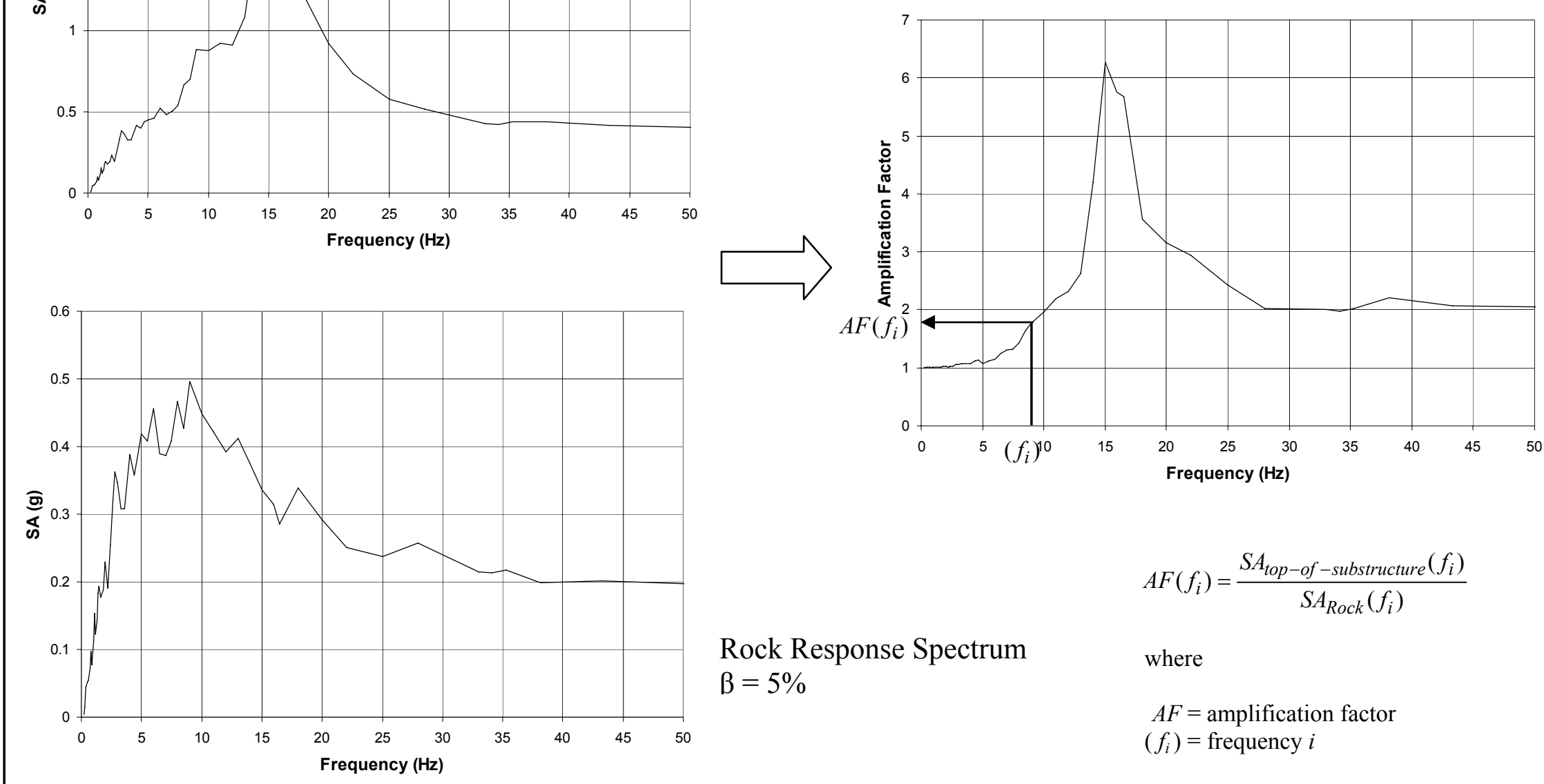

$$
A F\left(f_{i}\right)=\frac{S A_{\text {top-of-substructure }}\left(f_{i}\right)}{S A_{\text {Rock }}\left(f_{i}\right)}
$$

Rock Response Spectrum $\beta=5 \%$ where

$A F=$ amplification factor $\left(f_{i}\right)=$ frequency $i$

b. Construction of amplification factor curve from response spectrum

Figure 1-2. (Sheet 2 of 3 ) 


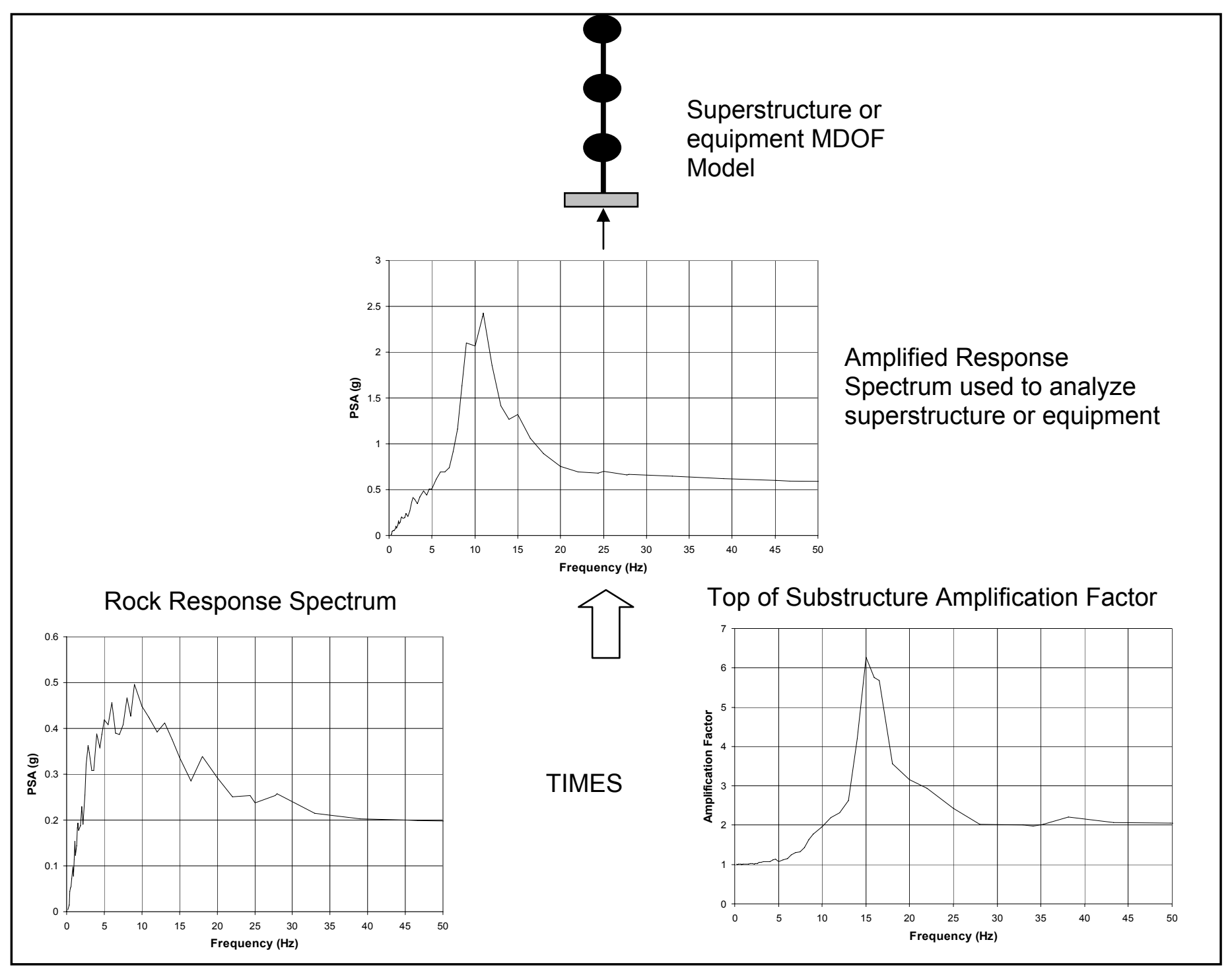

c. Application of amplification factor curve to compute top-of-substructure response spectra

Figure 1-2.(Sheet 3 of 3 ) 
A simplified modal analysis of the superstructure or equipment could then be conducted using this amplified response spectrum. By using this amplified response spectrum as the earthquake demand in the finite element model of the superstructure, the simplified analysis would approximately account for the amplification effects of the substructure during earthquake shaking without the need for directly modeling the substructure in the finite element model.

\subsection{Evaluating Nonlinear Behavior of Powerhouse Superstructures by Coupled or Decoupled Response Spectrum Analysis}

Linear elastic response spectrum analyses using coupled or decoupled analytical models can be used to evaluate the performance of powerhouse superstructures even when their behavior is nonlinear. The performance evaluation process would follow Federal Emergency Management Agency (FEMA) 356 (2000) Linear Dynamic Procedure (LDP) analysis procedures.

In LDP analyses a response spectrum analysis is used to determine the force and displacement demands on powerhouse superstructure elements.

Force-based demand-to-capacity evaluations are made for "brittle" failure modes (i.e., force-controlled actions). Force-controlled actions include shear (diagonal tension), sliding shear, reinforcing steel anchorage, and fracturing of tensile reinforcement. Performance is acceptable if the ratio of force demand to force capacity (DCR) is less than one (i.e., capacity is equal to or greater than demand). It is recognized in the LDP analysis process that capacity may decrease as greater displacement ductility demands are made on structural elements.

An equal displacement response or equal energy response is used to estimate the displacement demands on powerhouse superstructure elements that behave inelastically. Displacement demand (or displacement ductility demand) to capacity ratio (DCR) evaluations are made for "ductile" failure modes (i.e., displacement-controlled actions). Flexure is the displacement-controlled action of interest. Performance is acceptable if the DCRs are less than values deemed acceptable for those performance levels established for the powerhouse superstructure evaluation.

Force and displacement demand to capacity evaluations were conducted as part of the St. Stephen Hydropower Plant seismic evaluation (Ebeling et al. 2002), and as such illustrate the application of an LDP type analysis procedure with respect to performance acceptability.

\subsection{Time-History Modal Response Analysis}

A structural linear dynamic analysis was performed on a series of idealized powerhouse substructures. The earthquake loads were represented by acceleration time-histories at rock as will be explained in Chapter 2 of this report. A 
time-history modal response analysis consists of solving the equation of motion (1-1) using numerical methods:

$$
M \ddot{u}(t)+C \dot{u}(t)+K u(t)=-M \ddot{X}_{g}(t)
$$

In Equation 1-1, $M, C$, and $K$ represent the mass, damping, and stiffness matrices, respectively, of an MDOF system model. For these dynamic analyses, a simplified procedure is used to account for the effect of the upstream and downstream pool of water in the dynamic analyses; Westergaard's hydrodynamic water mass is added to the structure mass in the mass matrix $M$. In Equation 1-1, $\ddot{u}(t), \dot{u}(t)$, and $u(t)$ represent the relative acceleration, velocity, and displacement vectors, respectively (Headquarters, U.S. Army Corps of Engineers (HQUSACE) 2003). The earthquake ground motion acceleration is represented in Equation $1-1$ by the vector $\ddot{X}_{g}(t)$.

The equation of motion described in the previous paragraph uses step-by-step integration solution in the time domain. An alternative approach found in technical literature is to use the frequency domain procedure.

A time-history of acceleration contains acceleration values at regular, small, discrete intervals in time. In many instances, the maximum acceleration is used to quantify the level of dynamic response. A graph that presents the maximum acceleration for different structural periods (or frequencies) is referred to as a response spectrum (refer to Ebeling 1992). Figure 1-3 summarizes the procedure for the development of a response spectrum curve. A response spectrum curve is developed assuming the damping value of a structure. If total time-history acceleration is used, the acceleration in the response spectrum curve is referred to as total acceleration (SA) (sometimes referred as absolute acceleration (Ebeling 1992) and spectral acceleration (Chopra 1995)). When relative time-history acceleration is used, the response spectrum acceleration is called pseudo-spectral acceleration (PSA) or $\mathrm{S}_{\mathrm{A}}$. Table 1-1 lists the relationship between pseudo-spectral values and total values. The difference between PSA and SA is that the SA values take into account the damping characteristic of the structure, while PSA values do not. Chopra (1995) has shown that the difference between these two values is small for short-period systems and significant only in long-period structures with high damping values.

The dynamic analysis computations summarized in this report were made using the structural analysis software SAP2000 (Computers and Structures, Inc. (CSI), 1997). SAP2000 uses the mode superposition method to solve the dynamic equilibrium equation of motion. For linear transient analysis, the software assumes a linear variation of the time function and the response is computed by closed form integration of the modal equation. 


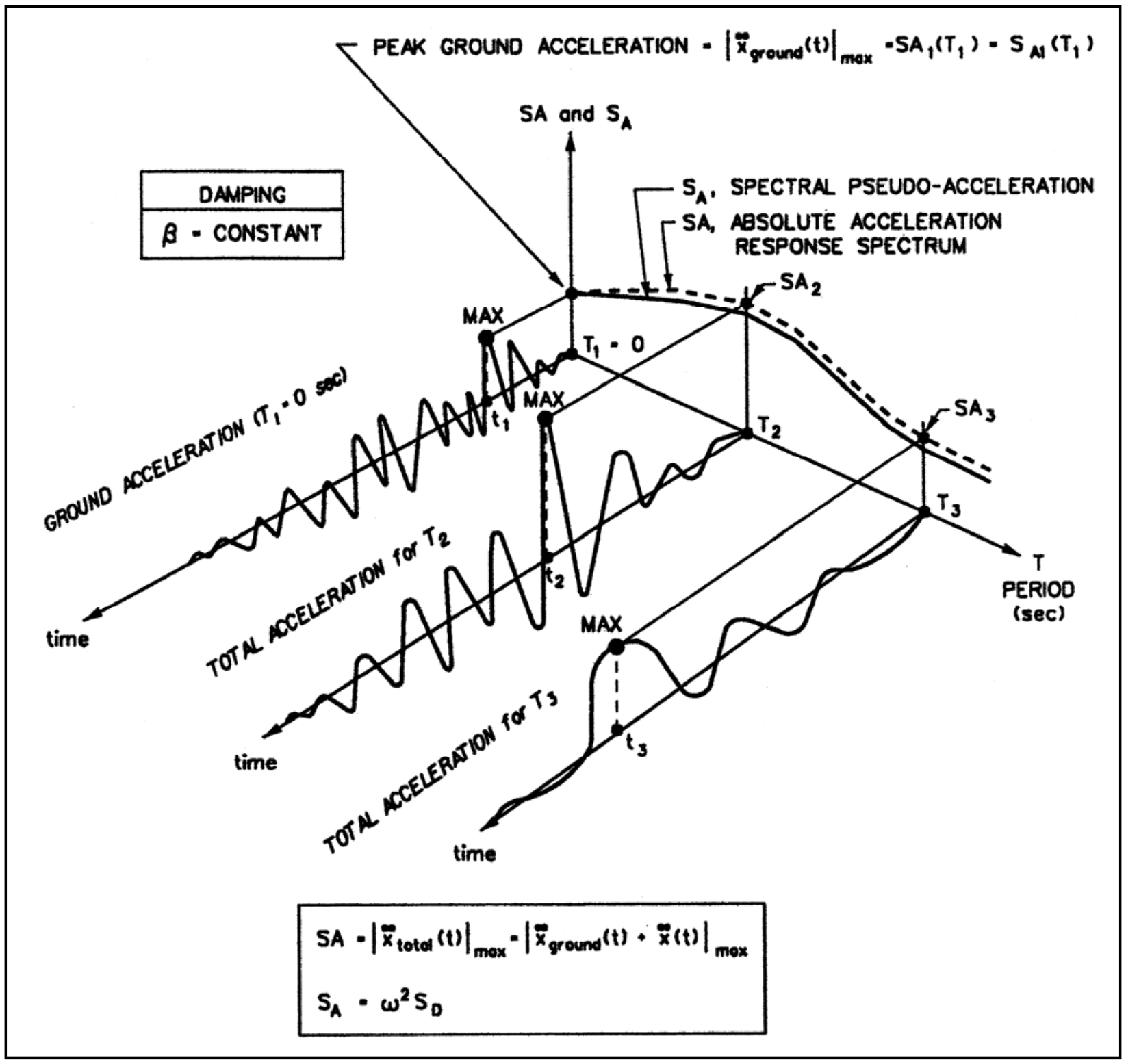

Figure 1-3. Development of a response spectrum curve (from Ebeling 1992)

\subsection{Monoliths Analyzed (Generator and Erection/Service Bay Monoliths)}

A powerhouse consists of an erection/service bay monolith and a series of generator bay monoliths. Most of the storage rooms are located in the erection/ service bay monolith. The erection/service bay monolith comprises mass concrete and internal frames for the floors of rooms and partitions. The turbine generators and other electrical and mechanical equipment are located in the generator bay. Construction drawings for 54 Corps powerhouses were reviewed. Appendix A lists these powerhouses and summarizes their key geometry characteristics. 


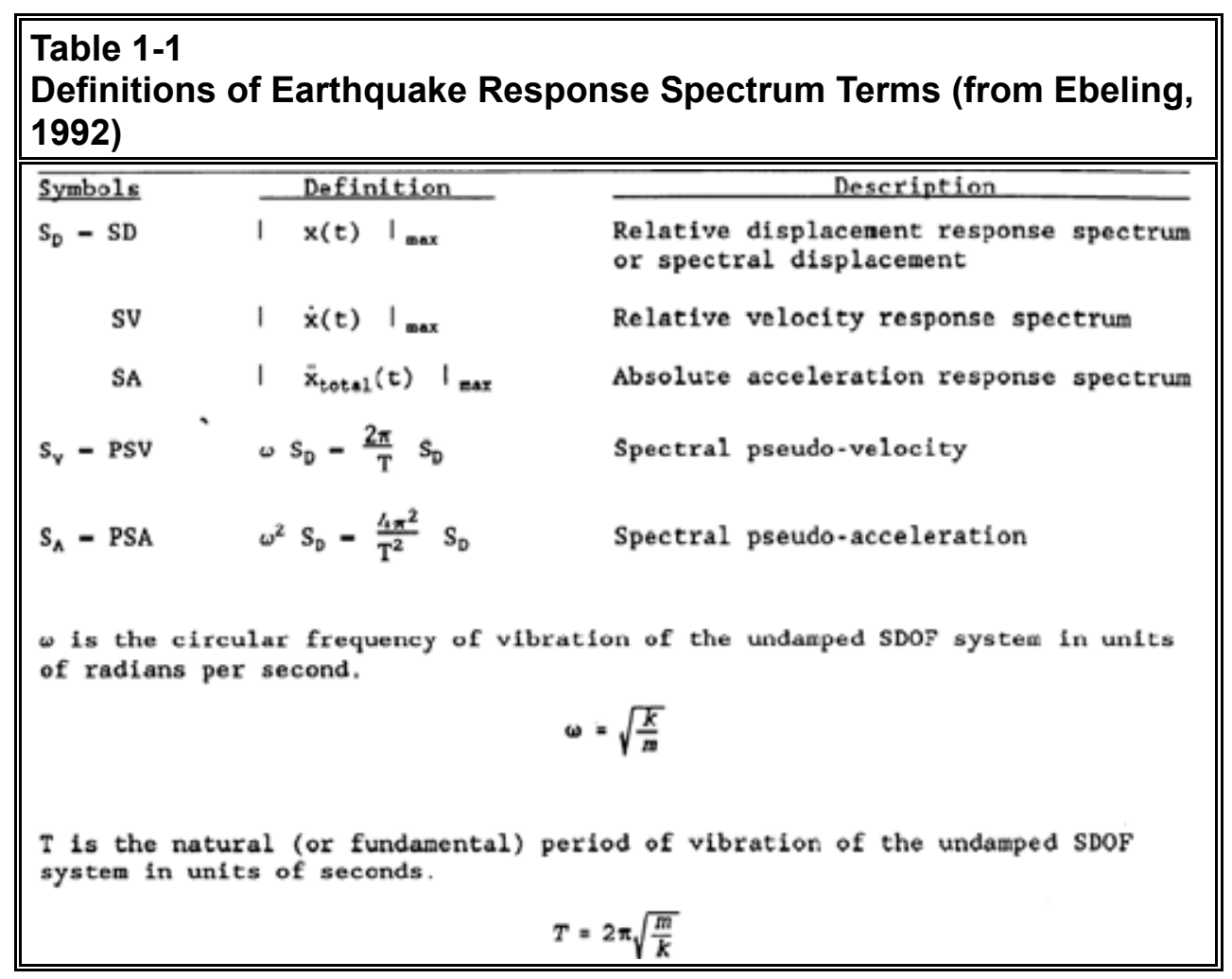

A generator bay monolith was categorized into one of four groups, depending on its height. For each group, an average height, an upstream/downstream dimension (transverse to the axis of the powerhouse), a plan width (along the axis of the powerhouse), and pool and tailrace water elevation were determined. Figure 1-4 shows a typical cross section of a generator bay, this one for the Cheatham Powerhouse. The plan view of the Cheatham Powerhouse generator bay is shown in Figure 1-5.

Figure 1-6 shows an example of a cross section of an erection/service bay monolith, this one for the Cordell Hull powerhouse. Four groups of erection/ service bay monoliths were created, and each of the 54 Corps powerhouses was assigned to one of the groups, depending on its height.

\subsection{Idealized Two-Dimensional Finite Element Models}

In this study, the amplified response spectrum at the top of the substructure will be determined in order to construct amplification factor curves representative for each model. In order to perform the dynamic analysis, the substructures were idealized into two-dimensional (2-D) representative finite element models. 


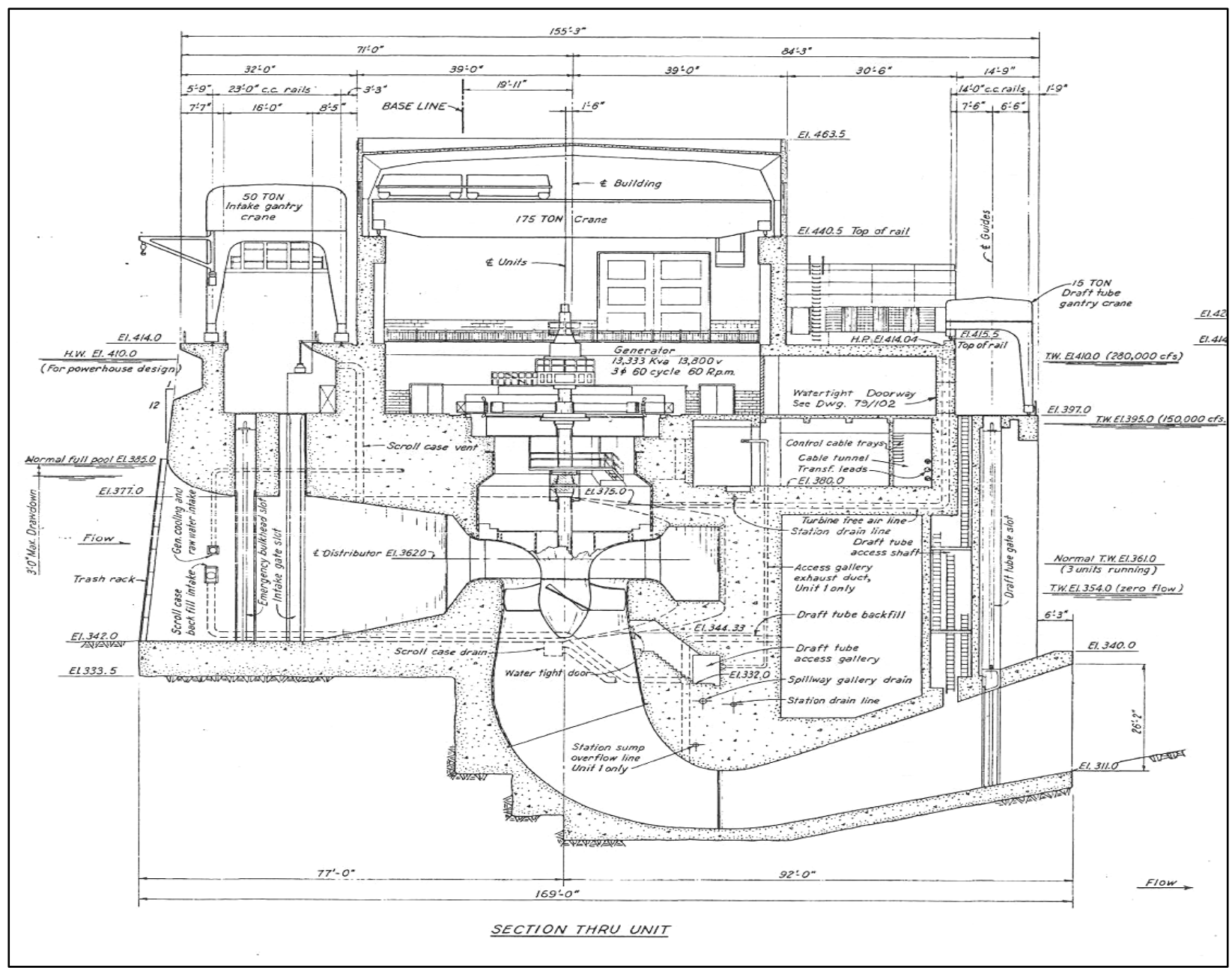

Figure 1-4. Cheatham Powerhouse generator bay cross section

A 2-D composite finite element model was selected for the idealization of the generator bay substructure. It consists of five structural members that form a three-dimensional (3-D) "box." In Figure 1-7, the concept of the composite model is presented. The walls that undergo upstream/downstream direction shearing deformations during earthquake shaking are referred to as shear walls (Walls 1 and 2). The base slab is referred to as 3. Walls 4 and 5 are flexural walls defining the upstream face and the downstream face of the generator bay monolith, respectively. The analyses will be a simplified, two-dimensional analysis using plane strain elements subjected to an upstream/downstream ground motion. Due to the nature of the simplified 2-D model of a single generator bay monolith, shear Wall 2 is superimposed on shear Wall 1 in the "composite" model. The nodal degrees of freedom for the "composite" element structure, consisting of the five structural features, are idealized in this figure.

Two simplified 2-D finite element models were created to represent the geometry and properties of the erection/service bay substructure, a block model and a block-frame-shear wall model. Block-frame-shear wall models have 


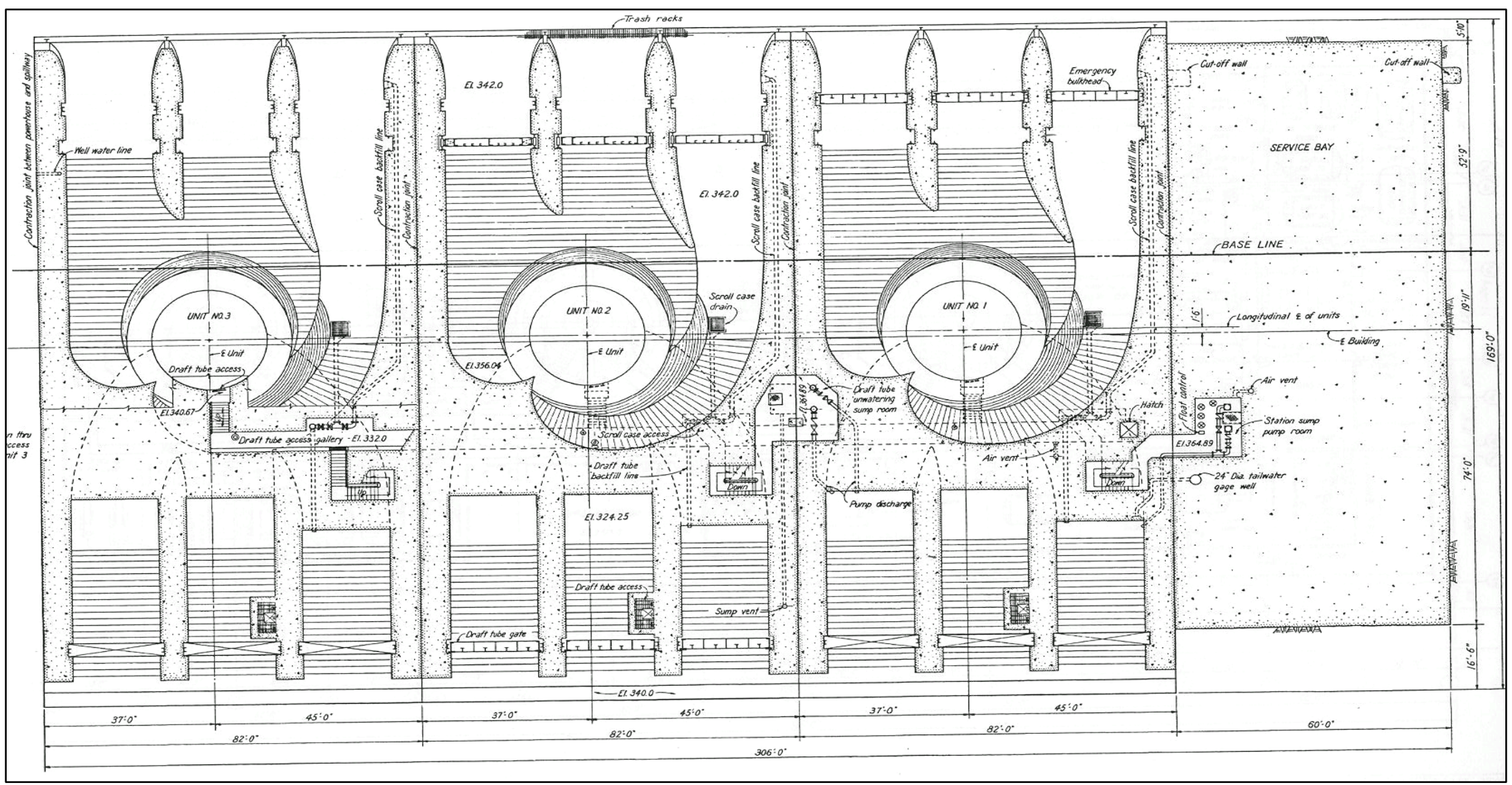

Figure 1-5. Cheatham Powerhouse plan view at generator area 


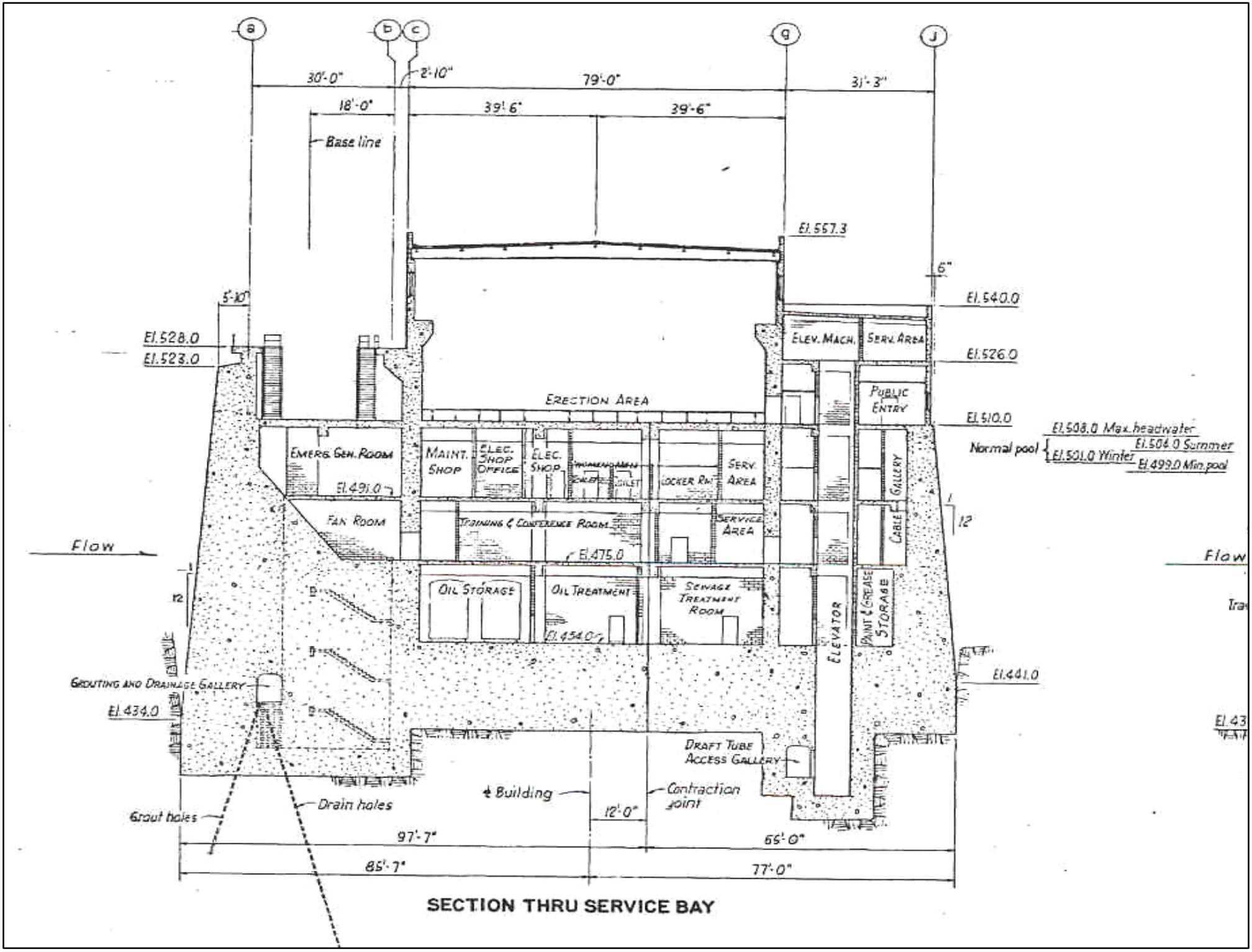

Figure 1-6. Cordell Hull Powerhouse erection/service bay cross section 


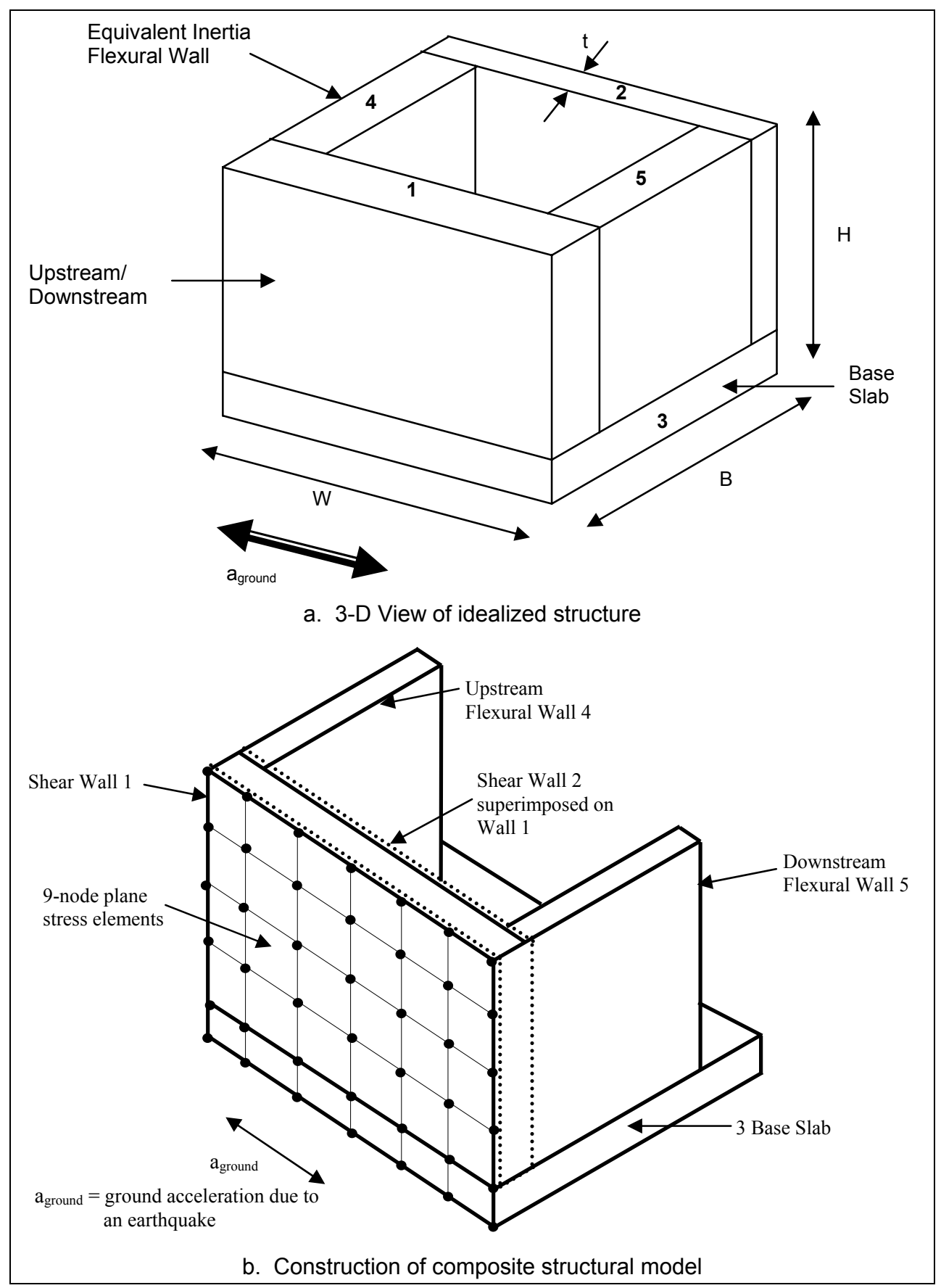

Figure 1-7. The idealized two-dimensional composite finite element model for the generator bay substructure used in this study

frame elements within the substructure to represent the partitions inside the powerhouse, providing flexibility to the models compared to the block models. For the three models, nine-node plane stress elements were used in the finite element models. The models were created using SAP2000 software. 


\subsection{Report Content}

This report summarizes the results obtained from a series of time-history analyses of generator bay and erection/service bay substructures. The development of the earthquake ground motions and their characteristics are presented in Chapter 2. Chapter 3 discusses the development of the amplification factor curves for the generator bay substructure. The amplification factor curves for the block and block-frame-shear wall model of the erection/service bay are presented in Chapter 4. The recommended amplification factor curves are summarized in Chapter 5 followed by two examples; (1) a comparison example between a complete and a decoupled analysis and (2) a demonstration example of an amplified rock response spectrum developed using the NEHRP (2000) procedure, to be used to analyze a simplified frame superstructure model.

Appendix A discusses geometry characteristics for 54 of the Corps powerhouses. Appendix B discusses the methodology used to idealize the upstream substructure wall (4) in the composite model of the generator bay. Appendix C discusses the results from a parametric study of planes stress, plane strain and shell elements. Appendix D describes the computation of the hydrodynamic added mass. Appendix E discusses PSA and SA curves. Appendix F summarizes amplification curves for 2 percent damping. 


\section{Development of Earthquake Time-Histories}

\subsection{Introduction}

Two earthquake load cases were developed for this study using design earthquake ground motions for a powerhouse site in the Pacific Northwest of the United States (PNW) and a powerhouse site in the central-eastern United States (CEUS). Each case was selected from an initial suite of sites considered for the respective cases. The Pacific Northwest site was selected from the suite Bonneville (symbol BnV), John Day (JDay), the Dalles (Dal), Chief Joseph (CJ), and McNary (McN) Dams. A central-eastern U.S. site was selected from the eastern sites St. Steven (StS), Carters Main Dam (CMD), and Richard B. Russell (RBR) and central U.S. sites Barkley (Brk), Greers Ferry (GrF), and Bull Shoals $(\mathrm{BuS})$. Site parameters (location and peak ground acceleration (PGA) for a range of exposure periods) for the two suites of sites are listed in Table 2-1 and mapped in Figures 2-1 and 2-2 for the PNW and CEUS sites, respectively. These figures also display the historical seismicity and any nearby active faults for the region to provide a general view of the seismic hazards that affect these sites. The final earthquake loading was provided as acceleration time-histories. These corresponding earthquake time-histories were based on probabilistic, mean level, equal hazard, 5 percent damped acceleration response spectra corresponding to the seismic hazard of the selected site for an exposure period of 1,000 years. The acceleration time-histories were developed synthetically using these initial response spectra as a target. Each resulting time-history was further modified to provide a close spectral match with the basis target spectra over the period range of interest for the structural response analyses.

\subsection{Spectra Selection}

This section describes the investigation and selection of the target spectra that were used to develop two "matching" acceleration time-histories (i.e., spectrum compatible), one each for the PNW and CEUS sites. The approach was to develop site-specific equal hazard spectra that are more suited as a basis to develop acceleration time-histories. These spectra were based on the seismic hazard curves from the probabilistic seismic hazard analysis (PSHA) conducted by the U.S. Geological Survey (USGS) for development of the 2002 


\begin{tabular}{|c|c|c|c|c|c|}
\hline \multicolumn{6}{|c|}{$\begin{array}{l}\text { Table } 2-1 \\
\text { Powerhouse Sites and Probabilistic PGA for Return Periods 500, } \\
1,000 \text {, and } 2,475 \text { Years }\end{array}$} \\
\hline \multirow[b]{3}{*}{ Powerhouse Site } & \multirow[b]{3}{*}{ Latitude } & \multirow[b]{3}{*}{ Longitude } & \multicolumn{3}{|c|}{ PGA, g } \\
\hline & & & \multicolumn{3}{|c|}{ Return Period, years } \\
\hline & & & 500 & 1,000 & 2,475 \\
\hline \multicolumn{6}{|c|}{ PNW } \\
\hline Bonneville & 45.642 & -121.933 & 0.1335 & 0.1808 & 0.2609 \\
\hline John Day & 45.717 & -120.685 & 0.0935 & 0.1283 & 0.1939 \\
\hline The Dalles & 45.615 & -121.138 & 0.0987 & 0.1337 & 0.1989 \\
\hline Chief Joseph & 47.996 & -119.627 & 0.0862 & 0.1222 & 0.1918 \\
\hline McNary & 45.930 & -119.295 & 0.0817 & 0.1162 & 0.1851 \\
\hline \multicolumn{6}{|c|}{ CEUS } \\
\hline \multicolumn{6}{|l|}{ Eastern } \\
\hline St. Steven & 33.425 & -79.933 & 0.2158 & 0.5748 & 1.2018 \\
\hline Carters Main Dam & 34.613 & -84.685 & 0.0705 & 0.1177 & 0.2273 \\
\hline Richard B. Russell & 34.025 & -82.592 & 0.0615 & 0.0991 & 0.1787 \\
\hline \multicolumn{6}{|l|}{ Central } \\
\hline Barkley & 33.022 & -88.220 & 0.1965 & 0.3230 & 0.5489 \\
\hline Greers Ferry & 35.525 & -92.000 & 0.1077 & 0.1897 & 0.3202 \\
\hline Bull Shoals & 36.363 & -92.573 & 0.0631 & 0.1063 & 0.1756 \\
\hline
\end{tabular}

U.S. National Seismic Hazard Maps (Frankel et al. 1996, 2000, 2002). An alternative would have been to use generalized design spectra such as provided in FEMA 302 (FEMA 1997) and ASCE 7-2 (American Society of Civil Engineers 2002) guidance for seismic analyses.

\subsubsection{Pacific Northwest site}

To facilitate selection of a single response spectrum to represent this case, 5 percent damped, equal hazard, pseudo-spectral acceleration response spectra (EHPSA) were developed for a suite of sites (shown in Figure 2-1) for return periods of $500,1,000$, and 2,475 years. It was decided to use 1,000-year design ground motions as the more appropriate exposure level for performance objectives considered important for this study. Inspection of these EHPSA plotted in Figure 2-3 shows a common spectral shape anchored to range of PGA. For the 1,000 -year return period the PGA ranges from 0.116 to $0.180 \mathrm{~g}$. These spectra peak in the 0.2 -sec-period range with a broader dispersion of 0.27 to $0.44 \mathrm{~g}$. The spectra for the Bonneville site is an upper bound for the 1,000-year spectra and additionally a representative lower bound to the 2,475-year spectra. Further analysis of this suite of spectra is presented in Figure 2-4 where these spectra are replotted as a ratio of PSA and PGA. This plot shows that the spectral shape is common and its relationship to the anchor PGA is very similar. Again, the selected Bonneville spectra are shown to be an upper bound in the shorter period 


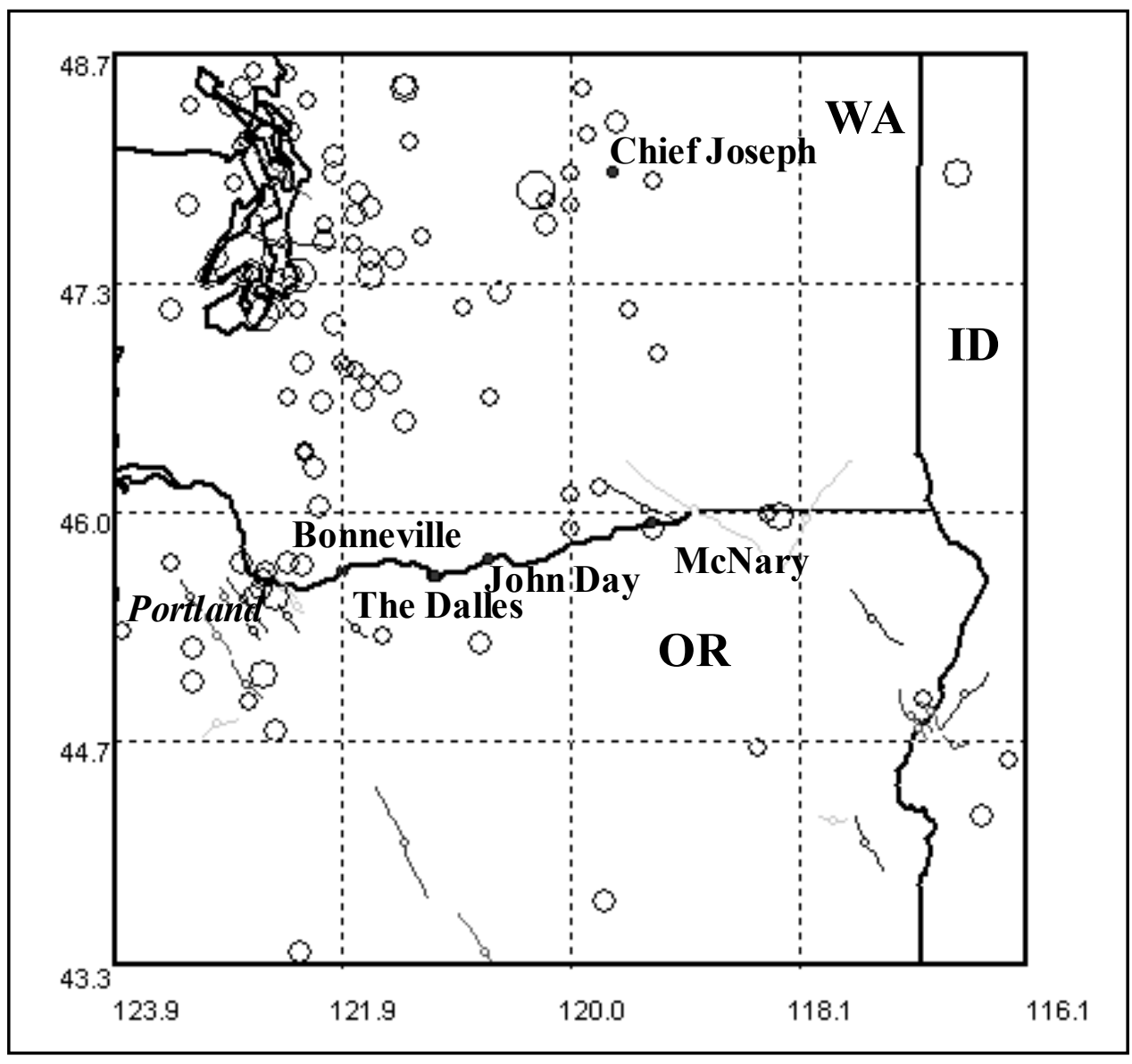

Figure 2-1. PNW powerhouse sites and active faults and seismicity $M>4.0$

(higher frequency) band, although not anomalously. For this study the higher frequency components of this loading are the more important. This plot also shows reasonableness in using PGA to scale ground motions for different ranges of loads while maintaining an analogous relative frequency content for this region.

Also presented in these two figures for comparison are the selected spectra for the CEUS site. This comparison shows that the spectra for the CEUS site are richer in high frequency as evidenced by the higher PGA and shift of the predominant frequencies to a higher band. The converse can be seen in the figures showing the spectra for the CEUS site.

One important aspect of a PSHA is that the resulting hazard is a sum of all significant sources that affect a given location. This is shown in Figure 2-5 as a graph of deaggregated seismic hazard for the selected Bonneville site. The presented component of hazard for deaggregation was the 0.2-sec, 974-year (nominal 1,000-year) data. It can be seen that this component of hazard for this site is composed mainly of large-magnitude $\mathrm{M}=8+$ earthquakes at ranges $>160 \mathrm{~km}$ and a cluster of small-magnitude $\mathrm{M}<7$ earthquakes within $80 \mathrm{~km}$ of the site. These two distinct clusters of sources correspond to large earthquakes from the Cascadia subduction zone and closer shallow crustal faults, respectively. 


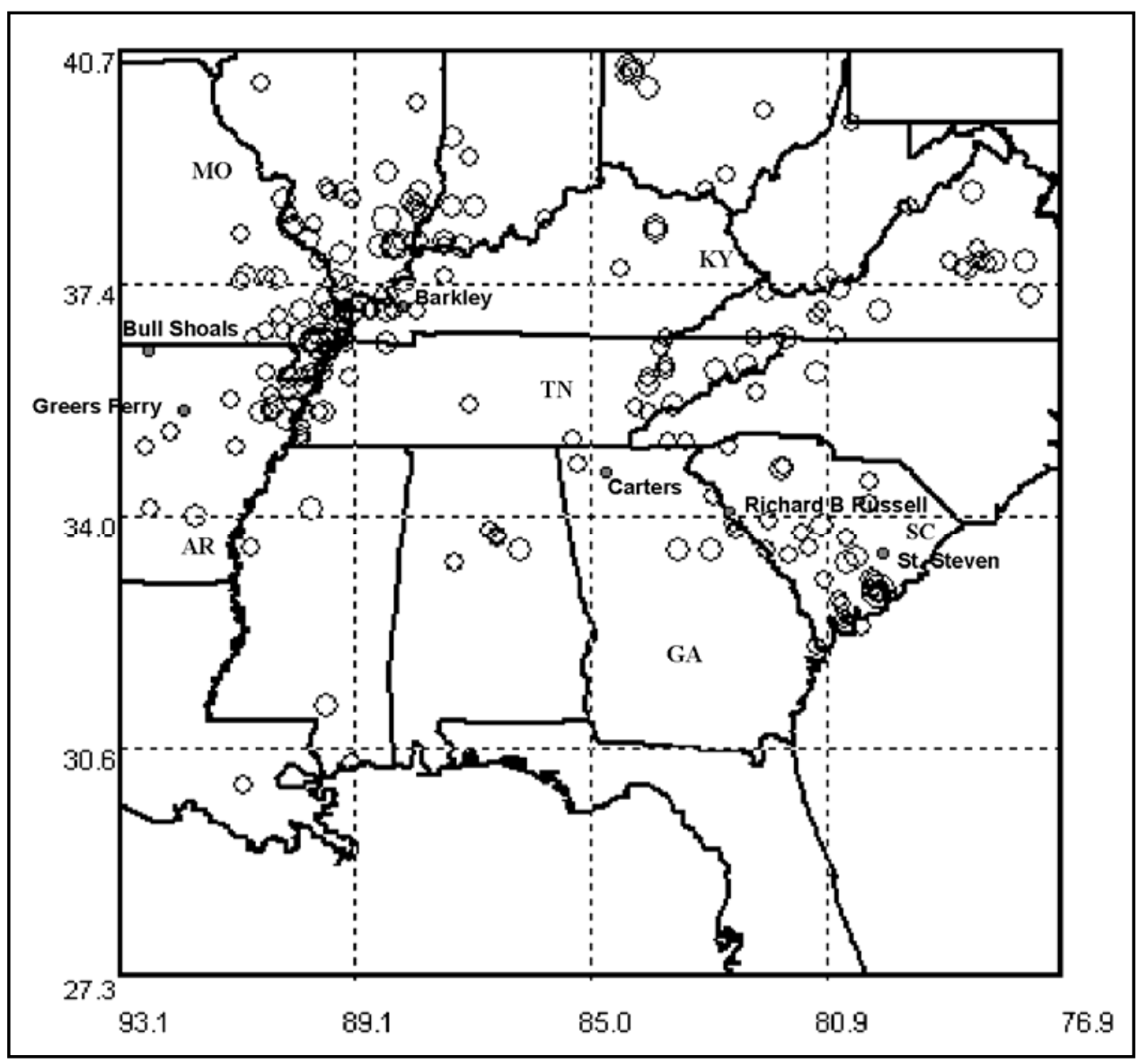

Figure 2-2. CEUS powerhouse sites and seismicity $M>4.0$

The calculated mean hazard for this spectral period and exposure period from all these sources is an $\mathrm{M}=6.77$ earthquake at a distance of $61 \mathrm{~km}$. This would not necessarily be the same for all spectral periods or exposure periods, which explains showing the component most appropriate for this study: 1,000-year, spectral peak in medium-high frequency range. A final related point follows: selecting a single recorded acceleration time-history (based on a single magnitude and distance) to represent spectra derived from a summation of sources at different magnitudes and ranges may be problematic. Therefore, using an accelerogram developed synthetically to realistically match an EHPSA is more reasonable, especially if phasing of the arriving waves is not an important aspect in the analysis, which is the case for this study.

\subsubsection{Central-eastern U.S. site}

As stated previously, to facilitate selection of a single response spectrum to represent this case, 5 percent damped EHPSA were developed for the suite of sites mapped in Figure 2-2 for return periods of 500, 1,000, and 2,475 years. The 1,000 -year ground motion was chosen as the appropriate exposure level for the 


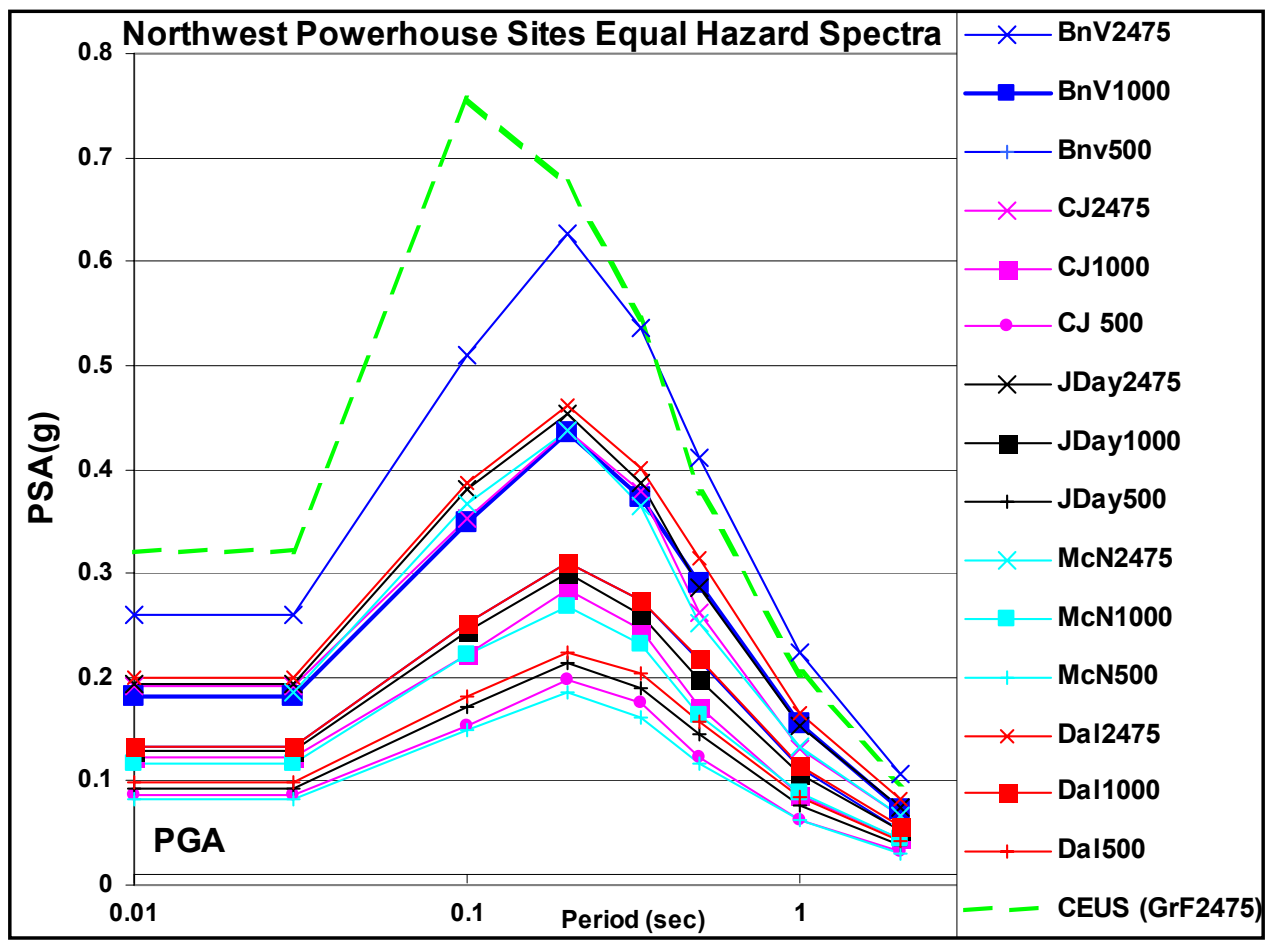

Figure 2-3. Northwest powerhouse site equal hazard spectra

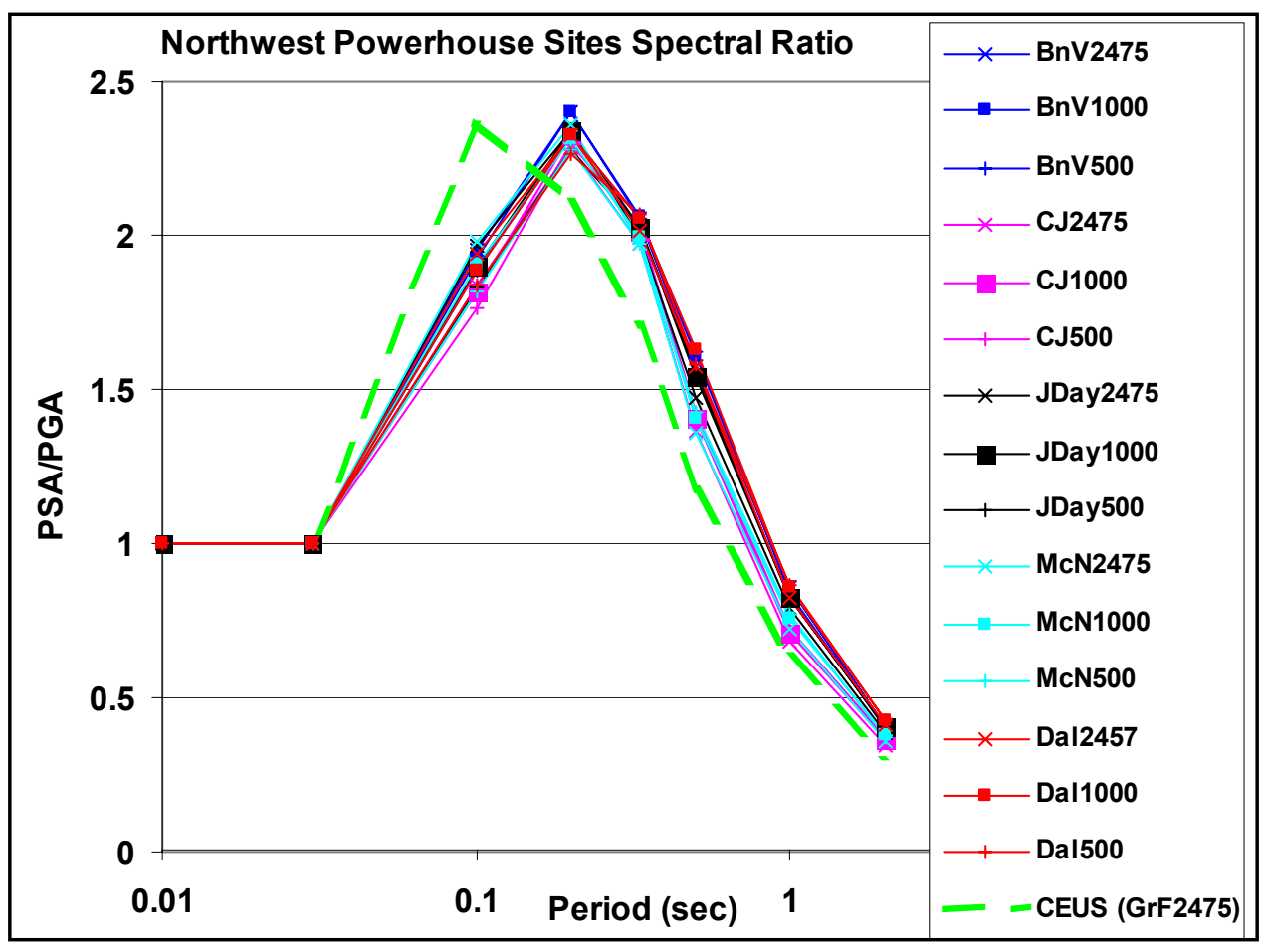

Figure 2-4. Northwest powerhouse site spectral ratios 


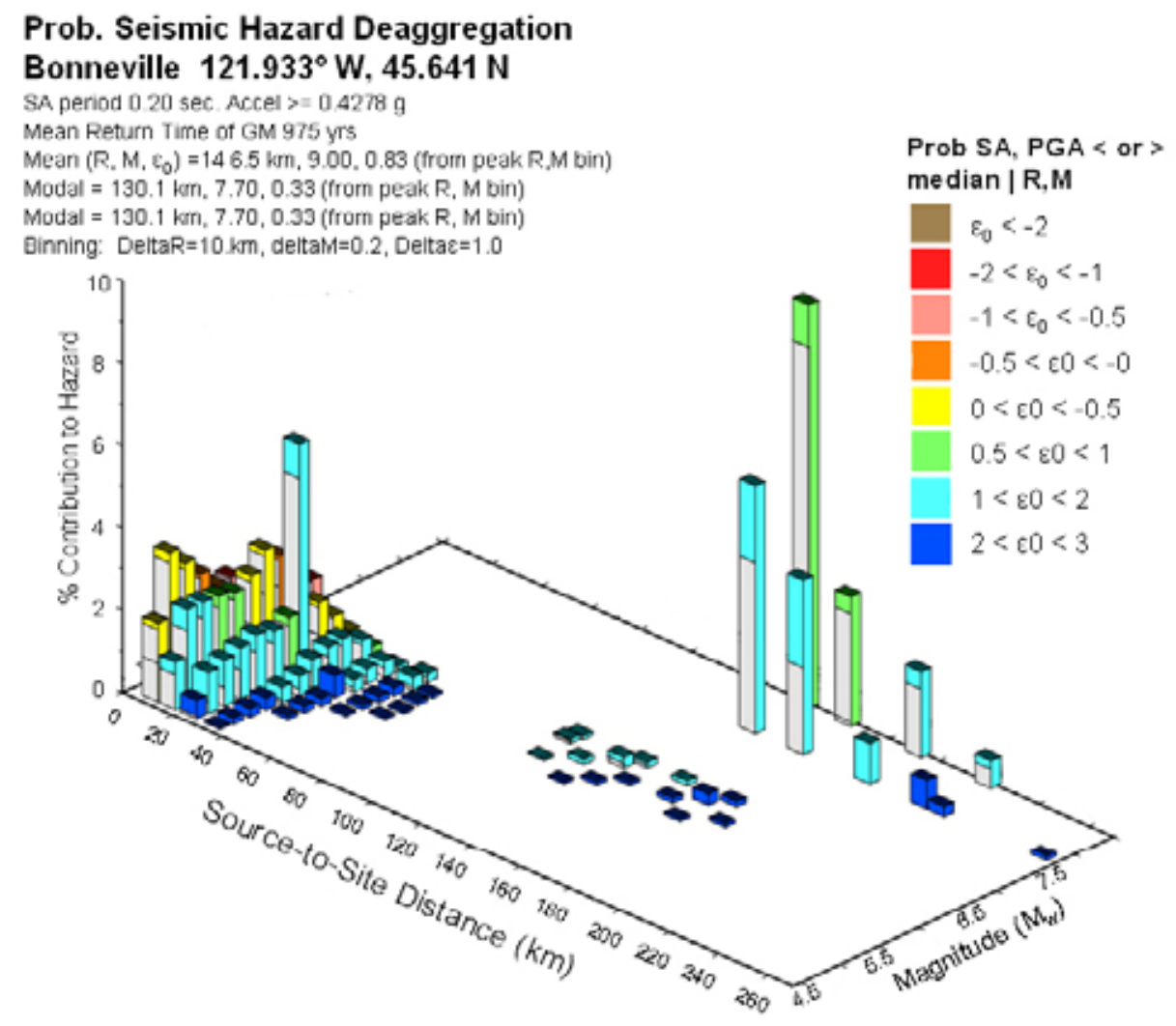

GMT Jon 819:01 Distance (R), magnitude (M), epsilon (EO,E) deaggregation for a site on rock

with average $v s=760 \mathrm{~m} / \mathrm{s}$ top $30 \mathrm{~m}$. USGS CGHT PSHA2002V3 UPDATE

Figure 2-5. Bonneville site probabilistic hazard deaggregation for $5-\mathrm{Hz}$ spectral component

performance objective considered important for this study. These EHPSA plotted in Figure 2-6 again show a common spectral shape anchored to range of PGA. For the 1,000-year return period the PGA ranged from 0.099 to $0.574 \mathrm{~g}$. These spectra peak in the 0.1-sec-period range with a broader dispersion of $\sim 0.2$ to $1.25 \mathrm{~g}$. This is a much wider spread with a peak at a higher frequency than the selected PNW site. The Greers Ferry site spectrum was selected to represent the CEUS region. Figure 2-7 shows it is not an upper bound for the 1,000-year spectra, surpassed by St. Steven and Barkley sites. However, St. Steven and Barkley were considered too severe for a general CEUS case. The PSA/PGA spectra plots in Figure 2-7 show that the Greers Ferry spectrum has a relatively high bounding ratio in the suite, which supports it as a good choice, especially for scaling load cases using PGA.

The seismic hazard deaggregation is shown in Figure 2-8 for the selected Greers Ferry site. The presented component of hazard for deaggregation was the 0.2 -sec, 974-year (nominal 1,000-year) data. It can be seen that this component of hazard for this site is composed mainly of large-magnitude $\mathrm{M}=7.5+$ earthquakes at ranges $>150 \mathrm{~km}$ and a broad cluster of small-magnitude $\mathrm{M}<7$ earthquakes within $50 \mathrm{~km}$ of the site. These two clusters of sources correspond to large earthquakes from the New Madrid zone and closer shallow crustal faults 


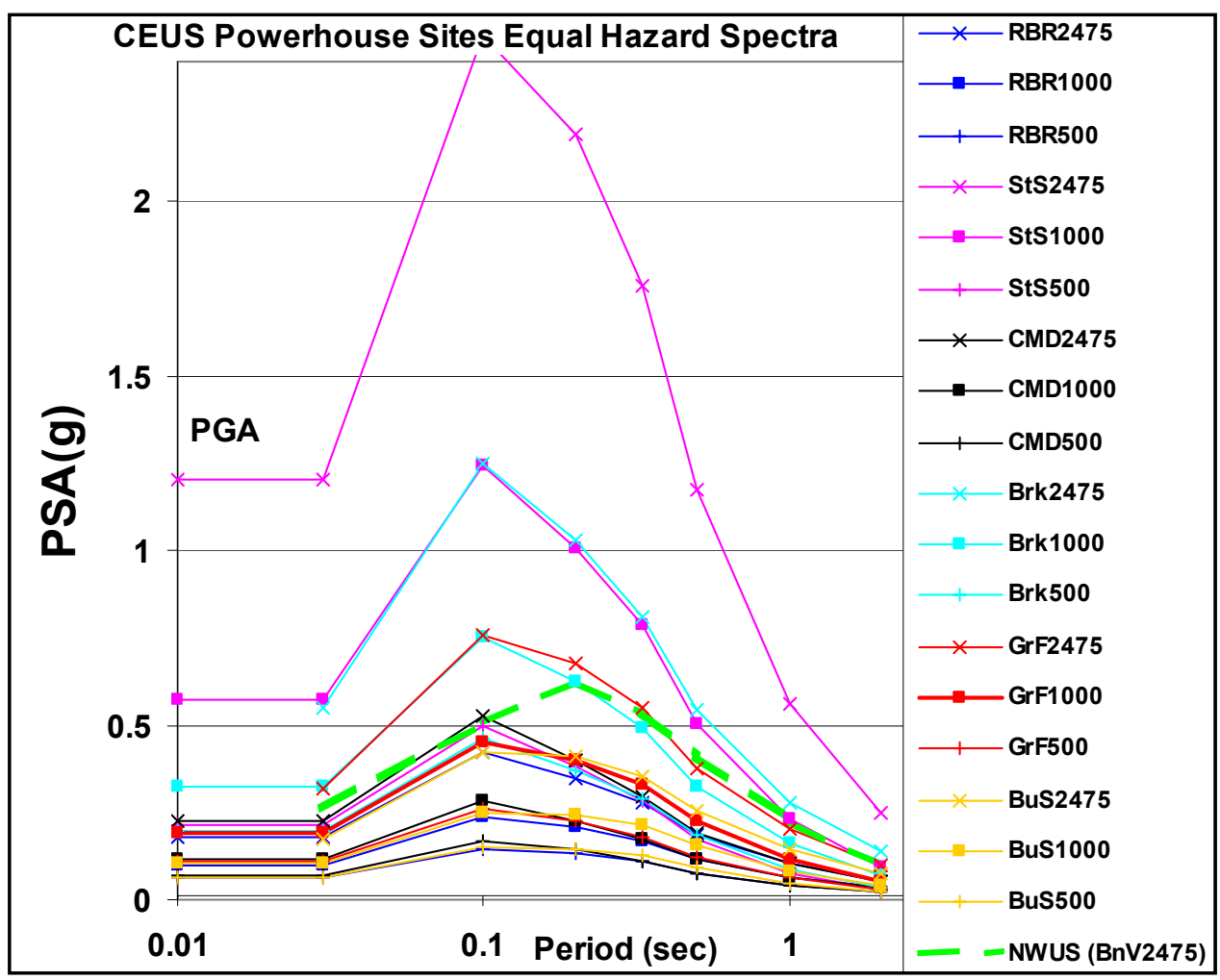

Figure 2-6. CEUS powerhouse site equal hazard spectra

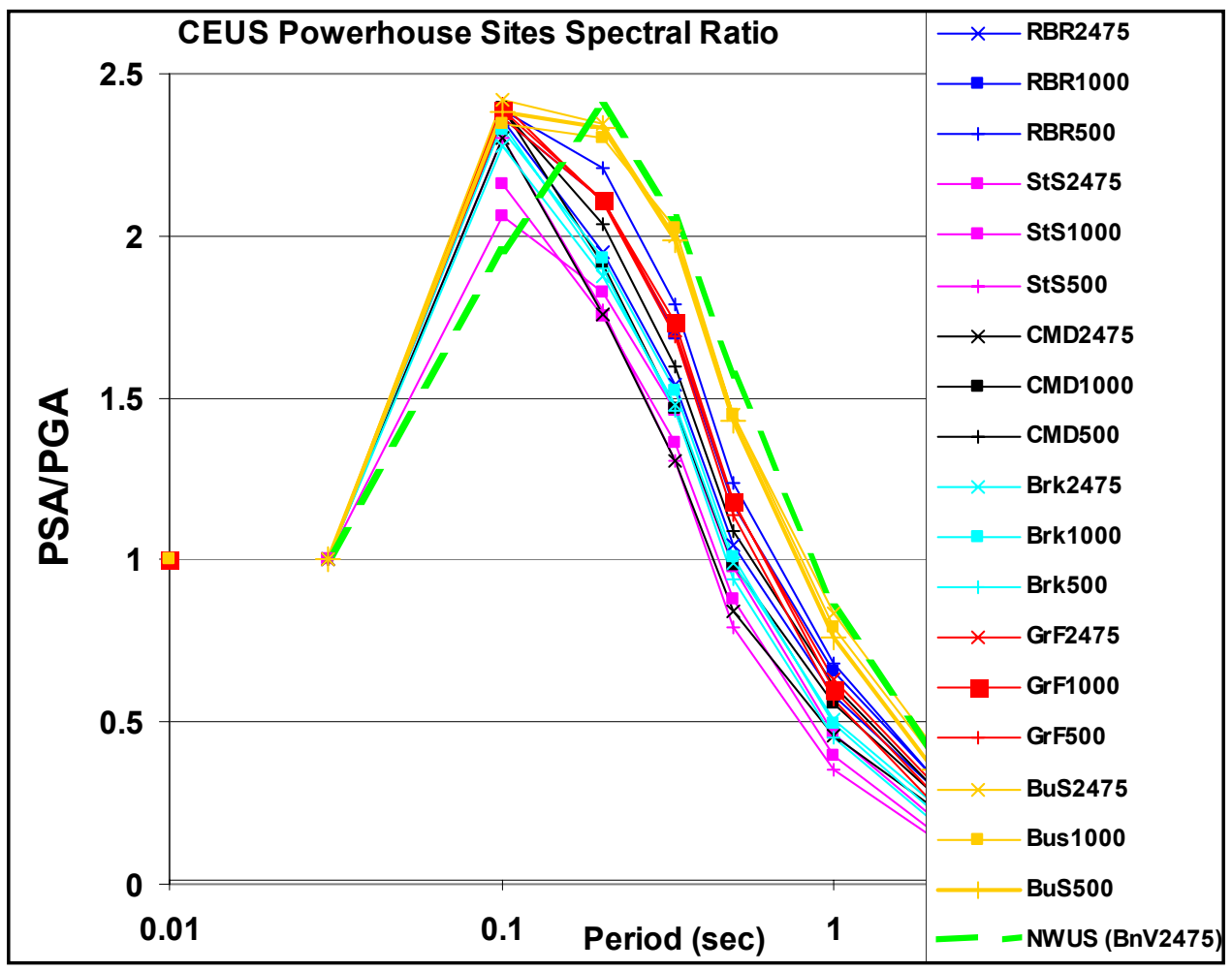

Figure 2-7. CEUS powerhouse site spectral ratios 


\section{Prob. Seismic Hazard Deaggregation}

Greers Ferry $92.000^{\circ}$ W. $35.525 \mathrm{~N}$

SA period $0.20 \mathrm{sec}$. Accel $>=0.4070 \mathrm{~g}$

Mean Return Time of GM 975 yrs

Mean (R, M, $\varepsilon_{0}$ ) $1079 \mathrm{~km}, 7.26,0.24$

Modal $=130.1 \mathrm{~km}, 7.70,0.33$ (from poak $R, M$ bin)

Prob $S A, P G A<$ or $>$ median | R, M

$\square \varepsilon_{0}<-2$

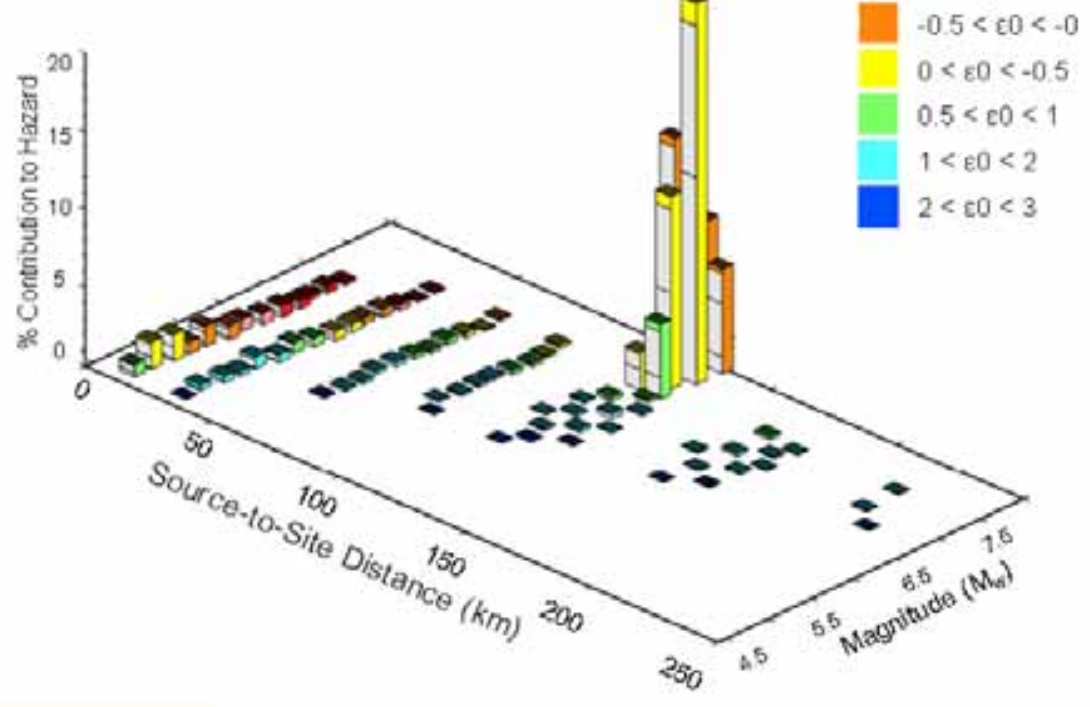

GMT Jun 120:20 Distanee (R), magnitude (M), apsilon (EO.E) deaggregation for a sitw on rock with aversge vsm $760 \mathrm{~m}$ s top $30 \mathrm{~m}$. USGS CGHT PSHA2002vJ UPDATE Bins with it $0.05 \%$ contrib. omitted

Figure 2-8. Greers Ferry site probabilistic hazard deaggregation for $5-\mathrm{Hz}$ spectral component

associated with diffuse seismicity, respectively. The calculated mean hazard for this spectral period and exposure period from all these sources is an $\mathrm{M}=7.26$ earthquake at a distance of $107 \mathrm{~km}$.

\subsection{Time-History Development}

The acceleration time-histories were developed in a two-step process once a basis or target site and EHPSA were selected: (a) develop a synthetic seismogram constrained to the site EHPSA and (b) further modify the synthetic accelerogram by close spectral matching with the site EHPSA.

\subsubsection{Synthetic development}

Considering the objectives, scope, and type of dynamic analysis of this overall study, it was decided to develop the time-histories synthetically instead of using recorded accelerograms. The scope was to employ one earthquake timehistory load for the site. The criteria for developing the load case was based on ground motion levels with a 5 percent probability of exceedance (PE) for an exposure period of 50 years or return period of 974 years, which was set 
nominally at 1,000 years. These probabilistically derived ground motion levels were specified as PGA and spectra accelerations as uniform or equal hazard response spectra for a mean level with 5 percent damping. Since these derived target spectra are smooth and derived from summing from multiple sources, it was considered that starting with a deterministic single earthquake source, single recording, would require considerable spectral modification. Since the original character of a recorded accelerogram would be basically overwritten to get the required good match, this negated one advantage for using a natural record. Finally, as the load case was not as severe as a Maximum Credible Earthquake (MCE) level event, an elastic response was expected with the results not as sensitive to the phasing of the load as a nonlinear, possibly large deformation response from an extreme event. The synthetic seismograms were developed from the strong ground motion model SMSIM_TD (Boore 2000). This is a simple model based on a stochastic point source, which is reasonable for the constraints and objectives of this study. The synthetic seismogram was developed using an attenuation relationship and source spectra appropriate for the region of the site scaled (constrained) by the target spectra associated with the spectral component and probability of exceedance of the EHPSA of the selected site (0.2-sec PSA, 5 percent PE in 50 years).

\subsubsection{Spectral Matching}

Spectral matching was accomplished using the RSPMATCH computer program (Abrahamson 1998) that is based on the time domain method of Tseng and Lilhanand (Lilhanand and Tseng 1988). The resulting spectrally matched synthetic ground motion time-histories are shown in Figures 2-9 and 2-10 for the PNW and CEUS sites, respectively. Note that these time-histories are generated at $0.005 \mathrm{sec}$, which can provide signal fidelity up to a frequency content of 100 Hz. However, these simulations have limited frequency content (insignificant) above $30 \mathrm{~Hz}$, which can be seen by inspection of the frequency versus amplitude plots shown in Figures 2-9 and 2-10. Also as seen in these figures, the timehistories are baseline corrected as evidenced by the zero velocity at the end of the time series. This is an important characteristic that avoids errors in the numerical analyses due to inadvertent long-period drift artifacts in the accelerogram. A more detailed plot of the final spectral matches showing the initial synthetics from SMSIM, the spectral targets, and the final spectral matched spectra for 2 percent and 5 percent damping are shown in Figures 2-11 and 2-12 for the PNW and CEUS sites, respectively. Each figure contains a plot of four 5 percent damped response spectra:

- Seed TH 5\% - spectra of original (or seed) synthetic time-history that was to be modified to match the spectral target.

- BnV Target 5 percent - the Bonneville (BnV, Figure 2.11) or Greers Ferry (GRF, Figure 2-12) site target spectra. The plotted points on these target spectra were the specific frequencies that controlled the spectral modification. This range for spectral matching was from 0.03 to $2.0 \mathrm{sec}$ (a minimum to maximum frequency of 0.05 to $33 \mathrm{~Hz}$ ). 


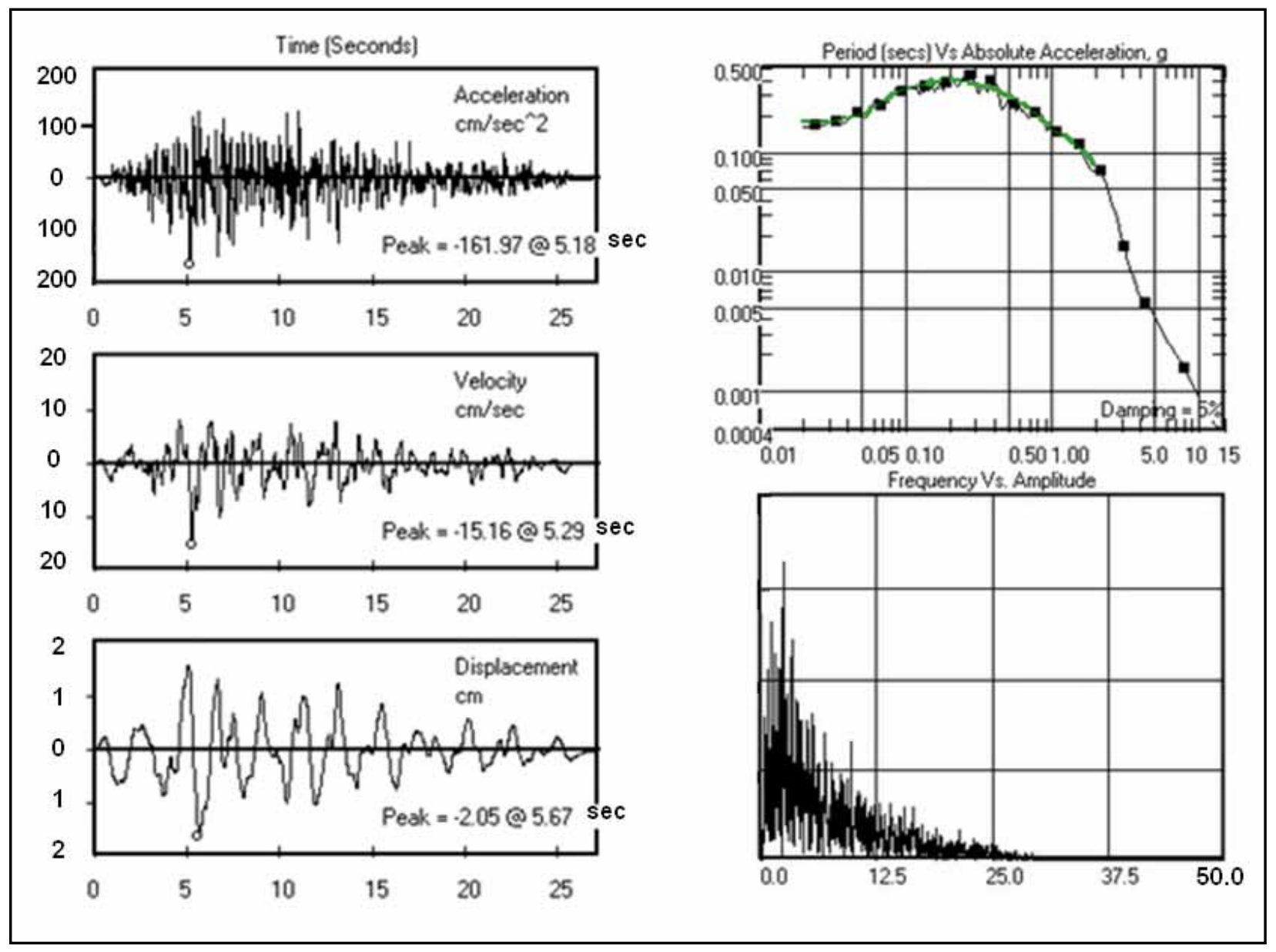

Figure 2-9. Acceleration time-history for PNW powerhouse - Bonneville 1,000-year equal hazard spectra synthetic and spectrally matched

- BnV RSPMatch 2\% and BnV RSPMatch 5\% or GRF RSPMatch $2 \%$ and GRF RSPMatch 5\%-the resulting 2 percent and 5 percent damped spectra from the accelerograms spectrally modified to approximately match the target spectra. 


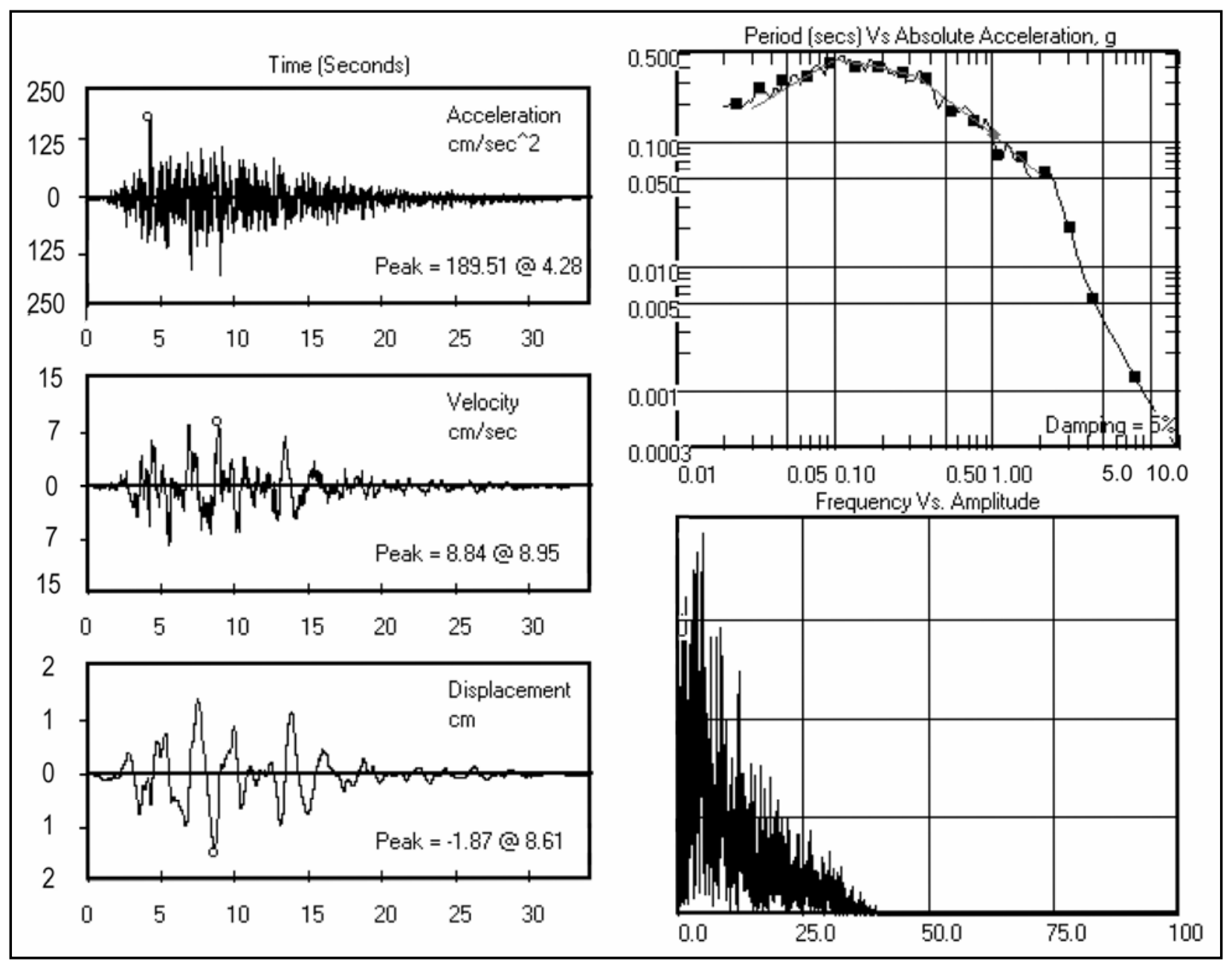

Figure 2-10. Acceleration time-history for CEUS powerhouse - Greers Ferry 1,000-year equal hazard spectra synthetic and spectrally matched 


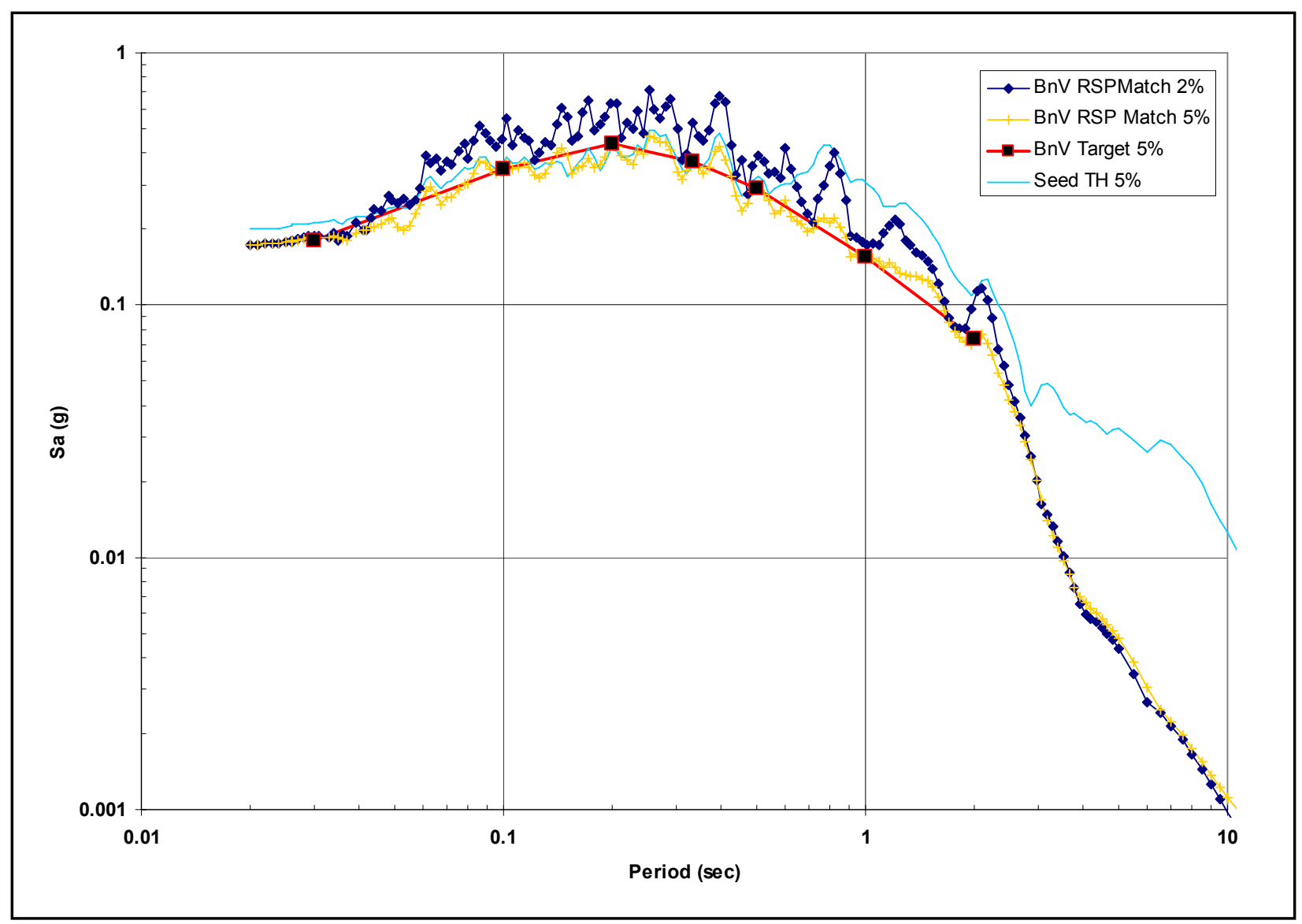

Figure 2-11. Comparison of original, target, and spectral matched spectra for the PNW powerhouse site 


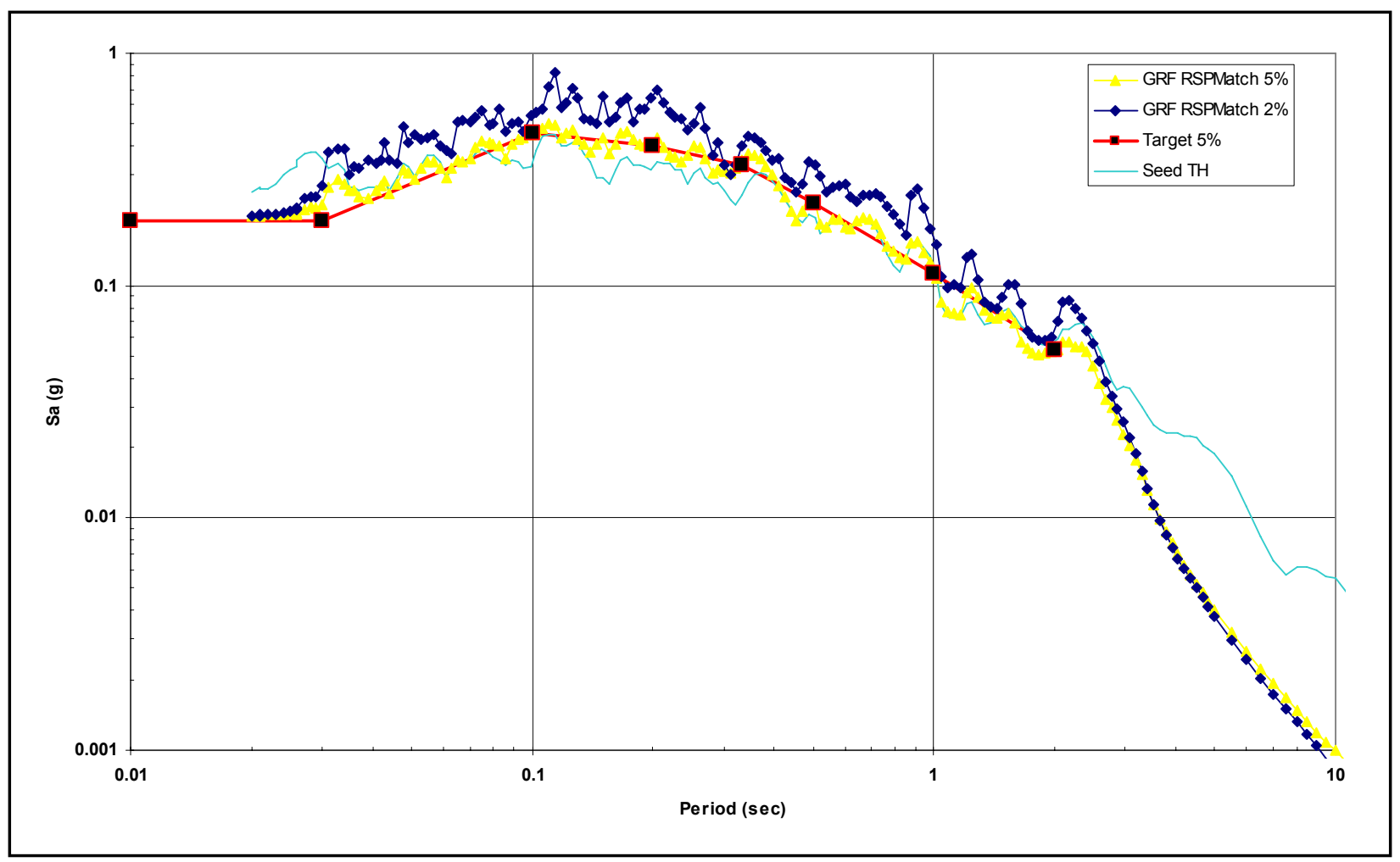

Figure 2-12. Comparison of original, target, and spectral matched spectra for CEUS powerhouse site 


\section{Time-History Finite Element Results for the Generator Bay Monoliths}

\subsection{Introduction}

This chapter discusses the results from analyses of a series of time-history/ modal responses of the four categories of generator bay monoliths to earthquake loading. The earthquake loading is represented by acceleration time-histories in the analyses discussed in this chapter. Two acceleration time-histories were used in the analysis, one representing a central-eastern United States earthquake event and a second representing a Pacific Northwest event. Each acceleration timehistory was specified at the base of the finite element model of each idealized powerhouse substructure (i.e., in-rock). Two-dimensional, plane stress finite elements were used in the SAP2000 (CSI 1997) finite element models of each of the four idealized generator bay models studied during the course of this research. From these computed time-history results, response spectra at top-ofsubstructure were then computed and converted into response spectra. These results, in turn, were converted into a plot of response spectra amplification factors (AF) versus frequency for use in decoupled response spectra modal analyses. The AF curves presented in this chapter are plotted up to $50 \mathrm{~Hz}$. However, the ground motion used in this study has frequencies up to $33 \mathrm{~Hz}$. The use of AF curves above $33 \mathrm{~Hz}$ is not recommended.

\subsection{Geometry of Four Height Monoliths}

The U.S. Army Corps of Engineers is responsible for approximately 79 powerhouses across the United States. Drawings for 54 of the generator bays at these powerhouses were studied and assigned to one of four groups according to height of substructure. For each group, average upstream/downstream widths (transverse to the axis of the powerhouse) and average monoliths widths (parallel to the axis of the powerhouse) were determined. Additionally, for each group, a representative normal pool elevation (upstream of the powerhouse) and a representative tailrace elevation (downstream of the powerhouse) were determined. 
The pool water elevation was taken as a constant $20 \mathrm{ft}^{1,2}$ above the top-ofsubstructure for all groups, and the tailrace water elevation varied as a function of group height. Table 3-1 lists the four groups with the values assigned and their respective pool and tailrace water elevations.

\section{Table 3-1}

Dimensions of Generator Bay Section

\begin{tabular}{||l|l|l|l|l|l|l||}
\hline \hline Group & $\begin{array}{l}\text { Height } \boldsymbol{H} \\
\mathrm{ft}\end{array}$ & $\begin{array}{l}\text { Upstream/ } \\
\text { Downstream } \\
\text { Width } \boldsymbol{W}, \mathrm{ft}\end{array}$ & $\begin{array}{l}\text { Plan } \\
\text { Width } \boldsymbol{B} \\
\mathrm{ft}\end{array}$ & $\begin{array}{l}\text { Pool } \\
\text { Water El } \\
\mathrm{ft}\end{array}$ & $\begin{array}{l}\text { Tailrace } \\
\text { El, ft }\end{array}$ & $\begin{array}{l}\text { Range in Height } \\
\text { for Group, ft }\end{array}$ \\
\hline \hline 1 & 125 & 135 & 85 & 145 & 89 & $115-135$ \\
\hline 2 & 100 & 130 & 75 & 120 & 74 & $90-115$ \\
\hline 3 & 70 & 110 & 60 & 90 & 60 & $60-75$ \\
\hline 4 & 40 & 65 & 50 & 60 & 36 & $25-60$ \\
\hline
\end{tabular}

Appendix A contains a summary table of the dimensions, pool and tailrace elevations, and general characteristics of each powerhouse reviewed in this study.

\subsection{Material Properties}

The generator bay monoliths are massive concrete structures. The material properties assumed in this study are listed in Table 3-2 for the massive concrete of the substructure. Most of this information was obtained from Ebeling et al. (2002).

\begin{tabular}{|l|l||}
\hline $\begin{array}{l}\text { Table 3-2 } \\
\text { Material Properties Used in the Generator Bay Mass Concrete } \\
\text { Substructure }\end{array}$ \\
\hline \hline Mass Concrete Properties \\
\hline \hline Compressive strength $f_{c}^{\prime}$ & $3,750 \quad \mathrm{psi}$ \\
\hline Modulus of elasticity $E_{c}$ & $3.7 \mathrm{E}+6 \quad \mathrm{psi}$ \\
\hline Mass of concrete $m_{c}$ & $4.6584 \quad \mathrm{bb}^{*} \mathrm{sec}^{2} / \mathrm{ft}$ \\
\hline Unit weight $\gamma_{c}$ & $150 \quad \mathrm{pcf}$ \\
\hline Poisson's ratio $v$ & 0.2 \\
\hline
\end{tabular}

A typical design value of compressive strength at 28 days for a mass concrete structure is $2,500 \mathrm{psi}$. For analysis purpose it was increased by a factor of 1.5 to account for aging effects. The modulus of elasticity for concrete was approximated by Equation 3-1 (Ebeling et al. 2002):

$$
E_{c}=33 w^{1.5} \sqrt{f_{c a}^{\prime}}
$$

\footnotetext{
1 A table of factors for converting non-SI units of measure to SI units is found on page xvii.

2 All elevations (el) cited in this report are in feet referenced to the National Geodetic Vertical Datum.
} 
where $w$ is the unit weight of concrete in pcf and $f_{c a}^{\prime}$ is the actual strength of concrete.

\subsection{Finite Element Models}

Finite element models were constructed using the preprocessor incorporated within the structural analysis software SAP2000 (CSI 1997). The generator bay idealized geometry was represented by a hollow 3-D box with five structural elements labeled by numbers from 1 to 5 as shown in Figure 3-1.

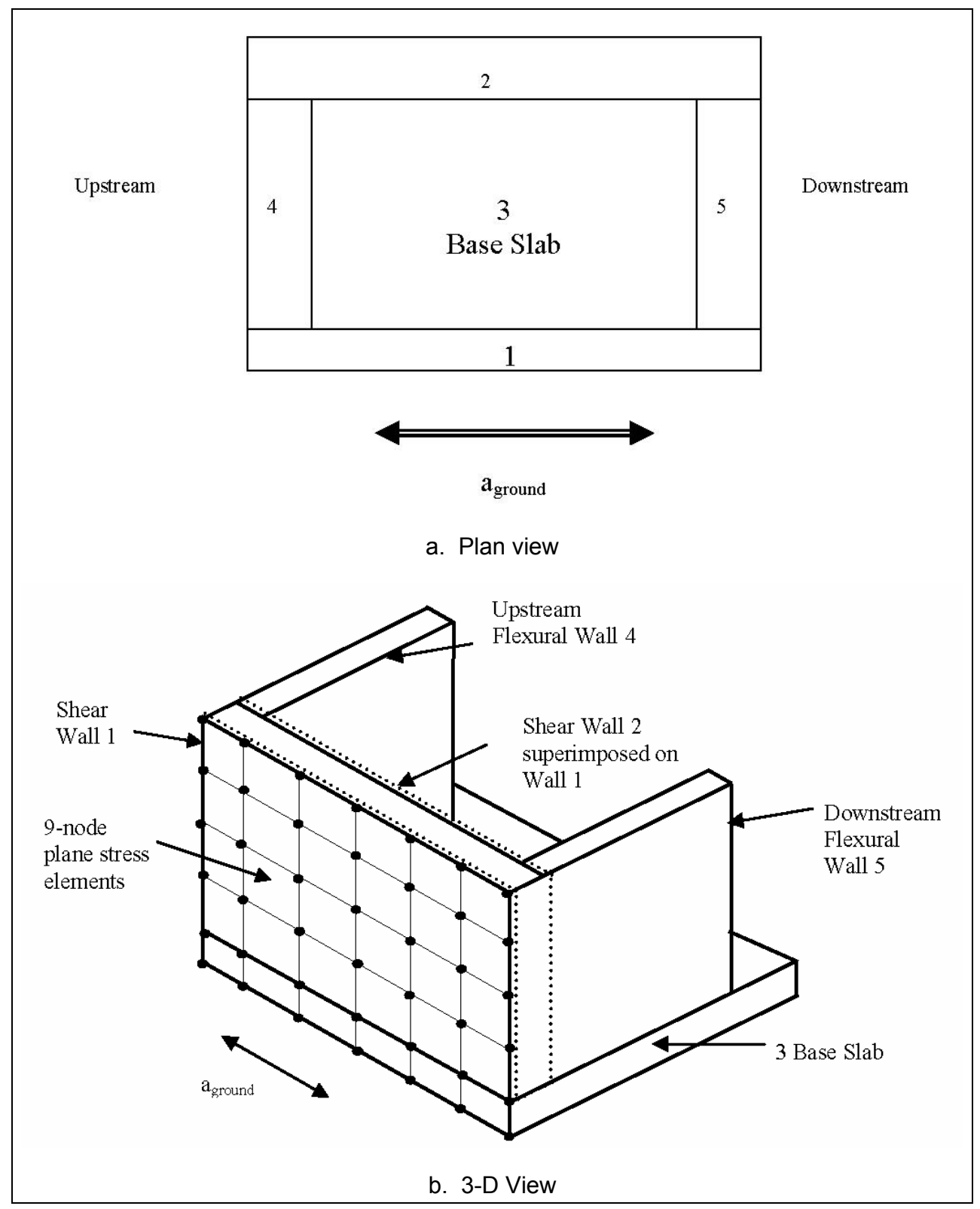

Figure 3-1. Idealized geometry of generator bay for composite finite element model (Continued) 


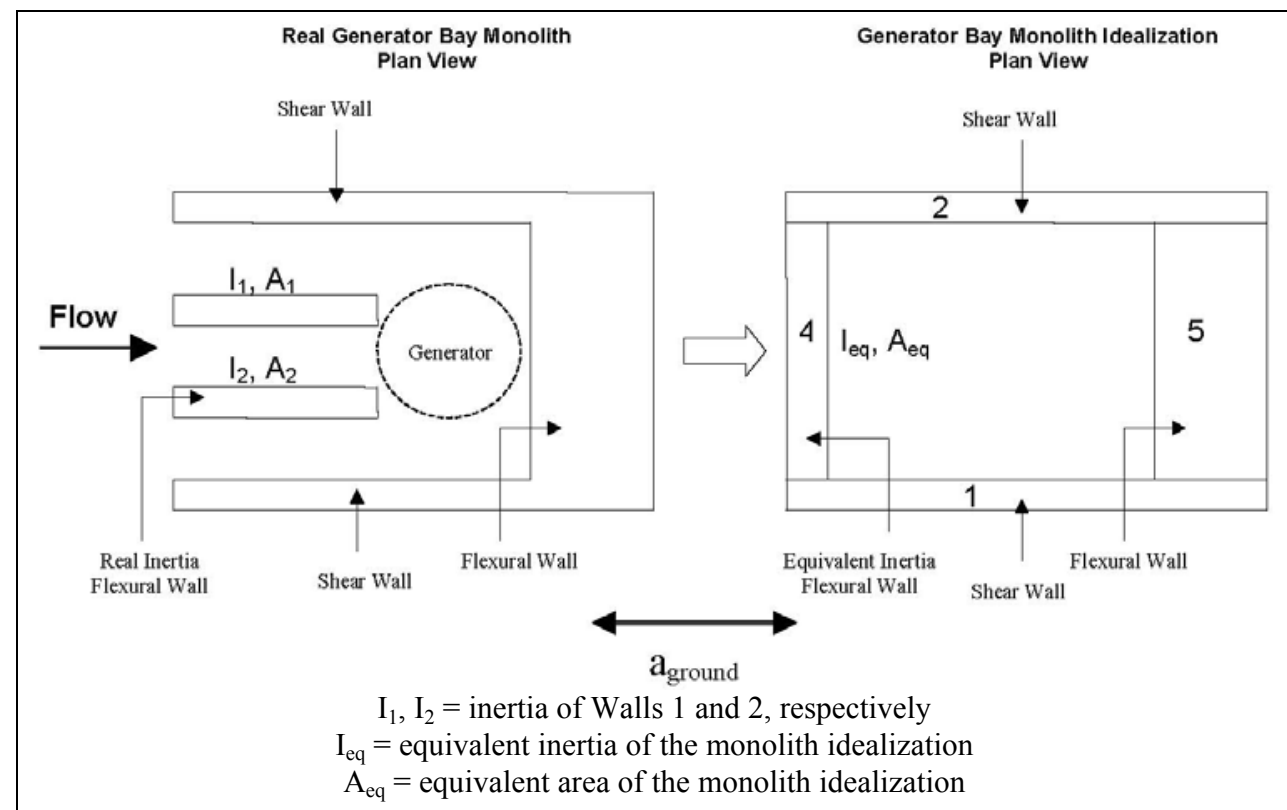

c. Equivalent inertia for the upstream flexural wall in generator bay geometry idealization

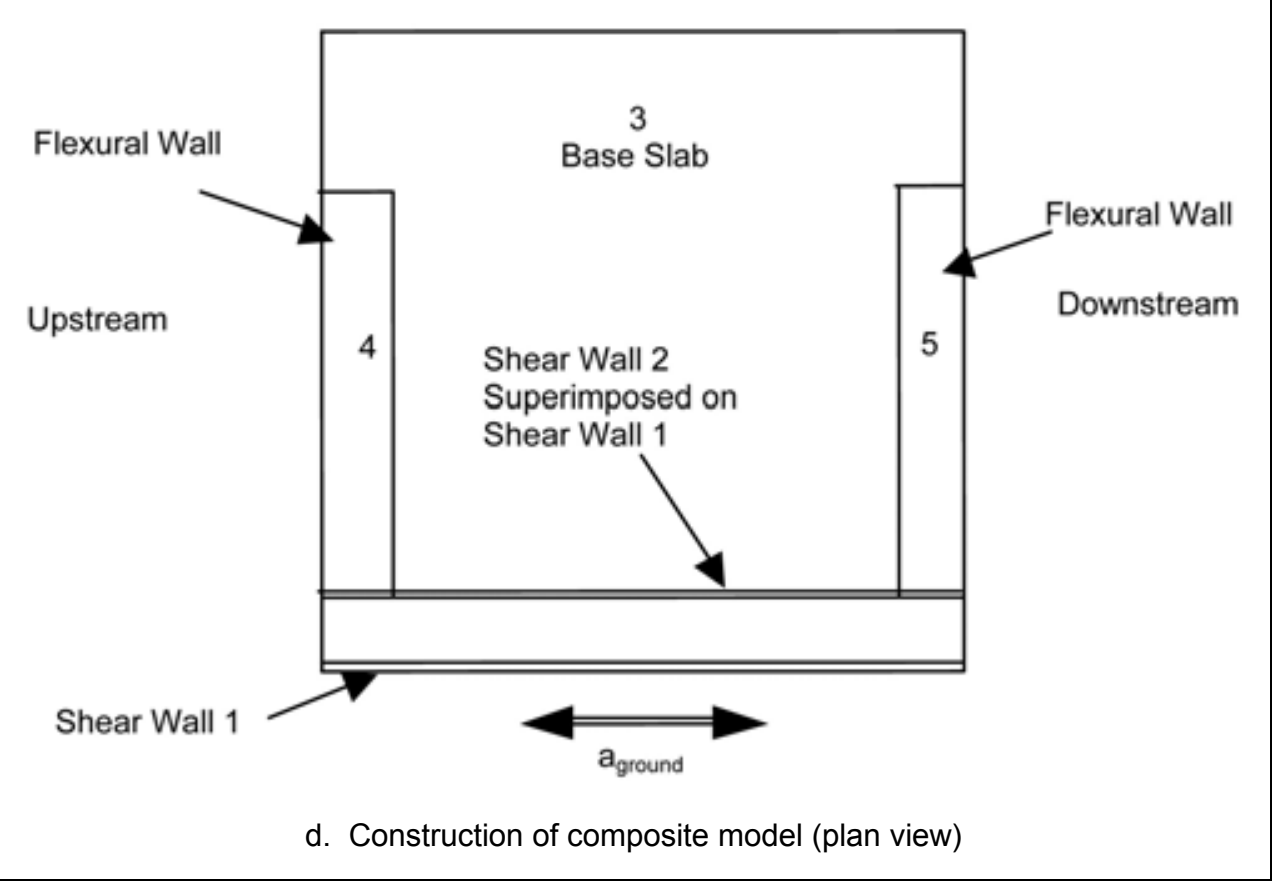

Figure 3-1. (Concluded) 
The idealized geometry consists of shear Walls 1 and 2 in plane with the upstream/downstream direction in which the ground motion is applied. The structural element 3 is the base slab of the idealized generator bay, and Walls 4 and 5 are the flexural walls. Some of the walls of the water intake points present on the upstream side form a channel through which the intake water passes (Figure 3-1c). A rectangular flexural wall is an idealization of the channel walls with equivalent inertia properties to those of the real walls. Appendix B provides an explanation and an example of the calculations made for the equivalent area and inertia for the upstream flexural wall for the model. The dimensions of each structural component of the idealized generator bay geometry are average values of the dimensions of the powerhouses in each group rounded to the nearest whole number. The dimension for each structural component of each group is presented in Table 3-3.

\begin{tabular}{|c|c|c|c|c|c|c|c|c|}
\hline \multicolumn{9}{|c|}{$\begin{array}{l}\text { Table 3-3 } \\
\text { Geometry of Composite Finite Element Model }\end{array}$} \\
\hline \multirow[b]{2}{*}{ Group } & \multirow[b]{2}{*}{$\begin{array}{l}\text { Height } \\
H \\
\mathrm{ft}\end{array}$} & \multirow{2}{*}{$\begin{array}{l}\text { Upstream/ } \\
\text { Downstream } \\
W \\
\mathrm{ft}\end{array}$} & \multirow[b]{2}{*}{$\begin{array}{l}\text { Out of Plane } \\
B \\
\mathrm{ft}\end{array}$} & \multicolumn{5}{|c|}{\begin{tabular}{|l} 
Thickness $\boldsymbol{t}, \mathrm{ft}$ \\
\end{tabular}} \\
\hline & & & & Wall 1 & Wall 2 & Base 3 & Wall 4 & Wall 5 \\
\hline 1 & 125 & 135 & 85 & 13 & 14 & 12 & 15 & 10 \\
\hline 2 & 100 & 130 & 75 & 14 & 13 & 12 & 8 & 6 \\
\hline \begin{tabular}{|l}
3 \\
3
\end{tabular} & \begin{tabular}{|l|}
70 \\
\end{tabular} & 1110 & 60 & 11 & \begin{tabular}{|l|}
14 \\
\end{tabular} & 8 & 8 & 6 \\
\hline 4 & 40 & 65 & 50 & 10 & 10 & 5 & 5 & 5 \\
\hline
\end{tabular}

Parametric studies were conducted to determine whether plane stress or plane strain finite elements would be used for the analysis. Plane stress finite elements assume zero stresses out of plane of the element, allowing out-of-plane deformation. The plane strain elements assume zero deformation out of plane of the element, permitting out-of-plane stress. Technical literature for concrete dams recommends plane stress elements because of the construction joints between monoliths. This assumption permits deformations between monoliths (HQUSACE 2003). Because powerhouse (substructure) monoliths have construction joints between them and are constructed in a similar manner to dams, plane stress elements were selected to account for out-of-plane deformations in the structure. The result of the parametric study between plane stress and plane strain elements for idealized powerhouse substructures is presented in Appendix C.

Nine-node plane stress elements were selected to represent the mass concrete of the generator bay after a parametric study was conducted of the various types of plane elements available in SAP2000. Plane elements have two degrees of freedom (vertical and horizontal translation) at each node. Because of the formulation for the nine-node elements, they show better flexural behavior in the model than four-node plane elements (Cook et al. 2002). In the parametric study between elements it was found that the fundamental period converges with fewer elements when using nine-node elements, reducing the number of elements needed in the model and the time for calculations. The SAP2000 finite element models are shown in Figure 3-2 for the four groups. Appendix C contains an explanation of the different types of elements available in SAP2000 and a comparison of results among them. 


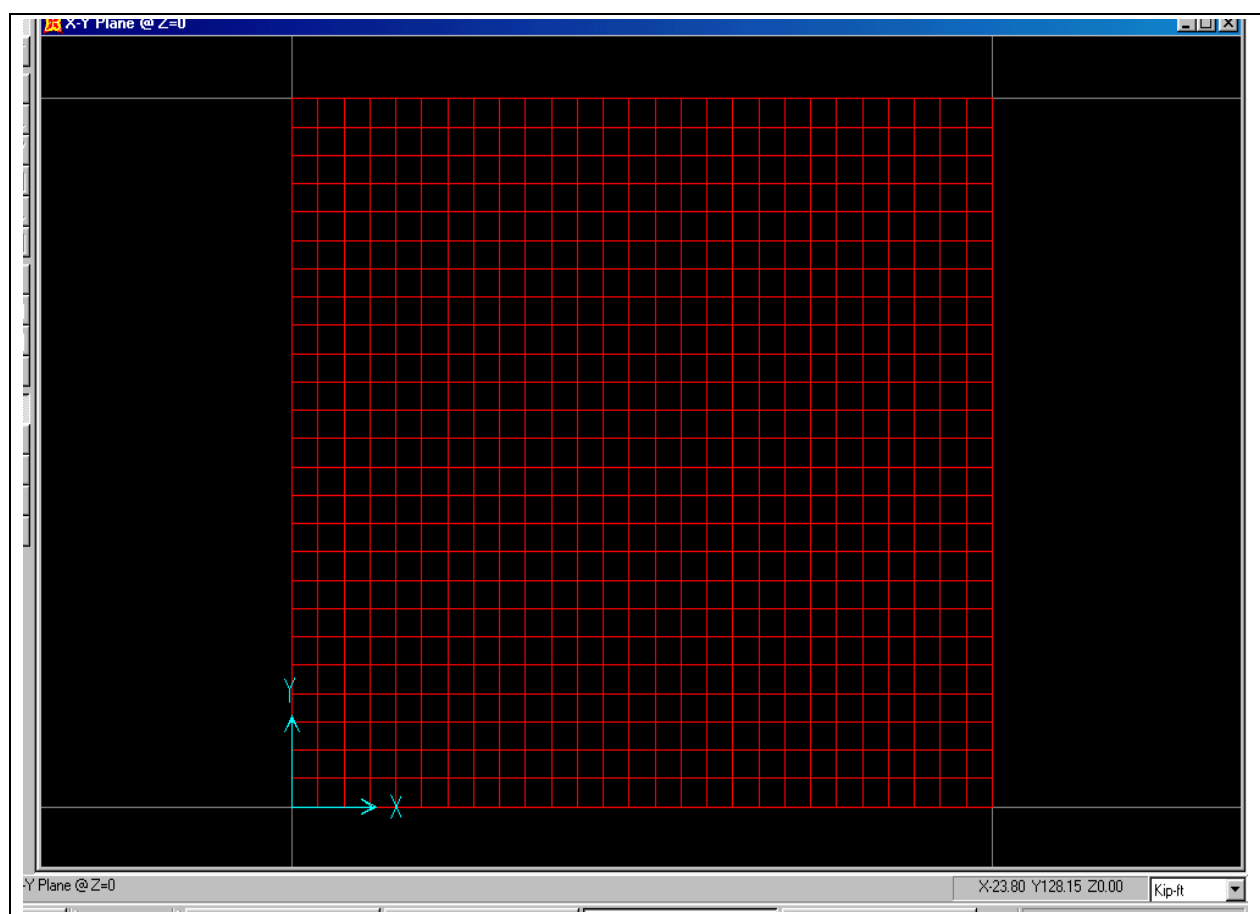

a. SAP2000 125-ft-high composite model

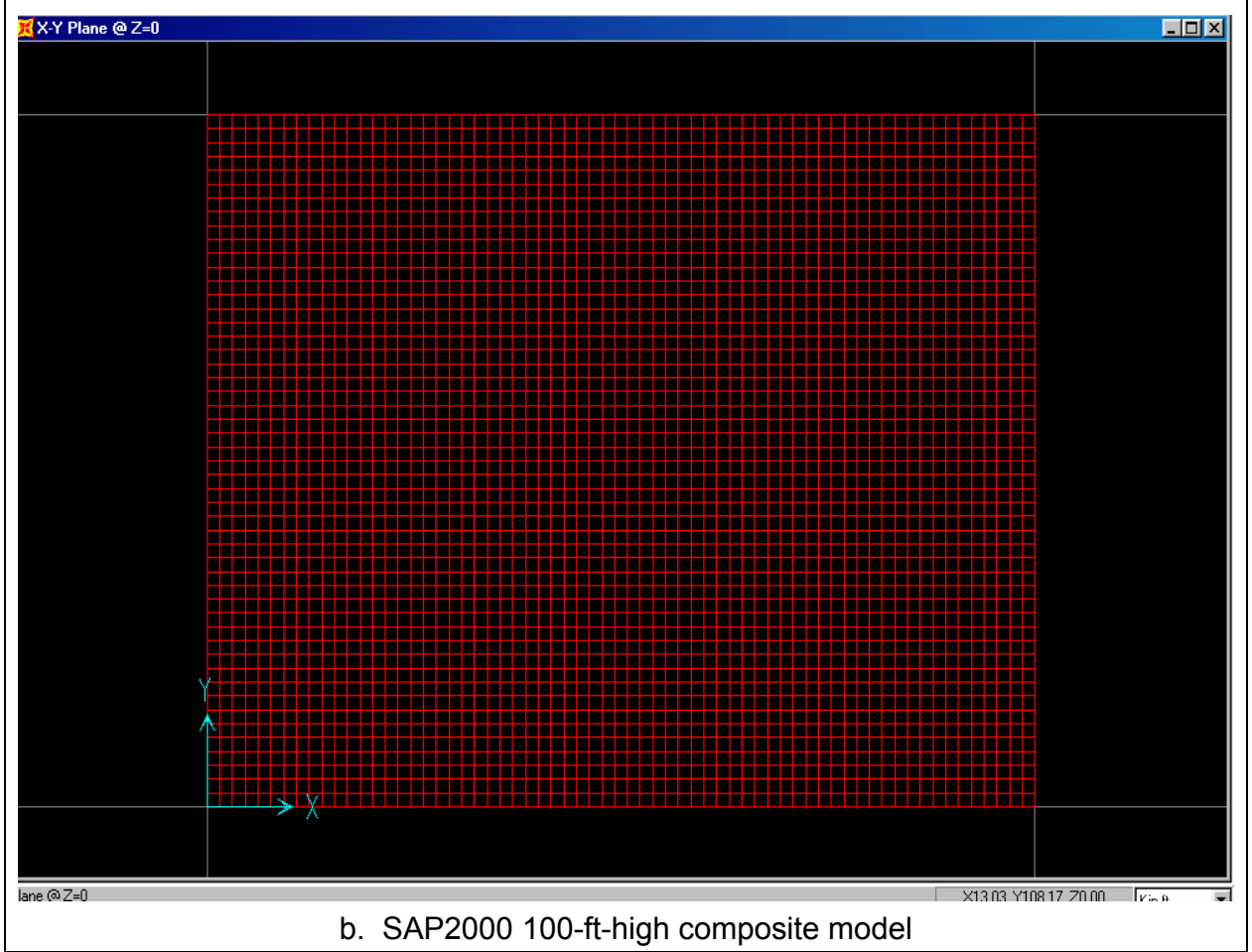

Figure 3-2. SAP2000 generator bay composite finite element models (Continued) 


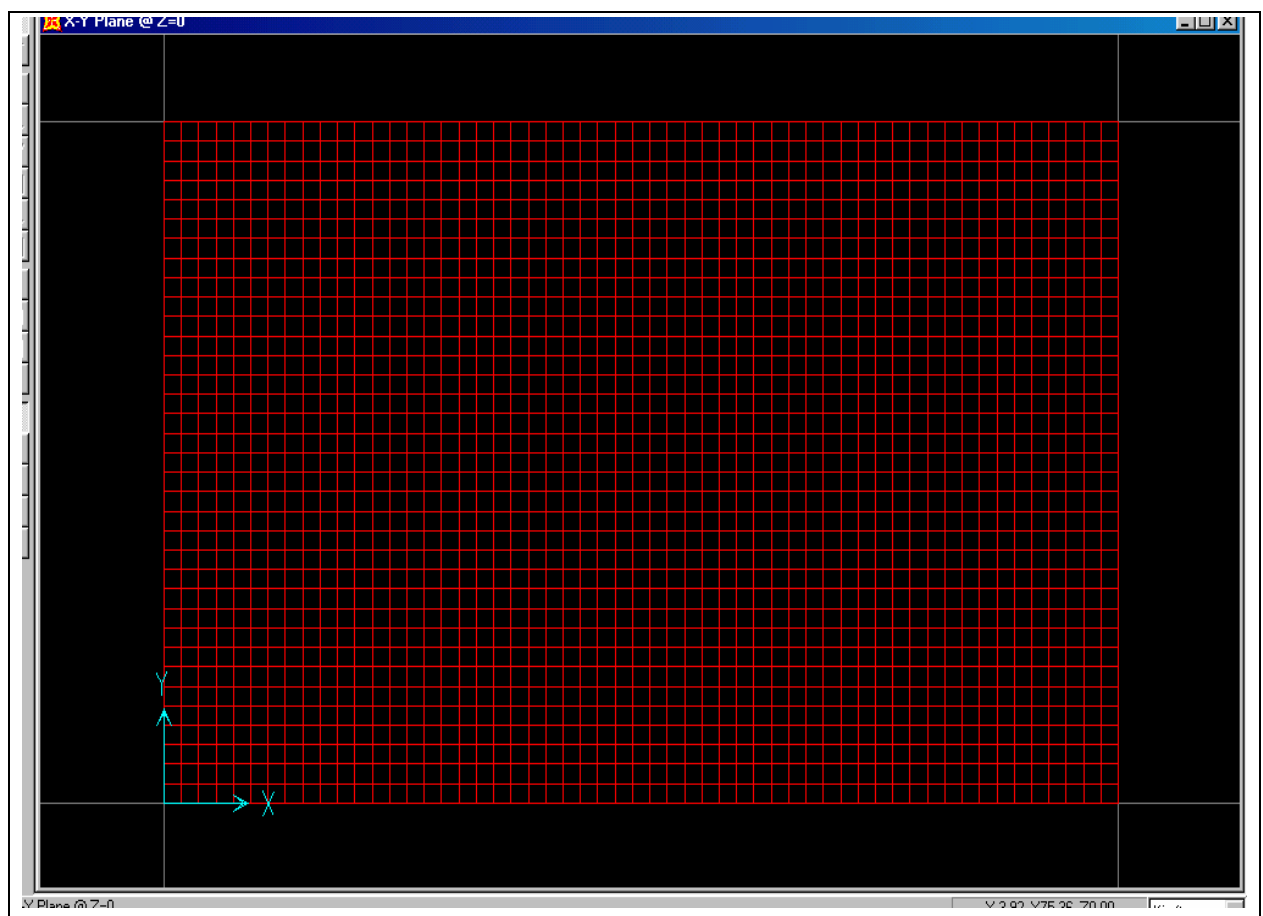

c. SAP2000 70-ft-high composite model

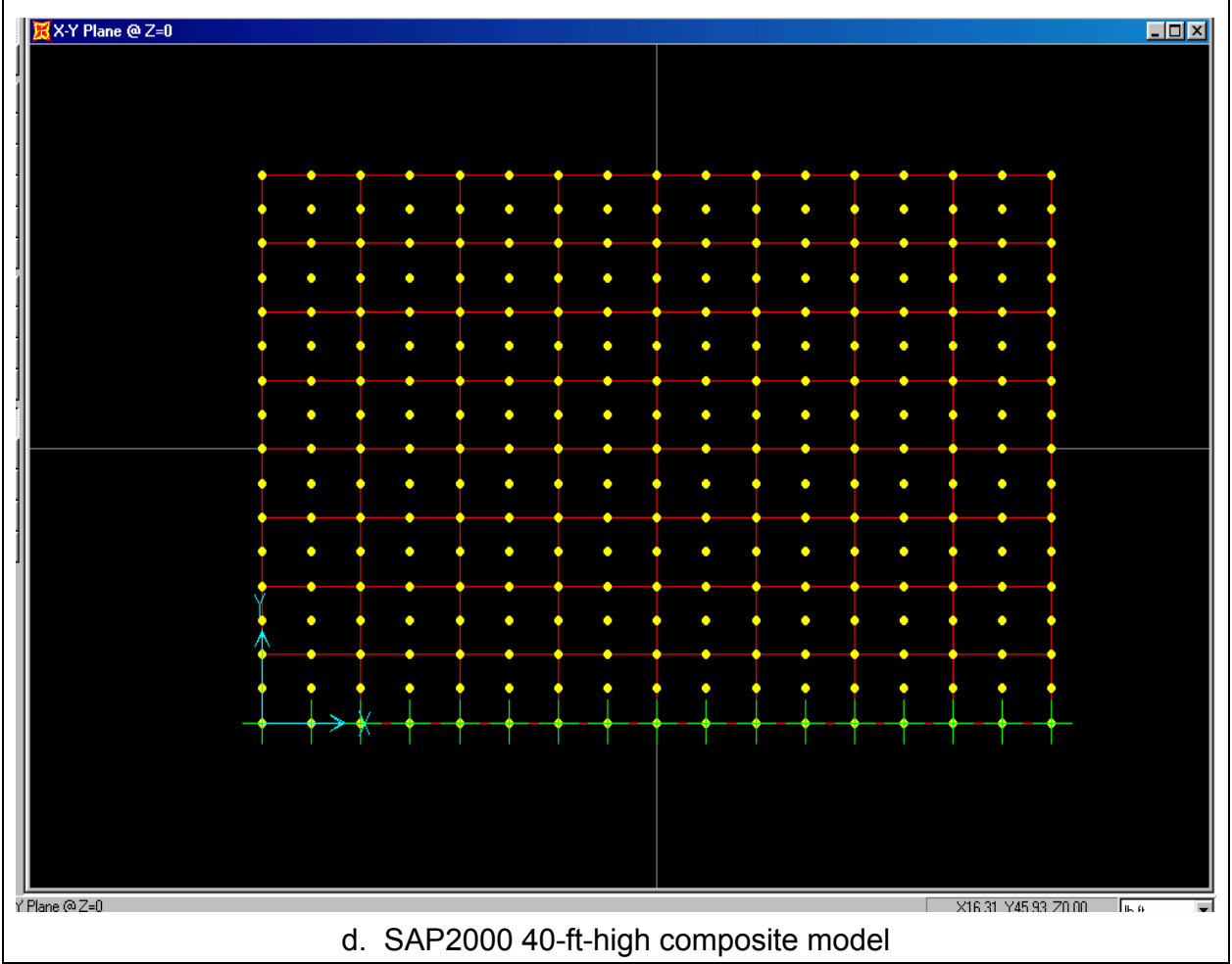

Figure 3-2. (Concluded) 


\subsection{Undamped Natural Frequencies and Modal Mass Participation Results}

The response to dynamic loads on the generator bay substructure will depend on the dynamic properties of the structure as well as the frequency of the ground motion. The natural periods and natural frequencies are two indices of the dynamic structural properties. The undamped natural period is the time required for an undamped system to complete one cycle of free vibration (Chopra 1995). The natural frequency is inversely proportional to the natural period and represents the number of cycles in one second (Ebeling 1992).

A structure will have a number of vibration modes, equal to the number of available degrees of freedom in the finite element mesh. Each vibration mode has a corresponding period/frequency. The total response of the structure will be a combination of the responses of each of the modes. In a modal analysis, the response of each mode is calculated and combined to determine the total response of the structure to dynamic loads. The number of modes needed for the dynamic analysis can be determined from the value of the modal Participating Mass Ratio (PMR). The PMR of a mode represents the contribution of the mode to the total response. For the analysis of buildings and other structures, it is recommended that the cumulative sum of the PMR be greater than or equal to 0.90 (FEMA 2001). The same criterion was used in this study to determine the number of modes that must be included in the time-history modal analysis.

A structural dynamic finite element analysis was performed on each of the four groups of generator bays to calculate the first mode of vibration for each group. The analyses were done assuming a "dry" condition (zero pool and tailrace water elevations) and a "wet" condition. The water contribution to the dynamic analysis was represented by hydrodynamic added mass on the upstream and downstream sides of the finite element models. A simplified procedure, Westergaard's solution, was used in the calculation of the added water mass (HQUSACE 1995a). More information on the calculation of hydrodynamic added mass can be found in Ebeling and Morrison (1992), and HQUSACE (1993, 1995b). Those calculations for the generator bays hydrodynamic added mass are presented in Appendix D.

The structural analysis software SAP2000 was used to calculate the natural periods and frequencies of each finite element model. The natural frequencies and periods obtained for each group of generator bays are presented in Table 3-4 for the dry condition and Table 3-5 for the wet condition. Data contained in these tables show that the models for the wet condition exhibited a smaller first mode natural frequency than did the models for the dry condition. This observation may be understood by referring to the relationship for the natural frequency $\omega$ $(\mathrm{rad} / \mathrm{sec})$ of a single degree of freedom (SDOF) system in Equation 3-2:

$$
\omega_{n}=\sqrt{\frac{k}{m}}
$$

where $k$ is the stiffness of the structure and $m$ is the mass. 


\begin{tabular}{|c|c|c|c|c|c|c|c|}
\hline \multicolumn{8}{|c|}{$\begin{array}{l}\text { Table 3-4 } \\
\text { Undamped Natural Frequencies and Modal Mass Participation Ratio } \\
\text { for Generator Bay Composite Models, Dry Condition }\end{array}$} \\
\hline \multirow[b]{2}{*}{ Model ID } & \multirow[b]{2}{*}{$\begin{array}{l}\text { Height } \\
\mathrm{ft}\end{array}$} & \multicolumn{2}{|c|}{ First Mode } & \multicolumn{4}{|c|}{ Final Mode } \\
\hline & & $T_{1}$, sec & $f_{1}, \mathrm{~Hz}$ & $\begin{array}{l}\text { Total No. } \\
i\end{array}$ & \begin{tabular}{|l|} 
PMR \\
$\%$ \\
\end{tabular} & $\begin{array}{l}T_{i} \\
\text { sec }\end{array}$ & \begin{tabular}{|l|}
$f_{i}$ \\
$\mathrm{~Hz}$
\end{tabular} \\
\hline 25S9GeD125C5 & 125 & 0.1008 & 9.92 & 40 & 90.4 & 0.007 & 143.86 \\
\hline 50S9GeD100C5 & 100 & 0.0737 & 13.58 & 34 & 90 & 0.0069 & 143.66 \\
\hline 35S9GeD70C5 & 70 & 0.048 & 20.7 & 40 & 90 & 0.0047 & 213.4 \\
\hline 8S9GeD40C5 & 40 & 0.0286 & 35 & 26 & 91.3 & 0.0033 & 305.42 \\
\hline
\end{tabular}

\begin{tabular}{|c|c|c|c|c|c|c|c|}
\hline \multicolumn{8}{|c|}{$\begin{array}{l}\text { Table 3-5 } \\
\text { Undamped Natural Frequencies and Modal Mass Participation Ratio } \\
\text { for Generator Bay Composite Models, Wet Condition }\end{array}$} \\
\hline \multirow[b]{2}{*}{ Model ID } & \multirow[b]{2}{*}{$\begin{array}{l}\text { Height } \\
\mathrm{ft}\end{array}$} & \multicolumn{2}{|c|}{ First Mode } & \multicolumn{4}{|c|}{ Final Mode } \\
\hline & & $T_{1}, \mathrm{sec}$ & $f_{1}, \mathrm{~Hz}$ & \begin{tabular}{|l} 
Total No. \\
$i$
\end{tabular} & $\begin{array}{l}\text { PMR } \\
\% \\
\end{array}$ & $\begin{array}{l}T_{i} \\
\text { sec } \\
\end{array}$ & $\begin{array}{l}f_{i} \\
\mathrm{~Hz}\end{array}$ \\
\hline 25S9GeW125C5 & 125 & 0.1311 & 7.63 & 24 & 90.5 & 0.0127 & 78.99 \\
\hline 50S9GeW100C5 & 100 & 0.095 & 10.53 & 34 & 90.45 & 0.0085 & 117.32 \\
\hline 35S9GeW70C5 & 70 & 0.0638 & 15.63 & 34 & 90.7 & 0.0069 & 145.4 \\
\hline $8 S 9 G e W 40 C 5$ & 40 & 0.0409 & 24.46 & 16 & 90.7 & 0.0055 & 180.6 \\
\hline
\end{tabular}

For a SDOF system with a constant stiffness $k$, an increase in mass $m$ reduces $\omega$. Recall that the natural frequency $f$, in $\mathrm{Hz}$, is given by Equation 3-3:

$$
f=\frac{\omega}{2 \pi}
$$

Figure 3-3 presents the first mode of vibration for the four groups of generator bays analyzed. Tables 3-4 and 3-5 summarize the first and final modes of vibrations included in each of the analyses for the four generator bay group models as well as the cumulative PMR values for each model. Figure 3-3 shows that a shear type deformation behavior, in the first vibration mode, controls the deformation shape in the models. This type of behavior is found in a structure with small height to width ratio, e.g., shear walls.

\subsection{CEUS and PNW Time-History Results}

A dynamic time-history analysis was performed on the four groups of generator bay substructures to determine the amplification of the rock acceleration due to the ground motion at the top of the substructure. A time-history of relative acceleration at the top of the substructure was calculated and then 


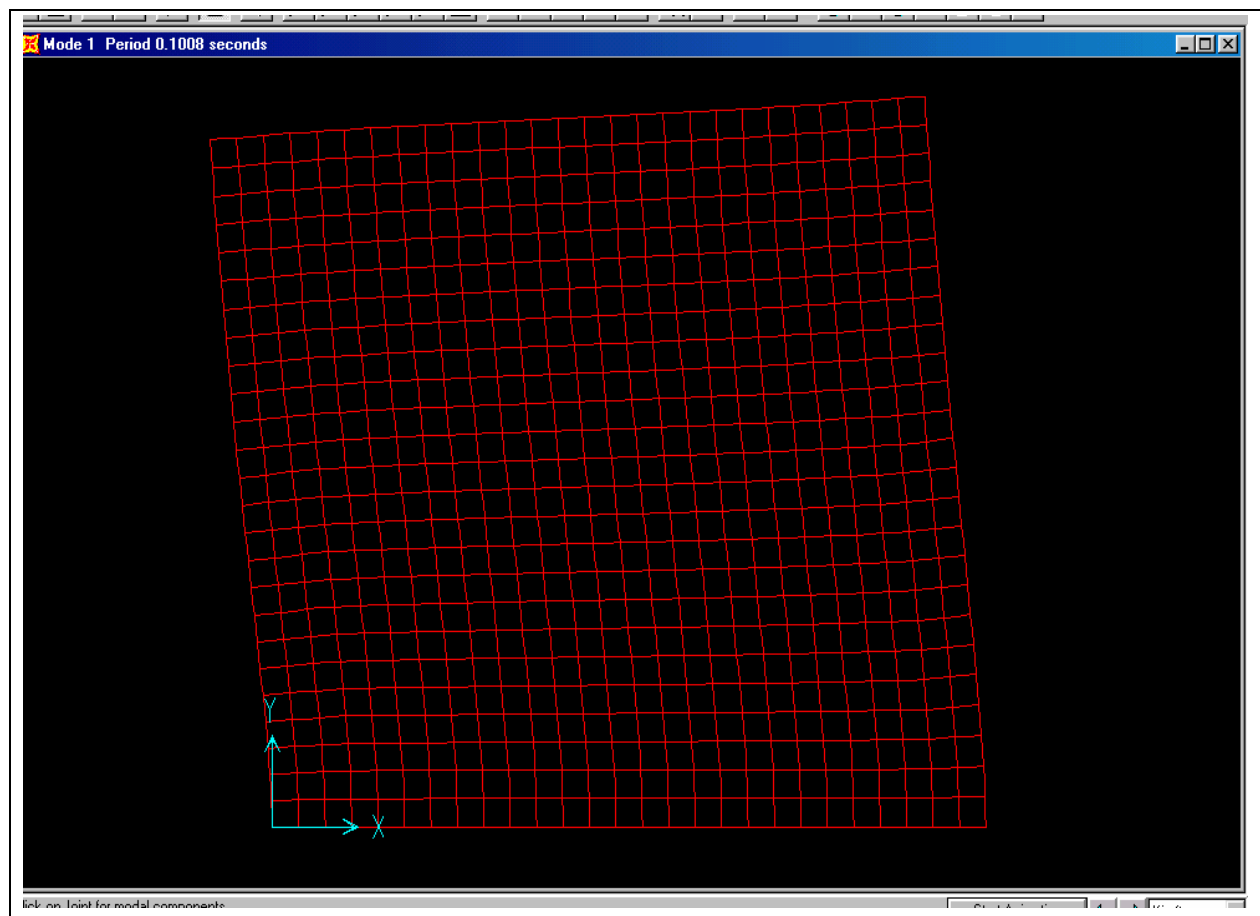

a. First mode of vibration for 125 -ft-high composite model

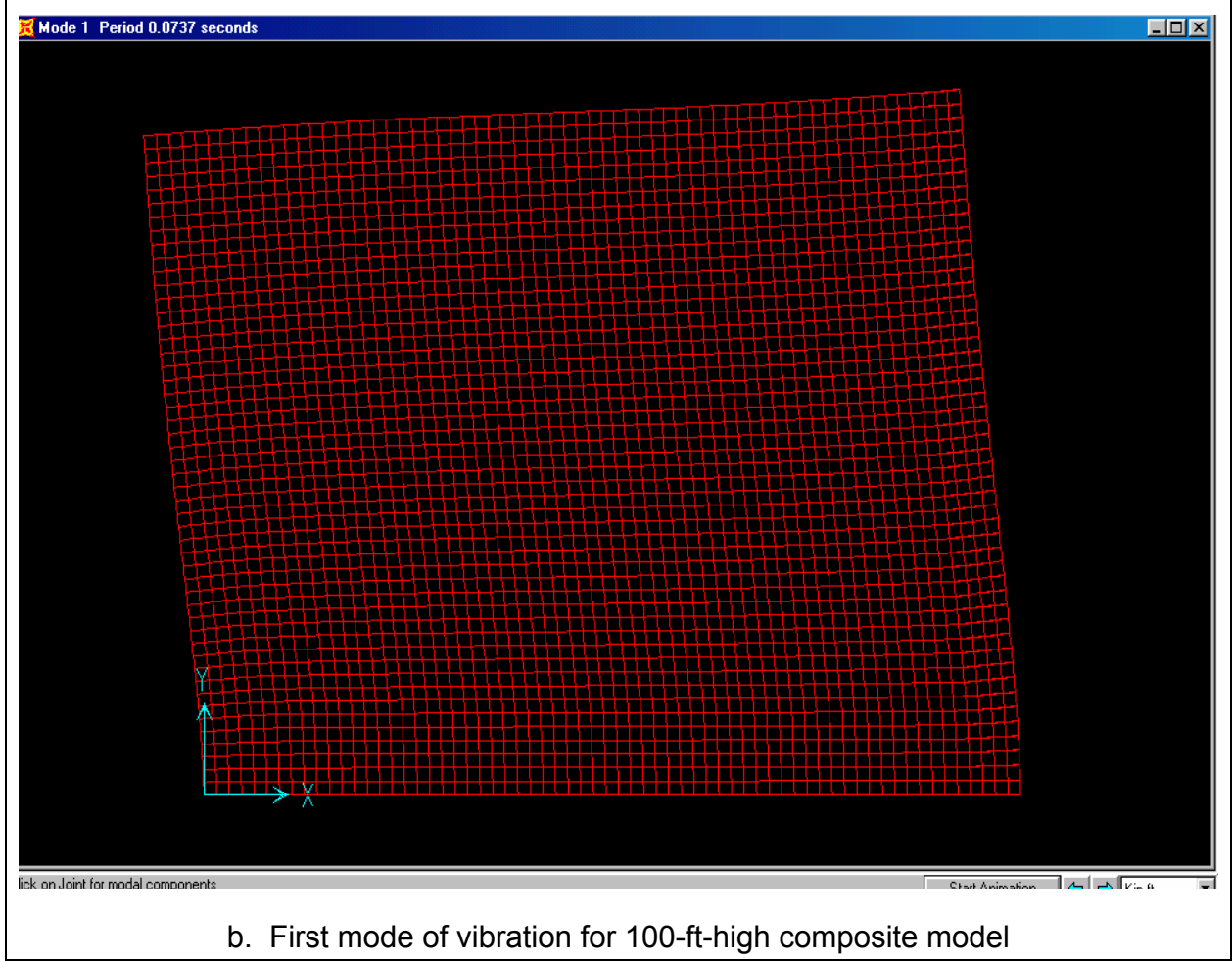

Figure 3-3. First mode of vibration for generator bay composite models (Continued) 


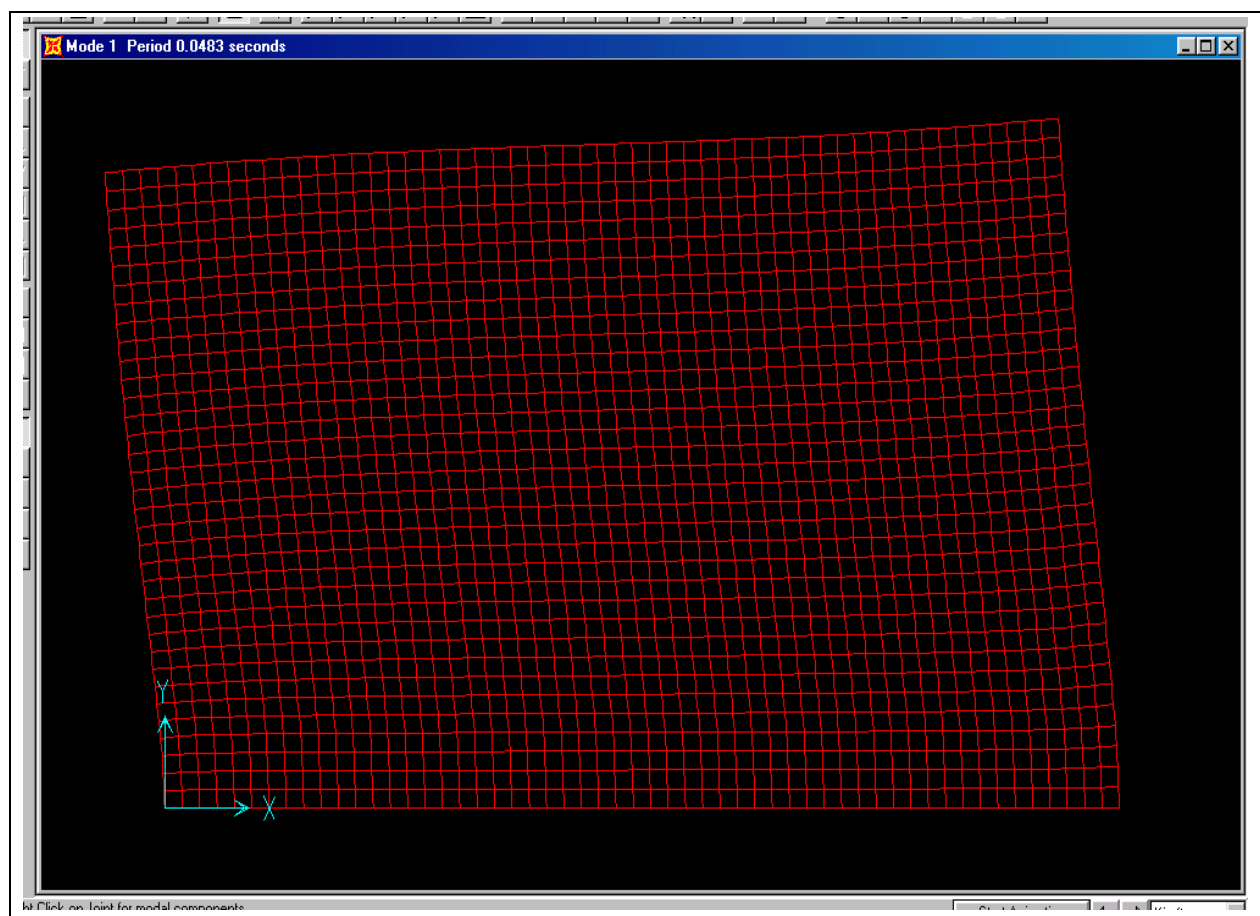

c. First mode of vibration for 70 -ft-high composite model

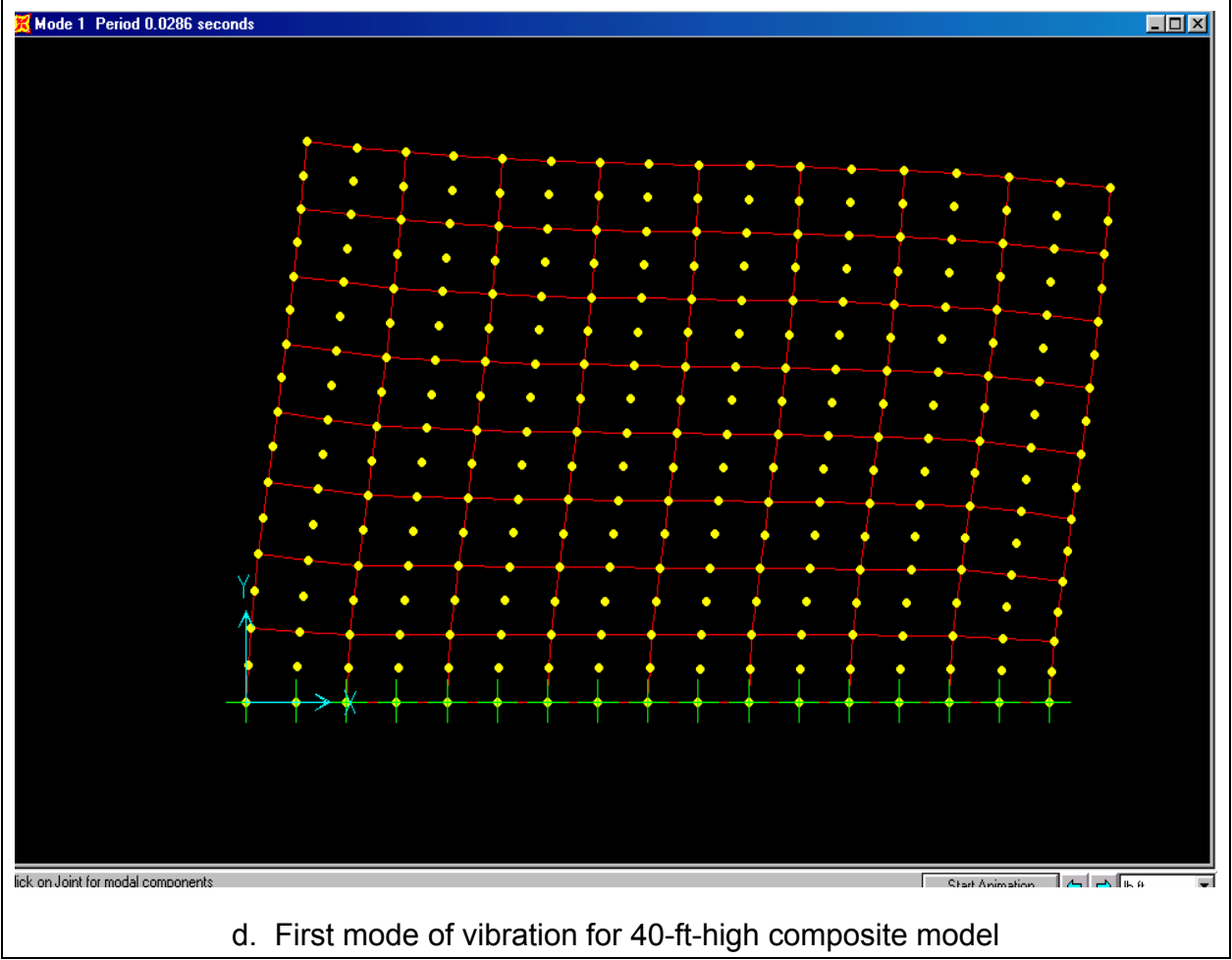

Figure 3-3. (Concluded) 
converted to absolute accelerations (SA). To calculate the top-of-substructure AFs, the SA at the top of the substructure was divided by the SA at rock for each frequency. As a result, a curve of AF as a function of frequency was created for each substructure model and for dry and wet conditions.

Tables 3-6 and 3-7 list the ratio of the total acceleration at a frequency of $50 \mathrm{~Hz}\left(\mathrm{SA}_{50 \mathrm{~Hz}}\right)$ divided by the PGA for dry and wet conditions, respectively. The PGA for the CEUS ground motion was $0.19 \mathrm{~g}$ and $0.16 \mathrm{~g}$ for the PNW ground motion. The SA and AF results presented in this chapter are for 5 percent damping ratio. It is envisioned that these AF curves will be used for the decoupled analysis of powerhouse superstructures. The SA and AF results for the same topof-substructure acceleration time-history but processed for a 2 percent damping ratio are presented in Appendix F. It is envisioned that those AF curves will be used for the decoupled analysis of powerhouse equipment.

\begin{tabular}{|c|c|c|c|c|c|}
\hline \multicolumn{6}{|c|}{$\begin{array}{l}\text { Table 3-6 } \\
\text { Absolute Acceleration (SA) at Frequency of } 50 \mathrm{~Hz} \text { for Generator } \\
\text { Bay Composite Models, Dry Condition }\end{array}$} \\
\hline \multirow[b]{2}{*}{ Model ID } & \multirow[b]{2}{*}{$\begin{array}{l}\text { Height } \\
\mathrm{ft}\end{array}$} & \multicolumn{2}{|c|}{ CEUS } & \multicolumn{2}{|c|}{ PNW } \\
\hline & & $\begin{array}{l}\text { SA }_{50 \mathrm{~Hz}} \\
\text { g's }\end{array}$ & \begin{tabular}{|l} 
SA/PGA \\
g's \\
\end{tabular} & \begin{tabular}{|l}
$\mathbf{S A}_{50 \mathrm{~Hz}}$ \\
g's
\end{tabular} & \begin{tabular}{|l} 
SA/PGA \\
g's \\
\end{tabular} \\
\hline 25S9GeD125C5 & 125 & 0.61 & 3.21 & 0.43 & 2.69 \\
\hline $50 \mathrm{~S} 9 \mathrm{GeD} 100 \mathrm{C5}$ & 100 & 0.51 & 2.68 & 0.30 & 1.88 \\
\hline 35S9GeD70C5 & 70 & 0.4 & 2.11 & 0.23 & 1.44 \\
\hline $8 \mathrm{~S} 9 \mathrm{GeD} 40 \mathrm{C} 5$ & 40 & 0.46 & 2.42 & 0.19 & 1.19 \\
\hline
\end{tabular}

Table 3-7

Absolute Acceleration (SA) at Frequency of $50 \mathrm{~Hz}$ for Generator Bay Composite Models, Wet Condition

\begin{tabular}{||l|l|l|l|l|l||}
\hline \multirow{2}{*}{ Model ID } & \multirow{2}{*}{$\begin{array}{l}\text { Height } \\
\mathbf{f t}\end{array}$} & $\begin{array}{l}\text { SA } \\
\text { g's }\end{array}$ & $\begin{array}{l}\text { SA/PGA } \\
\text { g's }\end{array}$ & $\begin{array}{l}\text { SA } \\
\text { g's }\end{array}$ & $\begin{array}{l}\text { SA/PGA } \\
\text { g's }\end{array}$ \\
\hline \hline 25 S9GeW125C5 & 125 & 0.54 & 2.84 & 0.41 & 2.56 \\
\hline 50 S9GeW100C5 & 100 & 0.56 & 2.95 & 0.38 & 2.38 \\
\hline 35 S9GeW70C5 & 70 & 0.36 & 1.89 & 0.29 & 1.81 \\
\hline 8S9GeW40C5 & 40 & 0.28 & 1.47 & 0.20 & 1.25 \\
\hline \hline
\end{tabular}

The maximum AFs at the top of the substructure are presented with their corresponding frequencies in Table 3-8 for the dry condition and Table 3-9 for the wet condition. Note that the maximum AFs were obtained at nearly the same frequency for both ground motions, CEUS and PNW. For the first two groups, Group 1 of 125 - $\mathrm{ft}$ height and Group 2 of 100-ft height, the maximum amplification results from the PNW ground motion. The substructure of the 70-ft height (Group 3) and 40-ft height (Group 4) has the maximum amplification in response to the CEUS ground motion. The same observation can be made for wet conditions listed in Table 3-9. For the wet cases, the amplifications were higher than the amplification for dry conditions. 


\begin{tabular}{|c|c|c|c|c|c|c|c|}
\hline \multicolumn{8}{|c|}{$\begin{array}{l}\text { Table 3-8 } \\
\text { Maximum AF and Its Corresponding SA for Generator Bay } \\
\text { Composite Models, Dry Condition }\end{array}$} \\
\hline \multirow[b]{2}{*}{ Model ID } & \multirow[b]{2}{*}{$\begin{array}{l}\text { Height } \\
\mathrm{ft}\end{array}$} & \multicolumn{3}{|c|}{ CEUS } & \multicolumn{3}{|c|}{$\begin{array}{l}\text { PNW } \\
\end{array}$} \\
\hline & & \begin{tabular}{|l}
$f$ \\
$\mathrm{~Hz}$ \\
\end{tabular} & $\begin{array}{l}\text { SA } \\
\text { g's }\end{array}$ & $\begin{array}{l}(\mathrm{AF})_{\mathrm{SA}} \\
\text { at } f\end{array}$ & \begin{tabular}{|l}
$f$ \\
$\mathrm{~Hz}$ \\
\end{tabular} & \begin{tabular}{|l|} 
SA \\
g's \\
\end{tabular} & $\begin{array}{l}(\mathrm{AF})_{\mathrm{SA}} \\
\text { at } f\end{array}$ \\
\hline 25S9GeD125C5 & 125 & 99 & 2.88 & 5.8 & 9.9 & 2.36 & 6.63 \\
\hline 50S9GeD100C5 & 100 & 13 & 2.75 & 6.76 & 13.6 & 1.91 & 7.21 \\
\hline $35 \mathrm{~S} 9 \mathrm{GeD} 70 \mathrm{C} 5$ & 70 & 20 & 1.90 & 6.53 & 22 & 0.79 & 3.80 \\
\hline 8S9GeD40C5 & 40 & 33 & 0.75 & 3.47 & 35 & 0.45 & 1.18 \\
\hline
\end{tabular}

\begin{tabular}{|c|c|c|c|c|c|c|c|}
\hline \multicolumn{8}{|c|}{$\begin{array}{l}\text { Table 3-9 } \\
\text { Maximum AF and Its Corresponding SA for Generator Bay } \\
\text { Composite Models, Wet Condition }\end{array}$} \\
\hline \multirow[b]{2}{*}{ Model ID } & \multirow[b]{2}{*}{$\begin{array}{l}\text { Height } \\
\mathrm{ft}\end{array}$} & \multicolumn{3}{|c|}{ CEUS } & \multicolumn{3}{|c|}{ PNW } \\
\hline & & \begin{tabular}{|l|}
$f$ \\
$\mathrm{~Hz}$ \\
\end{tabular} & $\begin{array}{l}\text { SA } \\
\text { g's } \\
\end{array}$ & $\begin{array}{l}(\mathrm{AF})_{\mathrm{SA}} \\
\text { at } f\end{array}$ & $\begin{array}{l}f \\
\mathrm{~Hz}\end{array}$ & \begin{tabular}{|l|} 
SA \\
g's \\
\end{tabular} & $\begin{array}{l}(\mathrm{AF})_{\mathrm{SA}} \\
\text { at } f \\
\end{array}$ \\
\hline 25S9GeW125C5 & $\begin{array}{ll}125 \\
\end{array}$ & 88 & 3.27 & 7.3 & 7.6 & 2 & 6.04 \\
\hline 50S9GeW100C5 & 100 & 9 & 2.24 & 4.84 & 10.5 & 1.96 & 5.85 \\
\hline 35S9GeW70C5 & 70 & 15 & 2.13 & 6.34 & 15.6 & 1.32 & 4.79 \\
\hline 8S9GeW40C5 & 40 & 24.5 & 1.16 & 4.76 & 24.5 & 0.48 & 2.45 \\
\hline
\end{tabular}

The AF curves for each model, in dry and wet conditions, for the two ground motions are presented in Figures 3-4 to 3-11. Table 3-10 lists the figure number for each curve. The shift in maximum AF response to higher frequency (due to the hydrodynamic added mass) is demonstrated in these figures. Note the solid line represents the dry condition SA and AF response and the dashed line represents the wet condition responses. The change in response due to the hydrodynamic added mass is dependent on the frequency change. Most of the differences in response between wet and dry conditions are near the first mode frequency. As the height of structure decreases, the value for this frequency at which maximum response occurs increases. An additional observation is that the AF value for wet and dry conditions converges to nearly the same value at higher frequencies.

\begin{tabular}{|c|c|c|c|}
\hline \multicolumn{4}{|c|}{$\begin{array}{l}\text { Table 3-10 } \\
\text { Figure Numbers of Generator Bay Composite Model Results for } \\
5 \text { Percent Damping }\end{array}$} \\
\hline Group & $\begin{array}{l}\text { Height } \\
\mathrm{ft}\end{array}$ & CEUS & PNW \\
\hline 1 & 125 & Figure 3-4 & Figure 3-8 \\
\hline 2 & 100 & Figure 3-5 & Figure 3-9 \\
\hline 3 & 70 & Figure 3-6 & Figure 3-10 \\
\hline 4 & 40 & Figure 3-7 & Figure 3-11 \\
\hline
\end{tabular}




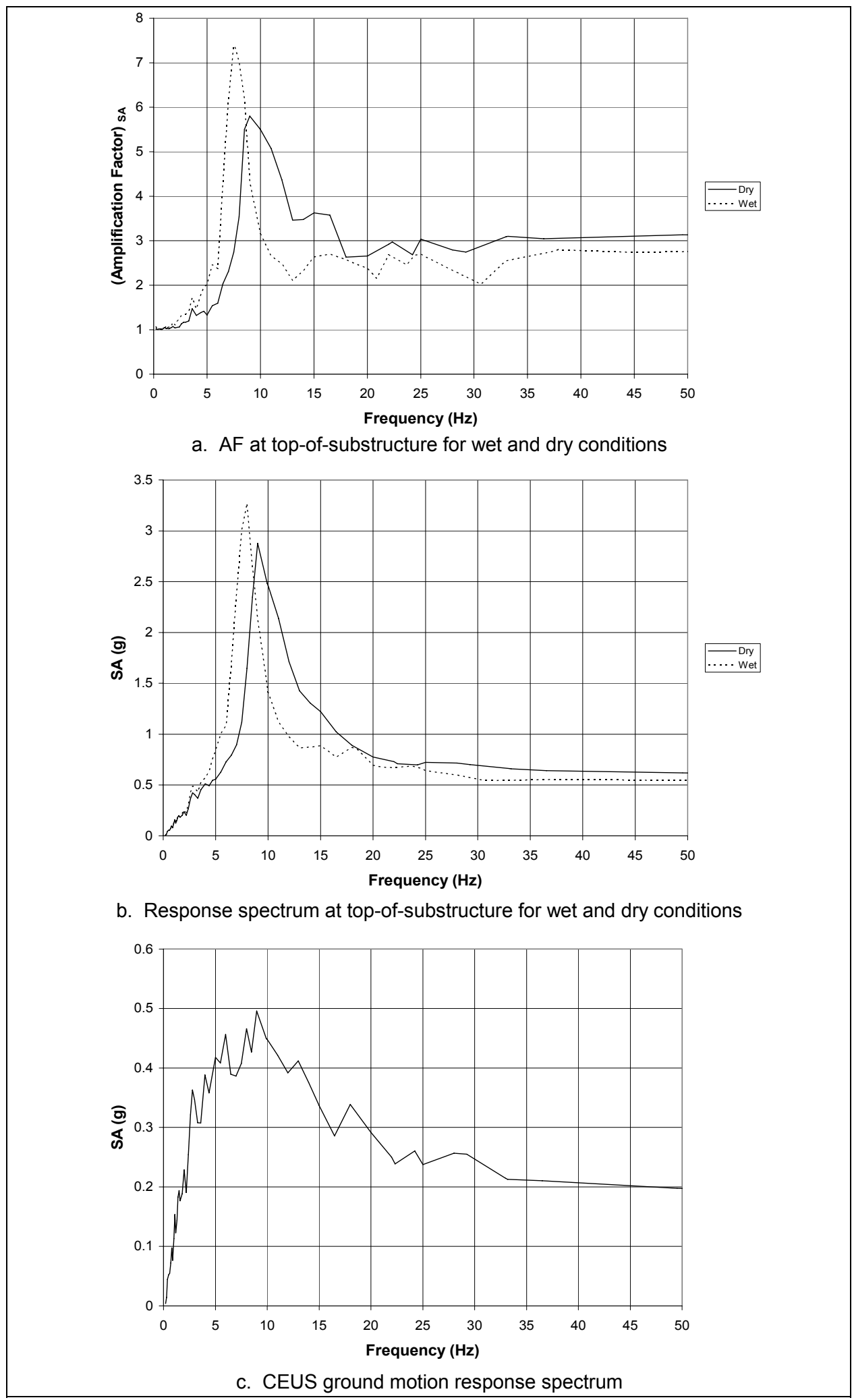

Figure 3-4. Response spectra and AF curves, generator bay, composite model, 125-ft height (Dry Model ID: 25S9GeD125C5, Wet Model ID:

25S9GeW125C5), for CEUS ground motion with 5 percent damping 


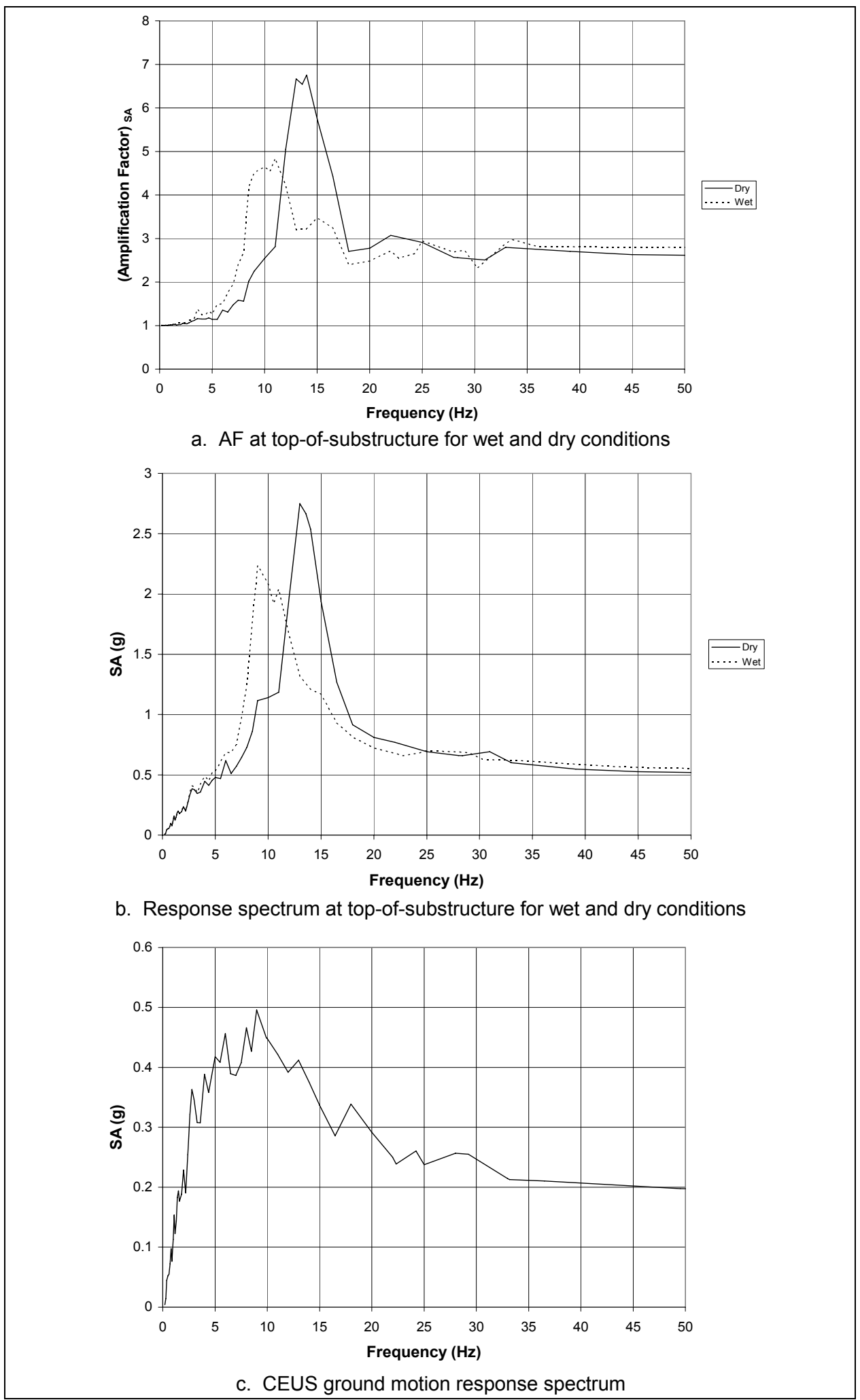

Figure 3-5. Response spectra and AF curves, generator bay, composite model, 100-ft height (Dry Model ID: 50S9GeD100C5, Wet Model ID:

$50 S 9 \mathrm{GeW} 100 \mathrm{C5})$, for CEUS ground motion with 5 percent damping 


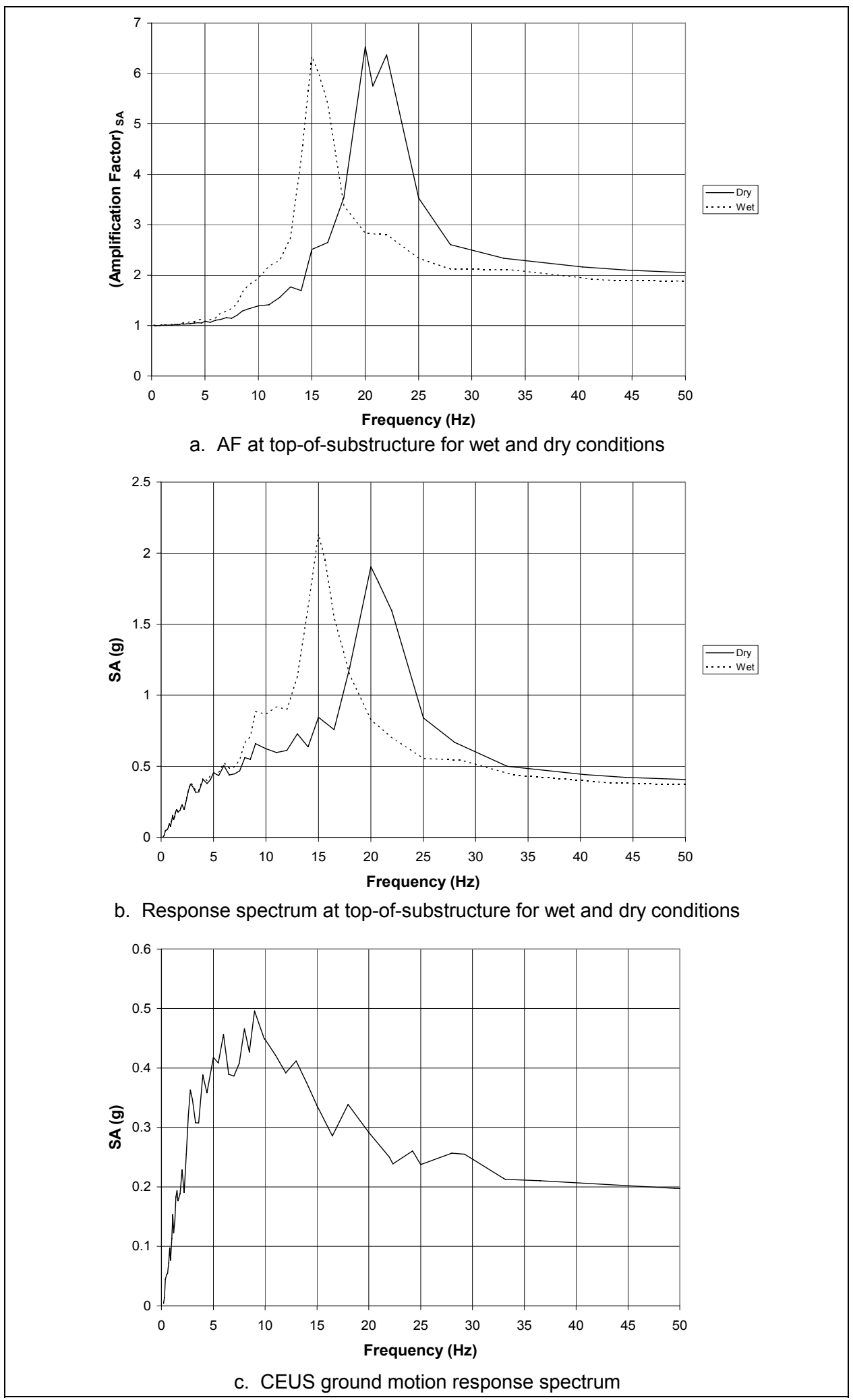

Figure 3-6. Response spectra and AF curves, generator bay, composite model, 70-ft height (Dry Model ID: 35S9GeD70C5, Wet Model ID: 35S9GeW70C5), for CEUS ground motion with 5 percent damping 


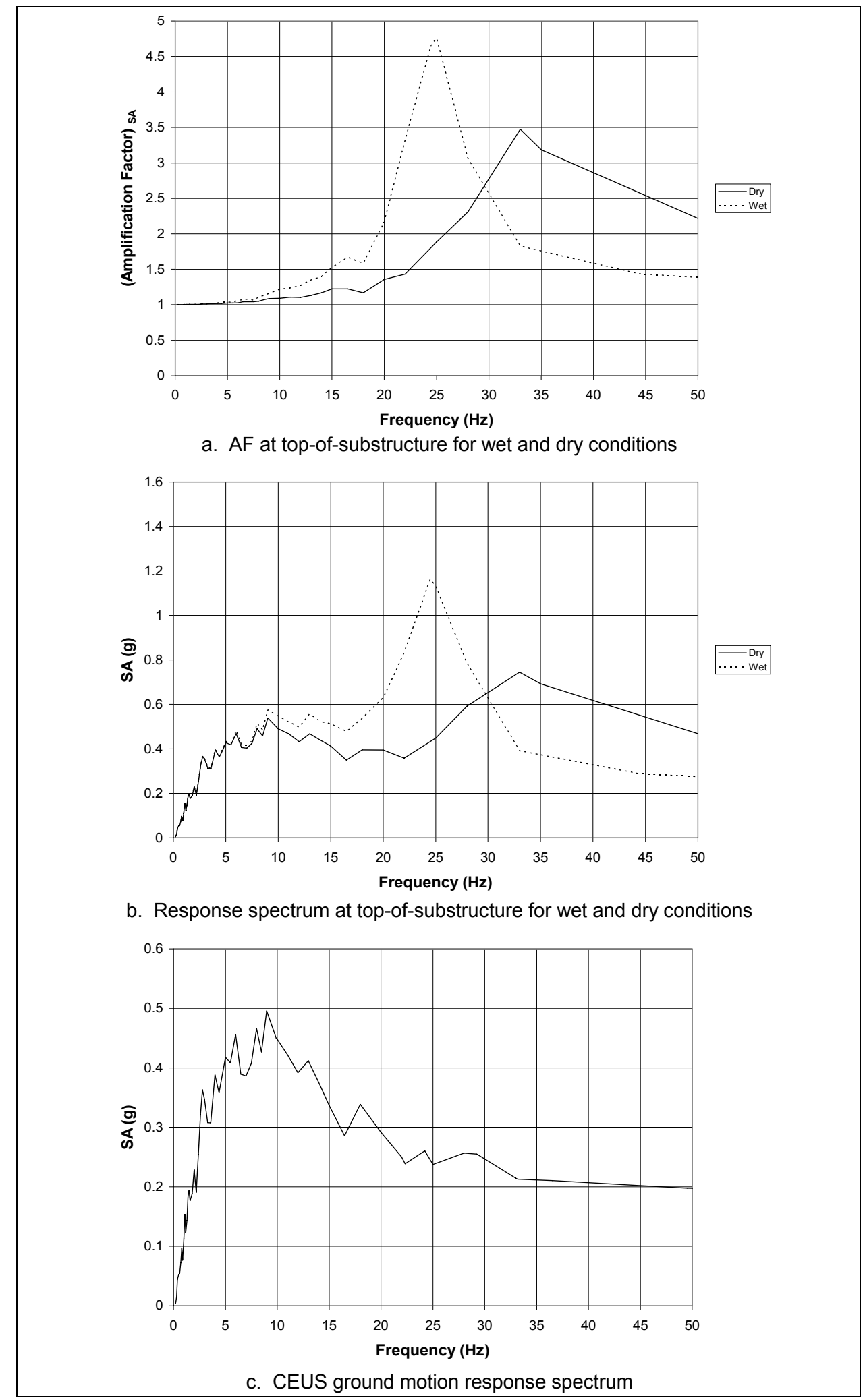

Figure 3-7. Response spectra and AF curves, generator bay, composite model, 40-ft height (Dry Model ID: 8S9GeD40C5, Wet Model ID:

$8 S 9 \mathrm{GeW} 40 \mathrm{C5}$ ), for CEUS ground motion with 5 percent damping 


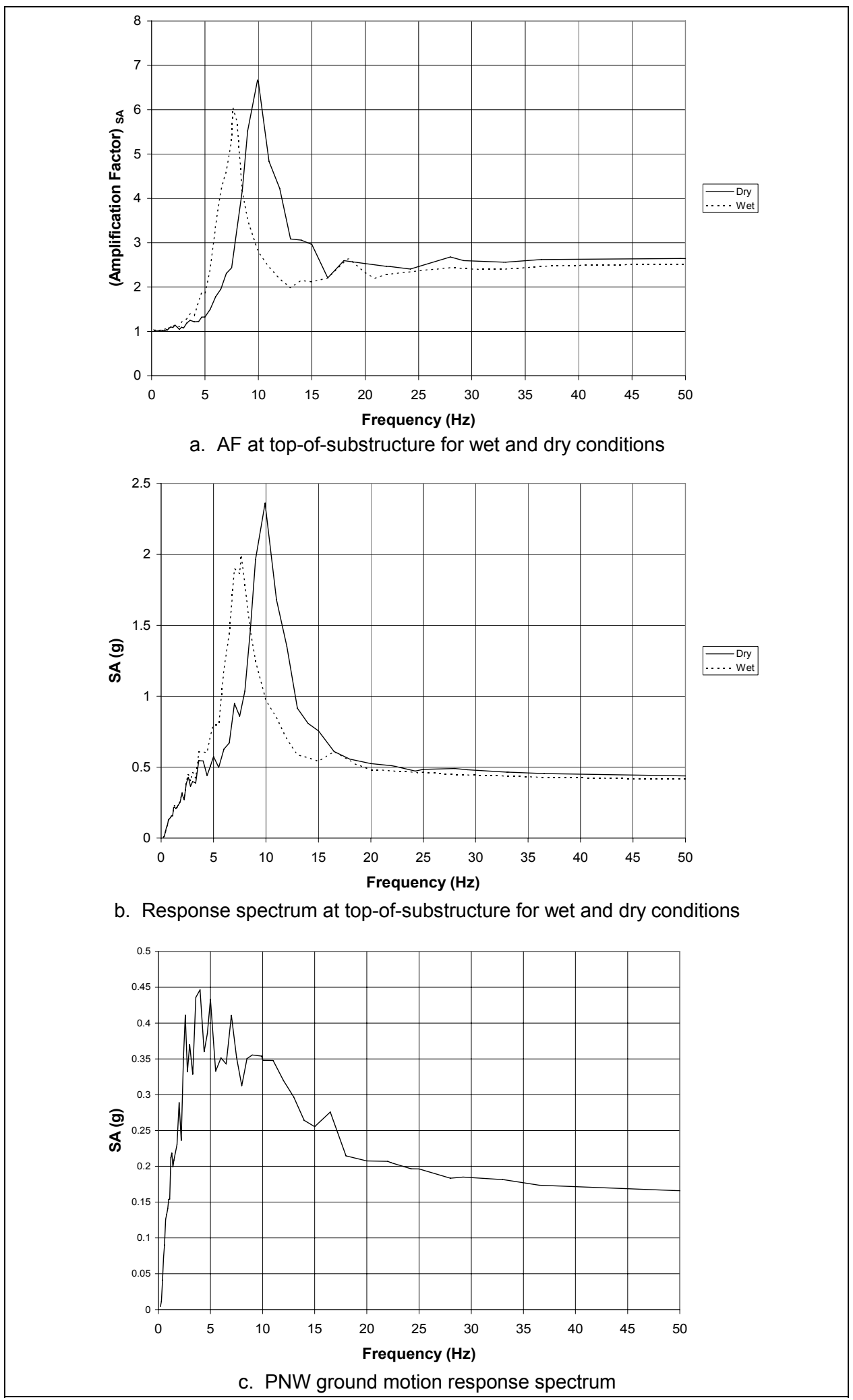

Figure 3-8. Response spectra and AF curves, generator bay, composite model, 125-ft height (Dry Model ID: 25S9GeD125C5, Wet Model ID:

25S9GeW125C5), for PNW ground motion with 5 percent damping 


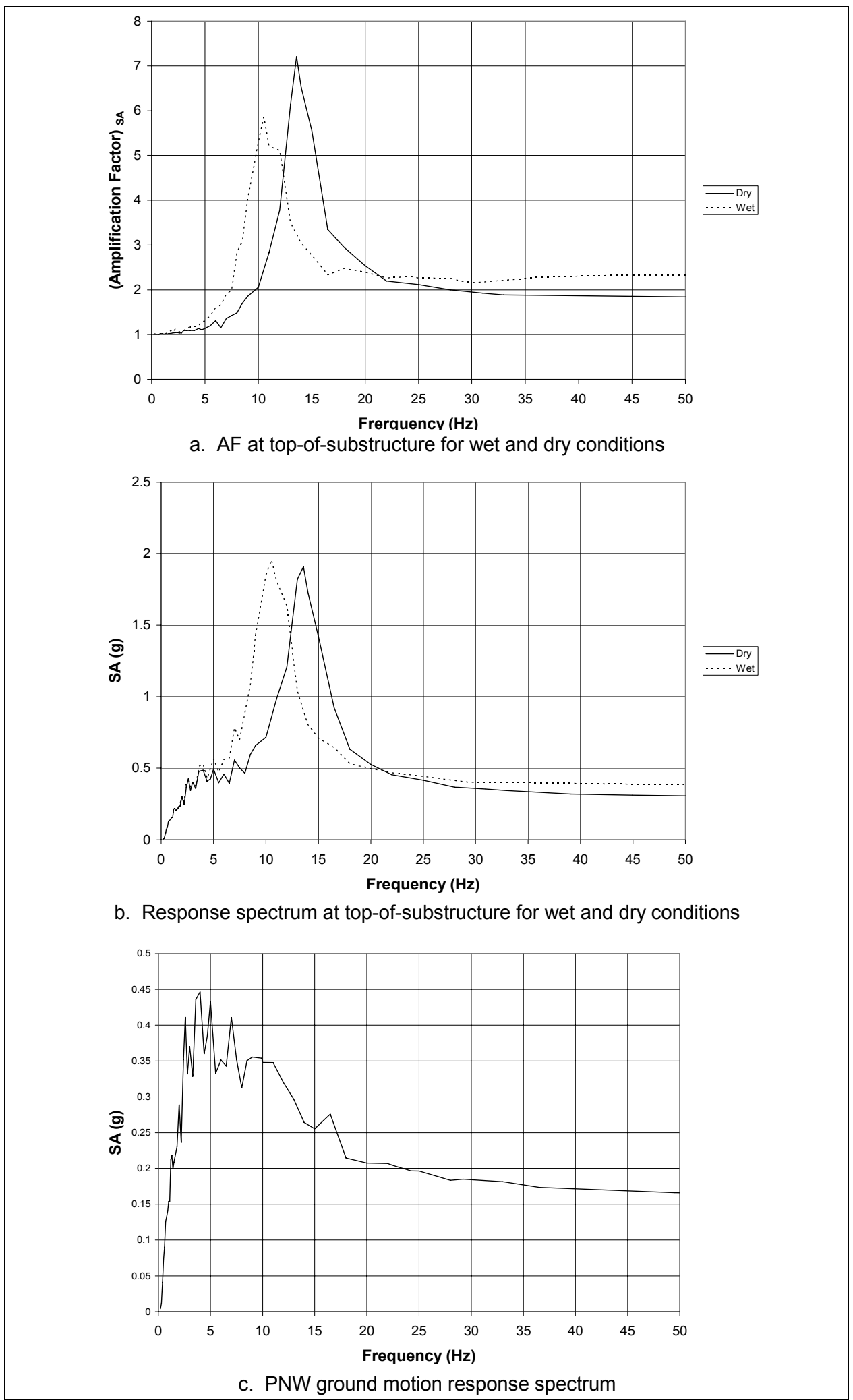

Figure 3-9. Response spectra and AF curves, generator bay, composite model, 100-ft height (Dry Model ID: 50S9GeD100C5, Wet Model ID: $50 S 9 \mathrm{GeW} 100 \mathrm{C} 5)$, for PNW ground motion with 5 percent damping 


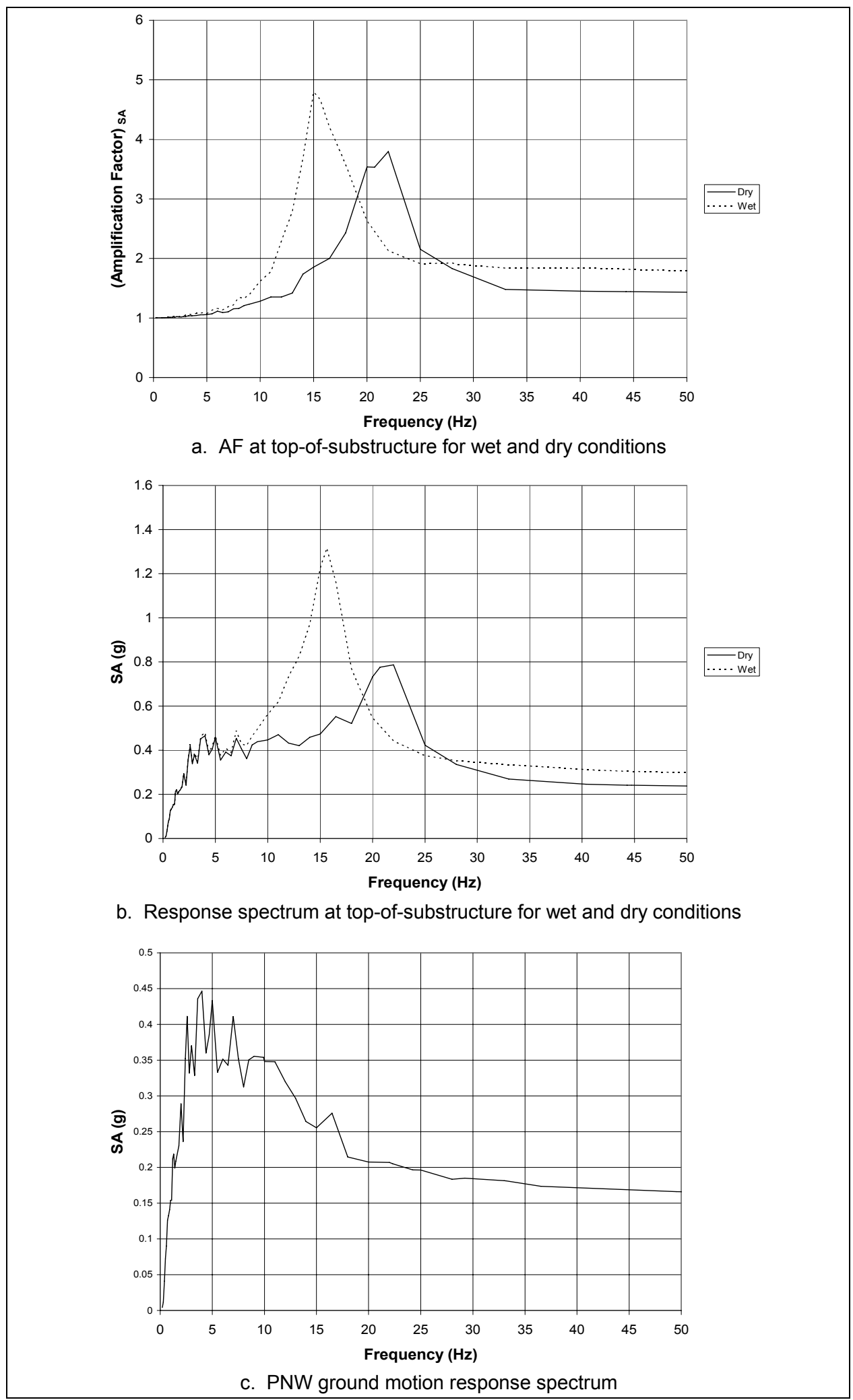

Figure 3-10. Response spectra and AF curves, generator bay, composite model, 70-ft height (Dry Model ID: 35S9GeD70C5, Wet Model ID:

35S9GeW70C5), for PNW ground motion with 5 percent damping 


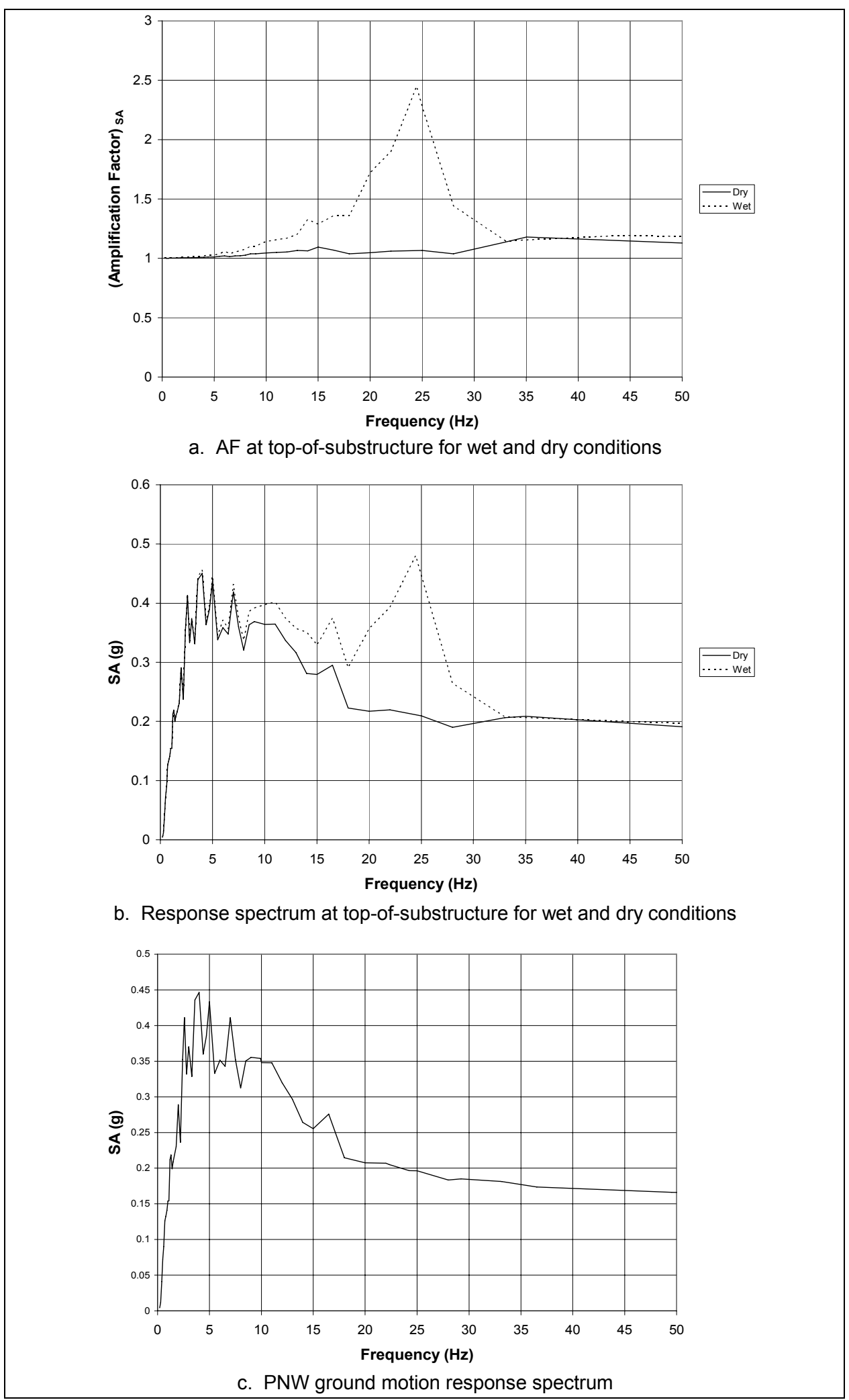

Figure 3-11. Response spectra and AF curves, generator bay, composite model, 40-ft height (Dry Model ID: 8S9GeD40C5, Wet Model ID:

$8 S 9 \mathrm{GeW} 40 \mathrm{C} 5)$, for PNW ground motion with 5 percent damping 


\subsection{Response Amplification Sensitivity to Location along the Top of the Substructure for the Generator Bay Composite Model}

The results presented in Section 3.5 were obtained by calculating the spectral acceleration at the top midnode of the composite finite element model. A parametric study was performed to investigate the variation in amplification across the top of the substructure. The spectral accelerations (5 percent damping) and AFs versus frequency curves were calculated at the three nodes identified in Figure 3-12. The finite element model used for this analysis was the 125-ftheight composite model, wet condition.

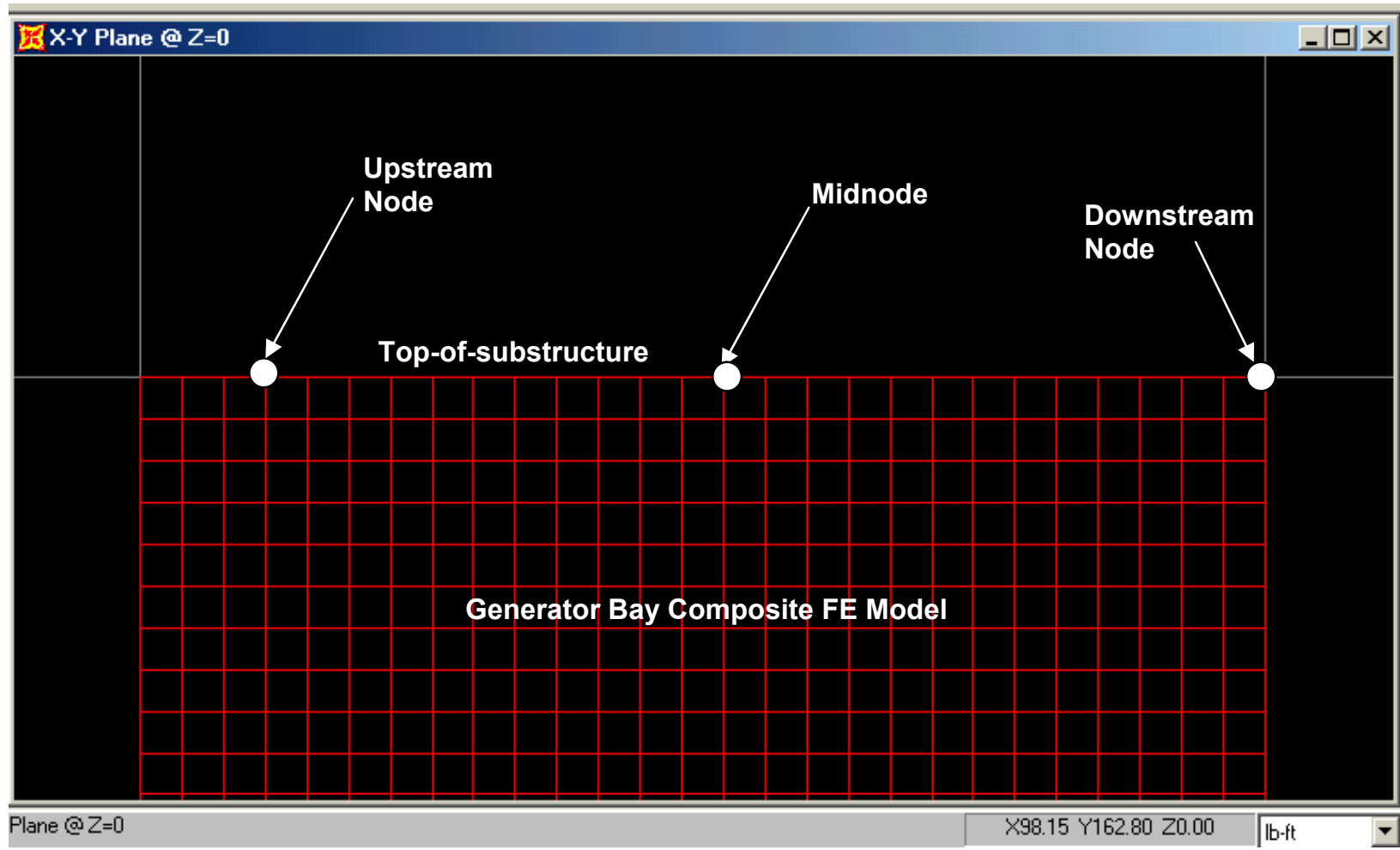

Figure 3-12. Location of the three nodes in the 125-ft-height generator bay composite model used to calculate AFs

Table 3-11 lists values of SA at $50 \mathrm{~Hz}$ and its ratio to the PGA for the two ground motions of CEUS and PNW. Table 3-12 lists the maximum AF and the corresponding frequency at the three different locations along the top of the substructure. Figure 3-13 shows the variation in spectral acceleration with frequency for the three locations at top of the substructure, and Figure 3-14 shows the corresponding AF curves. Because of the influence of the added water mass, as explained in Appendix D, the responses near the upstream side are higher than those for the midnode and the downstream node. At frequencies near the first mode of vibration of the finite element model, the AF at the middle of the substructure is equal to the AF at the downstream side. 


\begin{tabular}{|c|c|c|c|c|c|}
\hline \multicolumn{6}{|c|}{$\begin{array}{l}\text { Table } 3-11 \\
\text { SA at } 50 \mathrm{~Hz} \text { at Three Different Locations along the Top of the } \\
\text { 125-ft-Height Composite Substructure Model for the Wet Condition }\end{array}$} \\
\hline \multirow[b]{2}{*}{ Model ID } & \multirow[b]{2}{*}{$\begin{array}{l}\text { Height } \\
\mathrm{ft}\end{array}$} & \multicolumn{2}{|c|}{ " CEUS } & \multicolumn{2}{|c|}{ PNW } \\
\hline & & $\begin{array}{l}\mathrm{SA}_{50 \mathrm{~Hz}} \\
\text { g's }\end{array}$ & $\begin{array}{l}\text { SA / PGA } \\
\text { g's }\end{array}$ & $\begin{array}{l}\mathrm{SA}_{50 \mathrm{~Hz}} \\
\text { g's }\end{array}$ & $\begin{array}{l}\text { SA / PGA } \\
\text { g's }\end{array}$ \\
\hline $\begin{array}{l}\text { 25S9GeW125C5- } \\
\text { Upstream }\end{array}$ & $\begin{array}{l}125 \\
\end{array}$ & 0.73 & $\begin{array}{l}3.84 \\
\end{array}$ & $\begin{array}{c}0.5 \\
\end{array}$ & ב3.13 \\
\hline $\begin{array}{l}\text { 25S9GeW125C5- } \\
\text { Midnode }\end{array}$ & 125 & 0.54 & 2.84 & 0.41 & 2.56 \\
\hline $\begin{array}{l}\text { 25S9GeW125C5- } \\
\text { Downstream }\end{array}$ & 125 & 0.56 & 2.95 & 0.41 & 2.56 \\
\hline
\end{tabular}

\begin{tabular}{|c|c|c|c|c|c|c|c|}
\hline \multicolumn{8}{|c|}{$\begin{array}{l}\text { Table 3-12 } \\
\text { Maximum AF and Its Corresponding Frequency at Three Different } \\
\text { Locations along the Top of the 125-ft-Height Composite } \\
\text { Substructure Model for the Wet Condition }\end{array}$} \\
\hline \multirow[b]{2}{*}{ Model ID } & \multirow[b]{2}{*}{$\begin{array}{l}\text { Height } \\
\mathrm{ft}\end{array}$} & \multicolumn{3}{|c|}{ CEUS } & \multicolumn{3}{|c|}{ PNW } \\
\hline & & $\begin{array}{l}f \\
\mathrm{~Hz}\end{array}$ & $\begin{array}{l}\text { SA } \\
\text { g's }\end{array}$ & $\begin{array}{l}(\mathrm{AF})_{\mathrm{SA}} \\
\text { at } f\end{array}$ & $\begin{array}{l}f \\
\mathrm{~Hz}\end{array}$ & $\begin{array}{l}\text { SA } \\
\text { g's }\end{array}$ & $\begin{array}{l}(\mathrm{AF})_{\mathrm{SA}} \\
\text { at } f\end{array}$ \\
\hline $\begin{array}{l}\text { 25S9GeW125C5- } \\
\text { Upstream }\end{array}$ & 12125 & 7.62 & 3.55 & 8.45 & 7.62 & 2.32 & 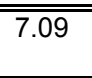 \\
\hline $\begin{array}{l}\text { 25S9GeW125C5- } \\
\text { Midnode }\end{array}$ & 125 & 8 & 3.27 & 7.3 & 7.6 & 2 & 6.04 \\
\hline $\begin{array}{l}\text { 25S9GeW125C5- } \\
\text { Downstream }\end{array}$ & 125 & 7.62 & 3.08 & 7.33 & 7.62 & 2.01 & 6.15 \\
\hline
\end{tabular}

\subsection{Response Amplification Sensitivity to Shear Wall Thickness for the Generator Bay Composite Finite Element Models}

The influence of shear wall thickness of Wall 1 plus Wall 2 on the computed results for the generator bay composite model was investigated. The 125-ftheight model in the wet condition was used for the additional pair of analyses. The total thickness of Walls 1 plus 2 in the original finite element model is $27 \mathrm{ft}$. For this parametric study, the shear wall thickness of the standard finite element model was decreased and increased by 50 percent, resulting in a total thickness of $13.5 \mathrm{ft}$ and $40.5 \mathrm{ft}$, respectively.

Table 3-13 lists the first mode period and frequency, the number of modes used in the analyses, and the PMR. Table 3-14 lists the SA at $50 \mathrm{~Hz}$ and its ratio to the PGA for the two ground motions. Table 3-15 lists the maximum AFs for the three shear wall thickness considered.

The results show a change in the model stiffness due to change in shear wall thickness. The fundamental mode frequency increases by $1.11 \mathrm{~Hz}$ when the total shear wall thickness is increased from $13.5 \mathrm{ft}$ to $27 \mathrm{ft}$. Conversely, the fundamental mode frequency decreases by $0.52 \mathrm{~Hz}$ when the total shear wall thickness is 

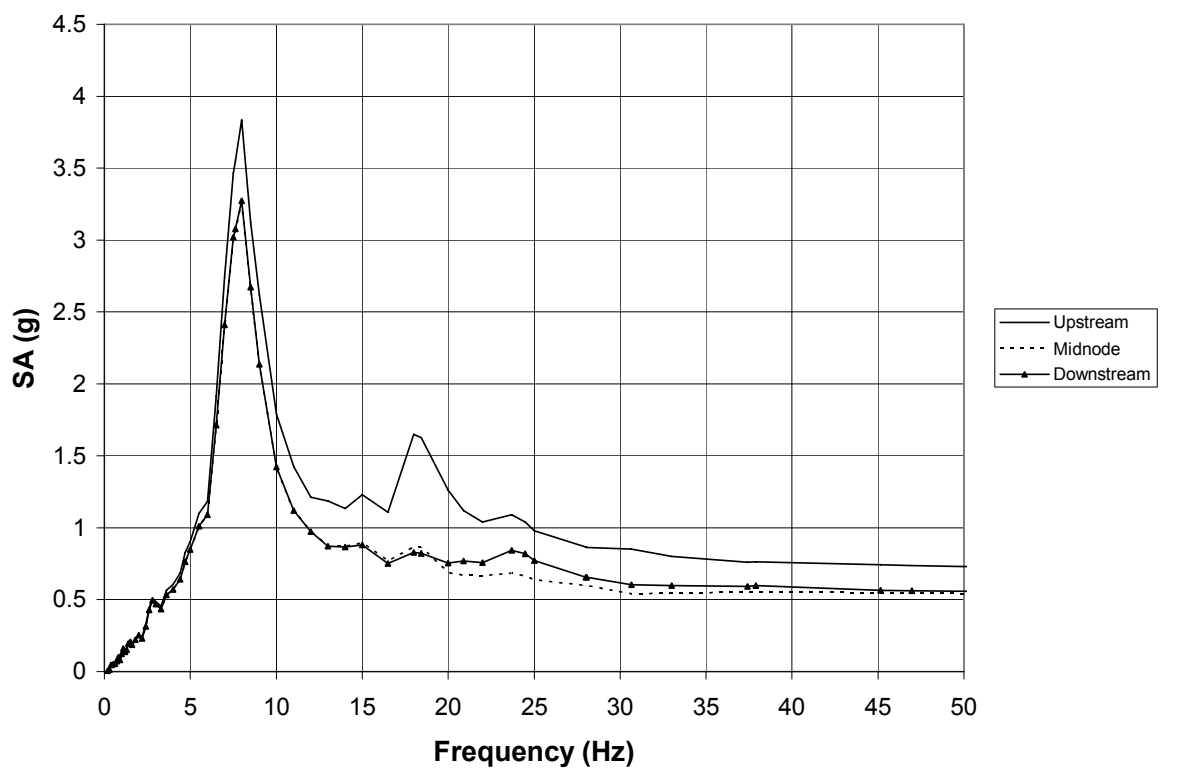

a. CEUS Ground Motion
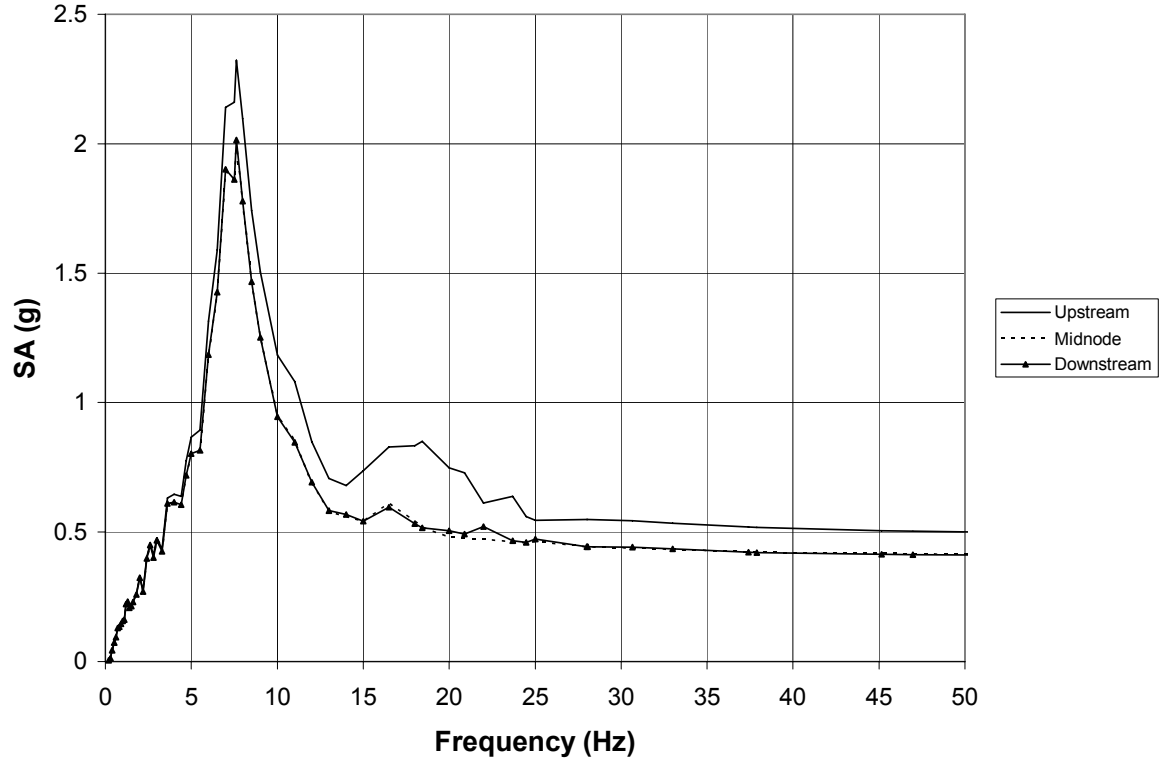

b. PNW Ground Motion

Figure 3-13. Response spectrum curves for nodes at three different locations along the top-of-substructure of the generator bay 125-ft-height, composite model, in the wet condition, using 5 percent damping 


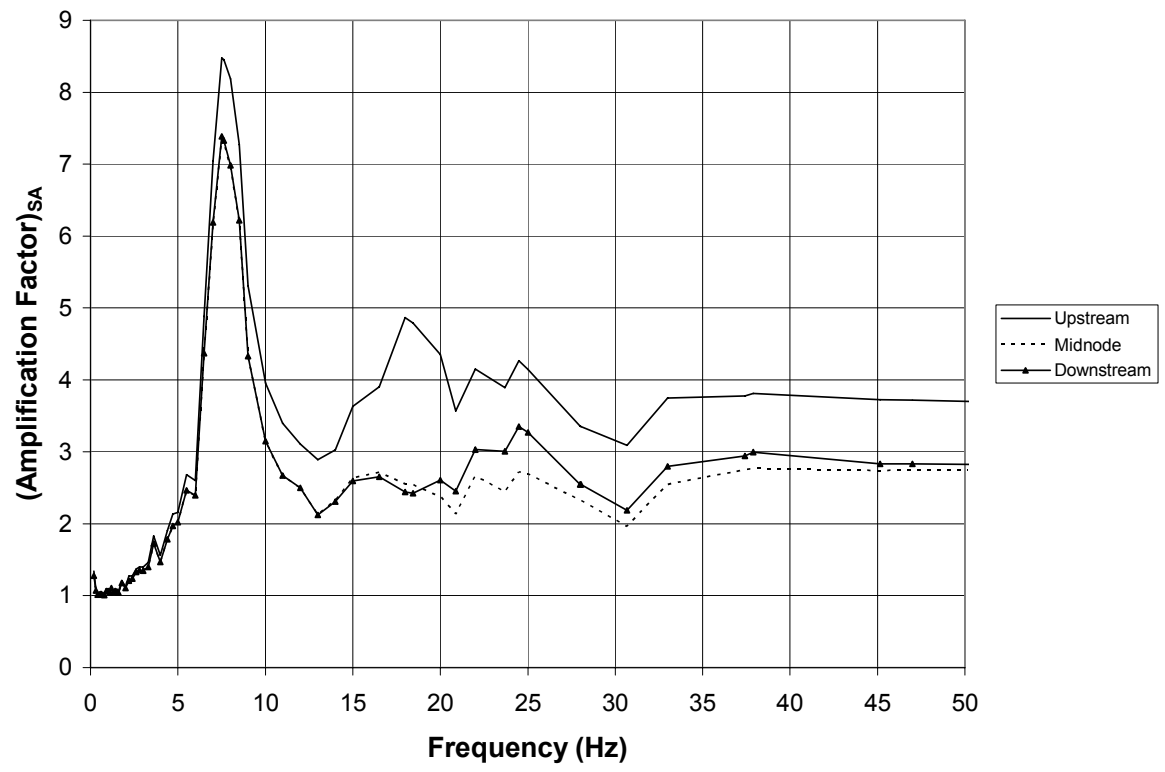

a. CEUS Ground Motion

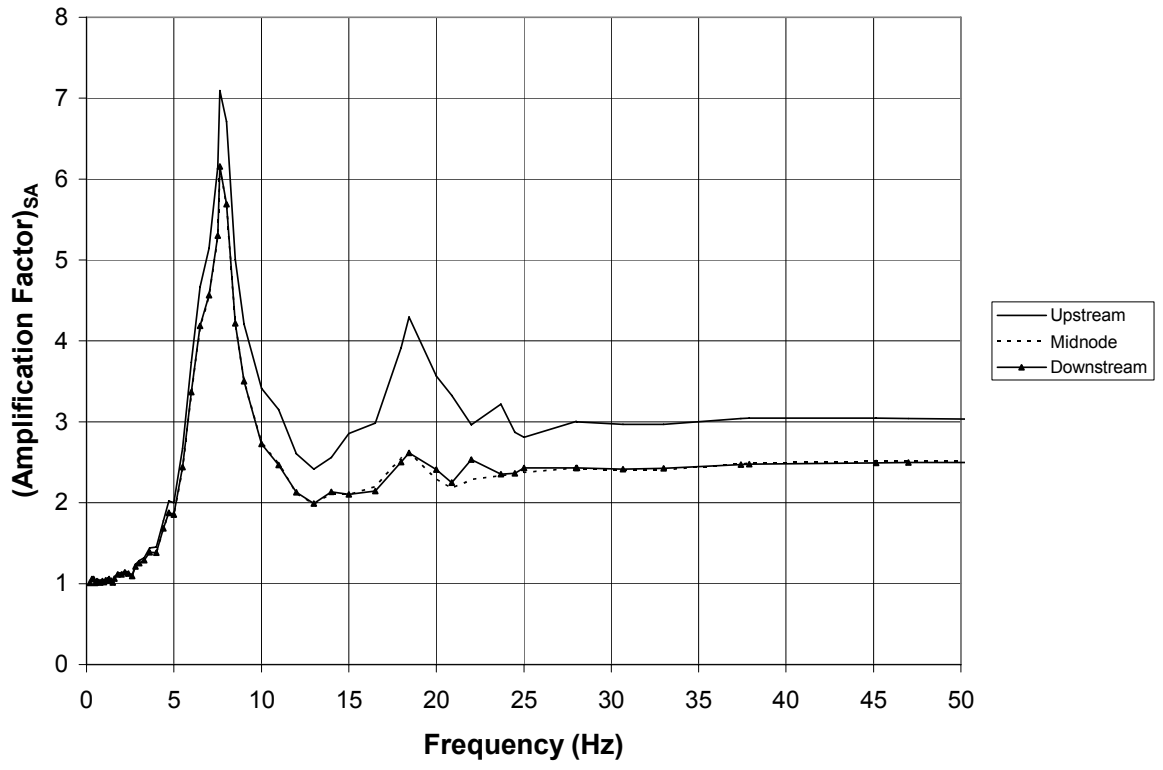

b. PNW Ground Motion

Figure 3-14. AF curves for nodes at three different locations along the top-ofsubstructure of the generator bay, 125-ft-height, composite model in the wet condition, using 5 percent damping 


\begin{tabular}{|c|c|c|c|c|c|c|c|}
\hline \multicolumn{8}{|c|}{$\begin{array}{l}\text { Table 3-13 } \\
\text { First Mode of Vibration and PMR for Three 125-ft-Height Generator } \\
\text { Bay Composite Models }\end{array}$} \\
\hline \multirow[b]{2}{*}{ Model ID } & \multirow[b]{2}{*}{$\begin{array}{l}\text { Height } \\
\mathrm{ft}\end{array}$} & \multicolumn{2}{|c|}{ First Mode } & \multicolumn{4}{|c|}{ Final Mode } \\
\hline & & \begin{tabular}{|l|}
$T_{1}$ \\
sec \\
\end{tabular} & $\begin{array}{l}f_{1} \\
\mathrm{~Hz} \\
\end{array}$ & \begin{tabular}{|l|}
$\begin{array}{l}\text { Total No. } \\
i\end{array}$ \\
\end{tabular} & \begin{tabular}{|l} 
PMR \\
$\%$
\end{tabular} & \begin{tabular}{|l|}
$T_{i}$ \\
sec \\
\end{tabular} & $\begin{array}{l}f_{i} \\
\mathrm{~Hz} \\
\end{array}$ \\
\hline $25 \mathrm{~S} 9 \mathrm{GeW} 125 \mathrm{C} 5-13.5 \mathrm{ft}$ & 125 & 0.1535 & 6.52 & 24 & 90 & 0.0135 & 73.89 \\
\hline $25 \mathrm{~S} 9 \mathrm{GeW} 125 \mathrm{C} 5-27 \mathrm{ft}$ & 125 & 0.1311 & 7.63 & 24 & 90.5 & 0.0127 & 78.99 \\
\hline $25 \mathrm{~S} 9 \mathrm{GeW} 125 \mathrm{C} 5-40.5 \mathrm{ft}$ & 125 & 0.1227 & 8.15 & 24 & 91.4 & 0.0119 & 84.16 \\
\hline
\end{tabular}

\begin{tabular}{|c|c|c|c|c|c|}
\hline \multicolumn{6}{|c|}{$\begin{array}{l}\text { Table 3-14 } \\
\text { SA at } 50 \mathrm{~Hz} \text { for the Three Finite Element Models Using the CEUS } \\
\text { and PNW Ground Motions }\end{array}$} \\
\hline \multirow[b]{2}{*}{ Model ID } & \multirow[b]{2}{*}{$\begin{array}{l}\text { Height } \\
\mathrm{ft}\end{array}$} & \multicolumn{2}{|c|}{ CEUS } & \multicolumn{2}{|c|}{ PNW } \\
\hline & & $\begin{array}{l}\mathrm{SA}_{50 \mathrm{~Hz}} \\
\mathrm{~g}^{\prime} \mathbf{s}\end{array}$ & \begin{tabular}{|l} 
SA / PGA \\
g's
\end{tabular} & $\begin{array}{l}\mathrm{SA}_{50 \mathrm{~Hz}} \\
\text { g's }\end{array}$ & $\begin{array}{l}\text { SA/PGA } \\
\text { g's }\end{array}$ \\
\hline $25 \mathrm{~S} 9 \mathrm{GeW} 125 \mathrm{C} 5-13.5 \mathrm{ft}$ & 125 & 0.49 & 2.58 & 0.4 & 2.50 \\
\hline 25S9GeW125C5-27 ft & 125 & 0.54 & 2.84 & 0.41 & 2.56 \\
\hline 25S9GeW125C5-40.5 ft & 125 & 0.6 & 3.16 & 0.40 & 2.50 \\
\hline
\end{tabular}

\begin{tabular}{|c|c|c|c|c|c|c|c|}
\hline \multicolumn{8}{|c|}{$\begin{array}{l}\text { Table 3-15 } \\
\text { Maximum AF and Its Corresponding Frequency for the Three 125-ft- } \\
\text { Height Generator Bay Models }\end{array}$} \\
\hline \multirow[b]{2}{*}{ Model ID } & \multirow[b]{2}{*}{$\begin{array}{l}\text { Height } \\
\mathrm{ft}\end{array}$} & \multicolumn{3}{|c|}{ CEUS } & \multicolumn{3}{|c|}{ PNW } \\
\hline & & \begin{tabular}{|l}
$f$ \\
$\mathrm{~Hz}$ \\
\end{tabular} & $\begin{array}{l}\text { SA } \\
\text { g's }\end{array}$ & \begin{tabular}{|l}
$(\mathrm{AF})_{\mathrm{SA}}$ \\
at $f$ \\
\end{tabular} & \begin{tabular}{|l|}
$f$ \\
$\mathrm{~Hz}$ \\
\end{tabular} & \begin{tabular}{|l} 
SA \\
g's
\end{tabular} & \begin{tabular}{|l}
$(\mathrm{AF})_{\mathrm{SA}}$ \\
at $f$
\end{tabular} \\
\hline $25 \mathrm{~S} 9 \mathrm{GeW} 125 \mathrm{C} 5-13.5 \mathrm{ft}$ & 125 & 6.52 & 2.84 & 7.14 & 6 & 2.03 & 5.78 \\
\hline $25 S 9 G e W 125 \mathrm{C} 5-27 \mathrm{ft}$ & 125 & 7.5 & 3.01 & 7.1 & 7.62 & 2 & 6.12 \\
\hline $25 \mathrm{~S} 9 \mathrm{GeW} 125 \mathrm{C} 5-40.5 \mathrm{ft}$ & 125 & 8.15 & 3.80 & 8.26 & 8.15 & 1.63 & 5.14 \\
\hline
\end{tabular}

decreased from $40.5 \mathrm{ft}$ to $27 \mathrm{ft}$. Figure 3-15 shows the absolute acceleration curves for the three models, and Figure 3-16 shows the AF curves for the two ground motions considered. The computed results show that the shear wall thickness can have a significant influence on the computed results, depending upon the frequency content of the ground motion. 


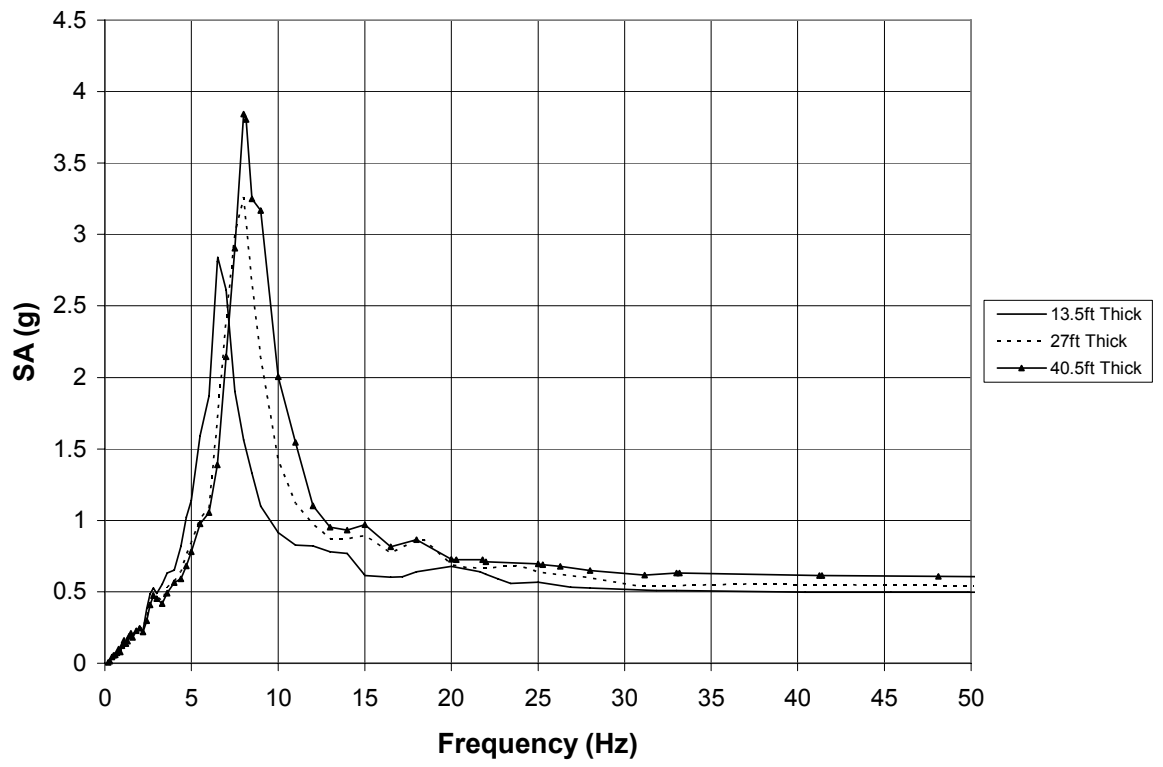

a. CEUS Ground Motion

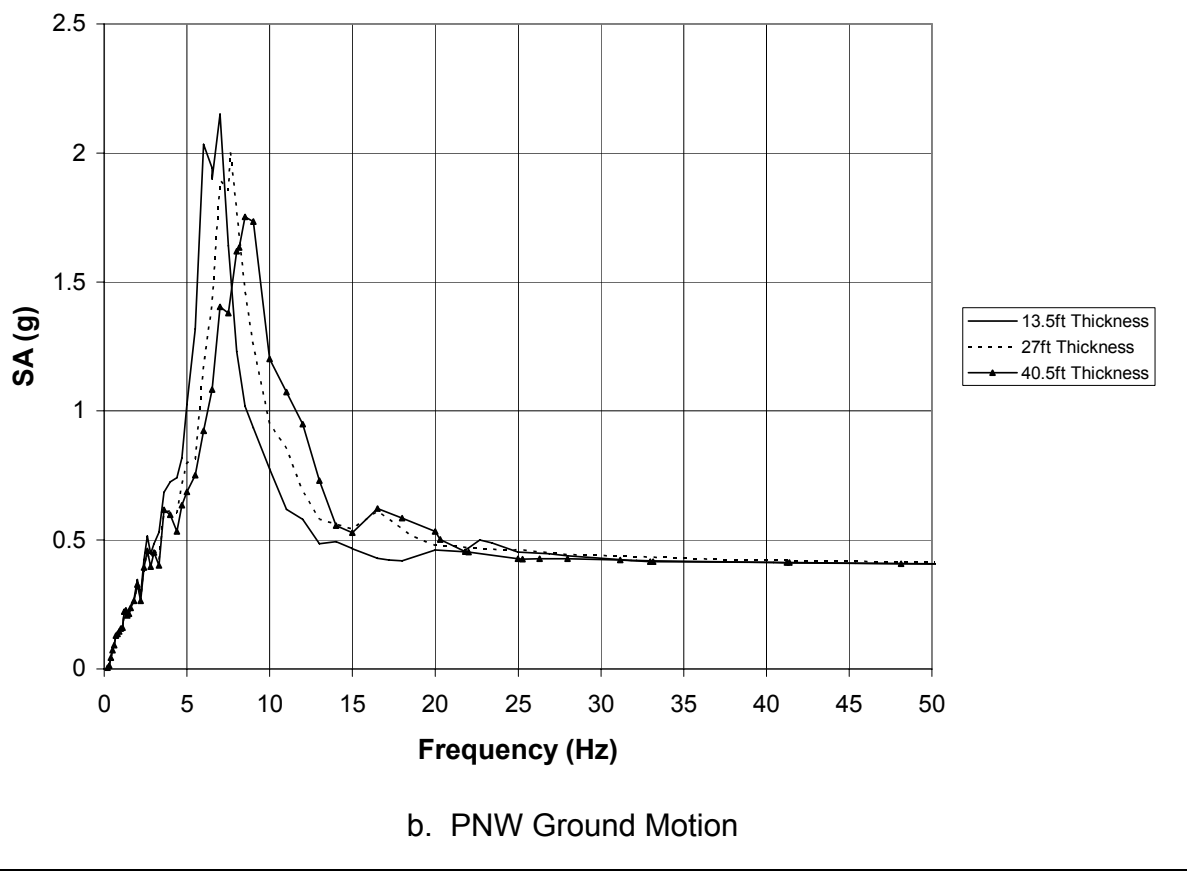

Figure 3-15. Response spectrum curves at top-of-substructure for three different shear wall thicknesses (sum of Wall 1 and 2 thicknesses) of the generator bay, 125-ft-height, composite model, in the wet condition, using 5 percent damping 


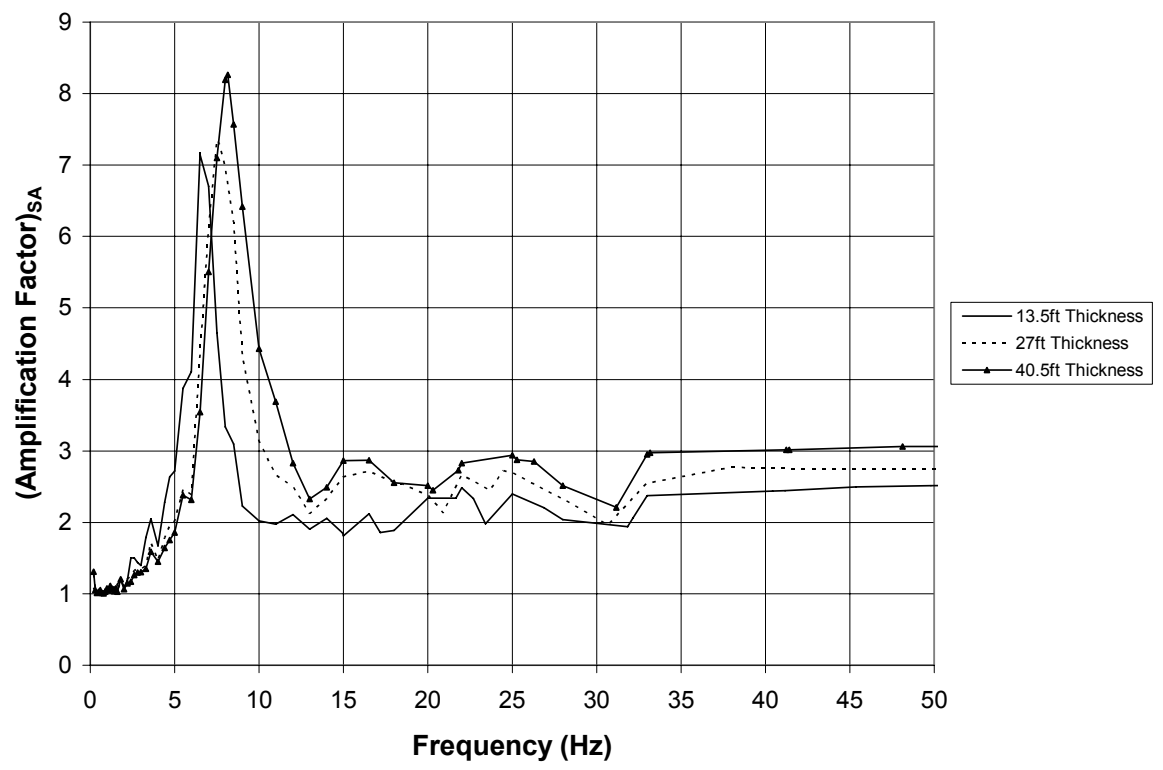

a. CEUS Ground Motion

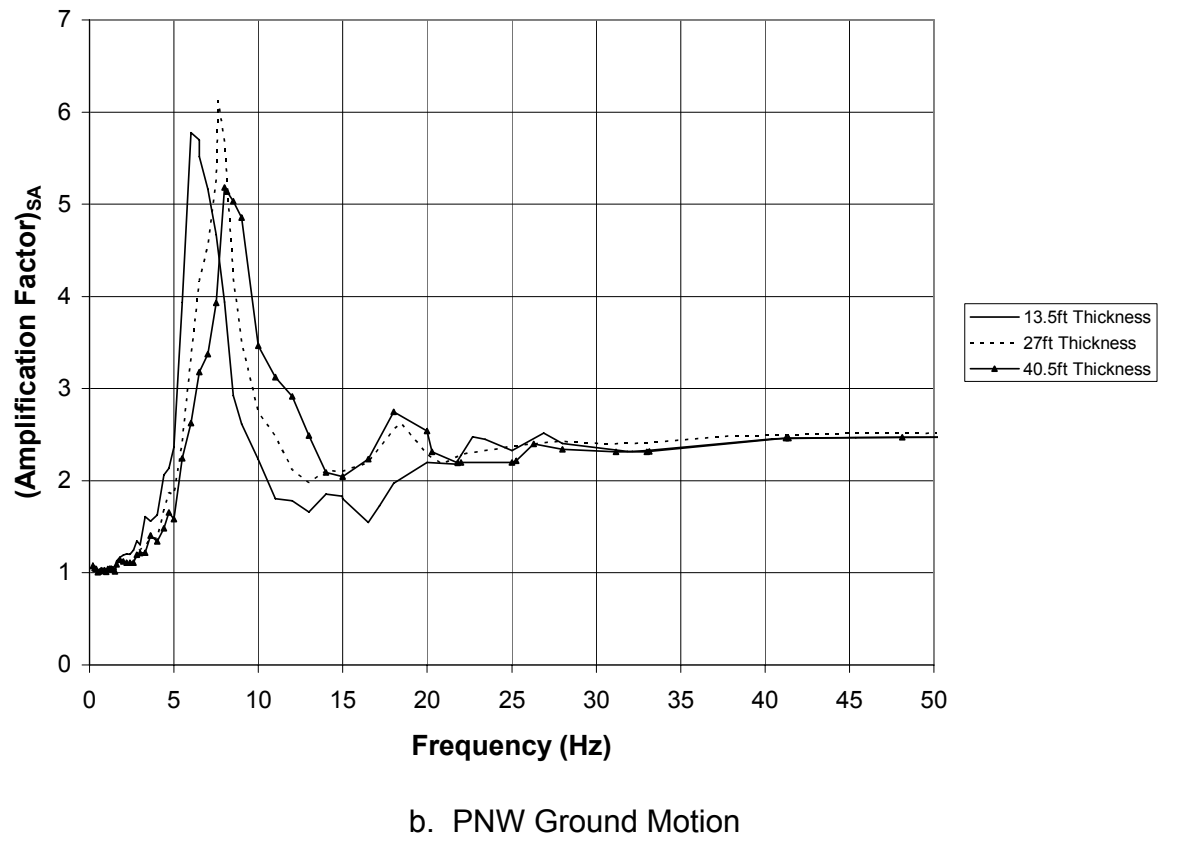

Figure 3-16. AF curves at top-of-substructure for three different shear wall thicknesses (sum of Wall 1 and 2 thicknesses) of the generator bay, 125 -ft-height, composite model, in the wet condition, using 5 percent damping 


\section{Time-History Finite Element Results for the Erection/Service Bay Monolith}

\subsection{Introduction}

This chapter discusses the results from the analysis of a series of timehistory/modal response of two models of erection/service bay substructure monoliths to earthquake loadings. Two acceleration time-histories were used in this study, one representing a CEUS earthquake event and a second representing a PNW event. A block model and a block-frame-shear wall finite element model of each idealized powerhouse substructure were created using the structural analysis software SAP2000 (CSI 1997). The acceleration time-history was specified at the base of the models, and time-histories at the top of the substructure were calculated and then converted into response spectra. The response spectra at the top of the substructure were converted to AFs versus frequency curves for use in a decoupled response spectra modal analysis. The AF curves presented in this chapter are plotted up to $50 \mathrm{~Hz}$. However, the ground motions used in this study have frequency content up to $33 \mathrm{~Hz}$. The use of AF curves above $33 \mathrm{~Hz}$ is not recommended.

\subsection{Geometry of Four Height Monoliths}

Fifty-four cross-sections of the erection/service bay substructures of Corps powerhouses were reviewed. The erection/service bay substructures were assigned to one of four groups according to their heights. Average heights, upstream/downstream dimensions, plan widths, pool water elevation, and tailrace elevation were determined for each substructure group. Appendix A summarizes the Corps erection/service bay monoliths geometry reviewed in this study.

Two types of finite element models were used to idealize the geometry of the erection/service bay substructure. One is referred to as a block model (Figure 4-1), and the second as a block-frame-shear wall model (Figure 4-2). The block idealization represents a stiff model of the substructure, and the blockframe-shear wall model represents a more flexible substructure. 


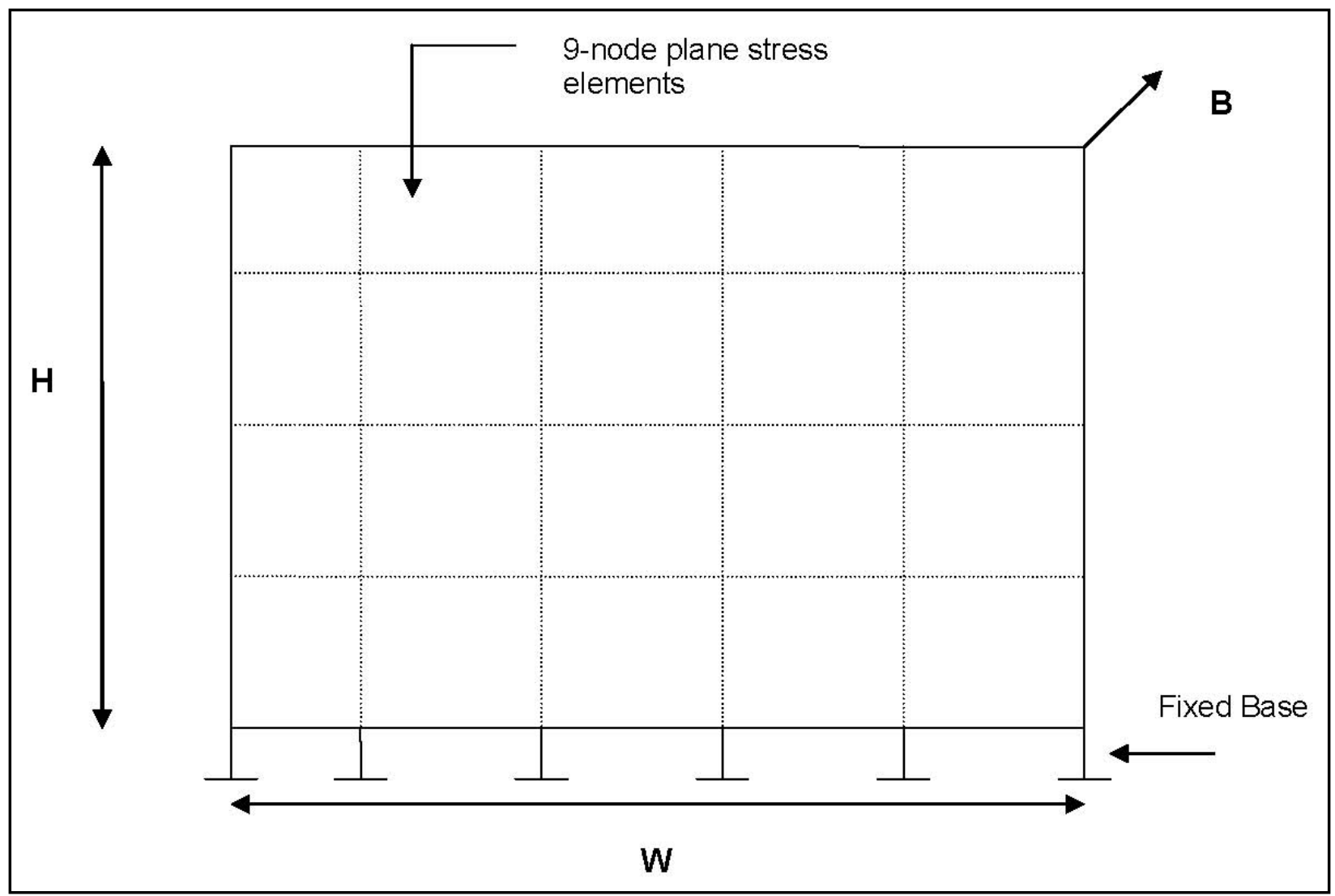

Figure 4-1. Geometry of erection/service bay block finite element model

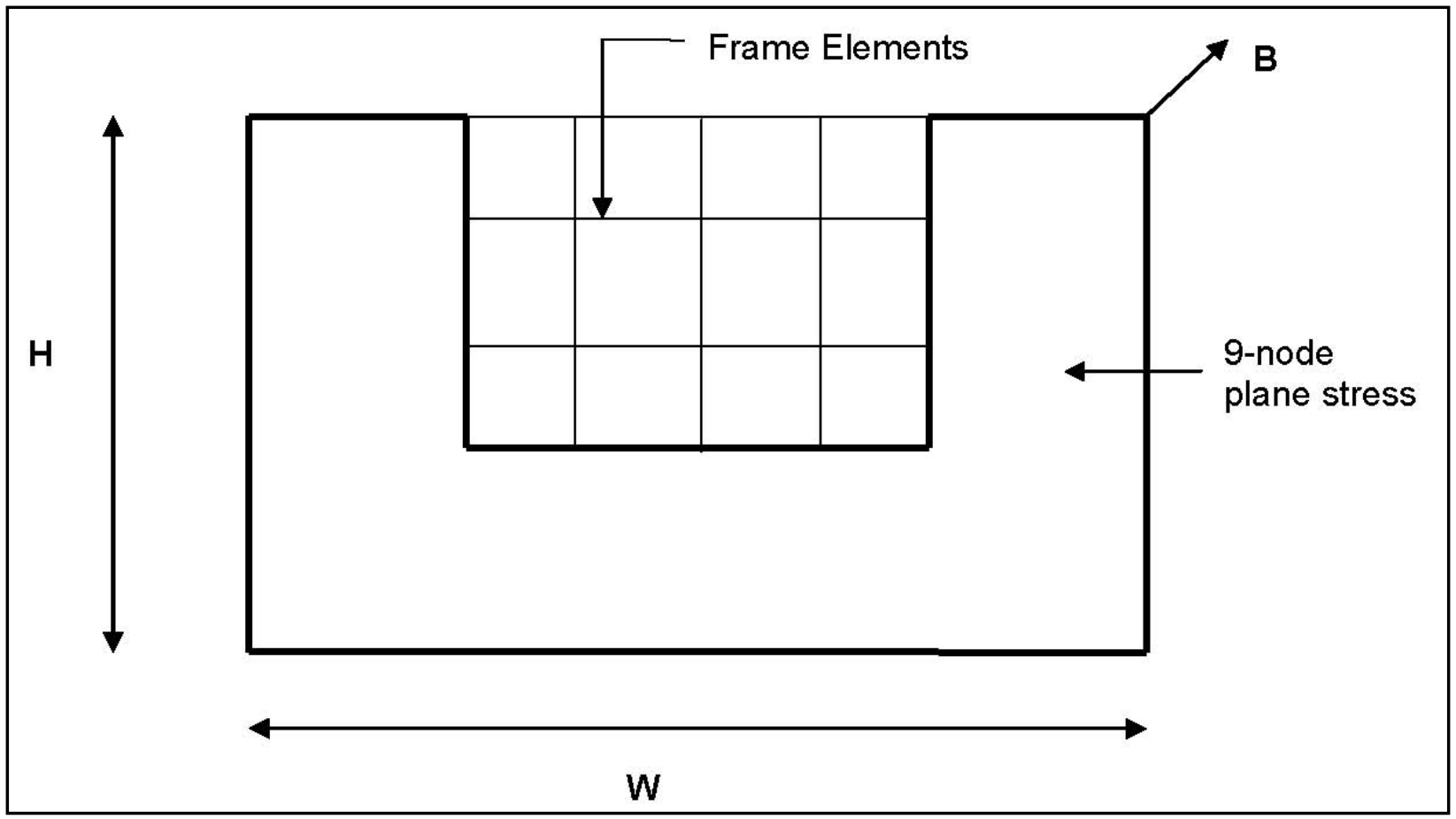

Figure 4-2. Geometry of an erection/service bay block-frame-shear wall finite element model 
The dimensions for each model are presented in Table 4-1. The shear wall thickness for the block-frame-shear wall model was selected by inspection of the construction drawings for different Corps powerhouses. An average 8-ft wall thickness was judged to represent the thickness of the shear wall(s).

\begin{tabular}{|c|c|c|c|c|c|c|}
\hline \multicolumn{7}{|c|}{$\begin{array}{l}\text { Table 4-1 } \\
\text { Geometry of Block and Block-Frame-Shear Wall Finite Element } \\
\text { Models }\end{array}$} \\
\hline Group & $\begin{array}{l}\text { Height } \\
H \\
\mathrm{ft} \\
\end{array}$ & $\begin{array}{l}\text { Upstream/ } \\
\text { downstream } \\
W \\
\mathrm{ft}\end{array}$ & $\begin{array}{l}\text { Out of Plane } \\
\text { Width } \\
B \\
\mathrm{ft} \\
\end{array}$ & $\begin{array}{l}\text { Pool Water } \\
\text { EI } \\
\mathrm{ft}\end{array}$ & $\begin{array}{l}\text { Tailrace } \\
\text { EI } \\
\mathrm{ft}\end{array}$ & $\begin{array}{l}\text { Range in } \\
\text { Height for } \\
\text { Group } \\
\mathrm{ft} \\
\end{array}$ \\
\hline 1 & 1110 & 125 & 75 & 130 & 75.5 & $90-135$ \\
\hline 2 & 75 & 120 & 60 & 95 & 49 & $60-90$ \\
\hline 3 & 45 & 1110 & 65 & 65 & 35 & $30-55$ \\
\hline 4 & 20 & 60 & 40 & 40 & 16 & $0-30$ \\
\hline
\end{tabular}

\subsection{Material Properties}

The material used in the construction of powerhouse substructures is concrete. For mass concrete 2,500 psi of compressive strength is typically selected as the design value and 3,000 psi for the reinforced concrete frames. To account for aging effects, the compressive strength for both entities was increased by a factor of 1.5. The general properties for mass concrete are listed in Table 4-2 and the concrete properties for the frame elements given in Table 4-3. The value assigned to Young's modulus of the mass and structural concrete was computed using Equation 3-1 for the aged compressive strength $f_{c}^{\prime}$ values.

\begin{tabular}{|c|c|c|}
\hline \multicolumn{3}{|c|}{$\begin{array}{l}\text { Table 4-2 } \\
\text { Material Properties Used in the Powerhouse Plane-Stress } \\
\text { Continua Finite Elements }\end{array}$} \\
\hline \multicolumn{3}{|c|}{$\begin{array}{ll} & \text { Mass Concrete Properties } \\
\end{array}$} \\
\hline$\overline{\text { Compressive strength } f_{c}^{\prime}}$ & 3,750 & psi \\
\hline Modulus of elasticity $E_{c}$ & $3.7 \mathrm{E}+6$ & psi \\
\hline Mass of concrete $m_{c}$ & 4.6584 & $\mathrm{Ib}^{*} \sec ^{2} / \mathrm{f}$ \\
\hline Unit weight $\gamma_{c}$ & 150 & pcf \\
\hline Poisson's ratio $u$ & 0.2 & \\
\hline
\end{tabular}

\begin{tabular}{|c|c|c|}
\hline \multicolumn{3}{|c|}{$\begin{array}{l}\text { Table 4-3 } \\
\text { Material Properties Used in the Frame Elements }\end{array}$} \\
\hline \multicolumn{3}{|c|}{$\begin{array}{ll} & \text { Concrete Properties } \\
\end{array}$} \\
\hline Compressive strength $f_{c}^{\prime}$ & 4,500 & psi \\
\hline Modulus of elasticity $E_{c}$ & $4.1 \mathrm{E}+6$ & psi \\
\hline Mass of concrete $m_{c}$ & 4.6584 & $\mathrm{Ib}^{*} \sec ^{2} / \mathrm{ft}$ \\
\hline Unit weight $\gamma_{c}$ & 150 & pcf \\
\hline Poisson's ratio $u$ & 0.2 & \\
\hline
\end{tabular}




\subsection{Finite Elements Models}

Nine-node plane stress elements were selected to represent the mass of concrete in the substructure for the block and block-frame-shear wall models. The plane stress elements assume zero stresses out of plane to the elements but allow for out-of-plane deformation. This assumption is consistent with the recommendation in the technical literature (HQUSACE 2003) because of the presence of construction joints between monoliths.

In the block-frame-shear wall model, flexural deformation is expected because of the frame's rotational degrees of freedom inside the model. The use of nine-node elements reduces the shear locking behavior of lower order elements (Cook et al. 2002). Shear locking is a behavior that allows an element to overestimate its shear deformations. When this occurs, more forces are needed to deform the structure in flexure (i.e., an analytically stiff element).

To represent the internal frame in the substructure, frame elements with three degrees of freedom (two translations and one rotation) at each node were selected. The frame elements were extended into the plane finite elements of the mass concrete to avoid the development of analytical hinges at their connection.

SAP2000 structural analysis software was used to create the models for the erection/service bay substructure. Figure 4-3 shows the four groups of block models. The minimum number of elements was determined by increasing the refinement of the mesh until a constant first mode period value was computed. Figure 4-4 shows the SAP2000 models for the block-frame-shear wall. To account for cracking effects in the frame elements, the gross inertia on these elements was reduced by 20 percent (Ebeling et al. 2002).

\subsection{Undamped Natural Frequencies and Modal Mass Participation Results}

Undamped natural frequencies and periods for the block models are reported in Table 4-4 for the dry condition and Table 4-5 for the wet condition. A 5 percent damping was assumed for the substructure in this chapter. The AF curves presented in this chapter were obtained using response spectra curves for 5 percent damping. The SA and AF results for 2 percent damping are presented in Appendix $\mathrm{F}$ for use with equipment. The number of modes considered for each model was increased until a cumulative PMR over 0.90 was attained. Tables 4-4 and 4-5 also list the period and frequency for the final mode considered for each substructure model. The modal analysis results showed that the hydrodynamic added mass reduced the natural frequency of the model, making the model behave as if it is more "flexible." This effect is more evident in the substructure groups of 110-ft-height and 75-ft-height substructure where the difference in SA and AF peak responses between dry and wet models is greater than for substructure groups 3 and 4 . 


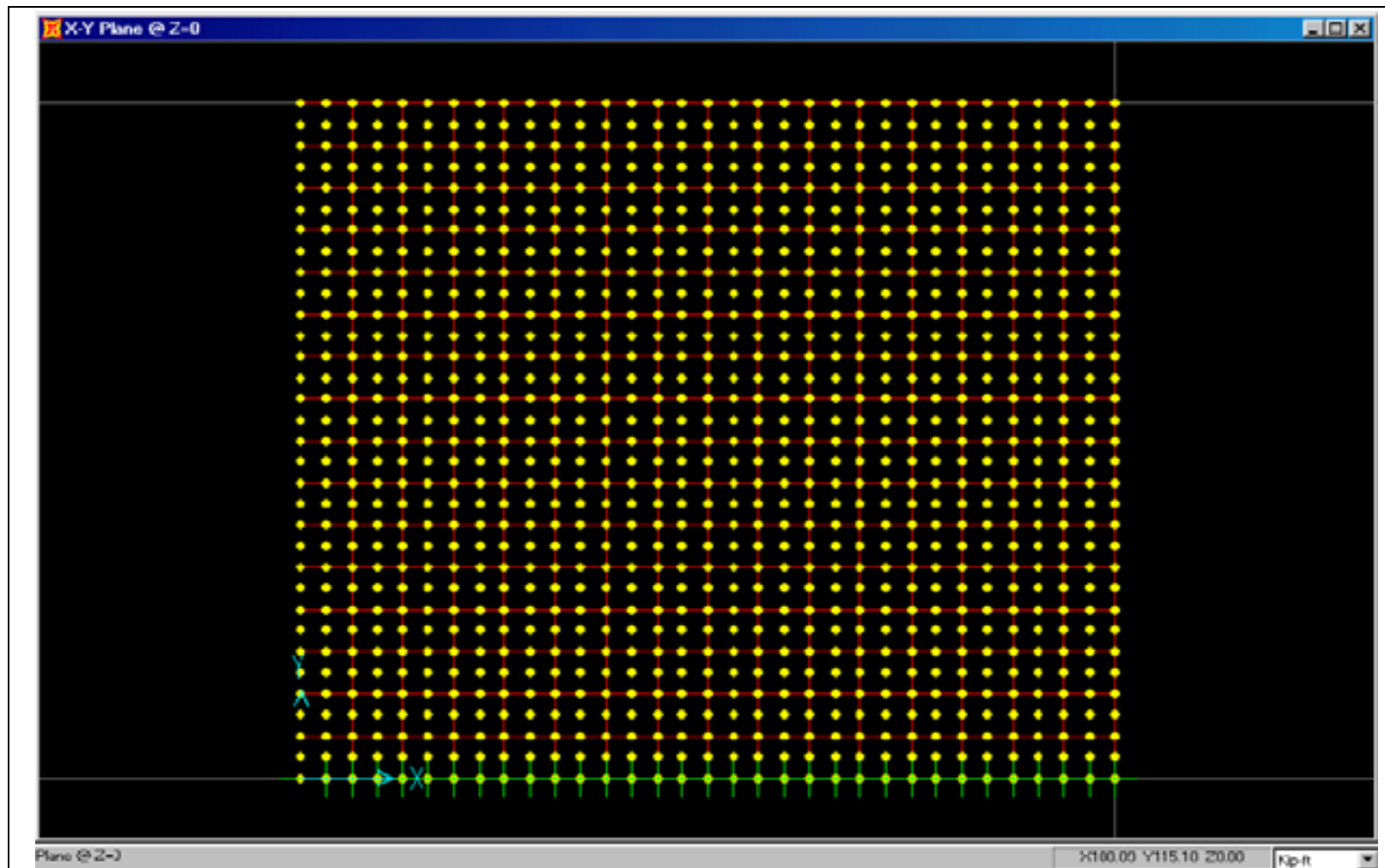

a. 110-ft height

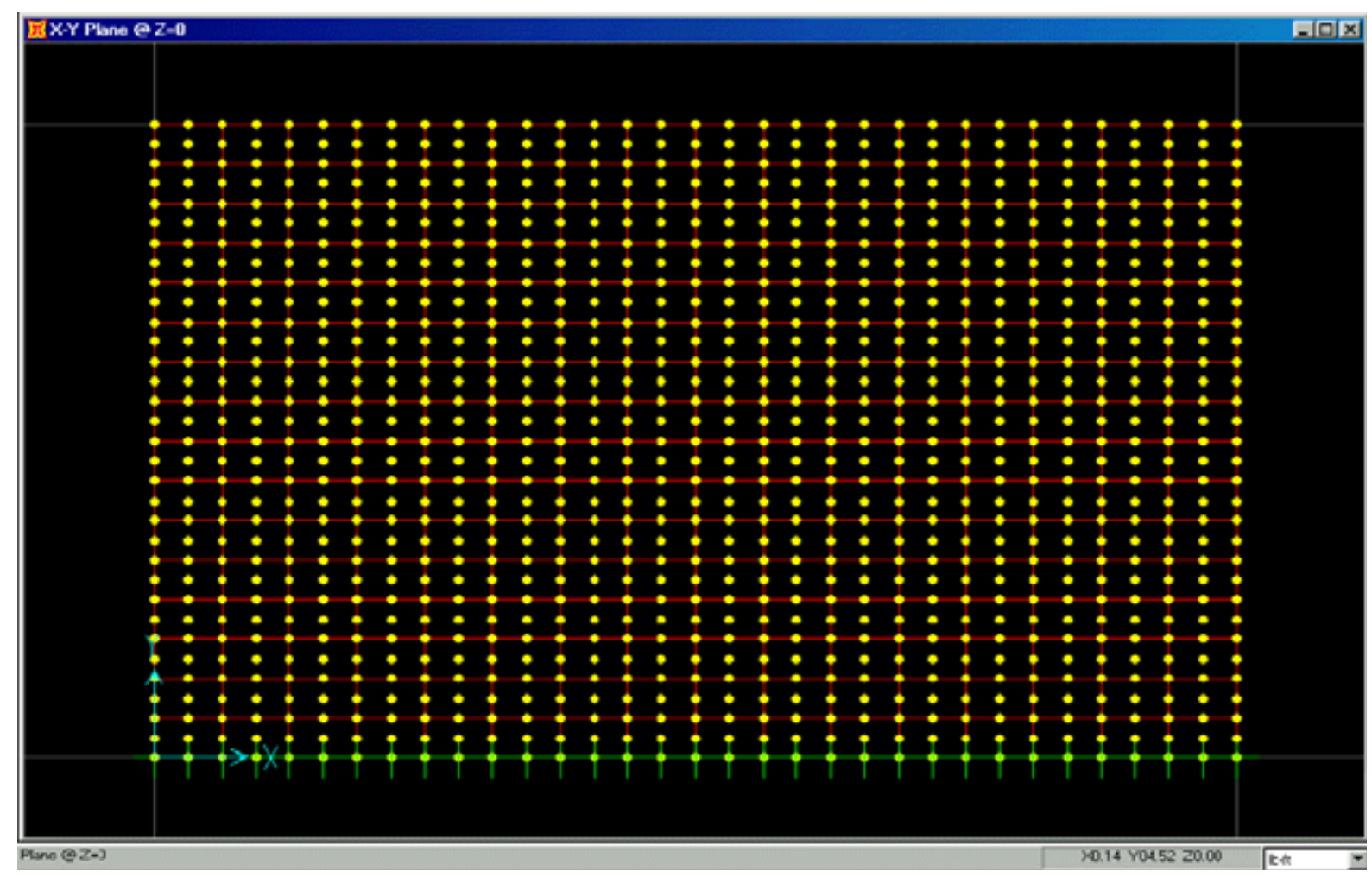

b. 75 -ft height

Figure 4-3. Erection/service bay block finite element models (Continued) 


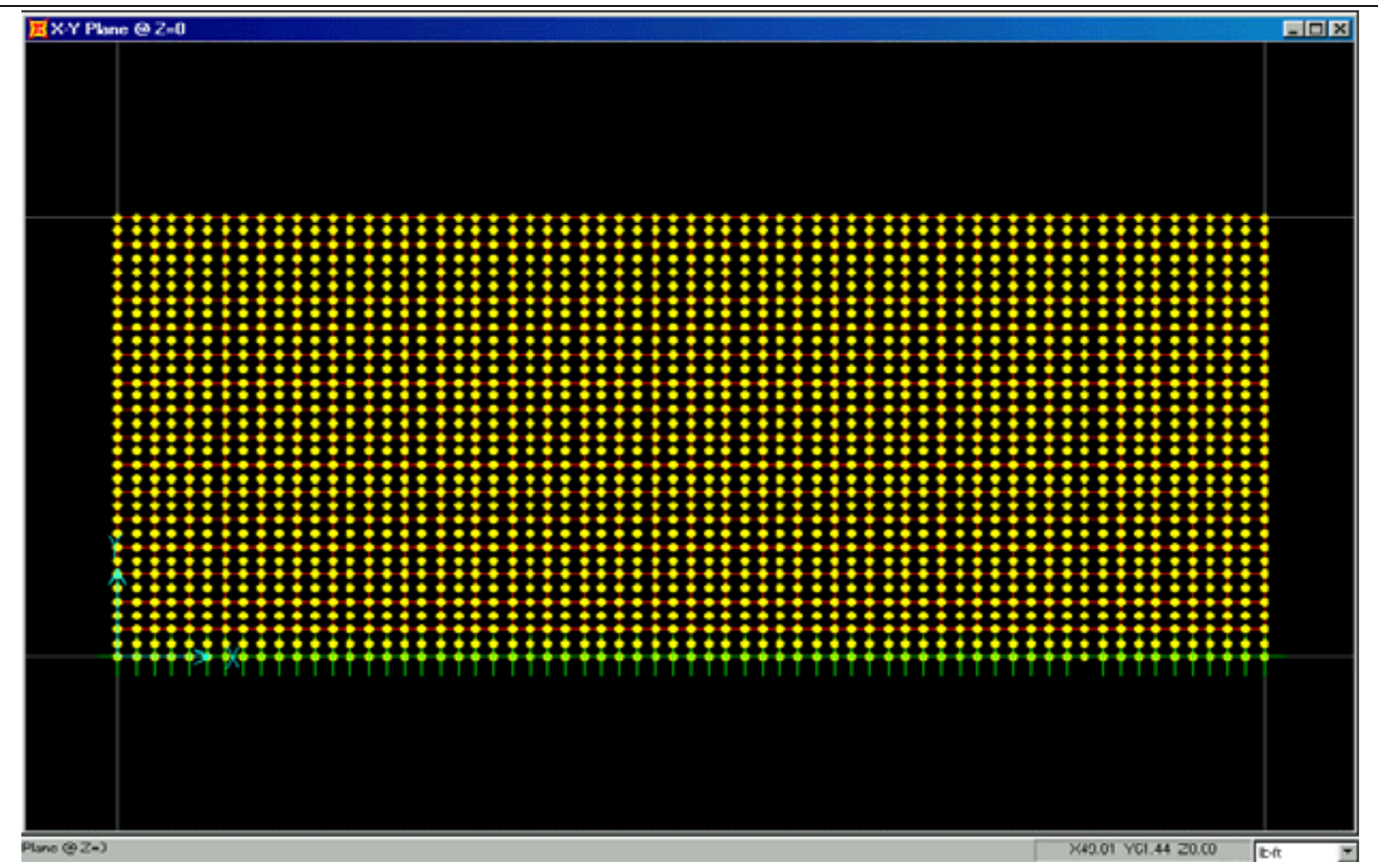

c. $45-\mathrm{ft}$ height

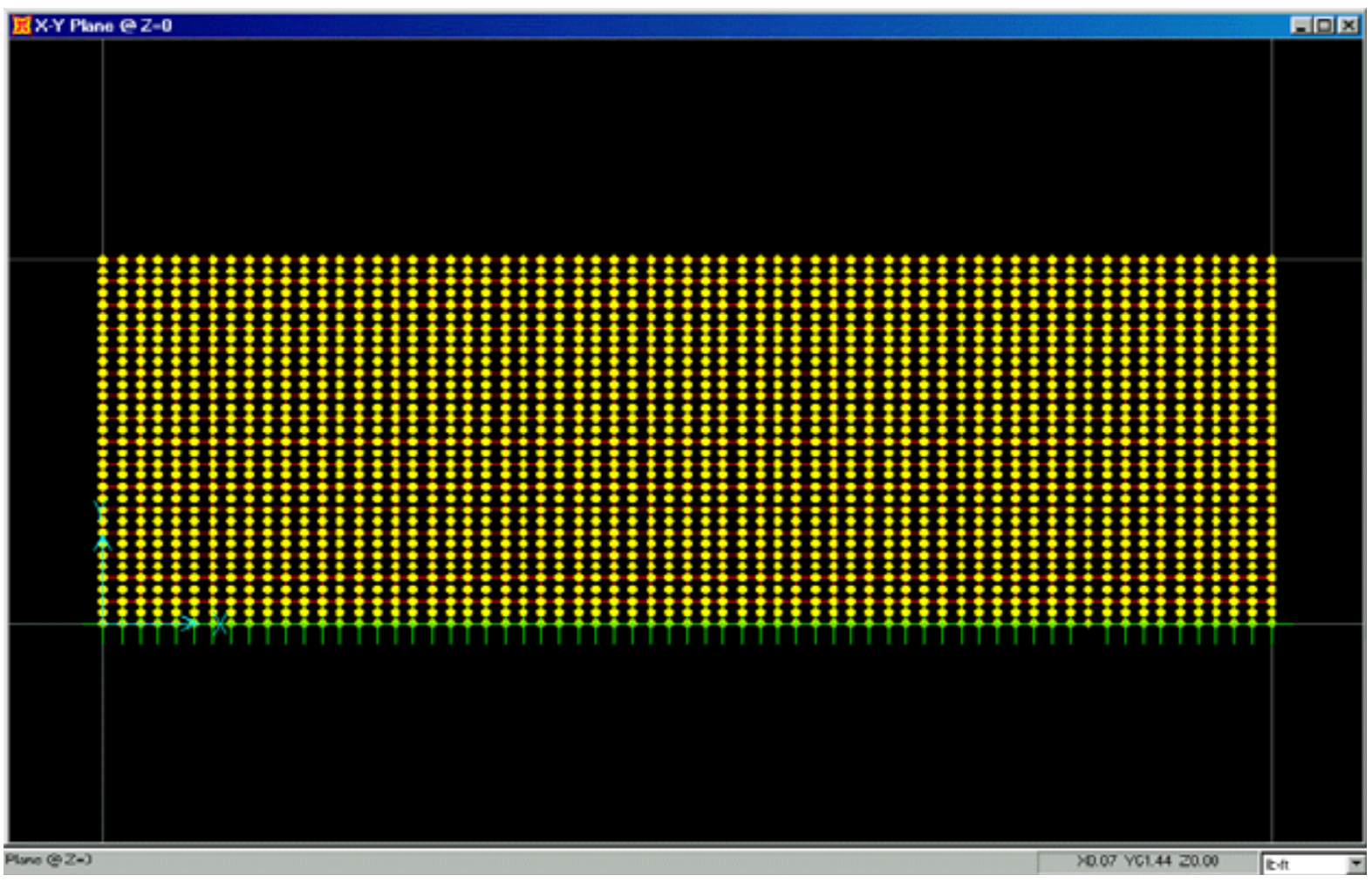

d. 20-ft height

Figure 4-3. (Concluded) 


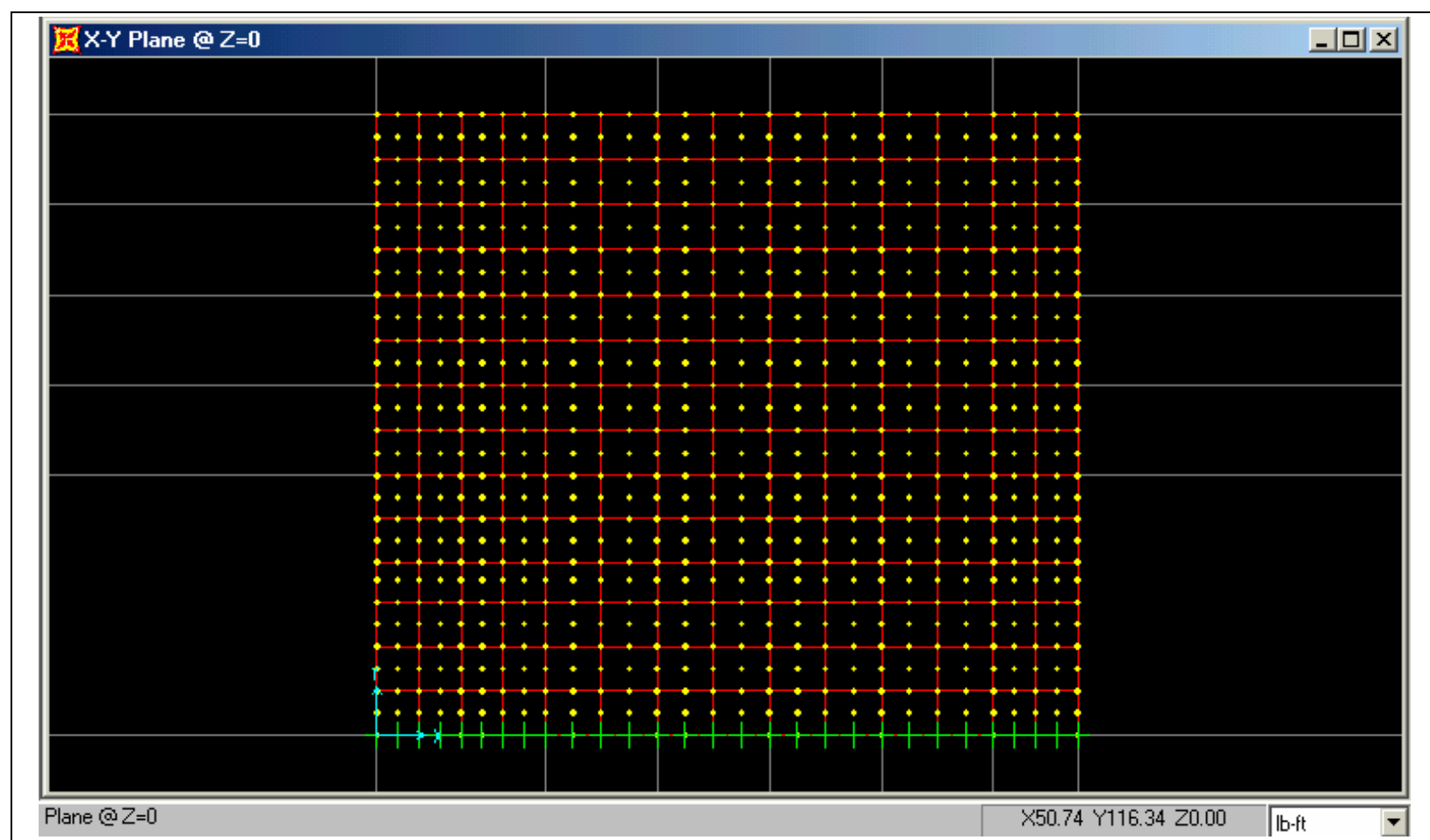

a. 110-ft height

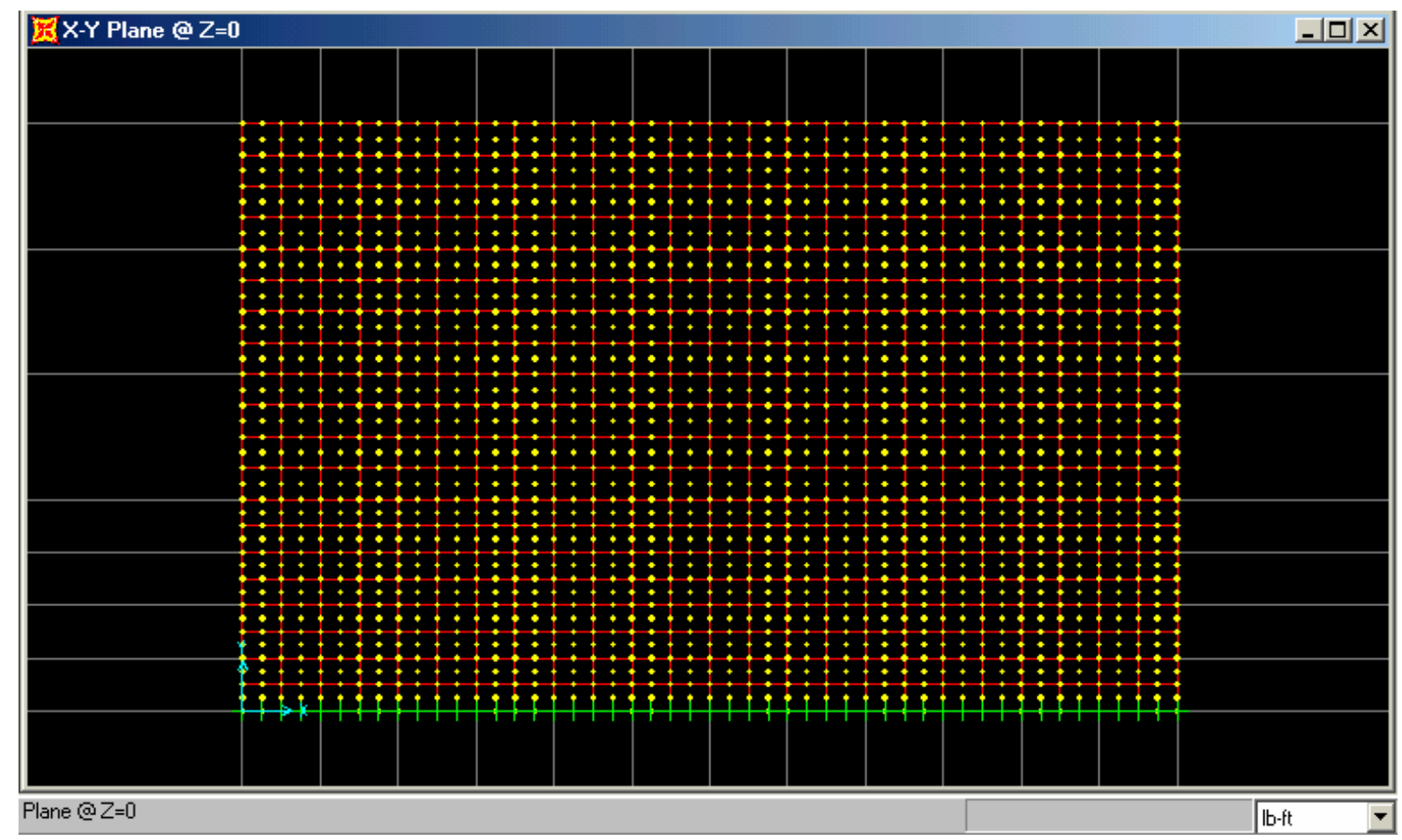

b. 75 -ft height

Figure 4-4. Erection/service bay block-frame-shear wall finite element models (Continued) 


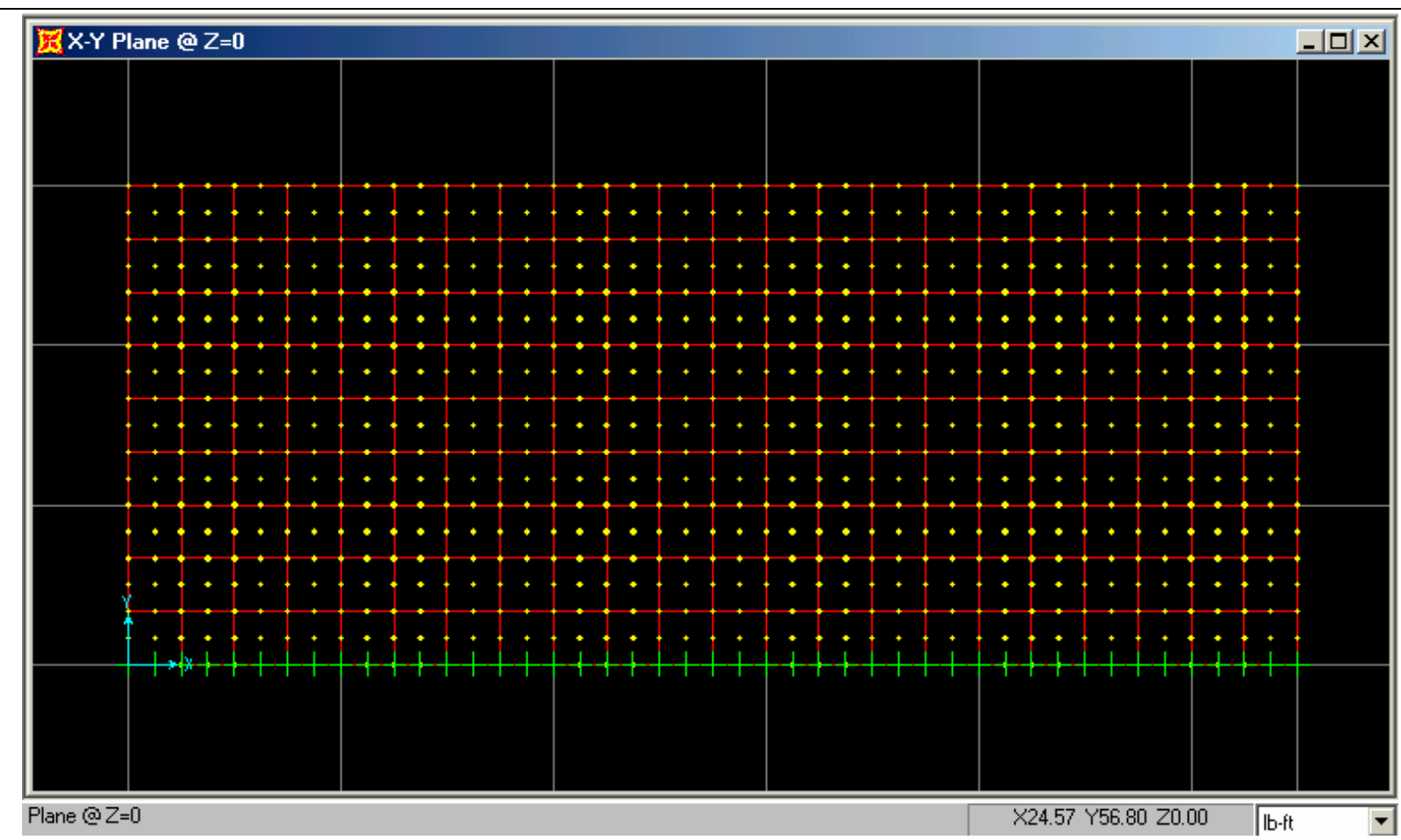

c. 45-ft height

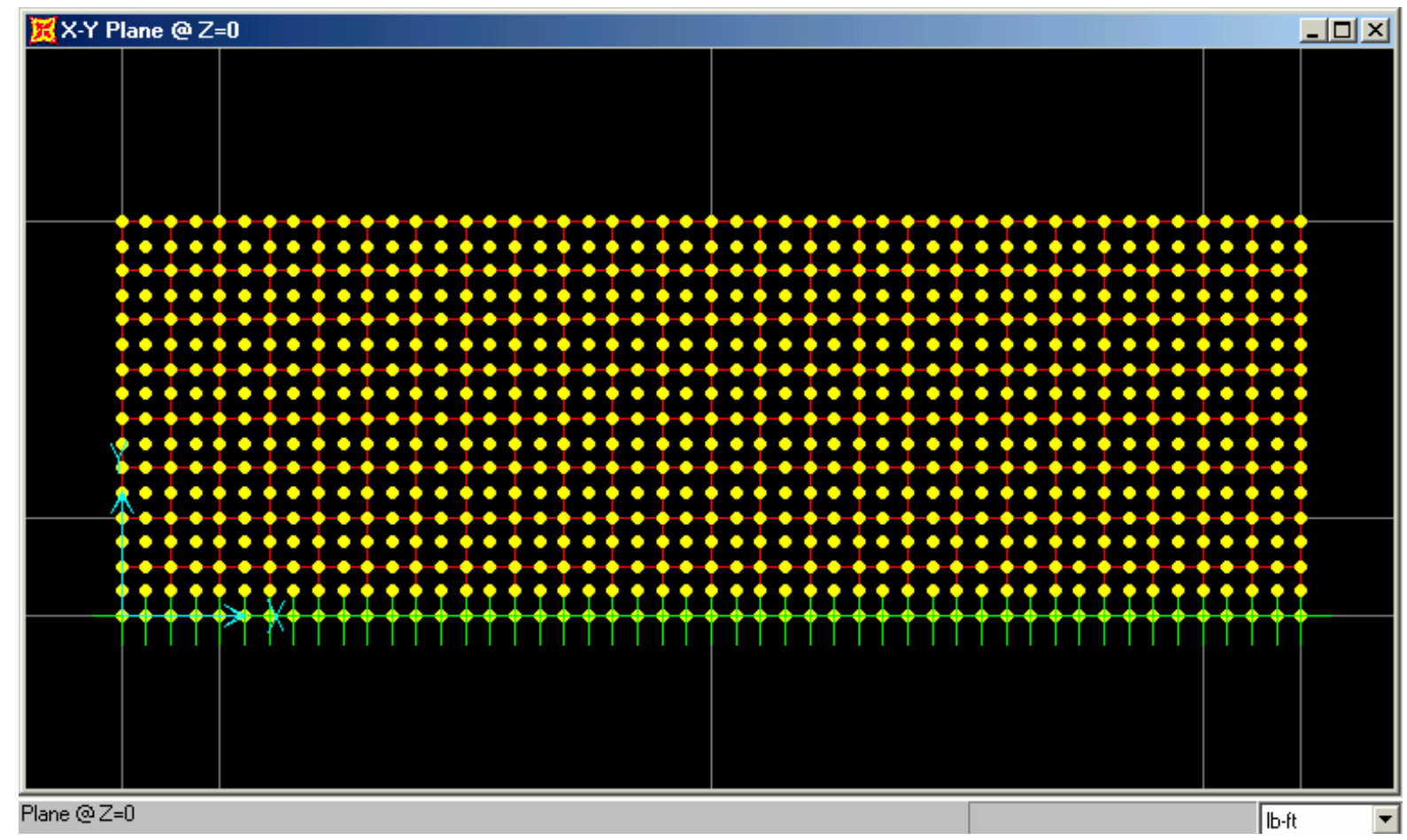

d. 20-ft height

Figure 4-4. (Concluded) 


\begin{tabular}{|c|c|c|c|c|c|c|c|}
\hline \multicolumn{8}{|c|}{$\begin{array}{l}\text { Table 4-4 } \\
\text { Undamped Natural Frequencies and Modal Mass Participation } \\
\text { Ratio for Erection/Service Bay Block Models, Dry Condition }\end{array}$} \\
\hline \multirow[b]{2}{*}{ Model ID } & \multirow[b]{2}{*}{$\begin{array}{l}\text { Height } \\
\mathrm{ft}\end{array}$} & \multicolumn{2}{|c|}{ First Mode } & \multicolumn{4}{|c|}{ Final Mode } \\
\hline & & $T_{1}, \mathrm{sec}$ & $f_{1}, \mathrm{~Hz}$ & $\begin{array}{ll}\text { Total No. } \\
\end{array}$ & \begin{tabular}{|l} 
PMR \\
$\%$
\end{tabular} & \begin{tabular}{|l|}
$T_{i}$ \\
sec \\
\end{tabular} & \begin{tabular}{|l|}
$f_{i}$ \\
$\mathrm{~Hz}$
\end{tabular} \\
\hline 16S9ErD110B5 & 110 & 0.0915 & 10.93 & 8 & 92.3 & 0.0155 & 64.45 \\
\hline 16S9ErD75B5 & 75 & 0.0554 & 18.04 & 8 & 90.2 & \begin{tabular}{|l|}
0.0125 \\
\end{tabular} & 79.69 \\
\hline 16S9ErD45B5 & 45 & 0.0304 & 32.91 & 12 & 90.6 & 0.0069 & 144.95 \\
\hline 8S9ErD20B5 & 20 & 0.0131 & 76.13 & 12 & 90.4 & 0.0036 & 274.19 \\
\hline
\end{tabular}

\begin{tabular}{|c|c|c|c|c|c|c|c|}
\hline \multicolumn{8}{|c|}{$\begin{array}{l}\text { Table 4-5 } \\
\text { Undamped Natural Frequencies and Modal Mass Participation } \\
\text { Ratio for Erection/Service Bay Block Models, Wet Condition }\end{array}$} \\
\hline \multirow[b]{2}{*}{ Model ID } & \multirow[b]{2}{*}{$\begin{array}{l}\text { Height } \\
\mathrm{ft}\end{array}$} & \multicolumn{2}{|c|}{ First Mode } & \multicolumn{4}{|c|}{$\begin{array}{ll}\text { Final Mode } \\
\end{array}$} \\
\hline & & $T_{1}$, sec & $f_{1}, \mathrm{~Hz}$ & $\begin{array}{l}\text { Total No. } \\
\end{array}$ & \begin{tabular}{|l|} 
PMR \\
$\%$
\end{tabular} & \begin{tabular}{|l|}
$T_{i}$ \\
sec \\
\end{tabular} & \begin{tabular}{|l|}
$f_{i}$ \\
$\mathrm{~Hz}$ \\
\end{tabular} \\
\hline 16S9ErW110B5 & 1110 & 0.1038 & 9.63 & 9 & 92.5 & 0.0189 & 52.75 \\
\hline $\begin{array}{l}\text { 16S9ErW75B5 } \\
\end{array}$ & 75 & 0.0627 & 15.96 & 10 & \begin{tabular}{|l|l}
90.7 \\
\end{tabular} & 0.0132 & 75.78 \\
\hline 16S9ErW45B5 & 45 & \begin{tabular}{|l|}
0.0357 \\
\end{tabular} & 27.99 & 14 & 90.8 & 0.0077 & 129.9 \\
\hline 8S9ErW20B5 & 20 & \begin{tabular}{|l|}
0.0213 \\
\end{tabular} & \begin{tabular}{|l|}
46.8 \\
\end{tabular} & 14 & 90.1 & 0.004 & 250.77 \\
\hline
\end{tabular}

The first mode of vibration of the four groups of block models is shown in Figure 4-5. A shear deformation behavior is dominant for these models as expected for a structure with a low height to width ratio subjected to lateral loads.

Tables 4-6 and 4-7 list the periods and frequencies for the block-frame-shear wall models for dry and wet conditions, respectively, and their corresponding accumulated participating mass ratio. The same hydrodynamic added mass effect on the natural periods is observed in the erection/service bay substructure models as for the generator bay, explained in Section 3.4 of this report.

The block-frame-shear wall models showed more flexibility than the block models because of the internal frame in the substructure. Figure 4-6 shows the first mode of vibration of the four groups of the block-frame-shear wall models.

\subsection{CEUS and PNW Time-History Results for Block Finite Element Models}

\subsubsection{Analysis results}

A time-history analysis was performed on the four erection/service bay substructure block models. The amplified acceleration time-histories were recorded at the midtop node of the finite element mesh. These time-histories were then 


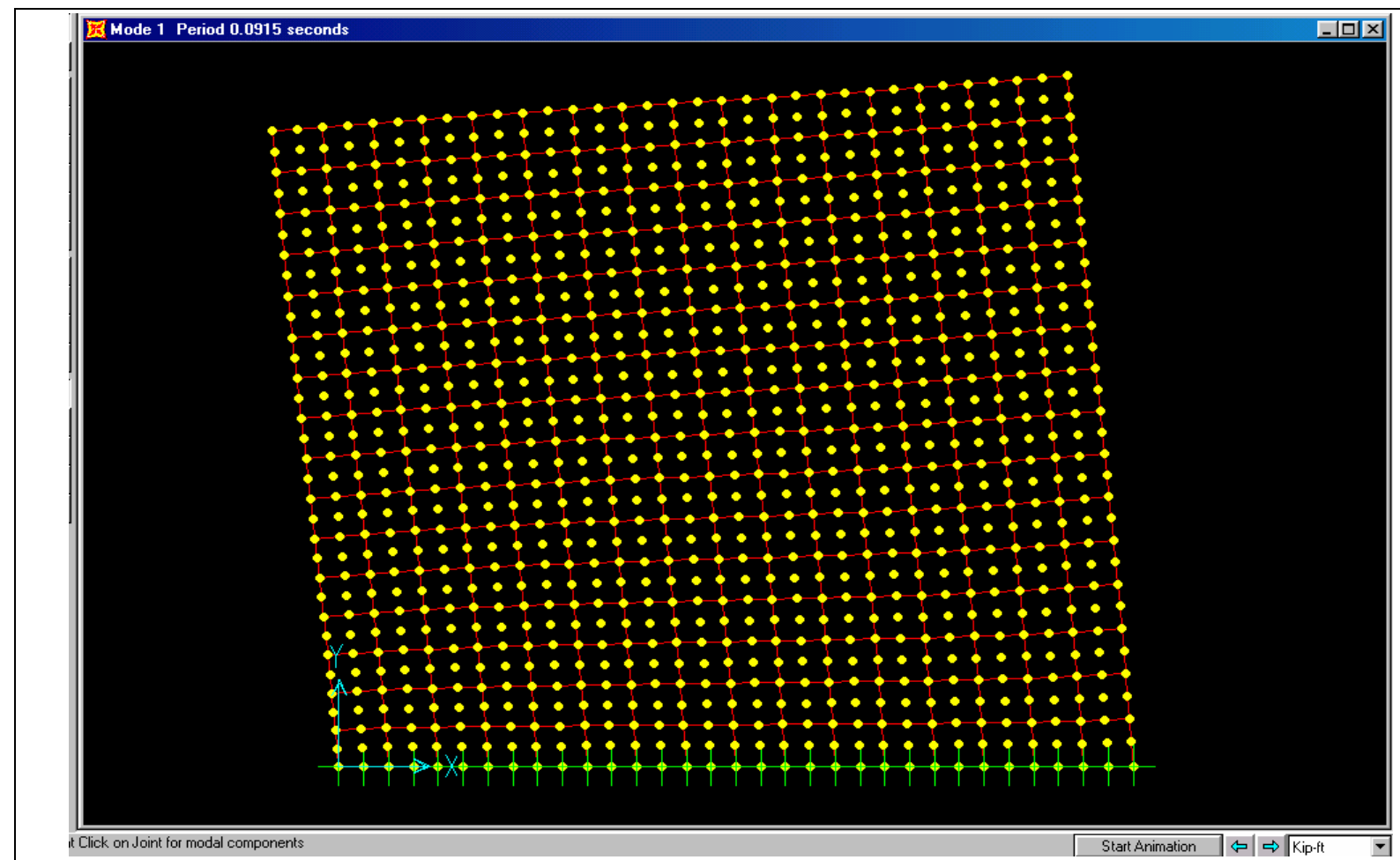

a. 110-ft height

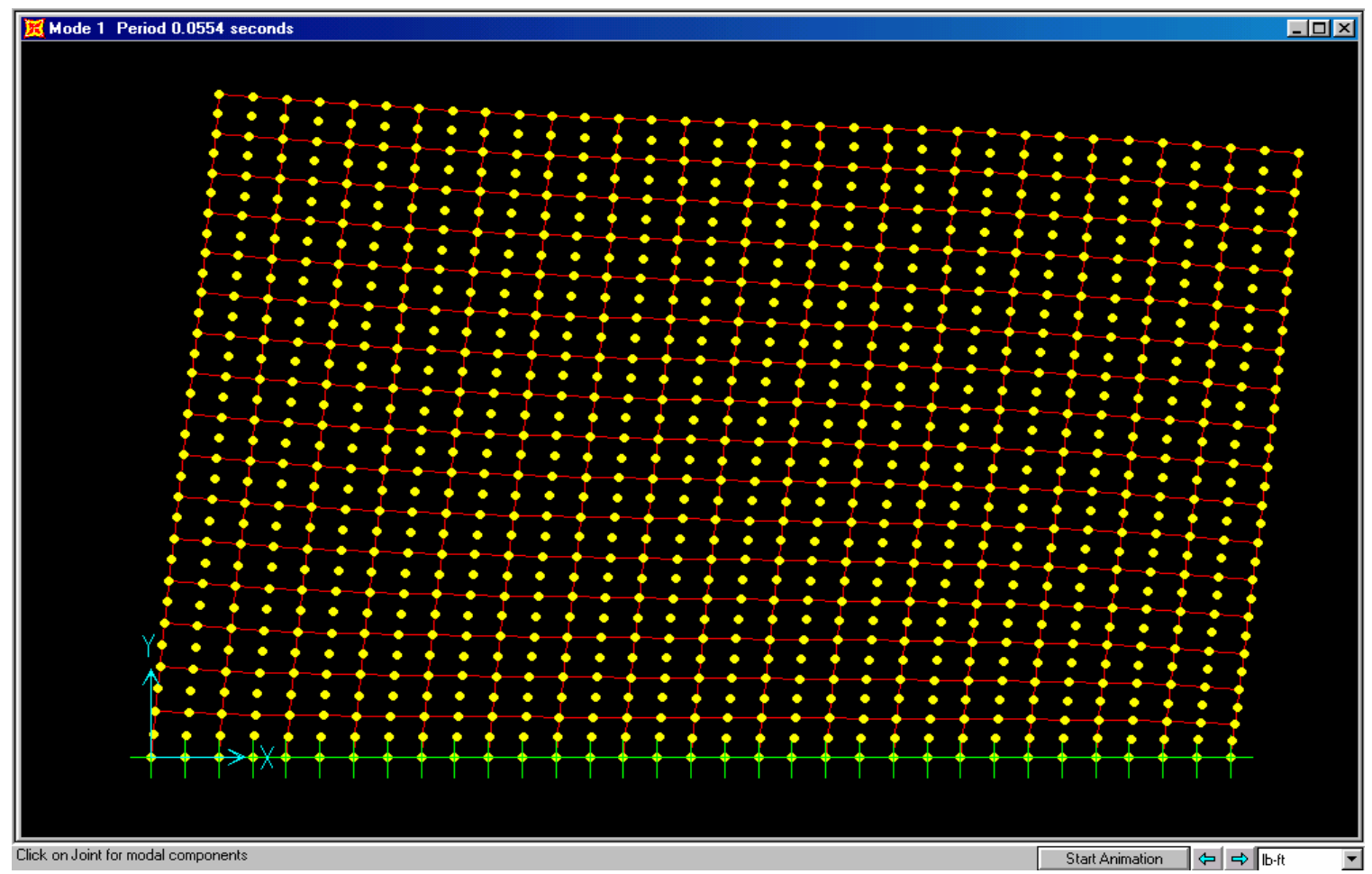

b. 75 -ft height

Figure 4-5. First mode of vibration for erection/service bay block models (Continued) 


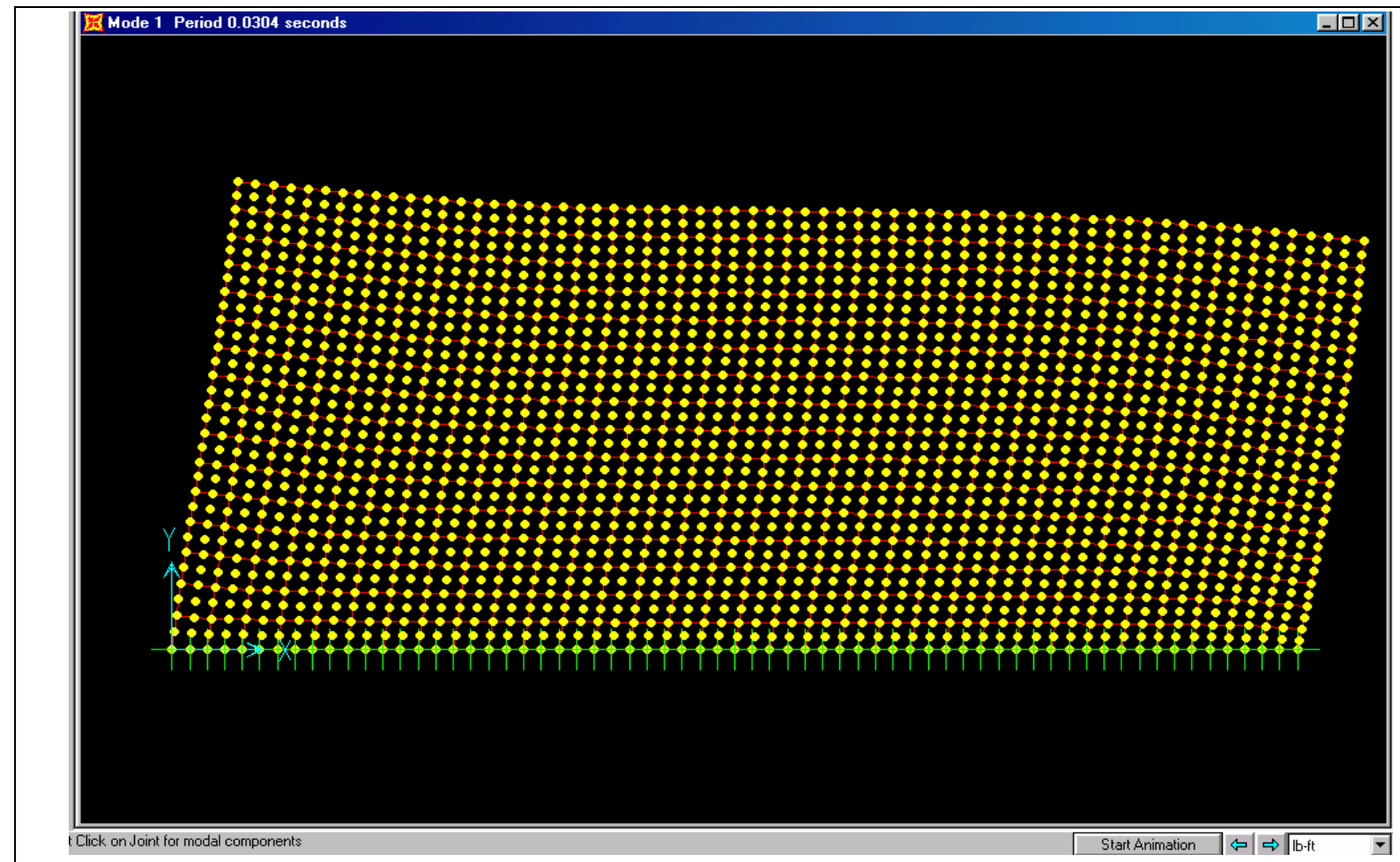

c. 45 -ft height

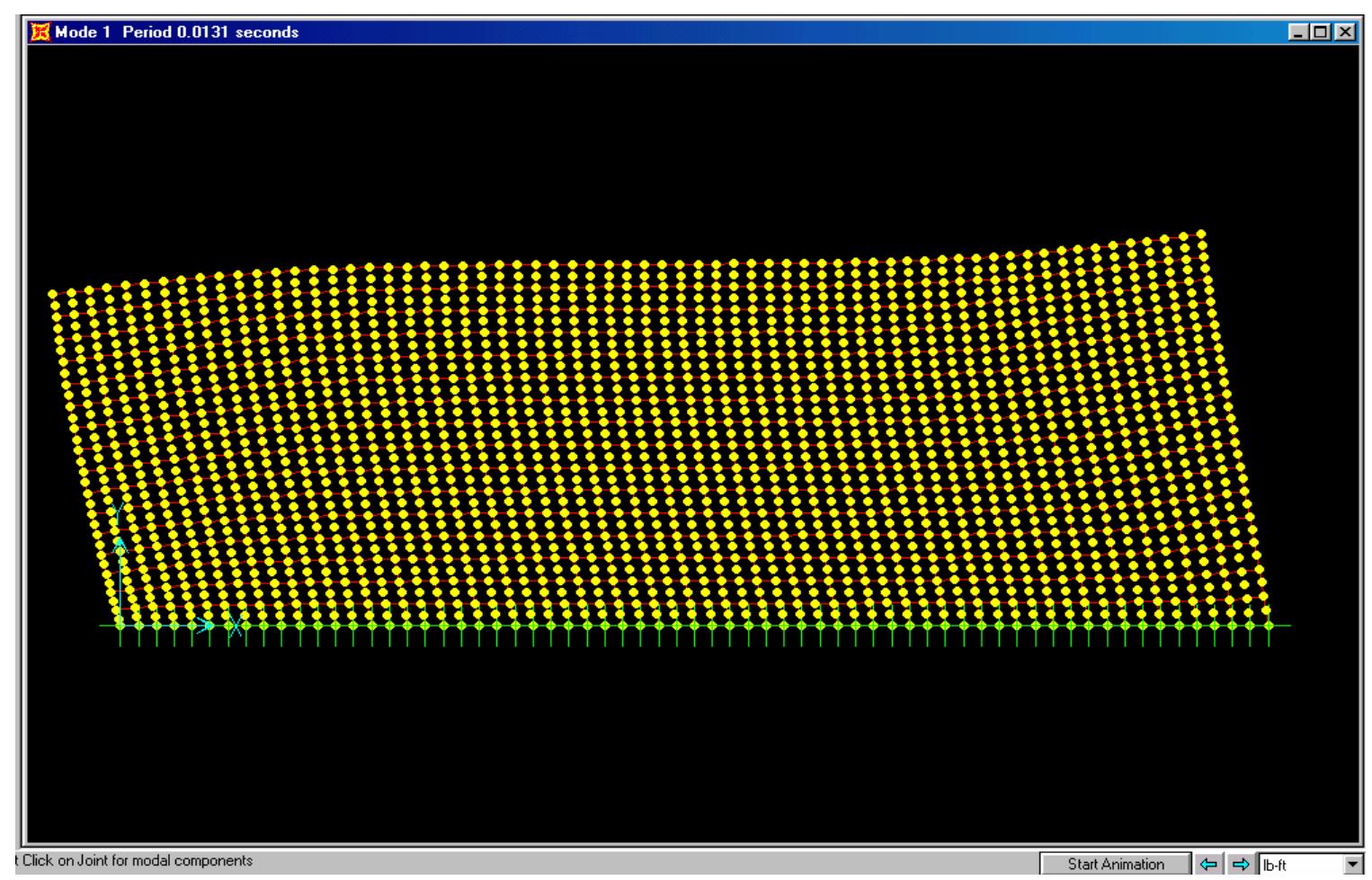

d. 20-ft height

Figure 4-5. (Concluded) 


\begin{tabular}{|c|c|c|c|c|c|c|c|}
\hline \multicolumn{8}{|c|}{$\begin{array}{l}\text { Table 4-6 } \\
\text { Undamped Natural Frequencies and Modal Mass Participation } \\
\text { Ratio for Erection/Service Bay Block-Frame-Shear Wall Models, } \\
\text { Dry Condition }\end{array}$} \\
\hline \multirow[b]{2}{*}{ Model ID } & \multirow[b]{2}{*}{$\begin{array}{l}\text { Height } \\
\mathrm{ft}\end{array}$} & \multicolumn{2}{|c|}{ First Mode } & \multicolumn{4}{|c|}{\begin{tabular}{|l} 
Final Mode \\
\end{tabular}} \\
\hline & & $T_{1}, \mathrm{sec}$ & $f_{1}, \mathrm{~Hz}$ & $\begin{array}{l}\text { Total No. } \\
i\end{array}$ & \begin{tabular}{|l|} 
PMR \\
$\%$
\end{tabular} & \begin{tabular}{|l|}
$T_{i}$ \\
sec \\
\end{tabular} & $\begin{array}{l}f_{i} \\
\mathrm{~Hz} \\
\end{array}$ \\
\hline 14S9ErD110FW5 & 110 & 0.0964 & 10.37 & 14 & 90.39 & 0.0136 & 73.72 \\
\hline 20S9ErD75FW5 & 75 & 0.0624 & 16.02 & 15 & 90.06 & 0.0098 & 101.8 \\
\hline 12S9ErD45FW5 & 45 & 0.0362 & 27.04 & 15 & 90.35 & 0.0075 & 132.94 \\
\hline 8S9ErD20FW5 & 20 & 0.0135 & 74.05 & 20 & 91.33 & 0.0025 & 405.21 \\
\hline
\end{tabular}

\begin{tabular}{|c|c|c|c|c|c|c|c|}
\hline \multicolumn{8}{|c|}{$\begin{array}{l}\text { Table 4-7 } \\
\text { Undamped Natural Frequencies and Modal Mass Participation } \\
\text { Ratio for Erection/Service Bay Block-Frame-Shear Wall Models, } \\
\text { Wet Condition }\end{array}$} \\
\hline \multirow[b]{2}{*}{ Model ID } & \multirow[b]{2}{*}{$\begin{array}{l}\text { Height } \\
\mathrm{ft}\end{array}$} & \multicolumn{2}{|c|}{ First Mode } & \multicolumn{4}{|c|}{$\begin{array}{ll}\text { Final Mode } \\
\end{array}$} \\
\hline & & $T_{1}, \sec$ & $f_{1}, \mathrm{~Hz}$ & $\begin{array}{l}\text { Total No. } \\
i\end{array}$ & \begin{tabular}{|l|} 
PMR \\
$\%$
\end{tabular} & \begin{tabular}{|l}
$T_{i}$ \\
sec \\
\end{tabular} & $\begin{array}{l}f_{i} \\
\mathrm{~Hz} \\
\end{array}$ \\
\hline 14S9ErW110FW5 & 110 & 0.1193 & 8.38 & 18 & 93.3 & 0.0141 & 71.03 \\
\hline 14S9ErW75FW5 & 75 & 0.0773 & 12.94 & 15 & 90.54 & 0.0112 & 89.58 \\
\hline 12S9ErW45FW5 & 45 & 0.0479 & 20.89 & 20 & 92.76 & 0.0071 & 141.35 \\
\hline 8S9ErW20FW5 & 20 & 0.0281 & 35.52 & 30 & 91.88 & 0.0027 & 372.33 \\
\hline
\end{tabular}

converted to SA at top-of-substructure for 5 percent damping. To develop the AF curves, the SA at top-of-substructure was divided by the SA for 5 percent damping at rock for the same frequency.

Tables 4-8 and 4-9 list the SA at top-of-substructures for dry and wet conditions, respectively, at a frequency of $50 \mathrm{~Hz}$ and the ratio with the PGA for each of the two ground motions. The in-rock PGA for the CEUS ground motion was taken as $0.19 \mathrm{~g}$ and for the PNW ground motion, $0.16 \mathrm{~g}$. The data given in these two tables show that the AF values decrease with the height of substructure.

The maximum AFs and their corresponding frequency are listed in Table 4-10 for the dry condition and Table 4-11 for the wet condition for the two ground motions. The results show that the 20 -ft-height block models can be considered as rigid structures because the AF is near one for dry and wet conditions for both earthquakes. This was expected because its natural frequency is well beyond the maximum ground motion frequency contents of $33 \mathrm{~Hz}$ (as reflected in the zero Fourier amplitudes in Figures 2-9 and 2-10).

Figures 4-7 to 4-14 show the AF curves, the response spectrum at top-ofsubstructure, and the response spectrum at rock for the block models with 5 percent damping. The results are presented first for the CEUS ground motion and then for the PNW ground motion. Table 4-12 lists the figure numbers of SA and $\mathrm{AF}$ results on this section. 


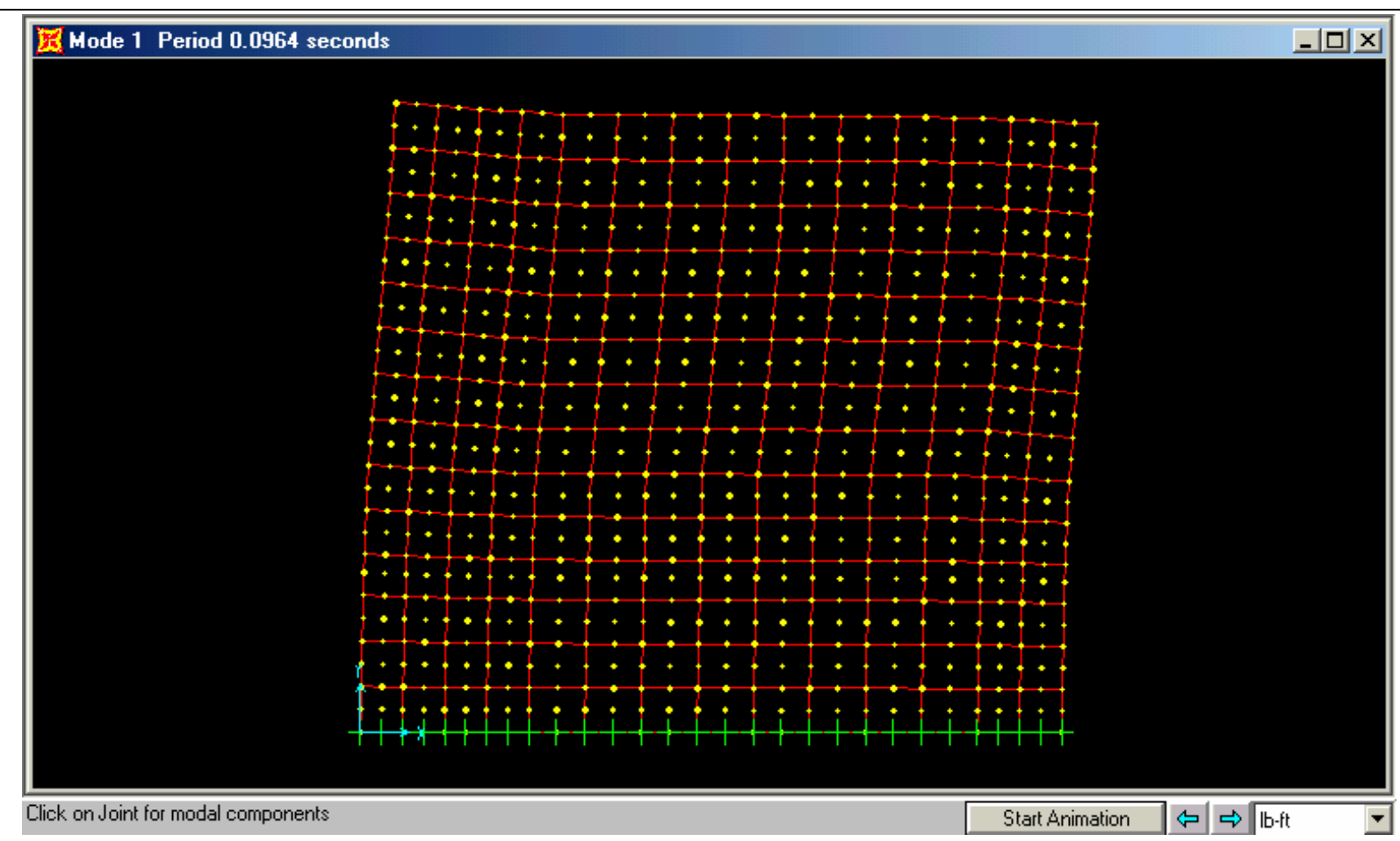

a. 110-ft height

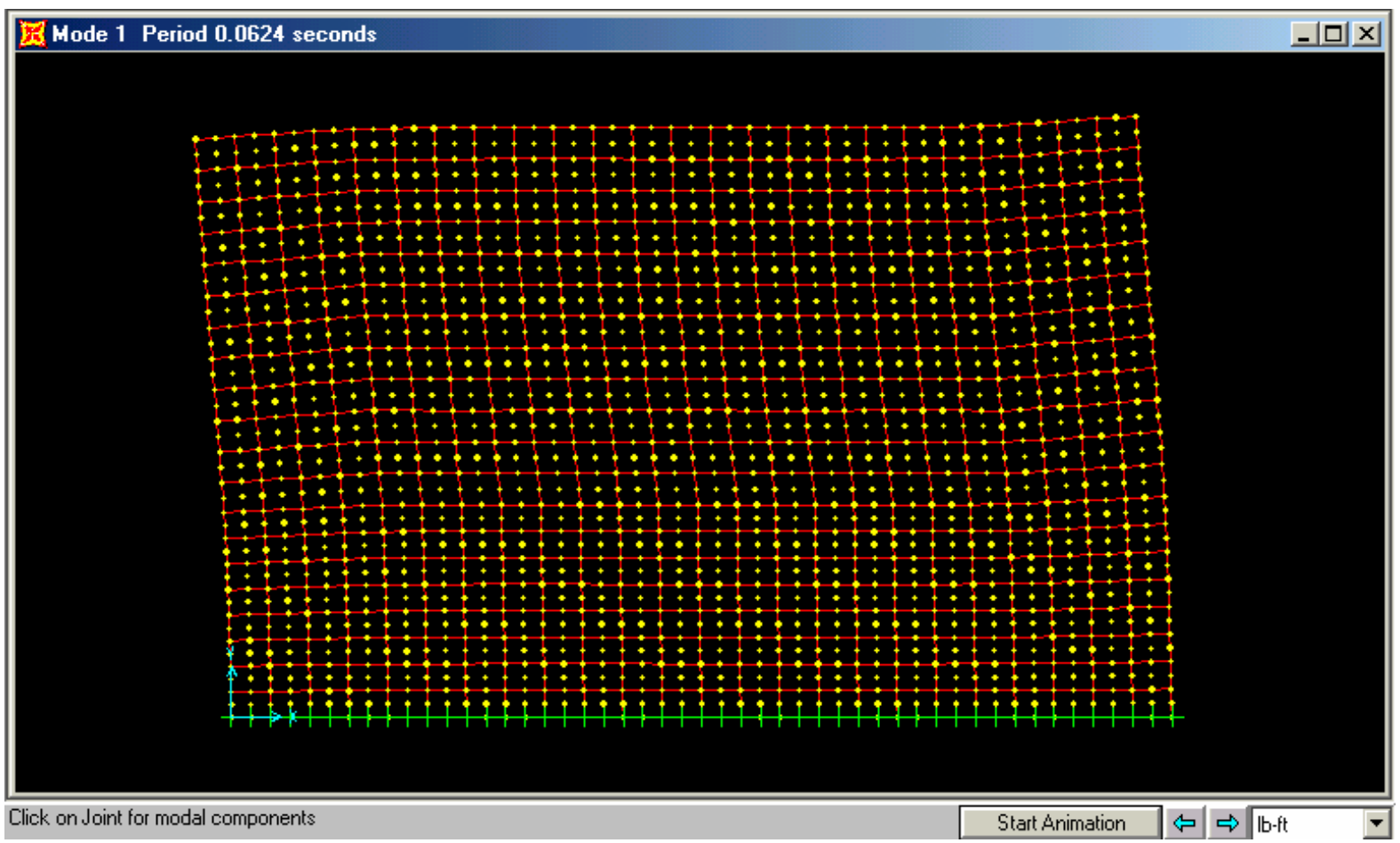

b. 75-ft height

Figure 4-6. First mode of vibration for erection/service bay block-frame-shear wall models (Continued) 


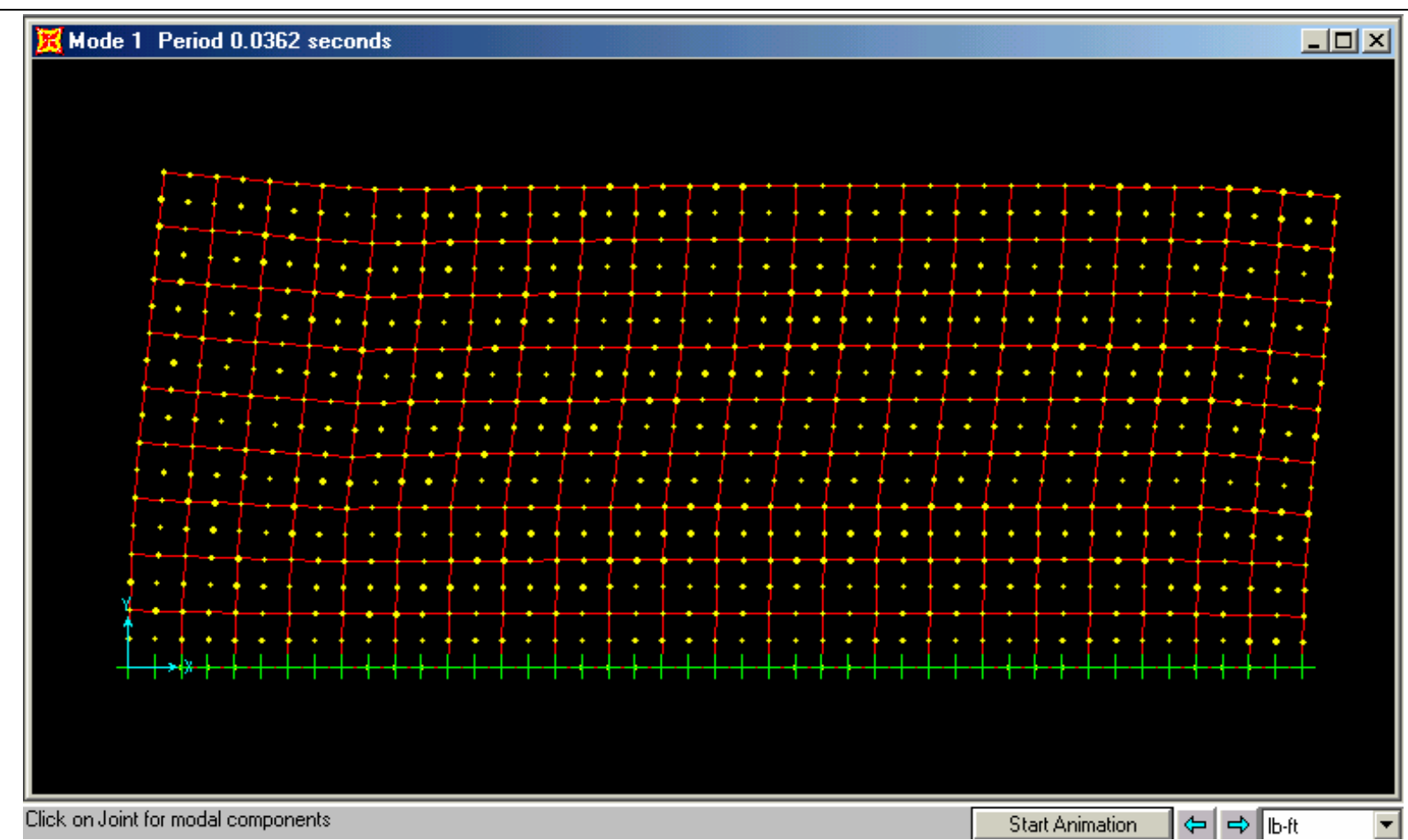

C. $45-\mathrm{ft}$ height

Tode 1 Period 0.0135 seconds

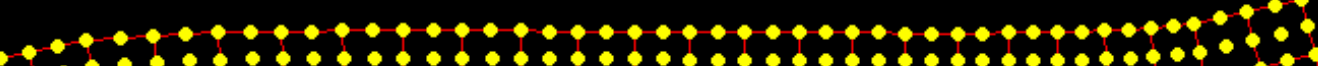
ค ( ० $\bullet \bullet \bullet \bullet \bullet \bullet \bullet \bullet \bullet \bullet \bullet \bullet \bullet \bullet \bullet \bullet \bullet \bullet \bullet \bullet \bullet \bullet \bullet \bullet \bullet \bullet \bullet \bullet \bullet \bullet \bullet \bullet \bullet \bullet \bullet \bullet \bullet \bullet \bullet \bullet \bullet \bullet \bullet \bullet \bullet \bullet, \bullet \bullet$

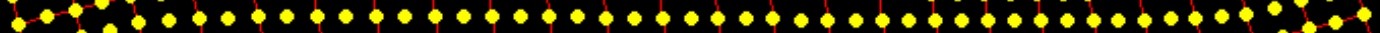
 $\bullet \bullet$ $\bullet \bullet \bullet \bullet \bullet \bullet \bullet \bullet \bullet \bullet \bullet \bullet \bullet \bullet \bullet \bullet \bullet \bullet \bullet \bullet \bullet \bullet \bullet \bullet \bullet \bullet \bullet \bullet \bullet \bullet \bullet \bullet \bullet \bullet \bullet \bullet \bullet \bullet \bullet \bullet \bullet \bullet \bullet \bullet \bullet \bullet \bullet \bullet$ (4)

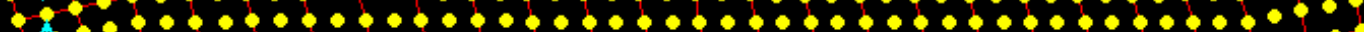
P

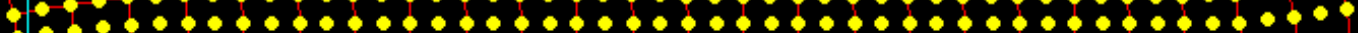
4 ,

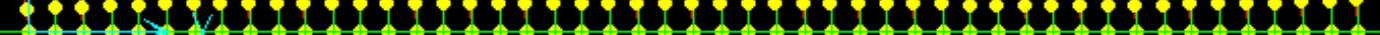

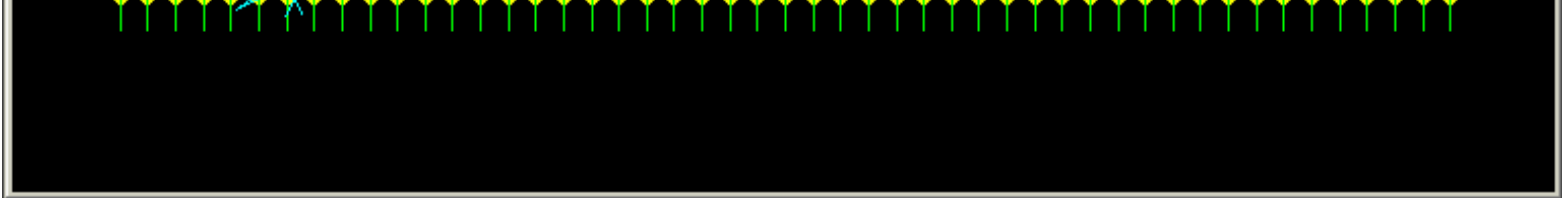

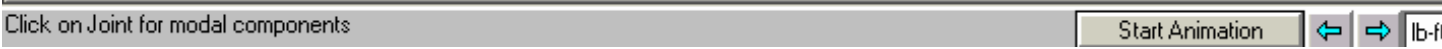

d. 20-ft height

Figure 4-6. (Concluded) 


\begin{tabular}{|c|c|c|c|c|c|}
\hline \multicolumn{6}{|c|}{$\begin{array}{l}\text { Table 4-8 } \\
\text { SA at Frequency of } 50 \mathrm{~Hz} \text { for Erection/Service Bay Block Models, } \\
\text { Dry Condition }\end{array}$} \\
\hline \multirow[b]{2}{*}{ Model ID } & \multirow[b]{2}{*}{$\begin{array}{l}\text { Height } \\
\mathrm{ft}\end{array}$} & \multicolumn{2}{|c|}{ CEUS } & \multicolumn{2}{|c|}{ PNW } \\
\hline & & $\begin{array}{l}\text { SA }_{50 \mathrm{~Hz}} \\
\text { g's }\end{array}$ & \begin{tabular}{|l|} 
SA/PGA \\
g's \\
\end{tabular} & $\begin{array}{l}S_{A_{50 H z}} \\
\text { g's } \\
\end{array}$ & $\begin{array}{l}\text { SA/PGA } \\
\text { g's }\end{array}$ \\
\hline 16S9ErD110B5 & 110 & 0.58 & 3.05 & 0.41 & 2.56 \\
\hline 16S9ErD75B5 & 75 & 0.4 & 2.11 & 0.22 & 1.38 \\
\hline 16S9ErD45B5 & 45 & 0.27 & 1.42 & 0.17 & 1.06 \\
\hline 8S9ErD20B5 & 20 & 0.2 & 1.05 & 0.16 & 1 \\
\hline
\end{tabular}

\begin{tabular}{|c|c|c|c|c|c|}
\hline \multicolumn{6}{|c|}{$\begin{array}{l}\text { Table } 4-9 \\
\text { SA at Frequency of } 50 \mathrm{~Hz} \text { for Erection/Service Bay Block Models, } \\
\text { Wet Condition }\end{array}$} \\
\hline \multirow[b]{2}{*}{ Model ID } & \multirow[b]{2}{*}{$\begin{array}{l}\text { Height } \\
\mathrm{ft}\end{array}$} & \multicolumn{2}{|c|}{ CEUS } & \multicolumn{2}{|c|}{ PNW } \\
\hline & & $\begin{array}{l}\mathrm{SA}_{50 \mathrm{~Hz}} \\
\text { g's }\end{array}$ & \begin{tabular}{|l} 
SA/PGA \\
g's \\
\end{tabular} & $\begin{array}{l}\text { SA }_{50 \mathrm{~Hz}} \\
\text { g's }\end{array}$ & \begin{tabular}{|l} 
SA/PGA \\
g's \\
\end{tabular} \\
\hline 16S9ErW110B5 & 110 & 0.68 & $\begin{array}{l}3.58 \\
\end{array}$ & 0.45 & 2.81 \\
\hline 16S9ErW75B5 & 75 & 0.39 & 2.05 & 0.31 & 1.94 \\
\hline 16S9ErW45B5 & 45 & 0.27 & 1.42 & 0.18 & 1.13 \\
\hline 8S9ErW20B5 & 20 & 0.19 & 1.00 & 0.16 & 1 \\
\hline
\end{tabular}

\begin{tabular}{|c|c|c|c|c|c|c|c|}
\hline \multicolumn{8}{|c|}{$\begin{array}{l}\text { Table 4-10 } \\
\text { Maximum Amplification Factor (AF) })_{S A} \text { and Its Corresponding SA for } \\
\text { Erection/Service Bay Block Models, Dry Condition }\end{array}$} \\
\hline \multirow[b]{2}{*}{ Model ID } & \multirow[b]{2}{*}{$\begin{array}{l}\text { Height } \\
\mathrm{ft}\end{array}$} & \multicolumn{3}{|c|}{ CEUS } & \multicolumn{3}{|c|}{ PNW } \\
\hline & & $\begin{array}{l}f \\
\mathrm{~Hz}\end{array}$ & $\begin{array}{l}\text { SA } \\
\text { g's }\end{array}$ & $\begin{array}{l}(\mathrm{AF})_{\mathrm{SA}} \\
\text { at } f\end{array}$ & $\begin{array}{l}f f \\
\mathrm{~Hz}\end{array}$ & $\begin{array}{l}\text { SA } \\
\text { g's }\end{array}$ & $\begin{array}{l}(\mathrm{AF})_{\mathrm{SA}} \\
\text { at } f\end{array}$ \\
\hline 16S9ErD110B5 & "110 & 111 & 2.43 & $\bar{~} 5.76$ & 111 & 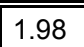 & 25.97 \\
\hline 16S9ErD75B5 & 75 & 18.04 & 2.08 & 6.16 & 16.5 & 0.99 & 4.38 \\
\hline 16S9ErD45B5 & 45 & 32.91 & 1.07 & 4.95 & 4 & 0.45 & 1.11 \\
\hline 8S9ErD20B5 & 20 & -- & -- & -- & -- & -- & -- \\
\hline
\end{tabular}

\begin{tabular}{|c|c|c|c|c|c|c|c|}
\hline \multicolumn{8}{|c|}{$\begin{array}{l}\text { Table 4-11 } \\
\text { Maximum Amplification Factor (AF) })_{S A} \text { and Its Corresponding SA for } \\
\text { Erection/Service Bay Block Models, Wet Condition }\end{array}$} \\
\hline \multirow[b]{2}{*}{ Model ID } & \multirow[b]{2}{*}{$\begin{array}{l}\text { Height } \\
\mathrm{ft}\end{array}$} & \multicolumn{3}{|c|}{ CEUS } & \multicolumn{3}{|c|}{ PNW } \\
\hline & & \begin{tabular}{|l}
$f$ \\
$\mathrm{~Hz}$ \\
\end{tabular} & \begin{tabular}{|l|} 
SA \\
g's
\end{tabular} & \begin{tabular}{|l}
$(\mathrm{AF})_{\mathrm{SA}}$ \\
at $f$
\end{tabular} & \begin{tabular}{|l|}
$f$ \\
$\mathrm{~Hz}$
\end{tabular} & $\begin{array}{l}\text { SA } \\
\text { g's }\end{array}$ & \begin{tabular}{|l|}
$(\mathrm{AF})_{\mathrm{SA}}$ \\
at $f$
\end{tabular} \\
\hline 16S9ErW110B5 & 1110 & 99 & 3.35 & 6.76 & 9.63 & 2.45 & 6.95 \\
\hline 16S9ErW75B5 & 75 & 15 & 2.11 & 6.26 & 15.96 & 1.44 & 5.11 \\
\hline 16S9ErW45B5 & 45 & 28 & 0.88 & 3.55 & 4 & 0.45 & 1.47 \\
\hline 8S9ErW20B5 & 20 & -- & -- & $\begin{array}{l}- \\
\end{array}$ & -- & -- & \begin{tabular}{|l|}
- \\
\end{tabular} \\
\hline
\end{tabular}




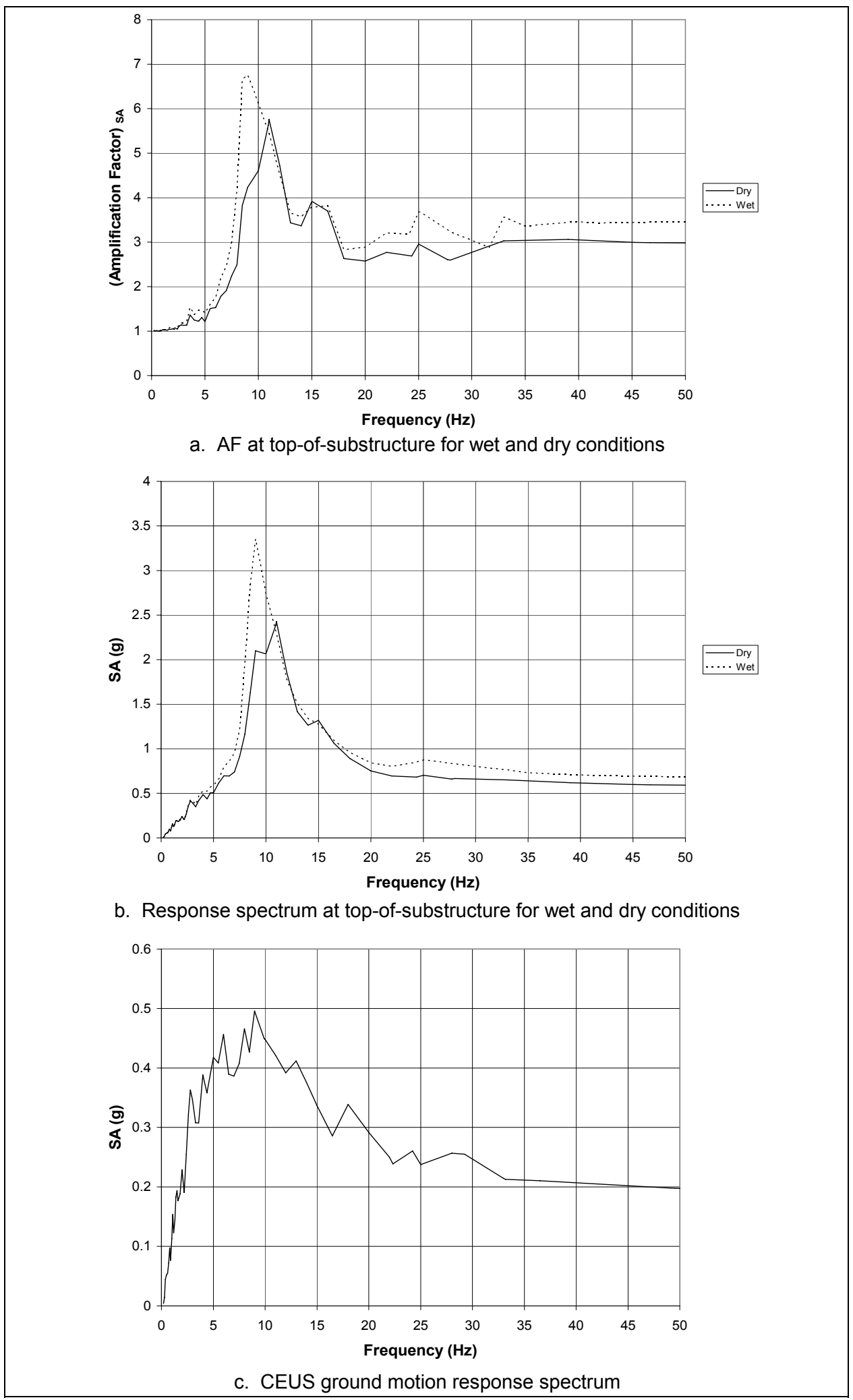

Figure 4-7. Response spectra and AF curves, erection/service bay, block model, 110-ft height (Dry Model ID: 16S9ErD110B5, Wet Model ID: 16S9ErW110B5), for CEUS ground motion with 5 percent damping 


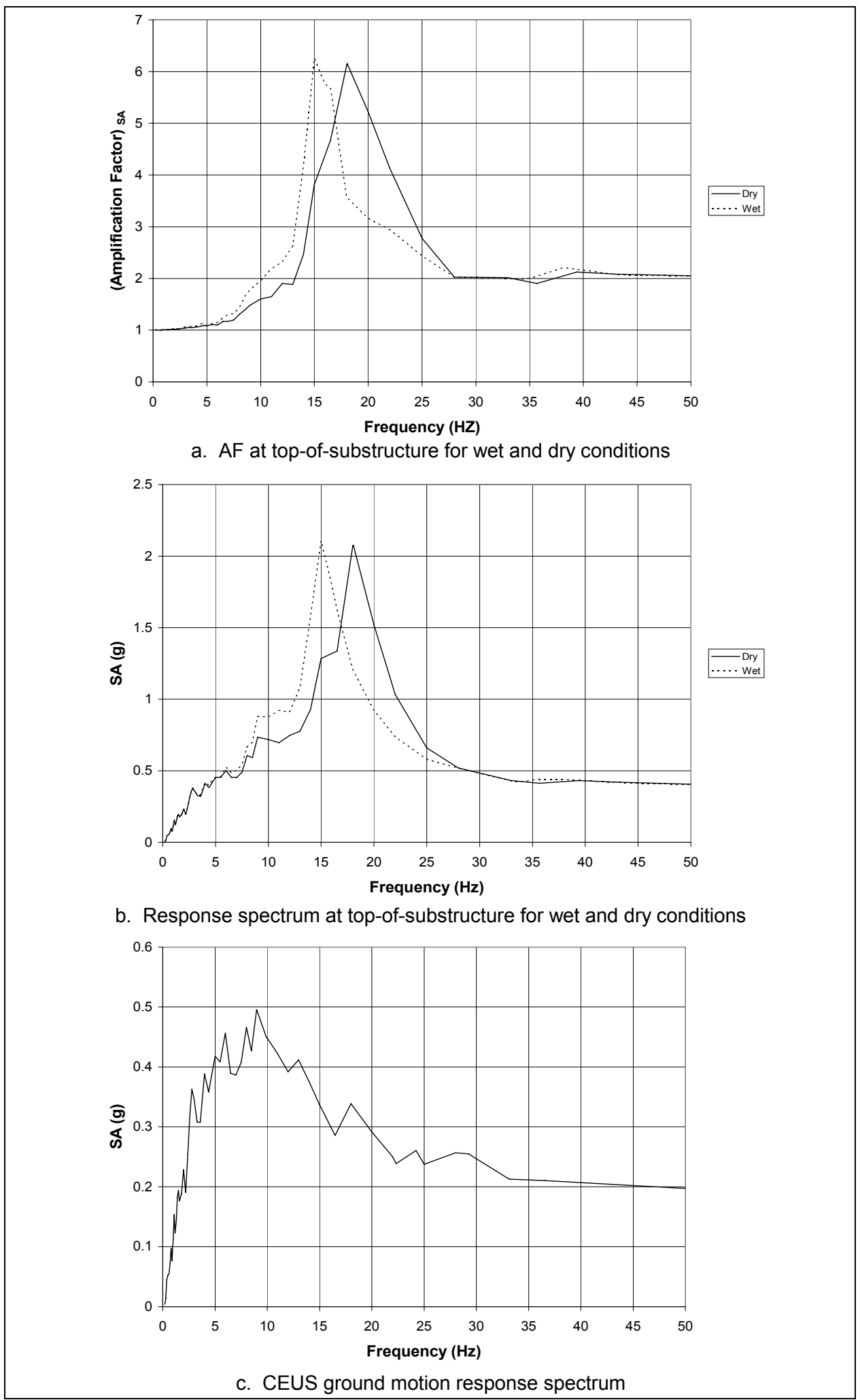

Figure 4-8. Response spectra and AF curves, erection/service bay, block model, 75-ft height (Dry Model ID: 16S9ErD75B5, Wet Model ID: 16S9ErW75B5), for CEUS ground motion with 5 percent damping 


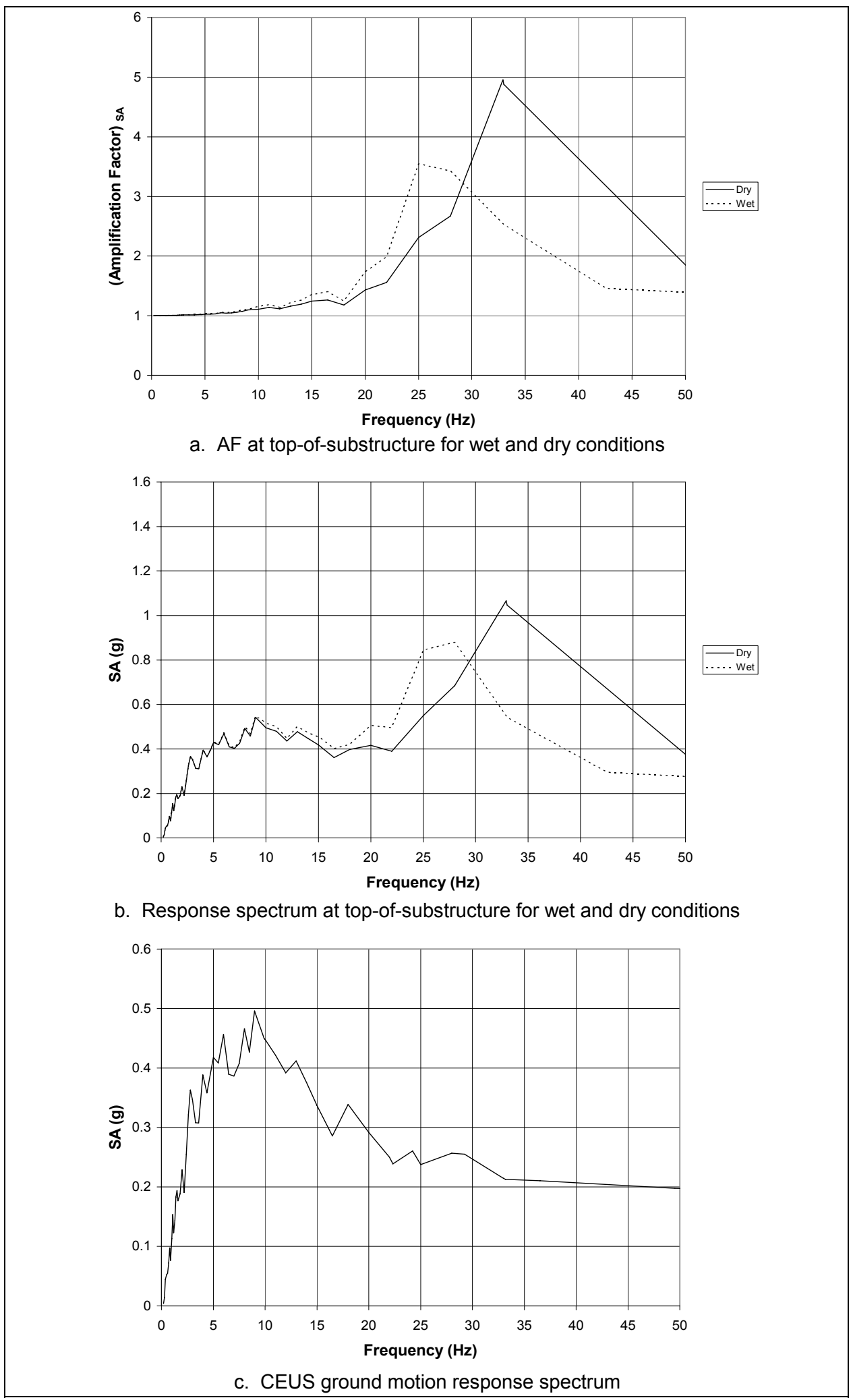

Figure 4-9. Response spectra and AF curves, erection/service bay, block model, 45-ft height (Dry Model ID: 16S9ErD45B5, Wet Model ID:

16S9ErW45B5), for CEUS ground motion with 5 percent damping 


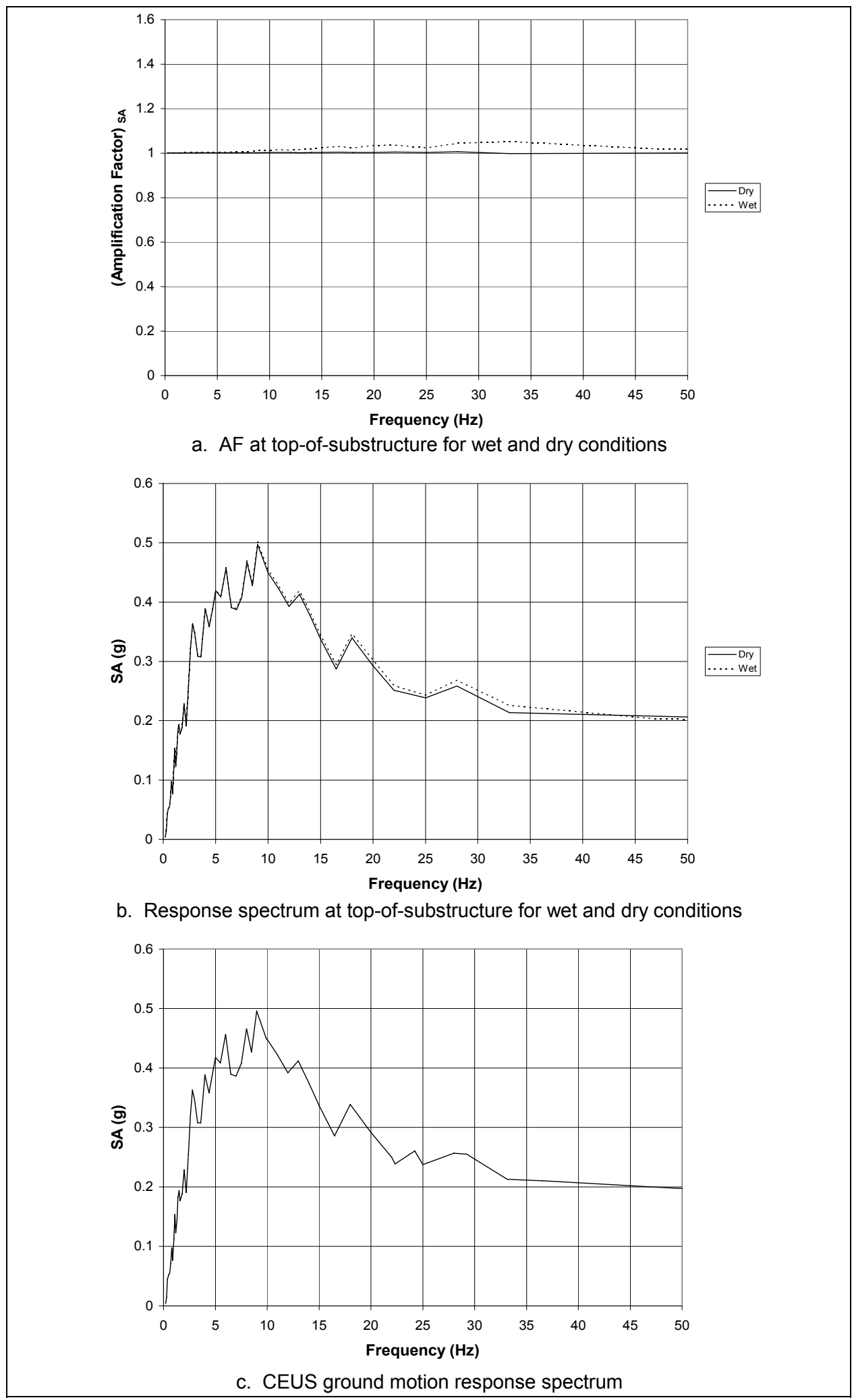

Figure 4-10. Response spectra and AF curves, erection/service bay, block model, 20-ft height (Dry Model ID: 8S9ErD20B5, Wet Model ID: 8S9ErW20B5), for CEUS ground motion with 5 percent damping 


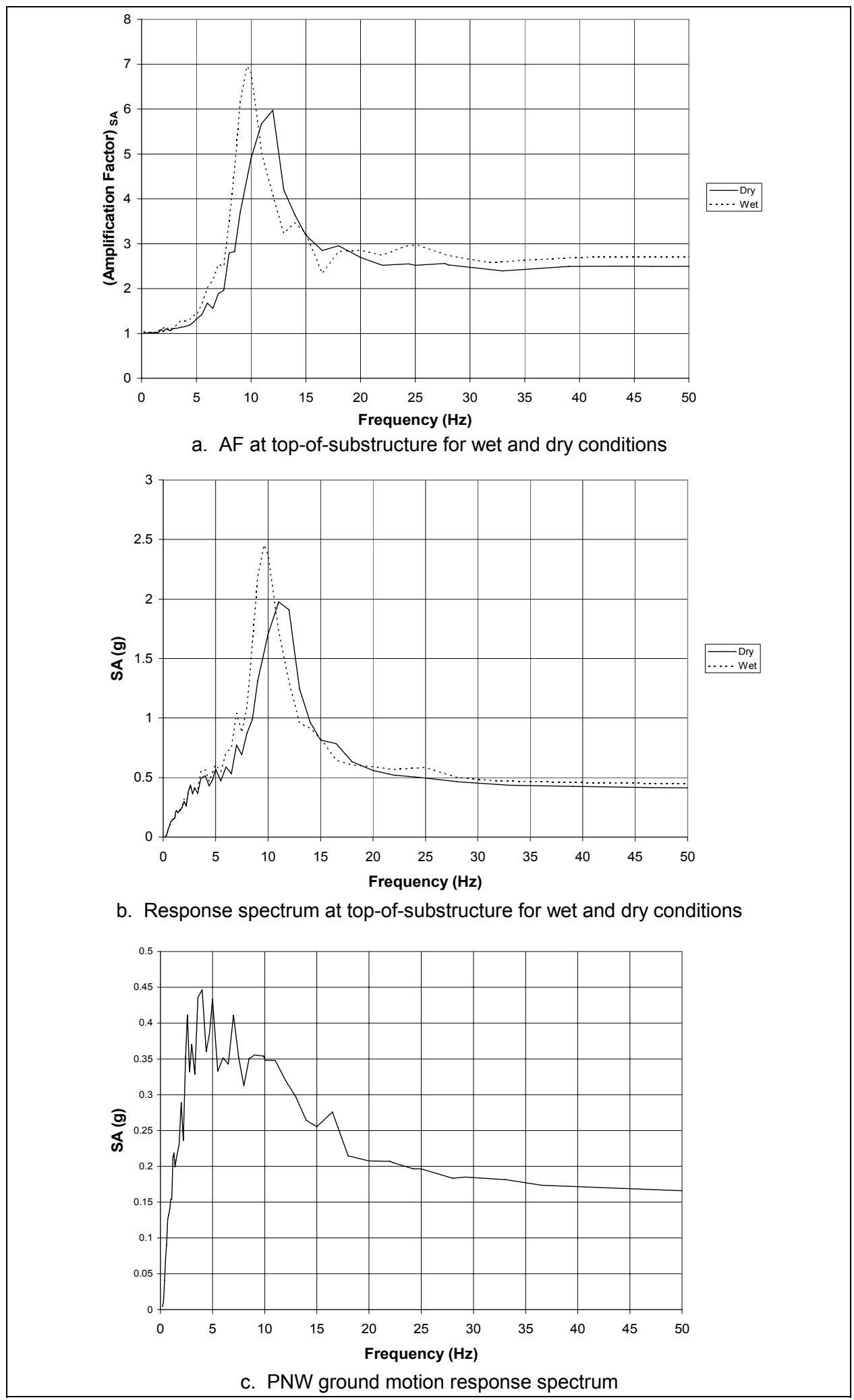

Figure 4-11. Response spectra and AF curves, erection/service bay, block model, 110-ft height (Dry Model ID: 16S9ErD110B5, Wet Model ID: 16S9ErW110B5), for PNW ground motion with 5 percent damping 


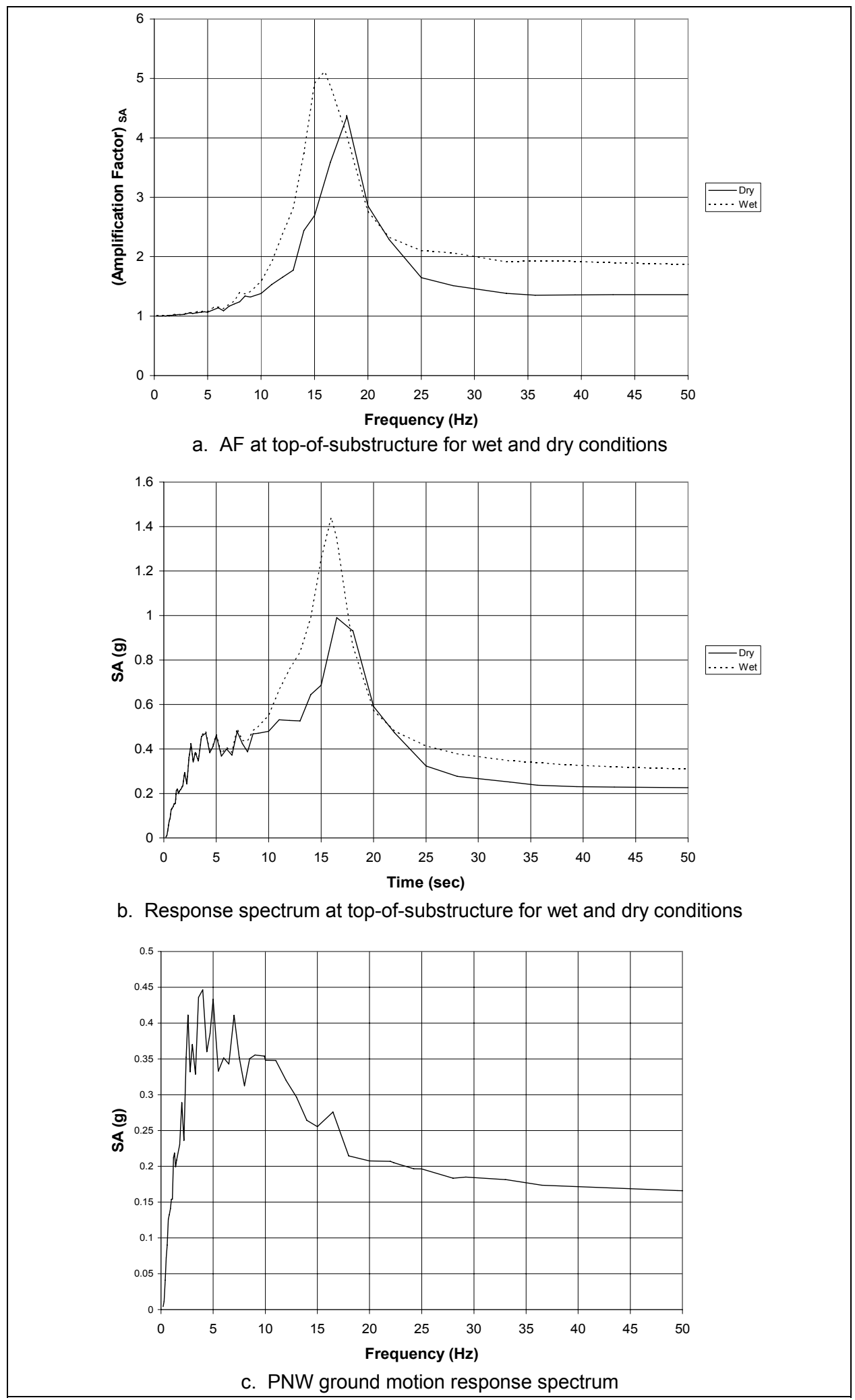

Figure 4-12. Response spectra and AF curves, erection/service bay, block model, 75-ft height (Dry Model ID: 16S9ErD75B5, Wet Model ID: 16S9ErW75B5), for PNW ground motion with 5 percent damping 


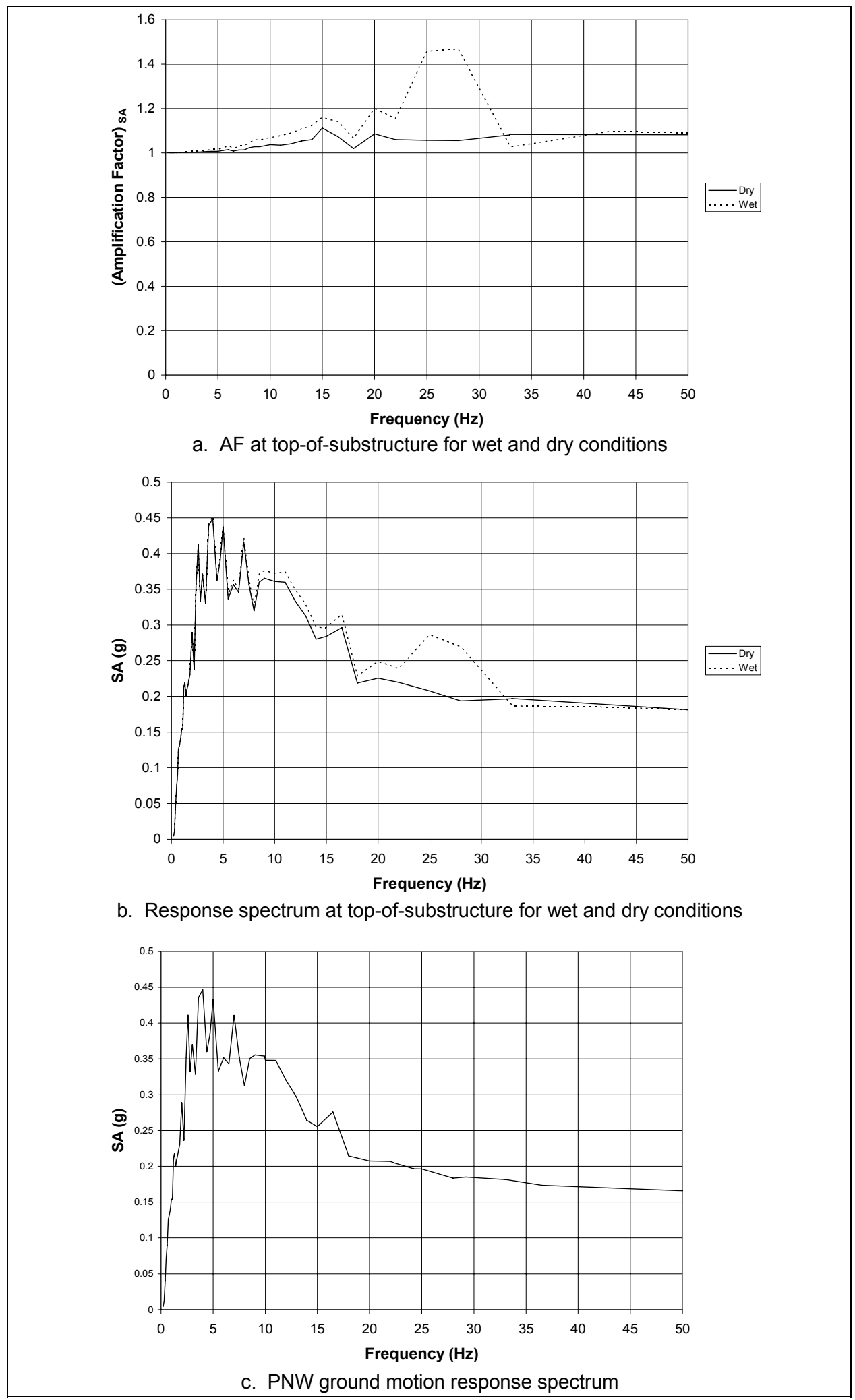

Figure 4-13. Response spectra and AF curves, erection/service bay, block model, 45-ft height (Dry Model ID: 16S9ErD45B5, Wet Model ID: 16S9ErW45B5), for PNW ground motion with 5 percent damping 


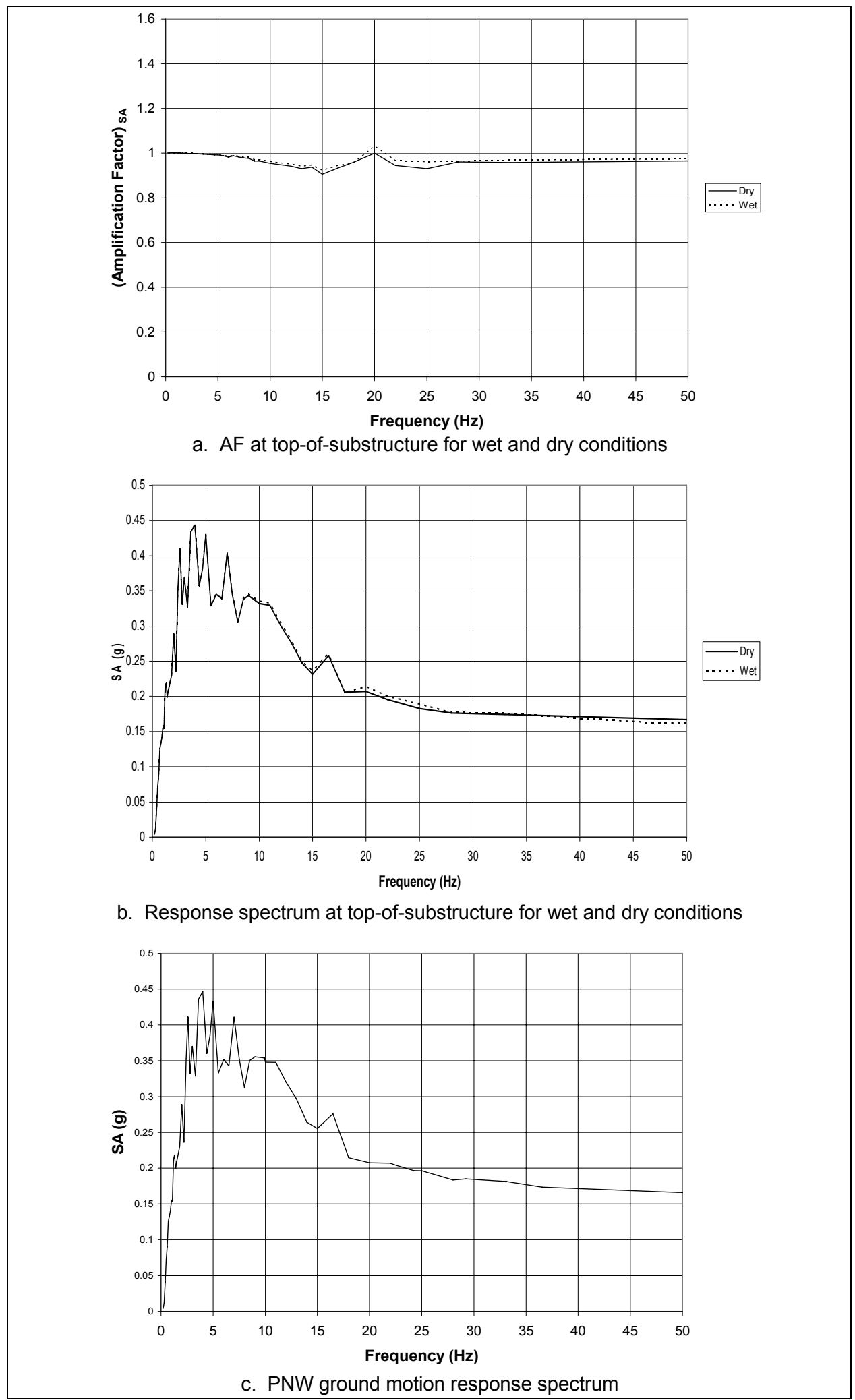

Figure 4-14. Response spectra and AF curves, erection/service bay, block model, 20-ft height (Dry Model ID: 8S9ErD20B5, Wet Model ID: 8S9ErW20B5), for PNW ground motion with 5 percent damping 


\begin{tabular}{|c|c|c|c|}
\hline \multicolumn{4}{|c|}{$\begin{array}{l}\text { Table } 4-12 \\
\text { Figure Numbers of Erection/Service Bay Block Model Results for } \\
5 \text { percent damping }\end{array}$} \\
\hline Group & Height & CEUS & PNW \\
\hline 1 & 110 & Figure 4-7 & Figure 4-11 \\
\hline 2 & 75 & Figure 4-8 & Figure $4-12$ \\
\hline 3 & 45 & Figure 4-9 & Figure 4-13 \\
\hline 4 & 20 & Figure 4-10 & Figure 4-14 \\
\hline
\end{tabular}

\subsubsection{Response amplification sensitivity to location at top of the substructure for the erection/service bay block model}

To investigate the variation of the results due to the location at top of the substructure of the erection bay block model, the absolute accelerations (5 percent damping) and AFs versus frequency curves were calculated at the three nodes identified in Figure 4-15. The finite element model used for this analysis was the 110-ft-height erection/service bay block model, in wet condition.

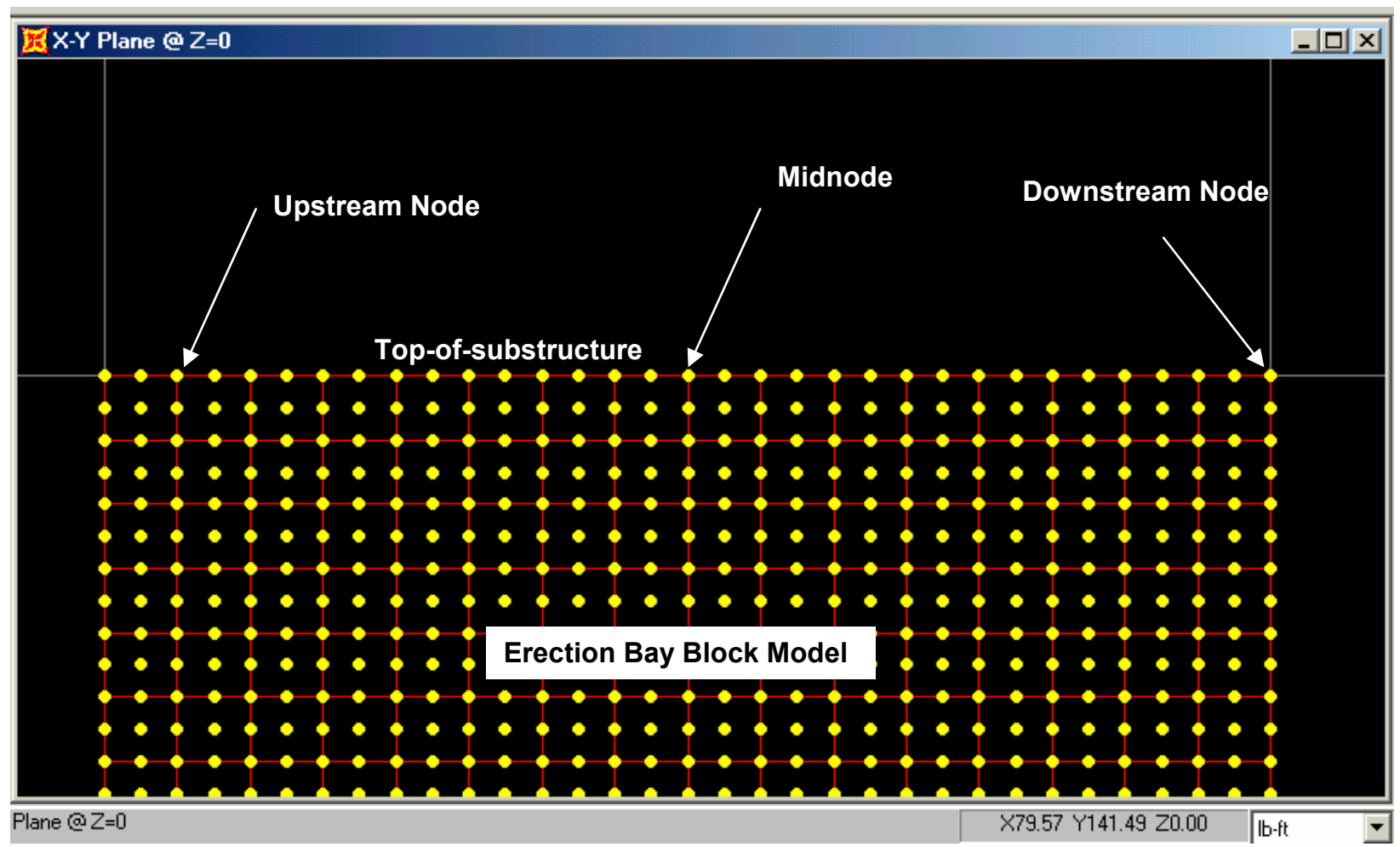

Figure 4-15. Location of the three nodes in the 110-ft-height erection/service bay block model used to calculate the AFs 
Table 4-13 lists the SA at $50 \mathrm{~Hz}$ and its ratio with the PGA at three locations in the substructure. Table 4-14 lists the maximum AF and its frequency at three locations in the substructure. Figure 4-16 shows the SA for the three locations at top of the substructure for both the CEUS and the PNW ground motions.

Figure 4-17 presents the AF curves at the three different locations along the top of the substructure.

\begin{tabular}{|c|c|c|c|c|c|}
\hline \multicolumn{6}{|c|}{$\begin{array}{l}\text { Table } 4-13 \\
\text { SA at } 50 \mathrm{~Hz} \text { at Three Different Locations along the Top of the } \\
\text { 110-ft-Height Block Substructure Model for the Wet Condition }\end{array}$} \\
\hline \multirow[b]{2}{*}{ Model ID } & \multirow[b]{2}{*}{$\begin{array}{l}\text { Height } \\
\mathrm{ft}\end{array}$} & \multicolumn{2}{|c|}{ CEUS } & \multicolumn{2}{|c|}{ PNW } \\
\hline & & $\begin{array}{l}\mathbf{S A}_{50 \mathrm{~Hz}} \\
\mathrm{~g}^{\prime} \mathbf{s}\end{array}$ & $\begin{array}{l}\mathrm{SA}_{50 \mathrm{~Hz}} / \mathrm{PGA} \\
\mathrm{g} \text { 's }\end{array}$ & $\begin{array}{l}\mathrm{SA}_{5 \mathrm{OHz}} \\
\text { g's }\end{array}$ & $\begin{array}{l}\mathrm{SA}_{50 \mathrm{~Hz}} / \mathrm{PGA} \\
\text { g's }\end{array}$ \\
\hline 16S9ErW110B5-Upstream & 110 & 0.79 & 4.16 & 0.48 & 3.00 \\
\hline 16S9ErW110B5-Midnode & 110 & 0.68 & 3.58 & 0.45 & 2.81 \\
\hline 16S9ErW110B5-Downstream & 110 & 0.68 & 3.58 & 0.45 & 2.81 \\
\hline
\end{tabular}

\begin{tabular}{|c|c|c|c|c|c|c|c|}
\hline \multicolumn{8}{|c|}{$\begin{array}{l}\text { Table 4-14 } \\
\text { Maximum AF and Its Corresponding Frequency at Three Different } \\
\text { Locations along the Top of the 110-ft-Height Block Substructure } \\
\text { Model for the Wet Condition }\end{array}$} \\
\hline \multirow[b]{2}{*}{ Model ID } & \multirow[b]{2}{*}{$\begin{array}{l}\text { Height } \\
\mathrm{ft} \\
\end{array}$} & \multicolumn{3}{|c|}{$\begin{array}{c}\text { CEUS } \\
\end{array}$} & \multicolumn{3}{|c|}{$\begin{array}{c}\text { PNW } \\
\end{array}$} \\
\hline & & $\begin{array}{l}f \\
\mathrm{~Hz} \\
\end{array}$ & $\begin{array}{l}\text { SA } \\
\text { g's } \\
\end{array}$ & $\begin{array}{l}\text { (AF) })_{\mathrm{SA}} \\
\text { at } f \\
\end{array}$ & $\begin{array}{l}f \\
\mathrm{~Hz} \\
\end{array}$ & $\begin{array}{l}\text { SA } \\
\text { g's }\end{array}$ & $\begin{array}{l}(\mathrm{AF})_{\mathrm{SA}} \\
\text { at } f\end{array}$ \\
\hline 16S9ErW110B5-Upstream & 110 & 9 & 3.64 & 7.37 & 9.62 & 2.72 & 7.8 \\
\hline 16S9ErW110B5-Midnode & 110 & 9 & 3.35 & 6.76 & 9.63 & 2.45 & 6.95 \\
\hline 16S9ErW110B5-Downstream & 110 & 9 & 3.43 & 6.94 & 9.62 & 2.55 & 7.32 \\
\hline
\end{tabular}

As shown in Figures 4-16 and 4-17 for frequencies near the first mode of vibration for the block model, the SA and the AF are similar at the midnode and the downstream node. The values at the upstream side are slightly higher because of the influence of the additional water mass included in the upstream top node as explained in Appendix D.

\subsection{CEUS and PNW Time-History Results for Block-Frame-Shear Wall Finite Element Models}

\subsubsection{Analysis Results}

To account for the internal frames in the erection/service bay substructure, a block-frame-shear wall finite element model was created and analyzed using the two ground motions of this study. It is observed in computed results that the internal frame makes the model more flexible than the block models, increasing the amplification at top of the substructure. 


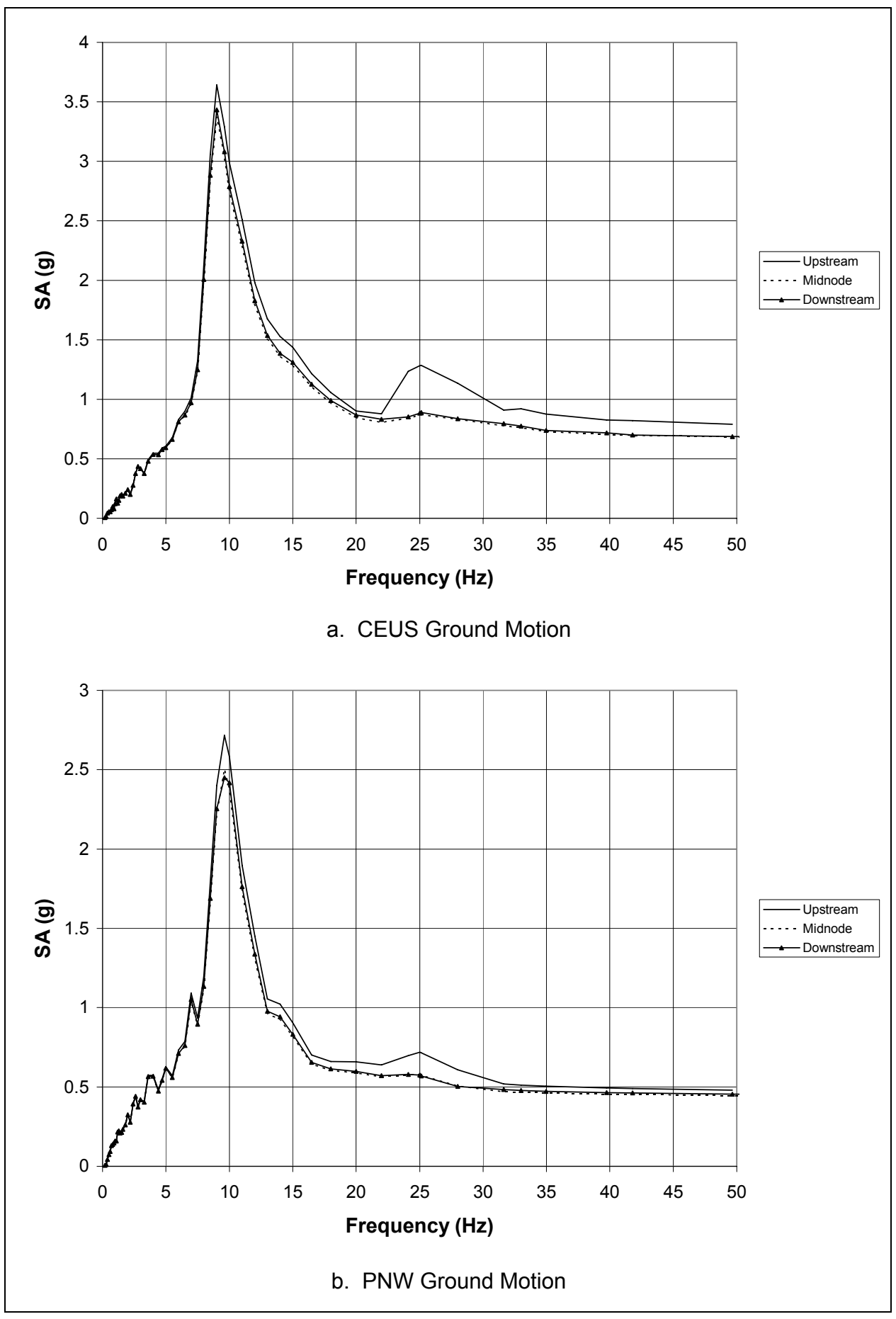

Figure 4-16. Response spectrum curves for nodes at three different locations along the top-of-substructure of the erection bay 110 -ft-height block model, in wet condition, using 5 percent damping 


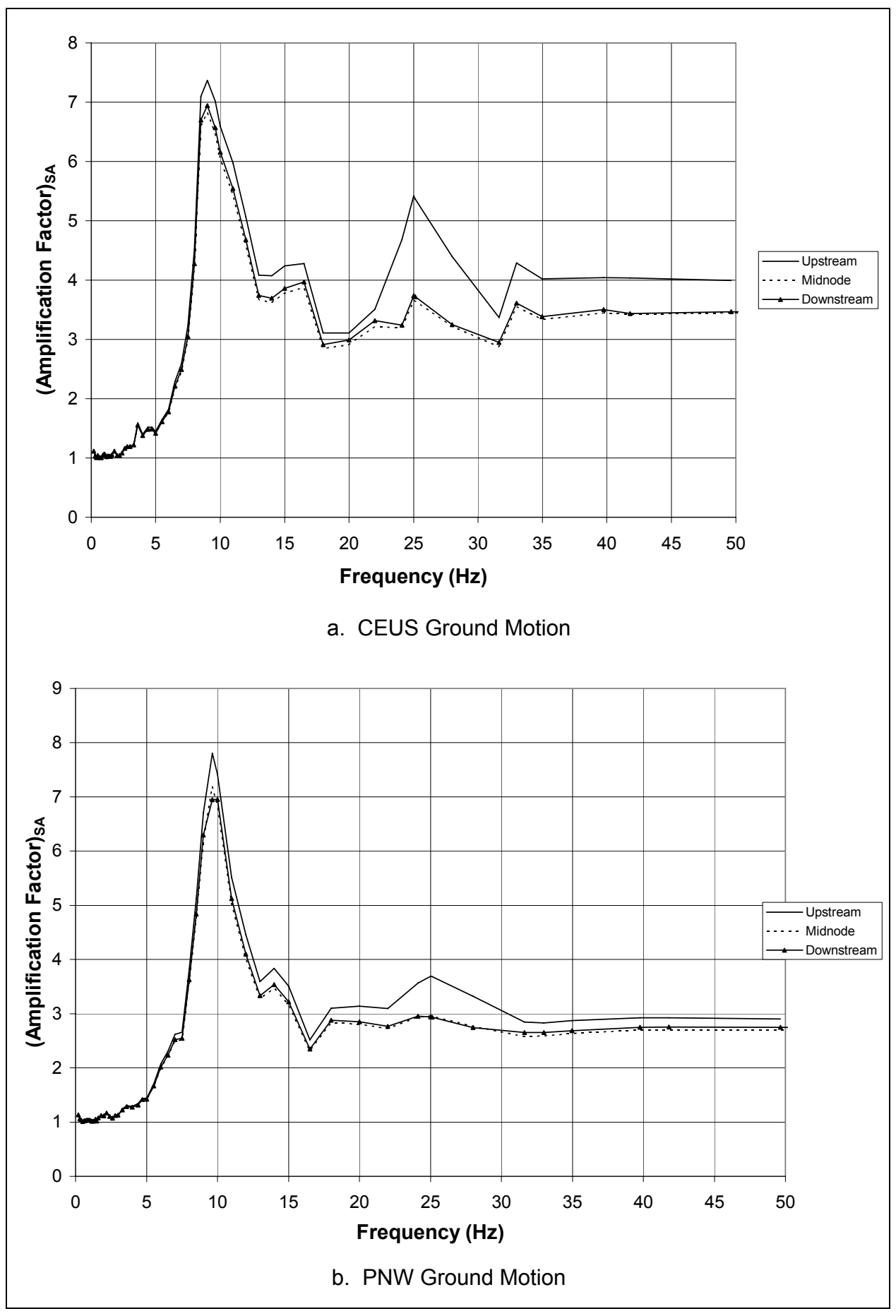

Figure 4-17. AF curves for nodes at three different locations along the top-ofsubstructure of the erection bay, 110-ft-height block model, in wet condition, using 5 percent damping 
Tables 4-15 and 4-16 list the SA at $50 \mathrm{~Hz}$ for the two ground motions and its ratio to the in-rock PGA for the wet and dry conditions, respectively. The results in this section were obtained assuming 5 percent damping for the substructure model. The AF curves were obtained using response spectrum curves for 5 percent damping and used in the decoupled analysis of the superstructure. The results for 2 percent damping are presented in Appendix F for use with the equipment. Tables 4-17 and 4-18 list the maximum AFs and their corresponding frequencies for the dry and wet conditions, respectively.

\begin{tabular}{|c|c|c|c|c|c|}
\hline \multicolumn{6}{|c|}{$\begin{array}{l}\text { Table 4-15 } \\
\text { SA at Frequency of } 50 \mathrm{~Hz} \text { for Erection/Service Bay Block-Frame- } \\
\text { Shear Wall Models, Dry Condition }\end{array}$} \\
\hline \multirow[b]{2}{*}{ Model ID } & \multirow[b]{2}{*}{$\begin{array}{l}\text { Height } \\
\mathrm{ft}\end{array}$} & \multicolumn{2}{|c|}{ CEUS } & \multicolumn{2}{|c|}{ PNW } \\
\hline & & $\begin{array}{l}\text { SA } \text { SOHz } \\
\text { g's }\end{array}$ & $\begin{array}{l}\text { SA / PGA } \\
\text { g's }\end{array}$ & $\begin{array}{l}\text { SA } \text { SOHz } \\
\text { g's }\end{array}$ & $\begin{array}{l}\text { SA/PGA } \\
\text { g's }\end{array}$ \\
\hline 14S9ErD110FW5 & 110 & 0.63 & 3.32 & 0.41 & 2.56 \\
\hline 20S9ErD75FW5 & 75 & 0.42 & 2.21 & 0.31 & 1.94 \\
\hline 12S9ErD45FW5 & 45 & 0.36 & 1.89 & 0.19 & 1.19 \\
\hline 8S9ErD20FW5 & 20 & 0.2 & 1.05 & 0.17 & 1.06 \\
\hline
\end{tabular}

\section{Table 4-16}

SA at Frequency of $50 \mathrm{~Hz}$ for Erection/Service Bay Block-FrameShear Wall Models, Wet Condition

\begin{tabular}{|c|c|c|c|c|c|}
\hline \multirow[b]{2}{*}{ Model ID } & \multirow[b]{2}{*}{$\begin{array}{l}\text { Height } \\
\mathrm{ft}\end{array}$} & \multicolumn{2}{|c|}{ CEUS } & \multicolumn{2}{|c|}{ PNW } \\
\hline & & $\begin{array}{l}\mathrm{SA}_{50 \mathrm{~Hz}} \\
\text { g's }\end{array}$ & $\begin{array}{l}\text { SA / PGA } \\
\text { g's }\end{array}$ & $\begin{array}{l}\mathrm{SA}_{50 \mathrm{~Hz}} \\
\text { g's }\end{array}$ & $\begin{array}{l}\text { SA / PGA } \\
\text { g's }\end{array}$ \\
\hline 14S9ErW110FW5 & 110 & 0.6 & 3.16 & 0.44 & 2.75 \\
\hline 14S9ErW75FW5 & 75 & 0.47 & 2.47 & 0.32 & 2.00 \\
\hline 12S9ErW45FW5 & 45 & 0.3 & 1.58 & 0.21 & 1.31 \\
\hline 8S9ErW20FW5 & 20 & 0.25 & 1.32 & 0.17 & 1.06 \\
\hline
\end{tabular}

\begin{tabular}{|c|c|c|c|c|c|c|c|}
\hline \multicolumn{8}{|c|}{$\begin{array}{l}\text { Table 4-17 } \\
\text { Maximum AF and Its Corresponding SA for Erection/Service Bay } \\
\text { Block-Frame-Shear Wall Models, Dry Condition }\end{array}$} \\
\hline \multirow[b]{2}{*}{ Model ID } & \multirow[b]{2}{*}{$\begin{array}{l}\text { Height } \\
\mathrm{ft}\end{array}$} & \multicolumn{3}{|c|}{ CEUS } & \multicolumn{3}{|c|}{ PNW } \\
\hline & & $\begin{array}{l}f \\
\mathrm{~Hz} \\
\end{array}$ & $\begin{array}{l}\text { SA } \\
\text { g's } \\
\end{array}$ & $\begin{array}{l}\text { (AF) })_{\mathrm{SA}} \\
\text { at } f\end{array}$ & $\begin{array}{l}f \\
\mathrm{~Hz} \\
\end{array}$ & $\begin{array}{l}\text { SA } \\
\text { g's }\end{array}$ & $\begin{array}{l}(\mathrm{AF})_{\mathrm{SA}} \\
\text { at } f\end{array}$ \\
\hline 14S9ErD110FW5 & 110 & 11 & 2.41 & 5.40 & 10.37 & 2.34 & 7.13 \\
\hline 20S9ErD75FW5 & 75 & 15 & 2.16 & 6.36 & 16 & 1.51 & 5.46 \\
\hline 12S9ErD45FW5 & 45 & 25 & 1.11 & 4.69 & 27.6 & 3.67 & 2.02 \\
\hline 8S9ErD20FW5 & 20 & -- & -- & -- & -- & -- & -- \\
\hline
\end{tabular}




\begin{tabular}{|c|c|c|c|c|c|c|c|}
\hline \multicolumn{8}{|c|}{$\begin{array}{l}\text { Table 4-18 } \\
\text { Maximum AF and Its Corresponding SA for Erection/Service Bay } \\
\text { Block-Frame-Shear Wall Models, Wet Condition }\end{array}$} \\
\hline \multirow[b]{2}{*}{ Model ID } & \multirow[b]{2}{*}{$\begin{array}{l}\text { Height } \\
\mathrm{ft}\end{array}$} & \multicolumn{3}{|c|}{ CEUS } & \multicolumn{3}{|c|}{$\begin{array}{c}\text { PNW } \\
\end{array}$} \\
\hline & & $\begin{array}{l}f \\
\mathrm{~Hz} \\
\end{array}$ & $\begin{array}{l}\text { SA } \\
\text { g's }\end{array}$ & $\begin{array}{l}(\mathrm{AF})_{\mathrm{SA}} \\
\text { at } f\end{array}$ & $\begin{array}{l}f \\
\mathrm{~Hz} \\
\end{array}$ & $\begin{array}{l}\text { SA } \\
\text { g's }\end{array}$ & $\begin{array}{l}(\mathrm{AF})_{\mathrm{SA}} \\
\text { at } f\end{array}$ \\
\hline 14S9ErW110FW5 & 110 & 8.5 & 3.51 & 8.18 & 8.38 & 1.97 & 5.78 \\
\hline 20S9ErW75FW5 & 75 & 13 & 2.72 & 6.64 & 13 & 1.9 & 6.48 \\
\hline 12S9ErW45FW5 & 45 & 20 & 1.30 & 4.50 & 20.89 & 6.07 & 2.77 \\
\hline 8S9ErW20FW5 & 20 & 33 & 0.36 & 1.68 & 33 & 0.19 & 1.03 \\
\hline
\end{tabular}

The PNW maximum AFs are less than those for the CEUS ground motion for the wet cases. The AF curves for each in dry and wet condition models are presented in Figures 4-18 through 4-25. The figures were obtained for both ground motions and assuming 5 percent damping for the substructure. The AF curves were computed by using response spectrum curves with 5 percent damping. The results for 2 percent damping are presented in Appendix F for use with the equipment. Table 4-19 lists the figure numbers for the AF curves obtained for the block-frame-shear wall models of the erection/service bay.

\begin{tabular}{|c|c|c|c|}
\hline \multirow[b]{2}{*}{ Group } & \multirow{2}{*}{$\begin{array}{l}\text { Height } \\
\mathrm{ft}\end{array}$} & \multicolumn{2}{|c|}{$\begin{array}{ll}\text { Ground Motion } \\
\end{array}$} \\
\hline & & CEUS & PNW \\
\hline 1 & 110 & Figure 4-18 & Figure 4-22 \\
\hline 2 & 75 & Figure 4-19 & Figure 4-23 \\
\hline 3 & 45 & Figure $4-20$ & Figure 4-24 \\
\hline 4 & 20 & Figure 4-21 & Figure 4-25 \\
\hline
\end{tabular}

\subsubsection{Response amplification sensitivity to shear wall thickness for the erection/service bay block-frame-shear wall finite element models}

The erection/service bay block-frame-shear wall finite element model discussed in the previous section includes a shear wall that provides lateral resistance to the ground motion. The horizontal ground motion was applied in the upstream/downstream direction in this study. The shear wall thickness was selected by inspection of the construction drawings for different Corps powerhouses. An average 8-ft wall thickness was judged to represent the thickness of the shear wall(s). A parametric study was performed in order to investigate the influence of the shear wall thickness on the response amplification of the erection/service bay block-frame-shear wall model. The 110-ft-high substructure model in wet condition was used in this study. The thicknesses of the shear walls used were 6,8 , and $10 \mathrm{ft}$. For each finite element model, the response spectrum and $\mathrm{AF}$ at top of the substructure were computed. 


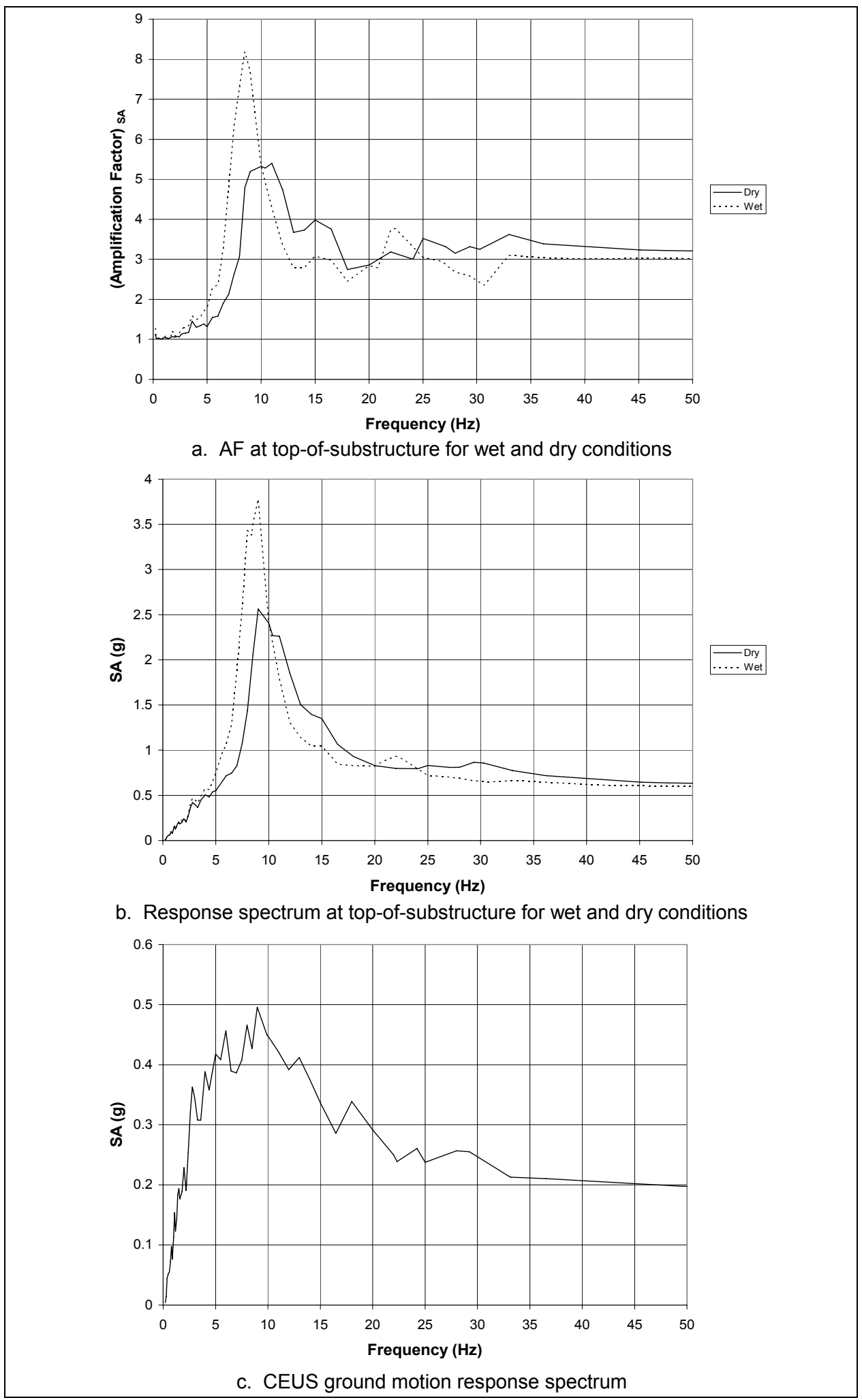

Figure 4-18. Response spectra and AF curves, erection/service bay, block-frameshear wall model, 110-ft height (Dry Model ID: 14S9ErD110FW5, Wet Model ID: 14S9ErW110FW5), for CEUS ground motion with 5 percent damping 


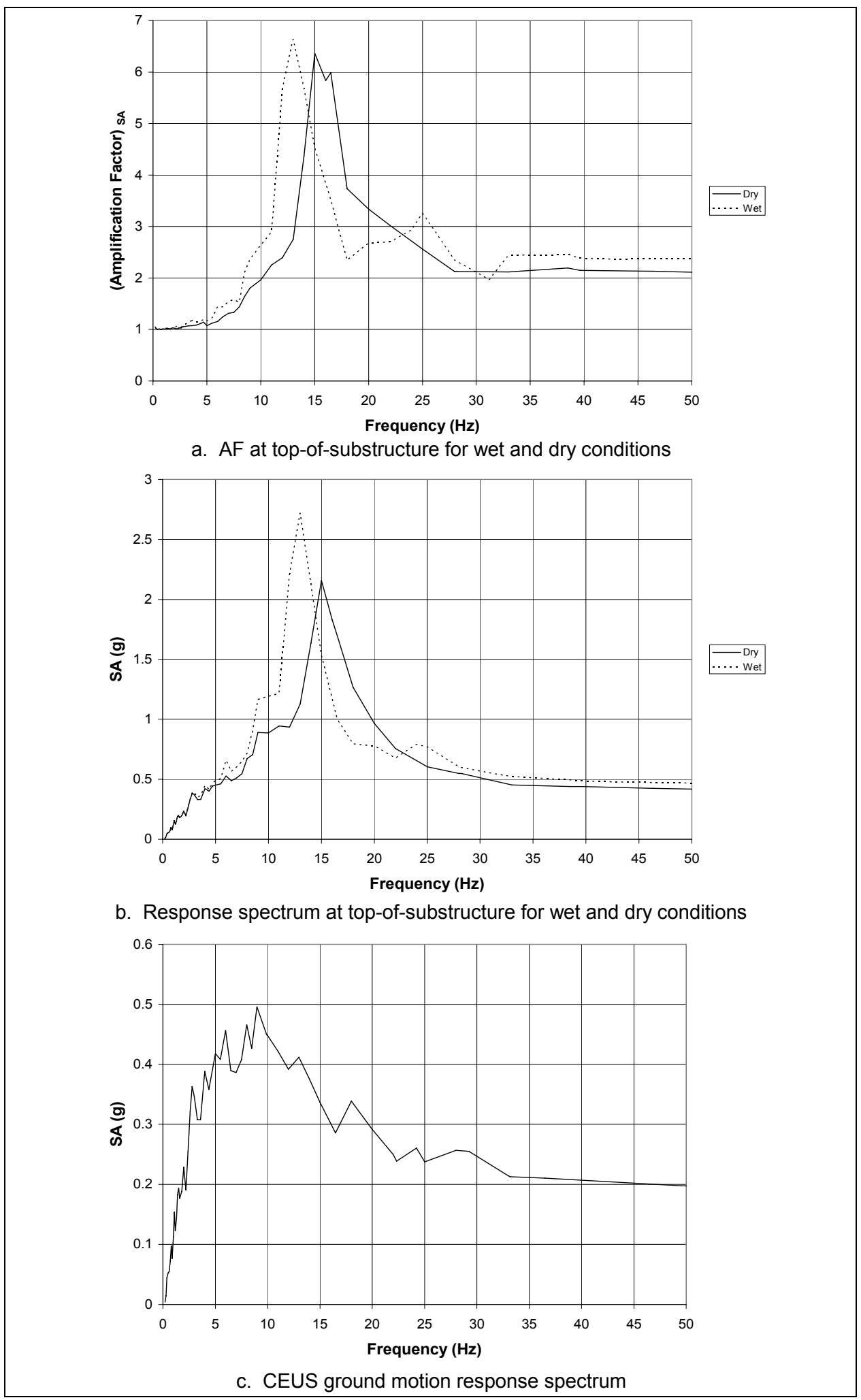

Figure 4-19. Response spectra and AF curves, erection/service bay, block-frameshear wall model, 75-ft height (Dry Model ID: 20S9ErD75FW5, Wet Model ID: 20S9ErW75FW5), for CEUS ground motion with 5 percent damping 


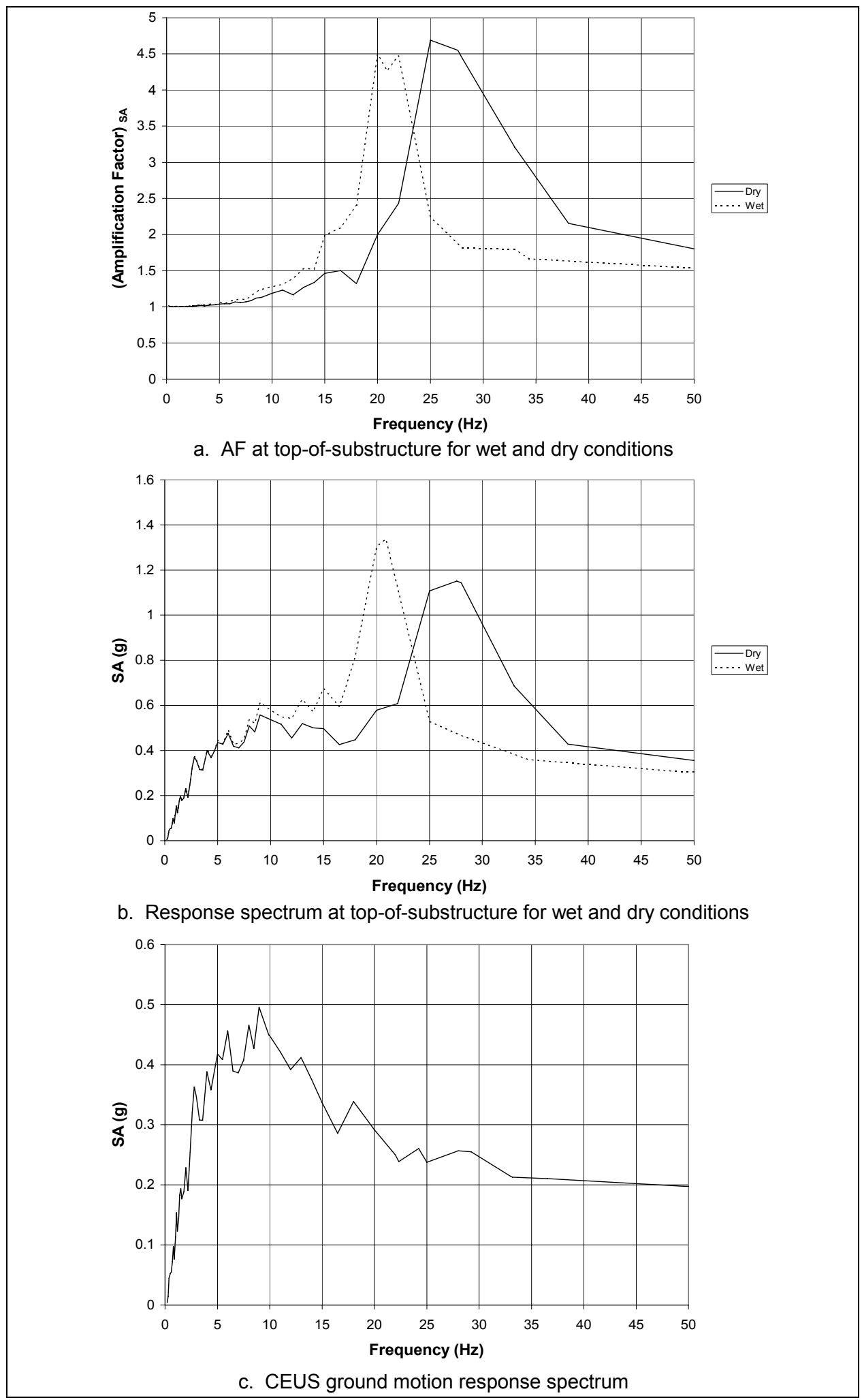

Figure 4-20. Response spectra and AF curves, erection/service bay, block-frameshear wall model, 45-ft height (Dry Model ID: 12S9ErD45FW5, Wet Model ID: 12S9ErW45FW5), for CEUS ground motion with 5 percent damping 


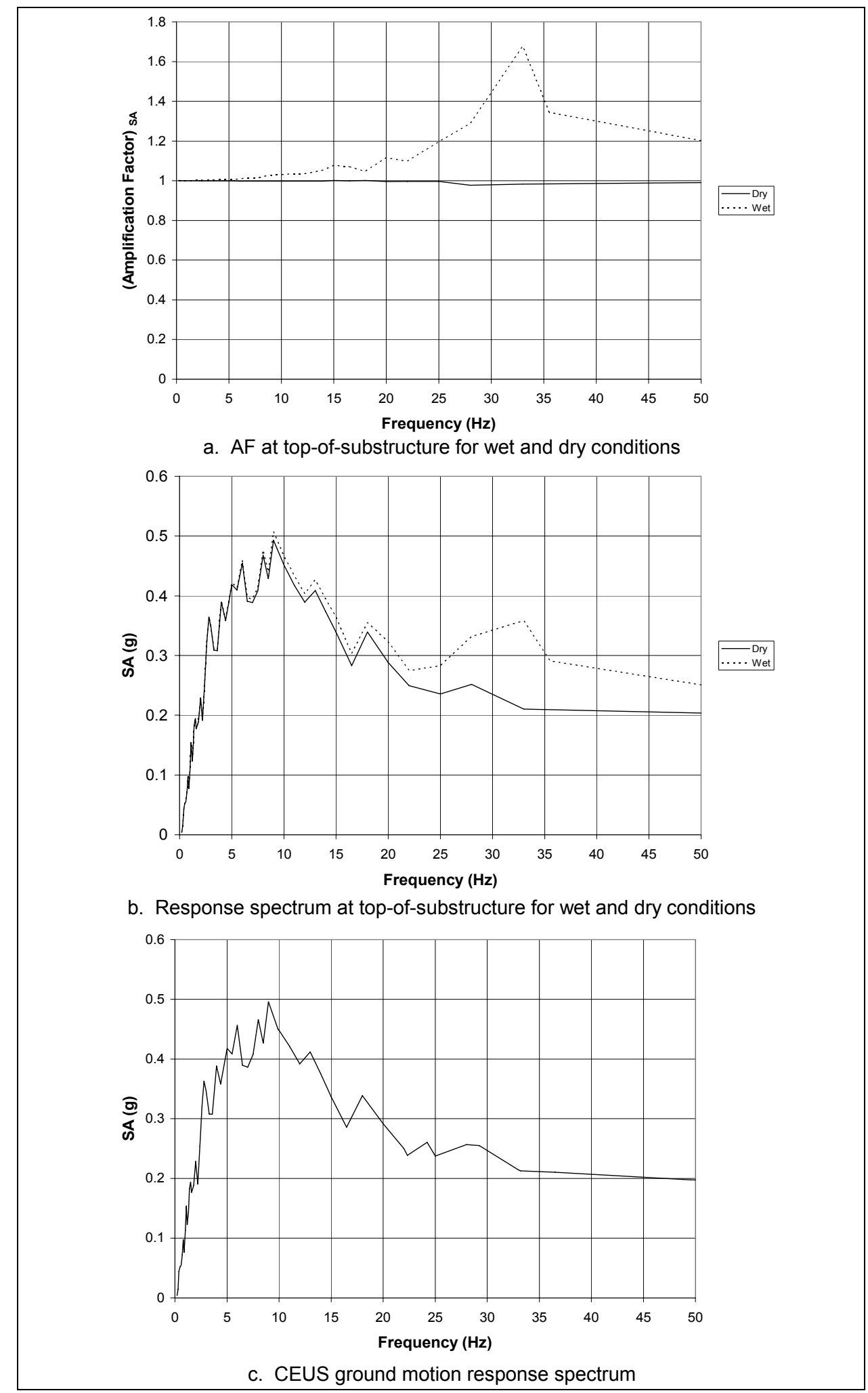

Figure 4-21. Response spectra and AF curves, erection/service bay, block-frameshear wall model, 20-ft height (Dry Model ID: 8S9ErD20FW5, Wet Model ID: 8S9ErW20FW5), for CEUS ground motion with 5 percent damping 


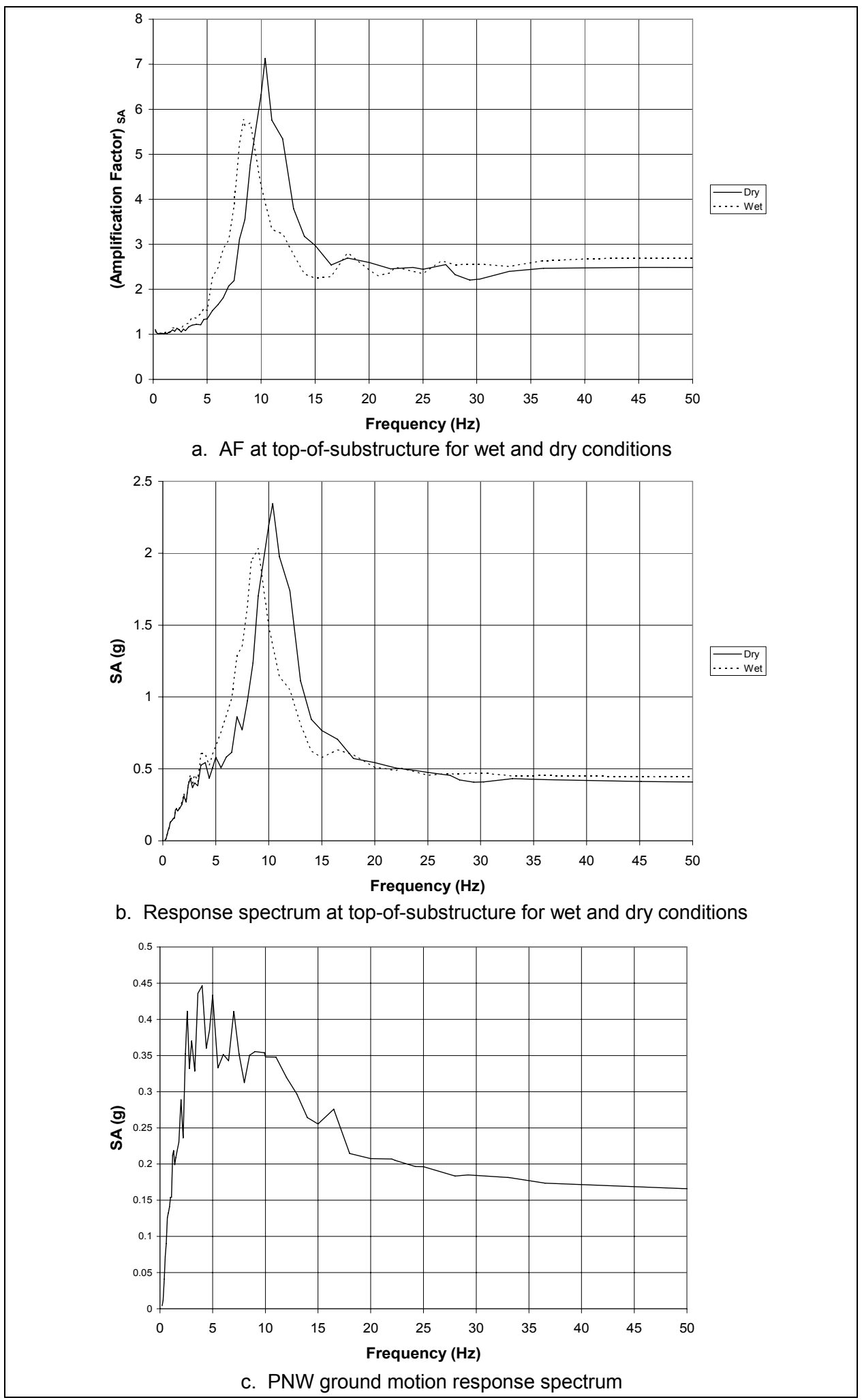

Figure 4-22. Response spectra and AF curves, erection/service bay, block-frameshear wall model, 110-ft height (Dry Model ID: 14S9ErD110FW5, Wet Model ID: 14S9ErW110FW5), for PNW ground motion with 5 percent damping 


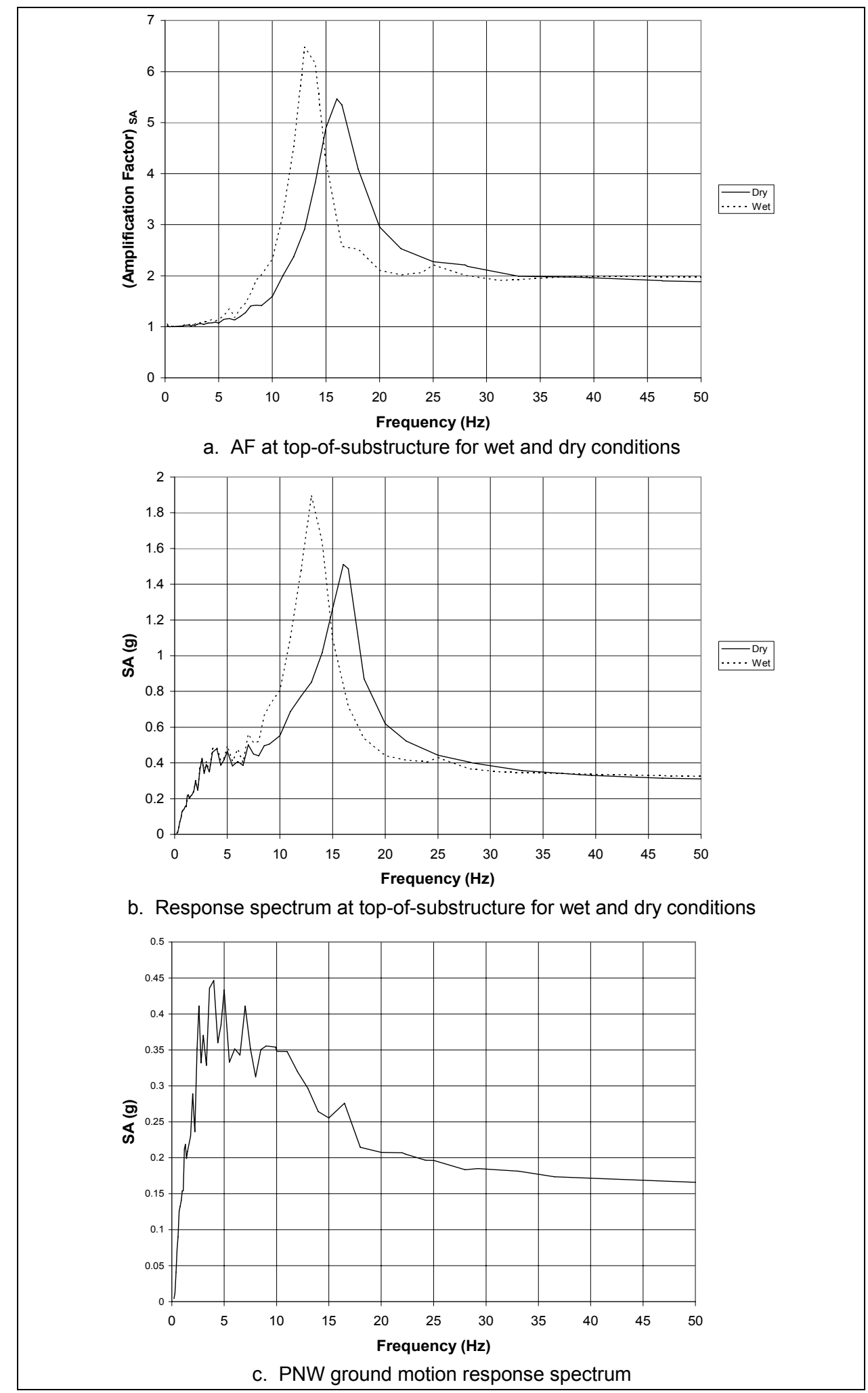

Figure 4-23. Response spectra and AF curves, erection/service bay, block-frameshear wall model, 75-ft height (Dry Model ID: 20S9ErD75FW5, Wet Model ID: 20S9ErW75FW5), for PNW ground motion with 5 percent damping 


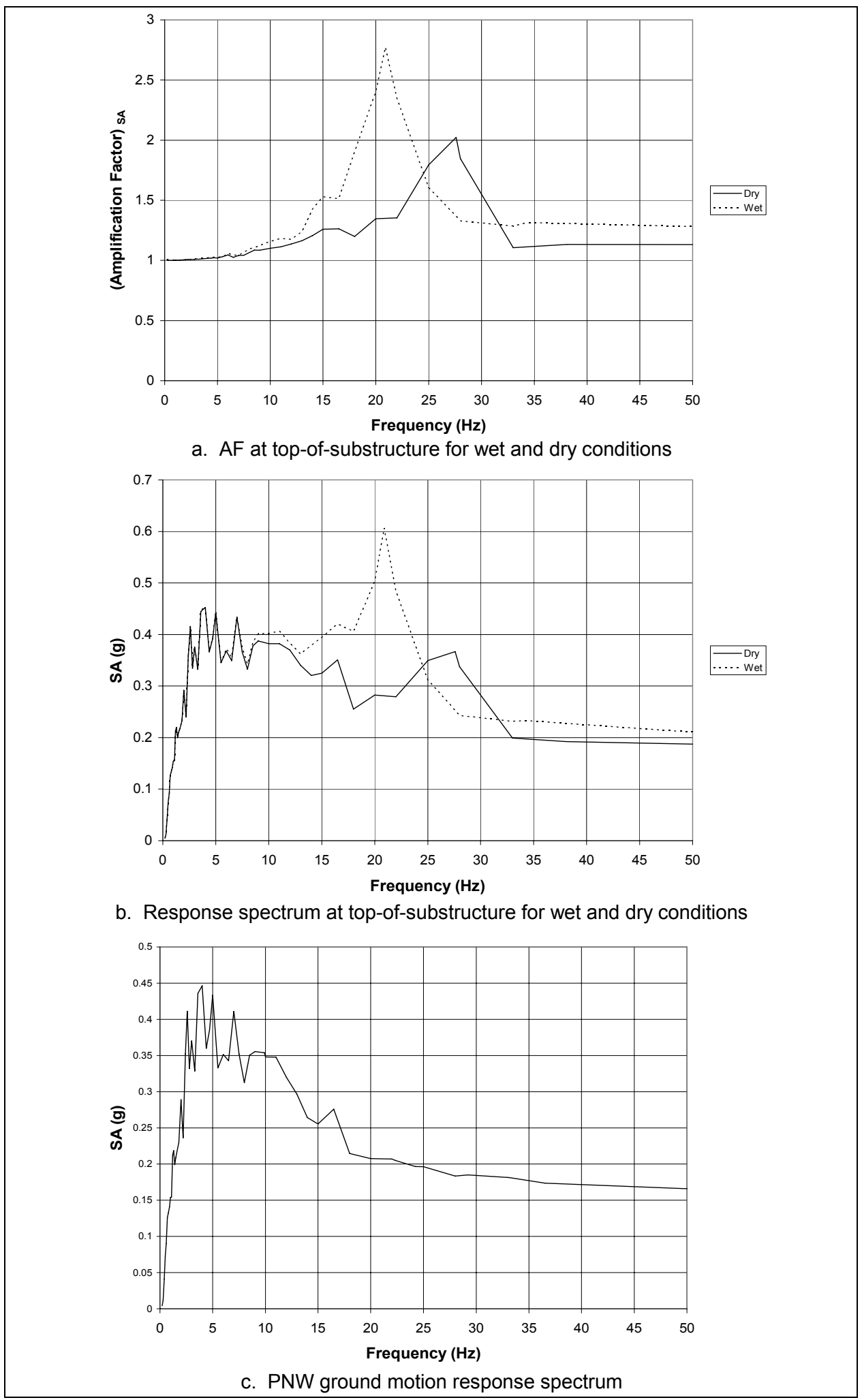

Figure 4-24. Response spectra and AF curves, erection/service bay, block-frameshear wall model, 45-ft height (Dry Model ID: 12S9ErD45FW5, Wet Model ID: 12S9ErW45FW5), for PNW ground motion with 5 percent damping 


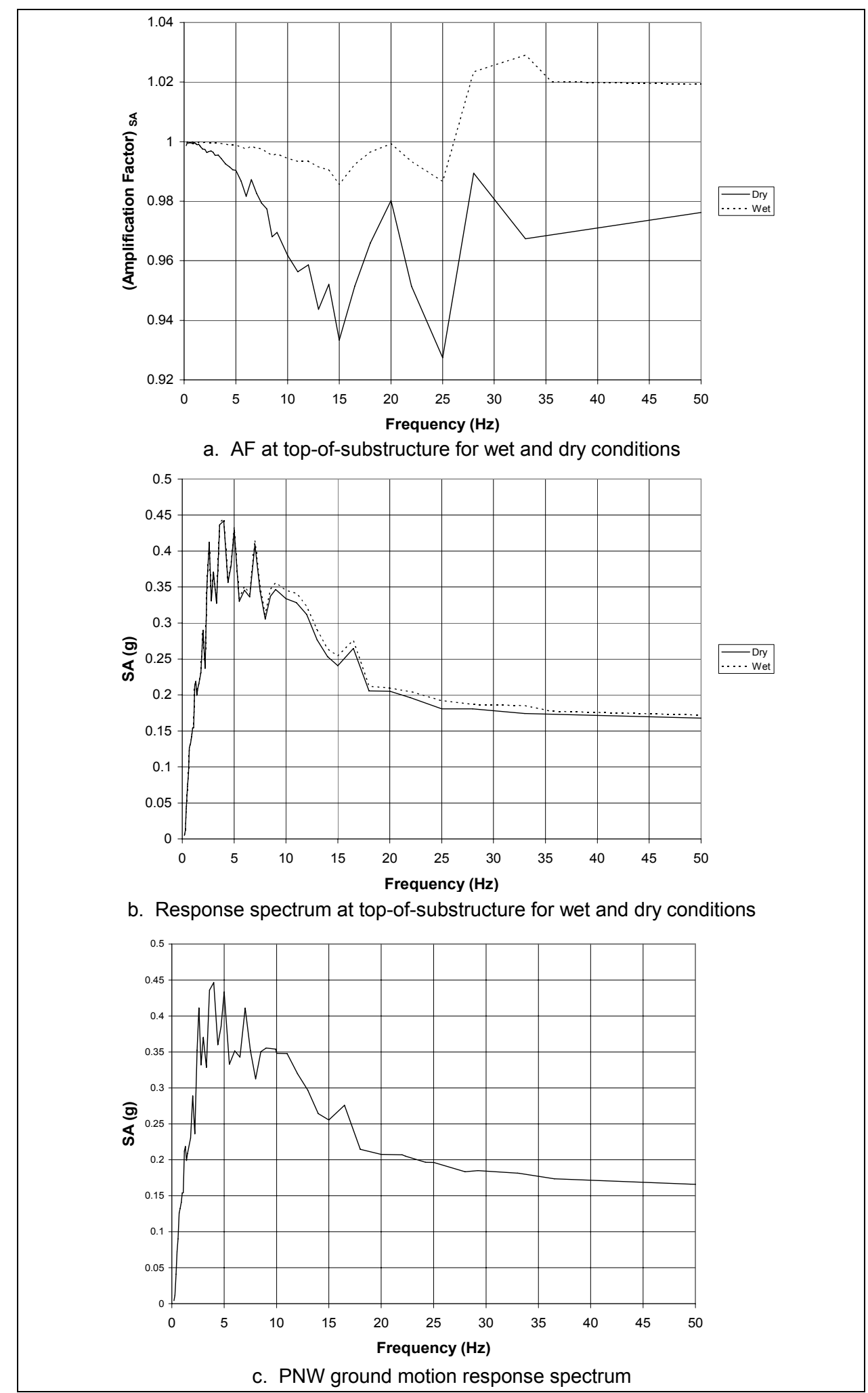

Figure 4-25. Response spectra and AF curves, erection/service bay, block-frameshear wall model, 20-ft height, (Dry Model ID: 8S9ErD20FW5, Wet Model ID: 8S9ErW20FW5), for PNW ground motion with 5 percent damping 
Table 4-20 lists the first mode period and frequency for the three 110-ftheight erection/service bay block-frame-shear wall models. The fundamental mode frequency increases by $0.74 \mathrm{~Hz}$ for the finite element models with an increase in shear wall thickness from 6 to $10 \mathrm{ft}$. Table 4-21 lists the values of the $\mathrm{SA}$ at $50 \mathrm{~Hz}\left(\mathrm{SA}_{50 \mathrm{~Hz}}\right)$ and its ratio with the PGA, which corresponds to the $\mathrm{AF}$ at a frequency of $50 \mathrm{~Hz}$ at top of the substructure. Table 4-22 lists the maximum AF and its corresponding frequency. For frequencies near the first natural mode of vibration of the finite element models, the 10 -ft-thick shear wall results in higher amplification than do the other two shear wall thicknesses.

\begin{tabular}{|c|c|c|c|c|c|c|c|}
\hline \multicolumn{8}{|c|}{$\begin{array}{l}\text { Table 4-20 } \\
\text { First Mode of Vibration and PMR for the 110-ft-Height Erection/ } \\
\text { Service Bay Block-Frame-Shear Wall Models }\end{array}$} \\
\hline \multirow[b]{2}{*}{ Model ID } & \multirow[b]{2}{*}{$\begin{array}{l}\text { Height } \\
\text { ft }\end{array}$} & \multicolumn{2}{|c|}{ First Mode } & \multicolumn{4}{|c|}{\begin{tabular}{|c|} 
Final Mode \\
\end{tabular}} \\
\hline & & $\begin{array}{l}T_{1} \\
\text { sec }\end{array}$ & $\begin{array}{l}f_{1} \\
\mathrm{~Hz} \\
\end{array}$ & \begin{tabular}{|l|} 
Total No. \\
\end{tabular} & \begin{tabular}{|l|} 
PMR \\
$\%$
\end{tabular} & \begin{tabular}{|l|}
$T_{i}$ \\
sec
\end{tabular} & $\begin{array}{l}f_{i} \\
\mathrm{~Hz} \\
\end{array}$ \\
\hline 14S9ErD110FW5-6 ft & 110 & 0.1252 & 7.98 & 18 & 93.14 & 0.014 & 70.76 \\
\hline 14S9ErD110FW5-8 ft & 110 & 0.1189 & 8.41 & 18 & 93.3 & 0.014 & 71.11 \\
\hline 14S9ErD110FW5-10 ft & 110 & 0.1147 & 8.72 & 18 & 93.4 & 0.014 & 71.11 \\
\hline
\end{tabular}

\begin{tabular}{|c|c|c|c|c|c|}
\hline \multicolumn{6}{|c|}{$\begin{array}{l}\text { Table 4-21 } \\
\text { SA at } 50 \mathrm{~Hz} \text { of the Three Finite Element Models Using the CEUS } \\
\text { and PNW Ground Motions }\end{array}$} \\
\hline \multirow[b]{2}{*}{ Model ID } & \multirow[b]{2}{*}{$\begin{array}{l}\text { Height } \\
\mathrm{ft}\end{array}$} & \multicolumn{2}{|c|}{ CEUS } & \multicolumn{2}{|c|}{ PNW } \\
\hline & & $\begin{array}{l}\mathbf{S A}_{5 \mathrm{OHz}} \\
\mathrm{g}^{\prime} \mathbf{s}\end{array}$ & $\begin{array}{l}\mathbf{S A}_{50 \mathrm{~Hz}} / \mathrm{PGA} \\
\mathrm{g}^{\prime} \mathrm{s}\end{array}$ & $\begin{array}{l}\mathbf{S A}_{5 \mathrm{OHz}} \\
\text { g's }\end{array}$ & $\begin{array}{l}\mathrm{SA}_{50 \mathrm{OZ}} / \mathrm{PGA} \\
\mathrm{g}^{\prime} \mathrm{S}\end{array}$ \\
\hline 14S9ErD110FW5-6 ft & 110 & 0.64 & 3.37 & 0.41 & 2.56 \\
\hline 14S9ErD110FW5-8 ft & 110 & 0.6 & 3.16 & 0.45 & 2.81 \\
\hline 14S9ErD110FW5-10 ft & 110 & 0.67 & 3.53 & 0.46 & 2.88 \\
\hline
\end{tabular}

\section{Table 4-22 \\ Maximum AF and Its Corresponding Frequency for the Three 110-ft-Height Erection/Service Bay Models}

\begin{tabular}{|c|c|c|c|c|c|c|c|}
\hline \multirow[b]{3}{*}{ Model ID } & \multirow[b]{3}{*}{$\begin{array}{l}\text { Height } \\
\mathrm{ft}\end{array}$} & \multicolumn{6}{|c|}{ Maximum AF } \\
\hline & & \multicolumn{3}{|c|}{ CEUS } & \multicolumn{3}{|c|}{ PNW } \\
\hline & & $f, \mathrm{~Hz}$ & SA, g's & $\begin{array}{l}(\mathrm{AF})_{\mathrm{SA}} \\
\text { at } f\end{array}$ & $f, \mathrm{~Hz}$ & SA, g's & $\begin{array}{l}(\mathrm{AF})_{\mathrm{SA}} \\
\text { at } f\end{array}$ \\
\hline 14S9ErD110FW5-6 ft & 110 & 8 & 4.09 & 8.72 & 8 & 1.76 & 5.62 \\
\hline 14S9ErD110FW5-8 ft & 110 & 8.5 & 3.59 & 8.35 & 8.5 & 2.03 & 5.82 \\
\hline 14S9ErD110FW5-10 ft & 110 & 9 & 4.69 & 9.50 & 9 & 2.44 & 6.83 \\
\hline
\end{tabular}

Because the ground motion response spectra used for the analysis are not smooth-shaped, broad-band spectra, a small change in frequency may result in an abrupt change in results. Figure 4-26 shows the SA for the CEUS and PNW ground motion for the three finite element models, and Figure 4-27 shows the corresponding AF curves. 


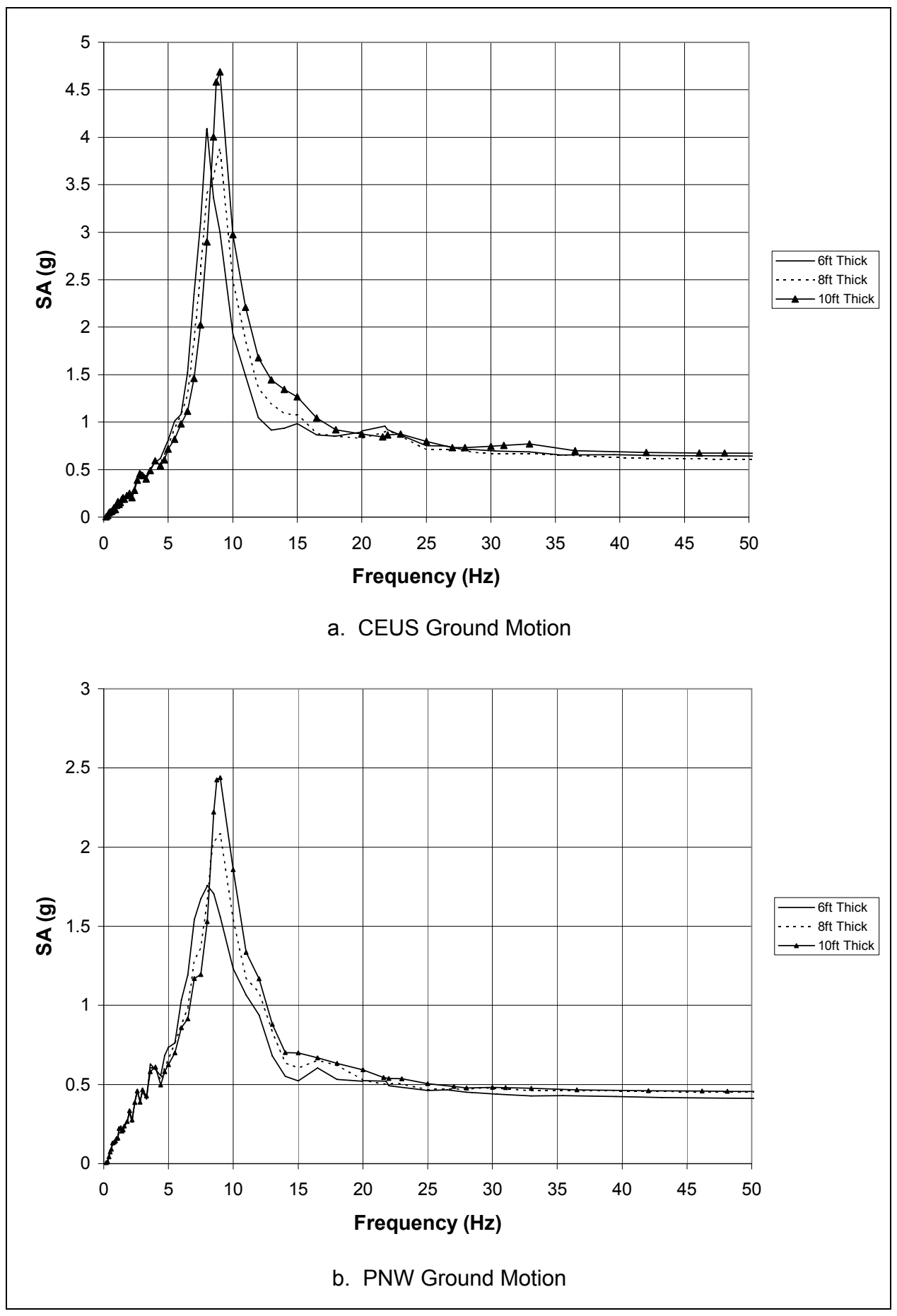

Figure 4-26. Response spectrum curves at top-of-substructure for three different shear wall thicknesses of the erection bay, 110-ft height, blockframe-shear wall model, using 5 percent damping 


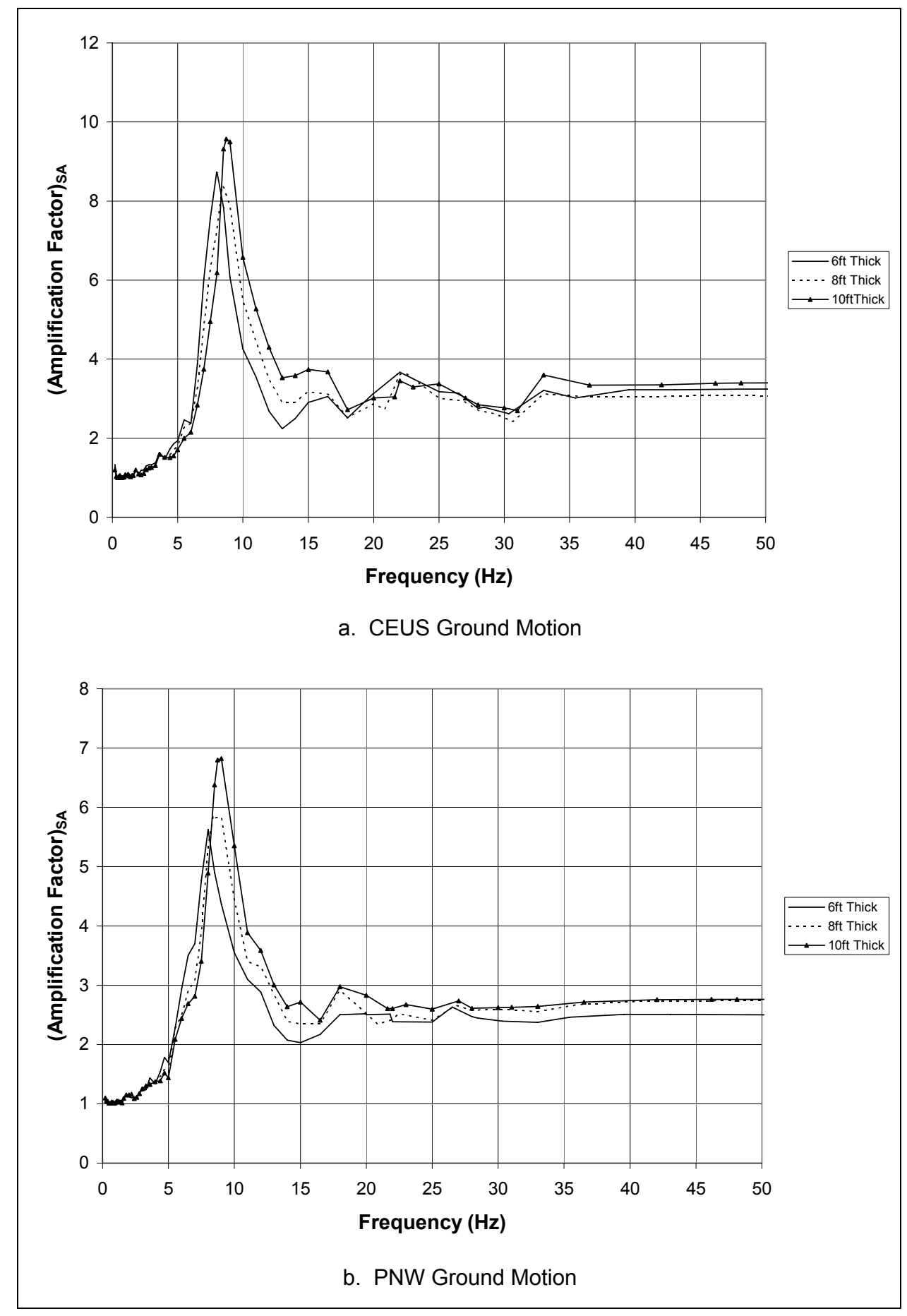

Figure 4-27. AF curves at top-of-substructure for three different shear wall thicknesses of the erection bay, 110-ft height, block-frame-shear wall model, using 5 percent damping 


\subsubsection{Response amplification sensitivity to location at top of the substructure for the erection/service bay block-frame-shear wall model}

Computed results reported in previous sections for the erection/service bay block-frame-shear wall models were based on the calculation of the spectral acceleration at the midnode along the top of the substructure. In order to investigate the variation in computed results along the top of the substructure, the spectral acceleration and AFs were obtained at two other locations along the top-ofsubstructure. For this parametric study, the 110-ft-height block-frame-shear wall model in the wet condition was used.

Table 4-23 lists the values of the SA at $50 \mathrm{~Hz}$ and its ratio with the PGA, which corresponds to the AF at a frequency of $50 \mathrm{~Hz}$. Table 4-24 lists the maximum AF and its corresponding frequency at the three nodes identified in Figure 4-28. Figure 4-29 shows the spectral acceleration for the three locations along the top of the substructure using the CEUS and the PNW ground motions. Figure 4-30 presents the AF curves for the three different nodes along the top-ofsubstructure.

The results show that the response of the substructure is higher for the upstream node location. For the midnode and the downstream location there is no significant difference in response. The higher response at the upstream node location is due to the added water mass applied to the upstream face of the substructure, as explained in Appendix D.

\begin{tabular}{|c|c|c|c|c|c|}
\hline \multicolumn{6}{|c|}{$\begin{array}{l}\text { Table } 4-23 \\
\text { SA at } 50 \mathrm{~Hz} \text { at Three Different Locations along the Top of the } 110-\mathrm{ft}-\text { Height Block- } \\
\text { Frame-Shear Wall Substructure for the Wet Condition }\end{array}$} \\
\hline \multirow[b]{2}{*}{ Model ID } & \multirow[b]{2}{*}{$\begin{array}{l}\text { Height } \\
\mathrm{ft}\end{array}$} & \multicolumn{2}{|c|}{ CEUS } & \multicolumn{2}{|c|}{ PNW } \\
\hline & & $\begin{array}{l}\mathbf{S A}_{50 \mathrm{~Hz}} \\
\mathbf{g}^{\prime} \mathbf{s}\end{array}$ & $\begin{array}{l}\mathrm{SA}_{50 \mathrm{~Hz}} / \mathrm{PGA} \\
\mathrm{g} \text { 's }\end{array}$ & $\begin{array}{l}\text { SA } \\
\text { g's }\end{array}$ & $\begin{array}{l}\mathrm{SA}_{50 \mathrm{~Hz}} / \mathrm{PGA} \\
\text { g's }\end{array}$ \\
\hline 14S9ErD110FW5-Upstream node & 1110 & 0.76 & 4 & 0.51 & 3.18 \\
\hline 14S9ErD110FW5-Midnode & 110 & 0.6 & 3.16 & 0.45 & 2.81 \\
\hline 14S9ErD110FW5-Downstream node & 110 & 0.69 & 3.63 & 0.46 & 2.88 \\
\hline
\end{tabular}

\begin{tabular}{|c|c|c|c|c|c|c|c|}
\hline \multirow[b]{3}{*}{ Model ID } & \multirow[b]{3}{*}{$\begin{array}{l}\text { Height } \\
\mathrm{ft}\end{array}$} & \multicolumn{5}{|c|}{ Maximum AF } & \\
\hline & & \multicolumn{3}{|c|}{ CEUS } & \multicolumn{3}{|c|}{ PNW } \\
\hline & & $\mathrm{f}, \mathrm{Hz}$ & SA, g's & $\begin{array}{l}\text { (AF) })_{S A} \\
\text { at } f\end{array}$ & $f, \mathrm{~Hz}$ & SA, g's & $\begin{array}{l}\text { (AF) })_{\mathrm{SA}} \\
\text { at } f\end{array}$ \\
\hline 14S9ErD110FW5-Upstream node & 110 & 8.5 & 4.50 & 9.96 & 9 & 2.55 & 7.03 \\
\hline 14S9ErD110FW5-Midnode & 110 & 8.5 & 3.59 & 8.35 & 8.5 & 2.03 & 5.82 \\
\hline 14S9ErD110FW5-Downstream node & 110 & 8.5 & 3.61 & 8.39 & 8.5 & 2.04 & 5.85 \\
\hline
\end{tabular}




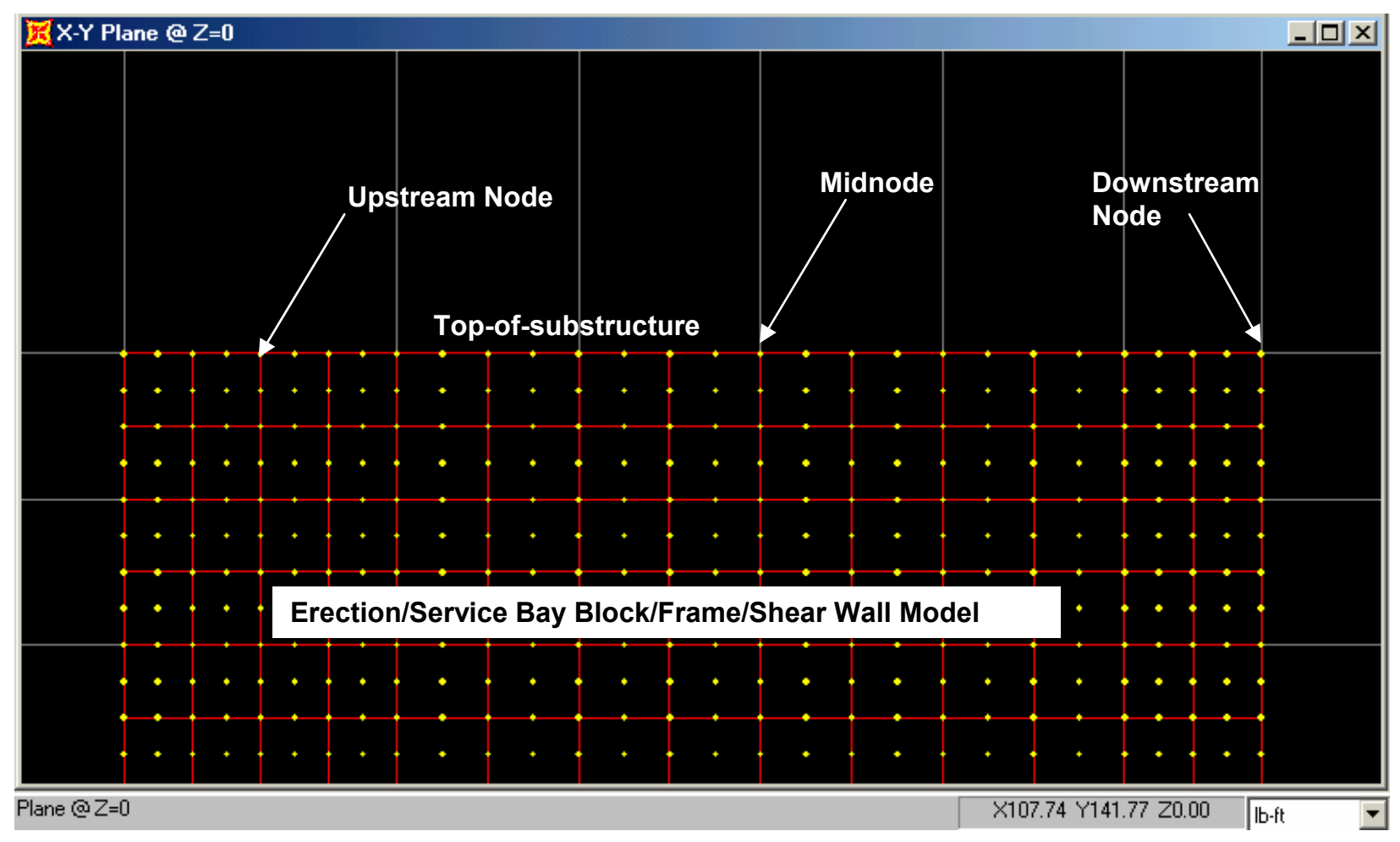

Figure 4-28. Location of nodes in the 110-ft-height erection bay block-frame-shear wall model used in the AF calculations 


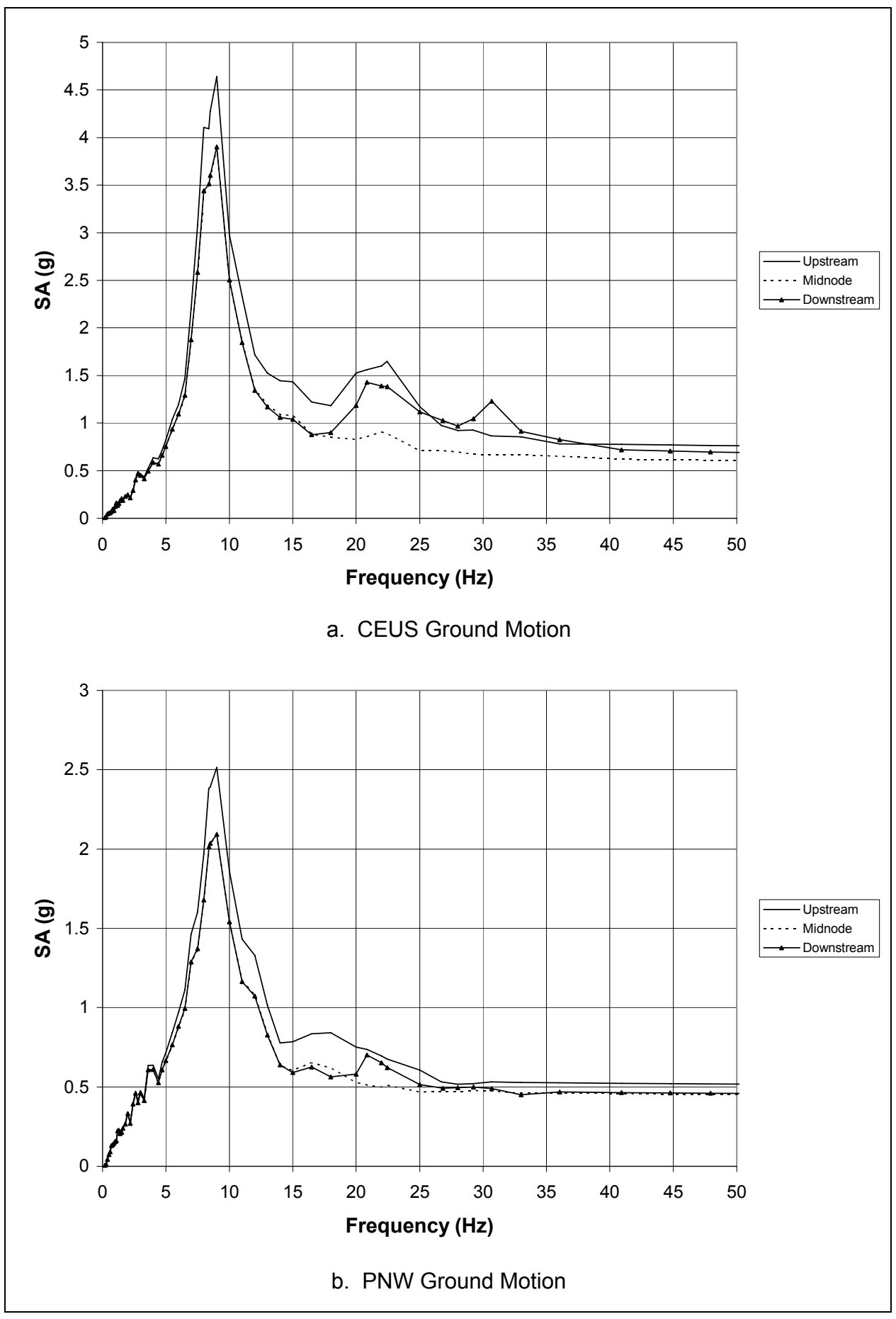

Figure 4-29. Response spectrum curves at three different locations along the topof-substructure of the erection bay, 110-ft-height block-frame-shear wall model, in wet condition, using 5 percent damping 


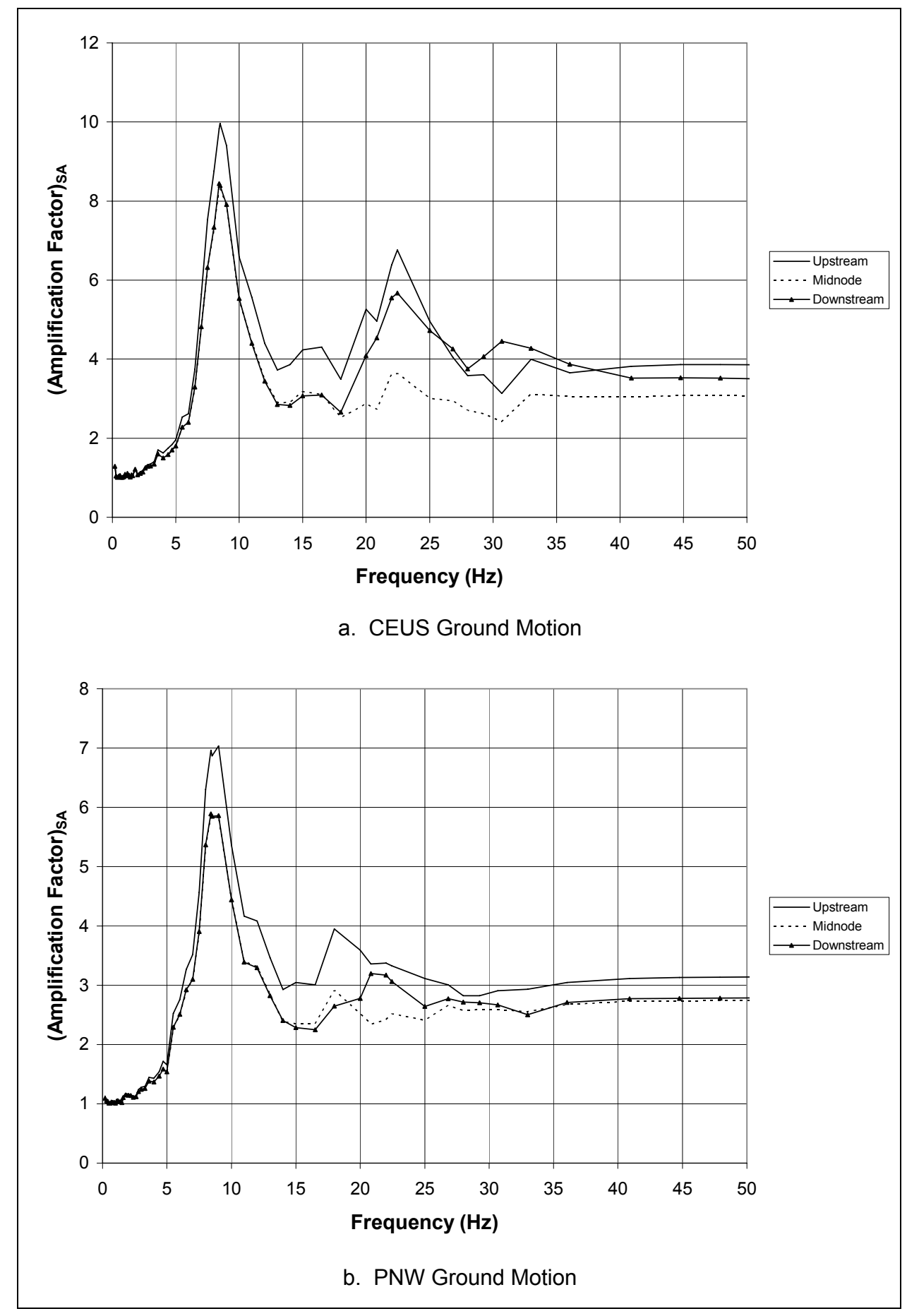

Figure 4-30. AF curves at three different locations along the top-of-substructure of the erection bay, 110-ft-height block-frame-shear wall model, in wet condition, using 5 percent damping 


\section{Amplification Factors for Response Spectra/Modal Analysis}

\subsection{Introduction}

The results from time-history, modal analyses of powerhouse substructures and corresponding AFs are presented in Chapter 3 for the generator bay substructure and in Chapter 4 for the erection/service bay substructure. In this chapter, the AF curves for the CEUS and for the PNW ground motions are plotted in the same graph but distinguished by dry and wet conditions.

Figure 5-1 shows the response spectra at rock for the two ground motions considered in this study. The two SAs were normalized by their respective peak ground accelerations at rock. The PNW ground motion possesses the largest SA value of $2.8 \mathrm{~g}$ at a frequency of $4 \mathrm{~Hz}$ compared with a maximum SA value of $2.6 \mathrm{~g}$ at $9 \mathrm{~Hz}$ for the CEUS ground motions.

In Section 5.2, the computed AF curves for the generator bay substructure are discussed. The AF curves for the erection/service bay block models are presented in Section 5.3 and for the block-frame-shear wall models in Section 5.4. An example comparison between (a) a complete model time-history analysis, (b) a complete model response spectra analysis, and (c) a decoupled response spectra analysis is presented in Section 5.5 for an erection/service bay monolith. Finally, in Section 5.6, a demonstration example of the construction of a top-ofsubstructure PSA versus frequency curve is given for an idealized erection/ service bay of the Cordell Hull Powerhouse superstructure using a National Earthquake Hazards Reduction Program (NEHRP) (FEMA 2001) design response spectra to represent the in-rock seismic event.

The differences between SA and PSA are explained in Appendix E. In that appendix it is proved that for a low percent damping and short-period structure, as for the case of powerhouse substructures, the differences between SA and PSA are insignificant. The exact solution of a decoupled analysis of an isolated superstructure is to subject it with a total acceleration time-history. Because in most of the cases, only the maximum response is of concern and not the response of the structure in time, the ground motion is approximated by a spectral acceleration 


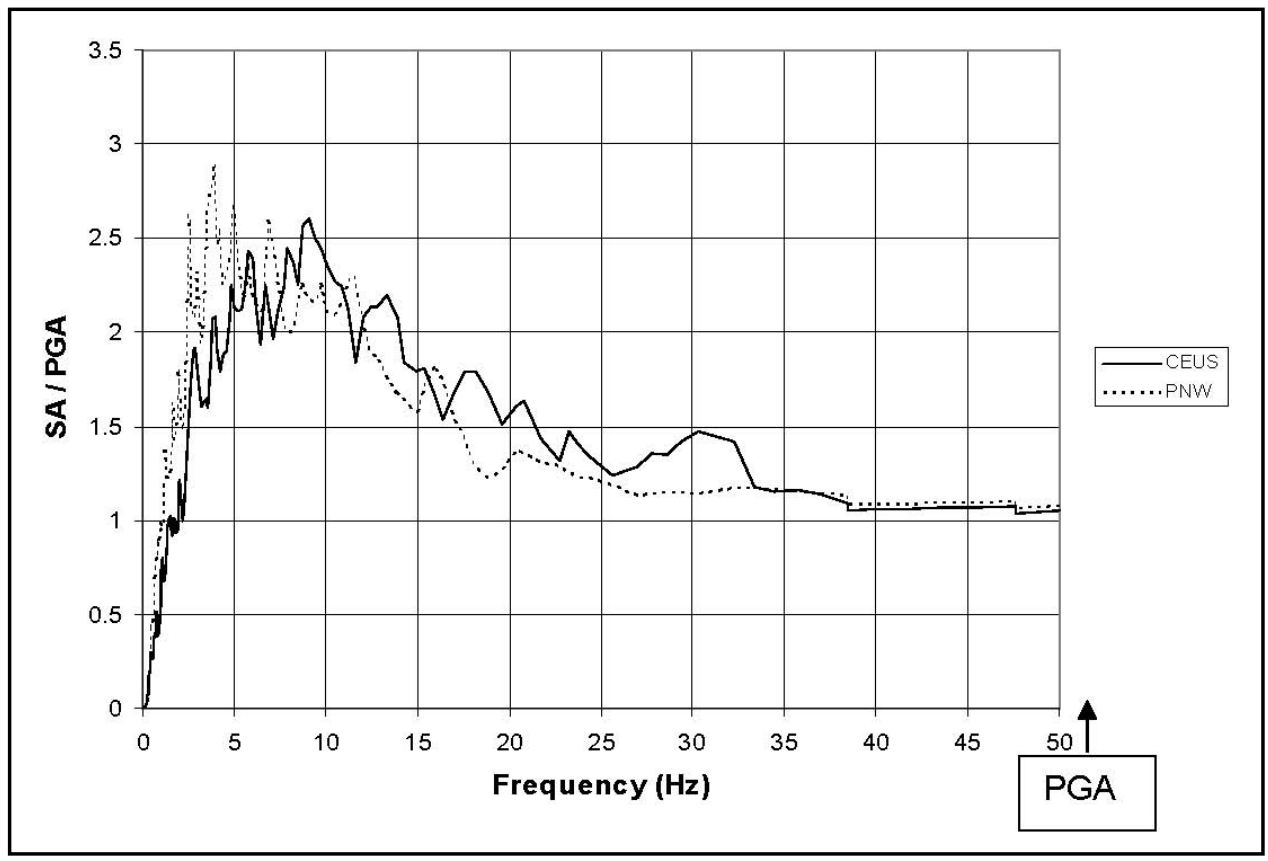

Figure 5-1. In-rock CEUS and PNW normalized response spectra versus frequency (5 percent damping)

and a modal/response spectra analysis is conducted. For simplicity in the calculations, and because of a low damping and short-period structure, a PSA is commonly used as input at the base of the finite element models. The PSA is then transferred from the rock to the top-of-substructure by the use of the AF curves developed in this study. The AF curves were calculated by using absolute accelerations that take into account the elastic and damping effects of the substructure, and are then approximately transferred to the superstructure.

\subsection{Computed AF Relationships for Generator Bay Composite Models}

The AF curves in Figures 5-2 to 5-5 for the generator bay substructure were obtained for the CEUS and PNW ground motions for dry and wet conditions. A value of 5 percent damping is assumed appropriate for the substructure in all dynamic analyses. The response spectra at rock and at top-of-substructure used for the development of the AF curves were developed using 5 percent damping. This value of damping is typically recommended for dynamic response spectra, modal analysis of a superstructure to earthquake shaking. The AF curves for analyzing equipment resting on top-of-substructure, which were developed using response spectra with 2 percent damping, are presented in Appendix F. 


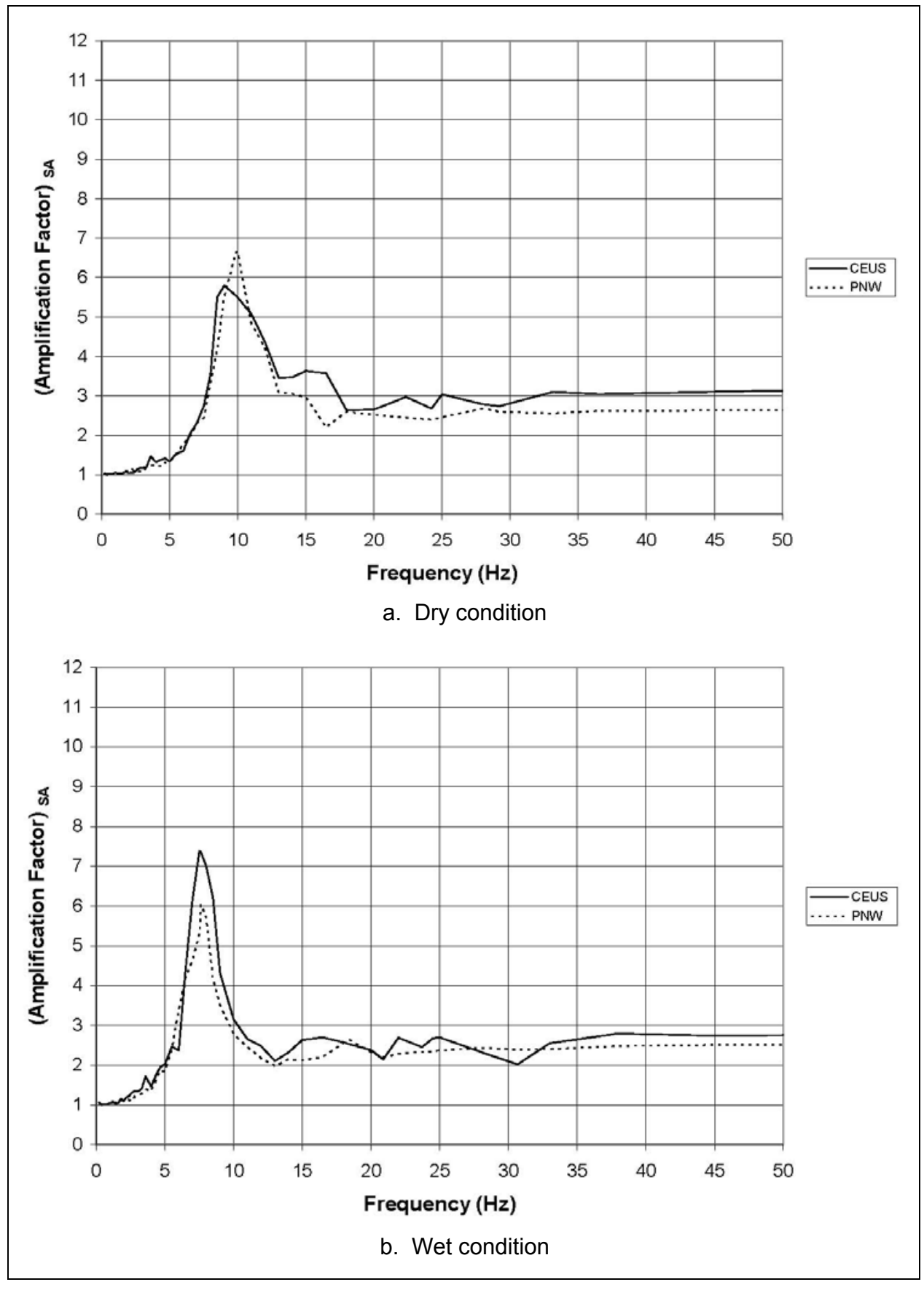

Figure 5-2. AF versus frequency curves, generator bay, composite model, 125-ft height with 5 percent damping 


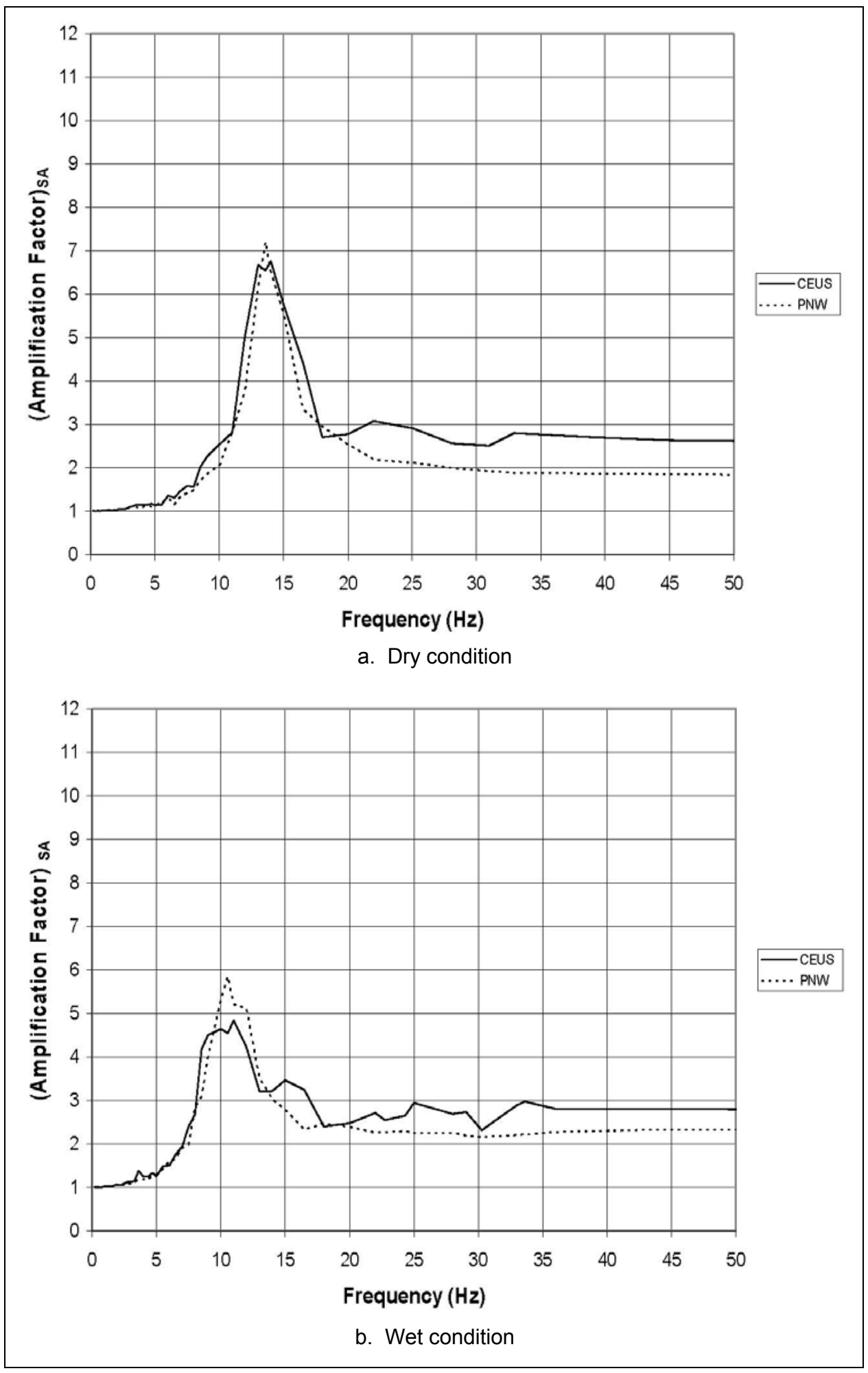

Figure 5-3. AF versus frequency curves, generator bay, composite model, 100-ft height with 5 percent damping 


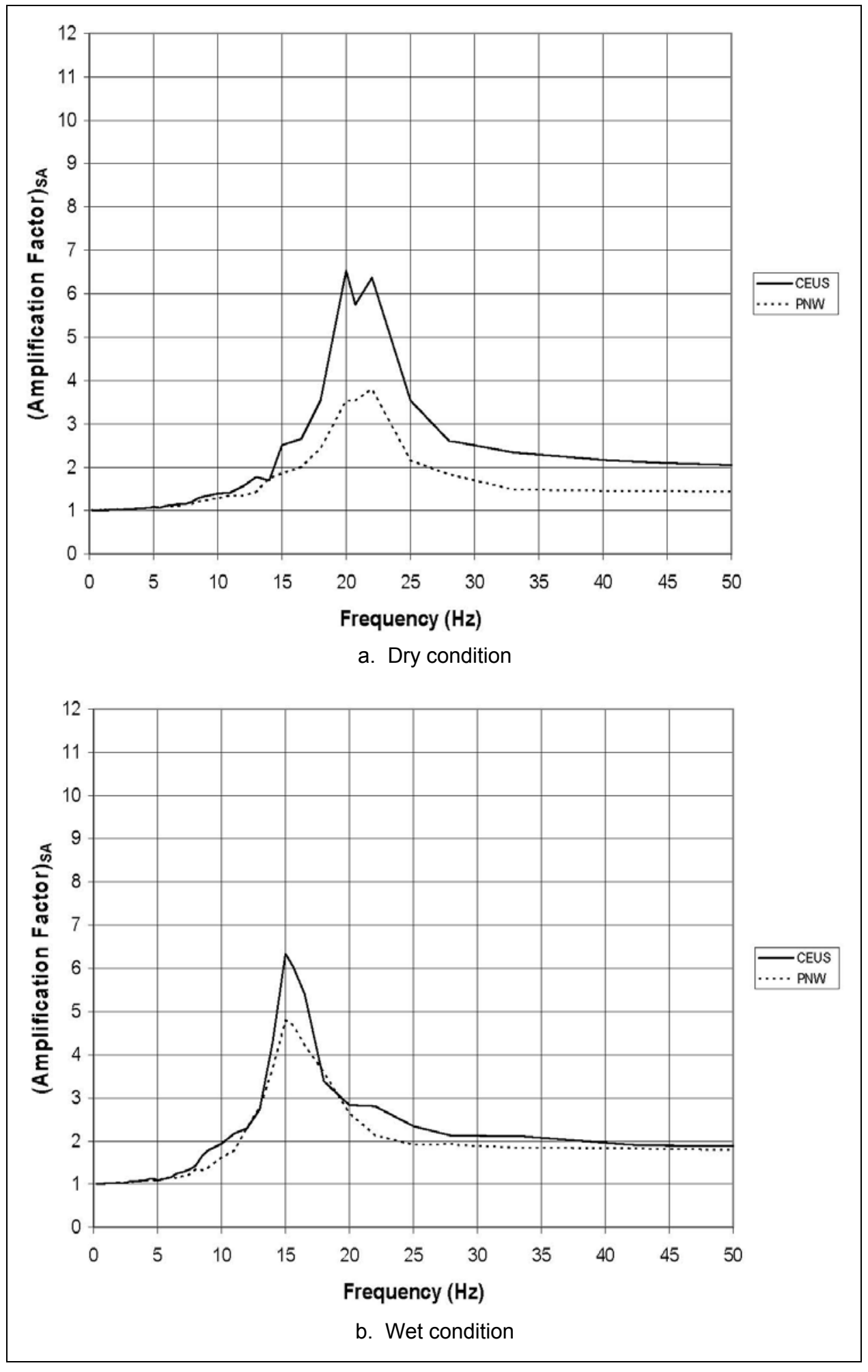

Figure 5-4. AF versus frequency curves, generator bay, composite model, 70-ft height with 5 percent damping 


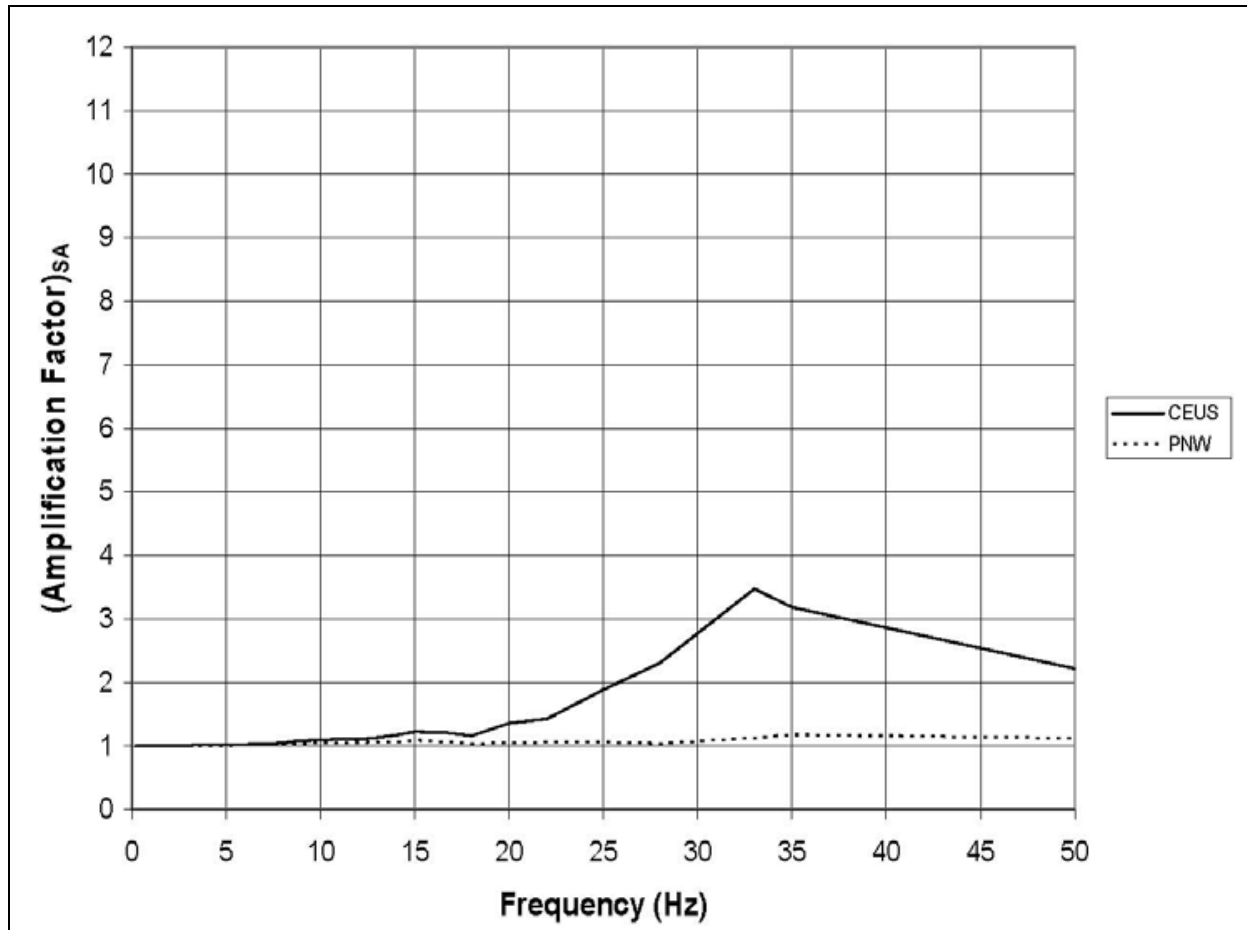

a. Dry condition

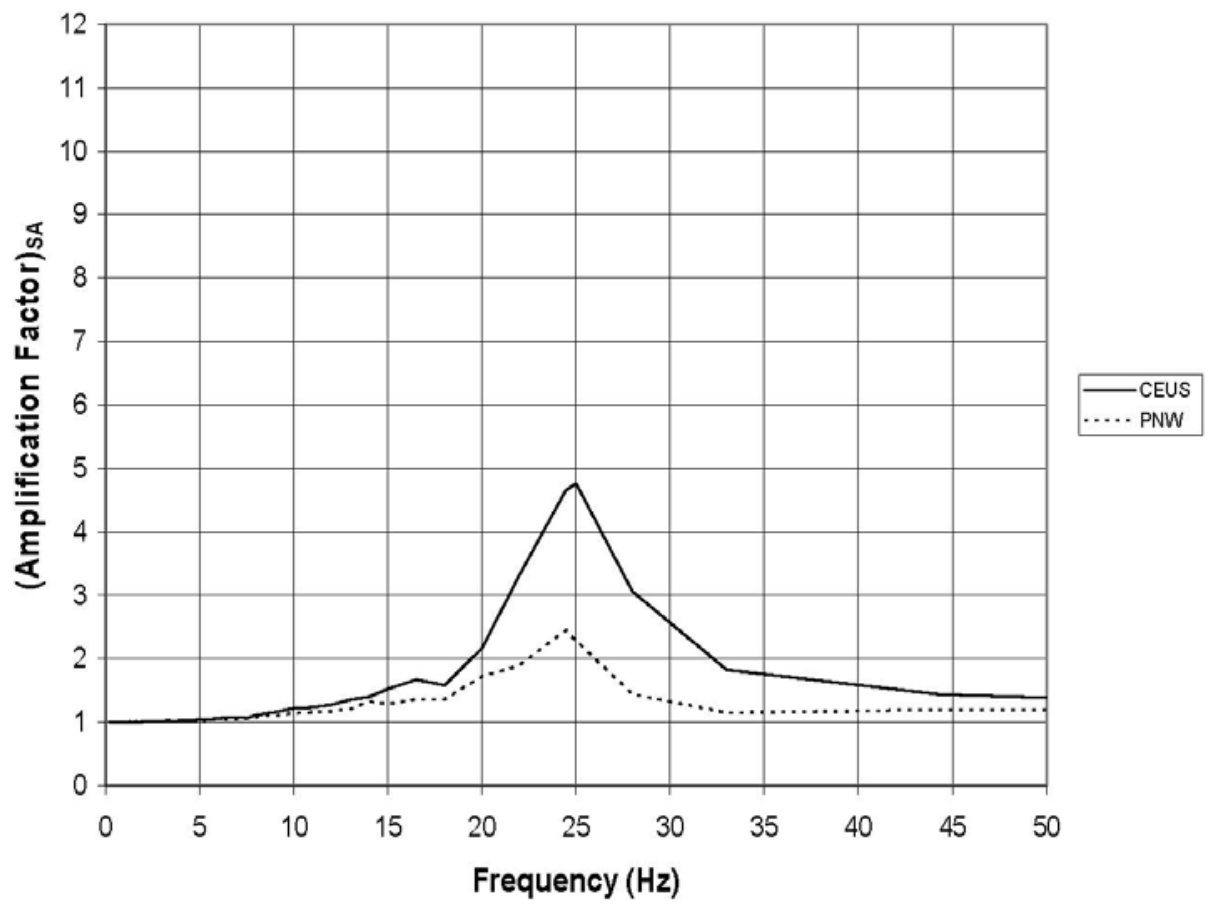

b. Wet condition

Figure 5-5. AF versus frequency curves, generator bay, composite model, 40-ft height with 5 percent damping 


\subsection{Computed AF Relationships for Erection/ Service Bay Block Models}

The AF curves presented in Figures 5-6 to 5-9 are for the erection/service bay block models. They were obtained using 5 percent damping and response spectra for the acceleration time-histories at rock and at the top-of-substructure. For dynamic response spectra, modal analysis of a superstructure to earthquake shaking, the 5 percent damping value is recommended. The AF curves for analyzing equipment, which were developed using response spectra with 2 percent damping, are presented in Appendix F. For the dynamic analysis of the substructure, 5 percent damping was assumed in the finite element block models.

\subsection{Computed AF Relationships for Erection/ Service Bay Block-Frame-Shear Wall Model}

A second type of finite element model that was used to idealize the erection/ service bay substructure is referred to as a block-frame-shear wall model. It consists of a U-frame shaped mass concrete structure with structural frames and shear walls inside the $U$ of the model. The geometry and details of the models and discussion of the AF were presented in Chapter 4. This section summarizes the AF curves for the CEUS and PNW ground motions.

Figures 5-10 to 5-13 show the AF curves for each of the two ground motions. Results were divided for each block-frame-shear wall model group into dry and wet conditions and were developed using 5 percent damping.

\subsection{Comparison Example: Time-History/Modal Response, Response Spectra Analysis, and Decoupled Response Spectra Analysis of an Erection/Service Bay}

This section discusses a comparison of the results of a complete dynamic response spectra analysis and a decoupled response spectra analysis. The finite element models considered are of an erection/service bay substructure and superstructure. The superstructure dimensions were an idealization of the Cordell Hull Powerhouse that was in Group 2, the 75-ft-height block model, assuming a wet condition. The ground motion considered was the representative one of the CEUS. A value of 5 percent damping was used for the response spectra at rock and at top-of-substructure calculations.

The structural analysis software SAP2000 was used to create and analyze the finite element models. Two models were constructed for this example. The first model is identified as a complete model. It consists of the 75-ft-height block model for the substructure with a frame structure constructed on top of a solid "block" of mass concrete. The Cordell Hull superstructure was used as a guide 


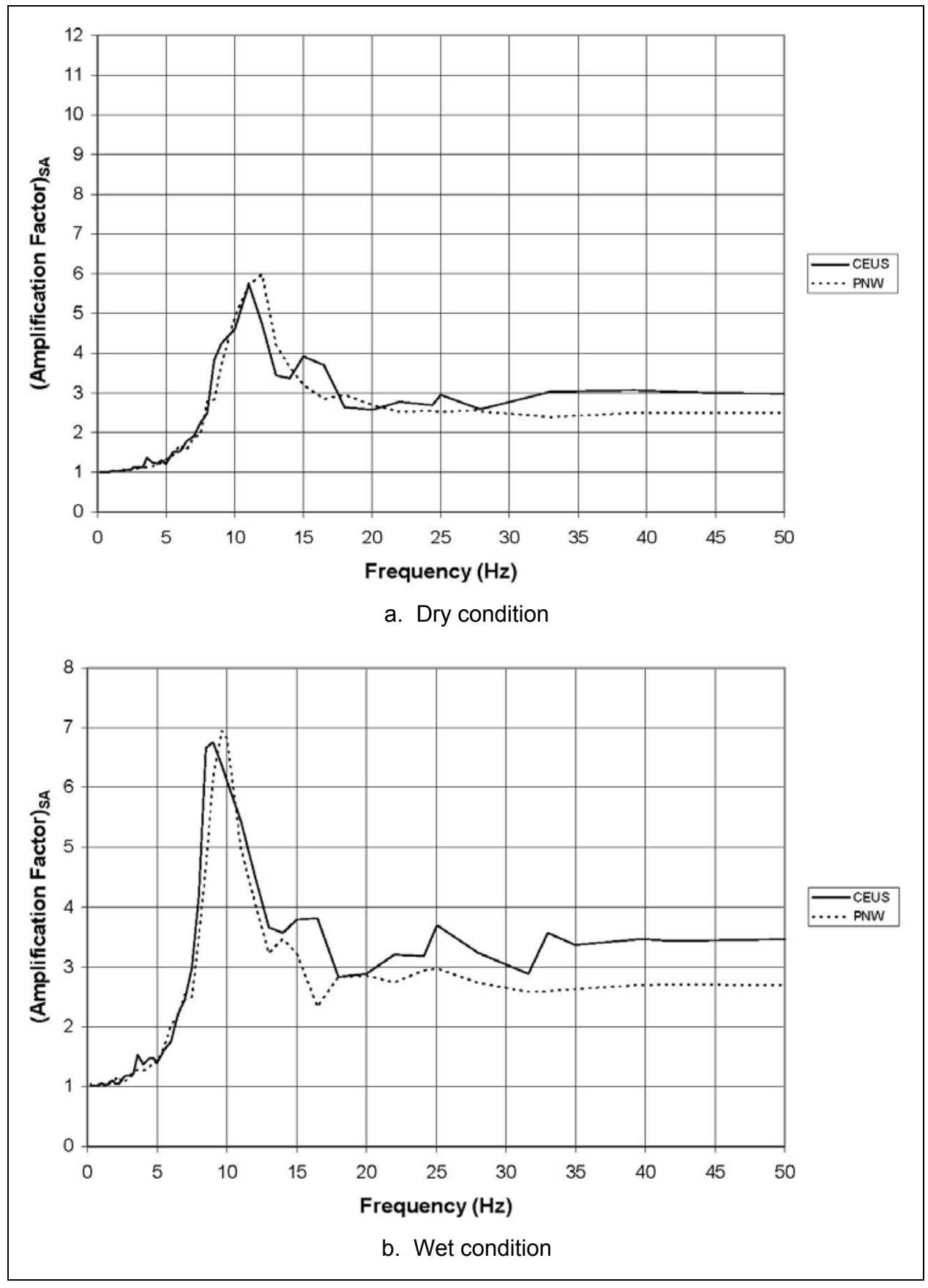

Figure 5-6. AF versus frequency curves, erection/service bay, block model, 110 -ft height with 5 percent damping 


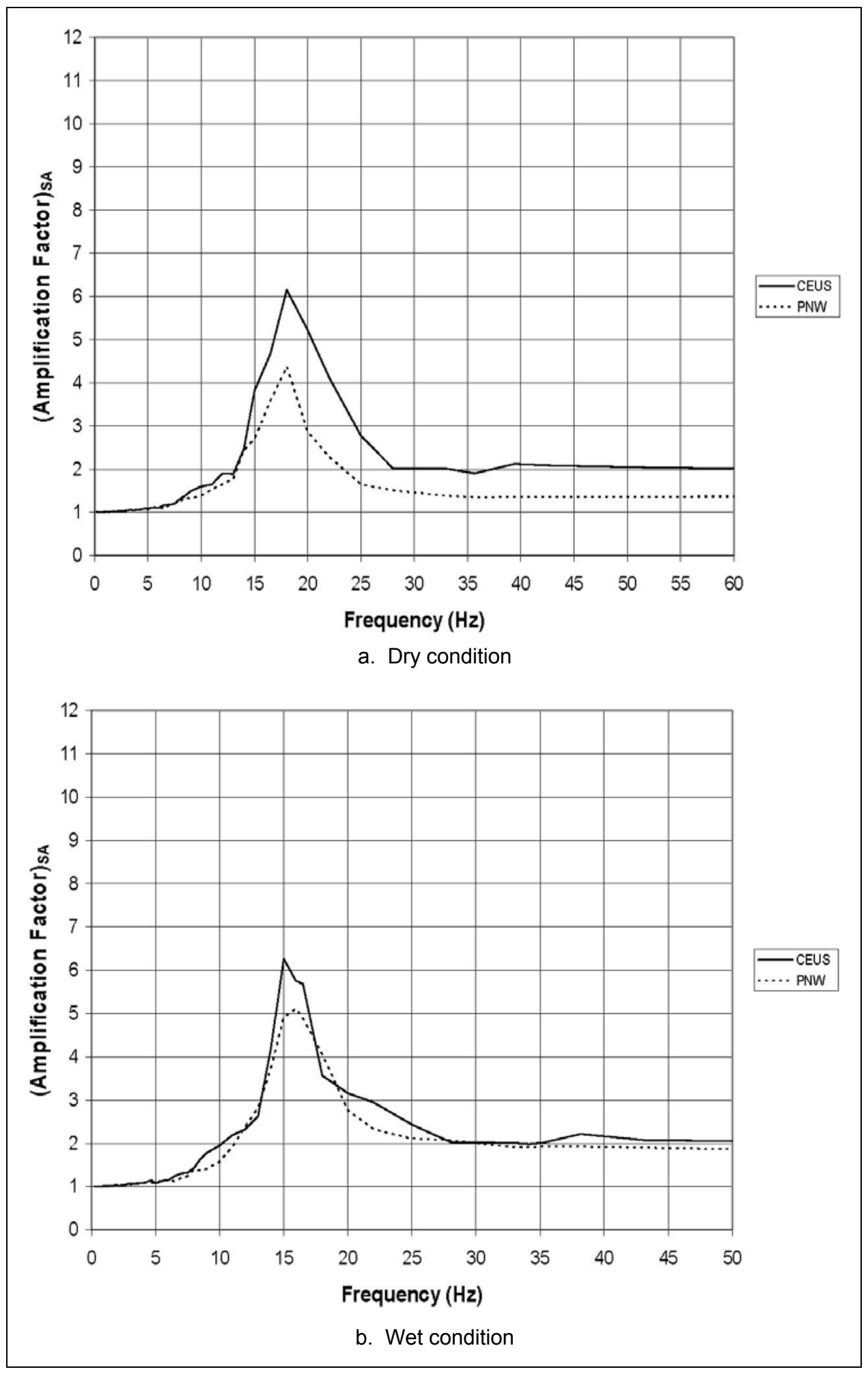

Figure 5-7. AF versus frequency curves, erection/service bay, block model, 75-ft height with 5 percent damping 


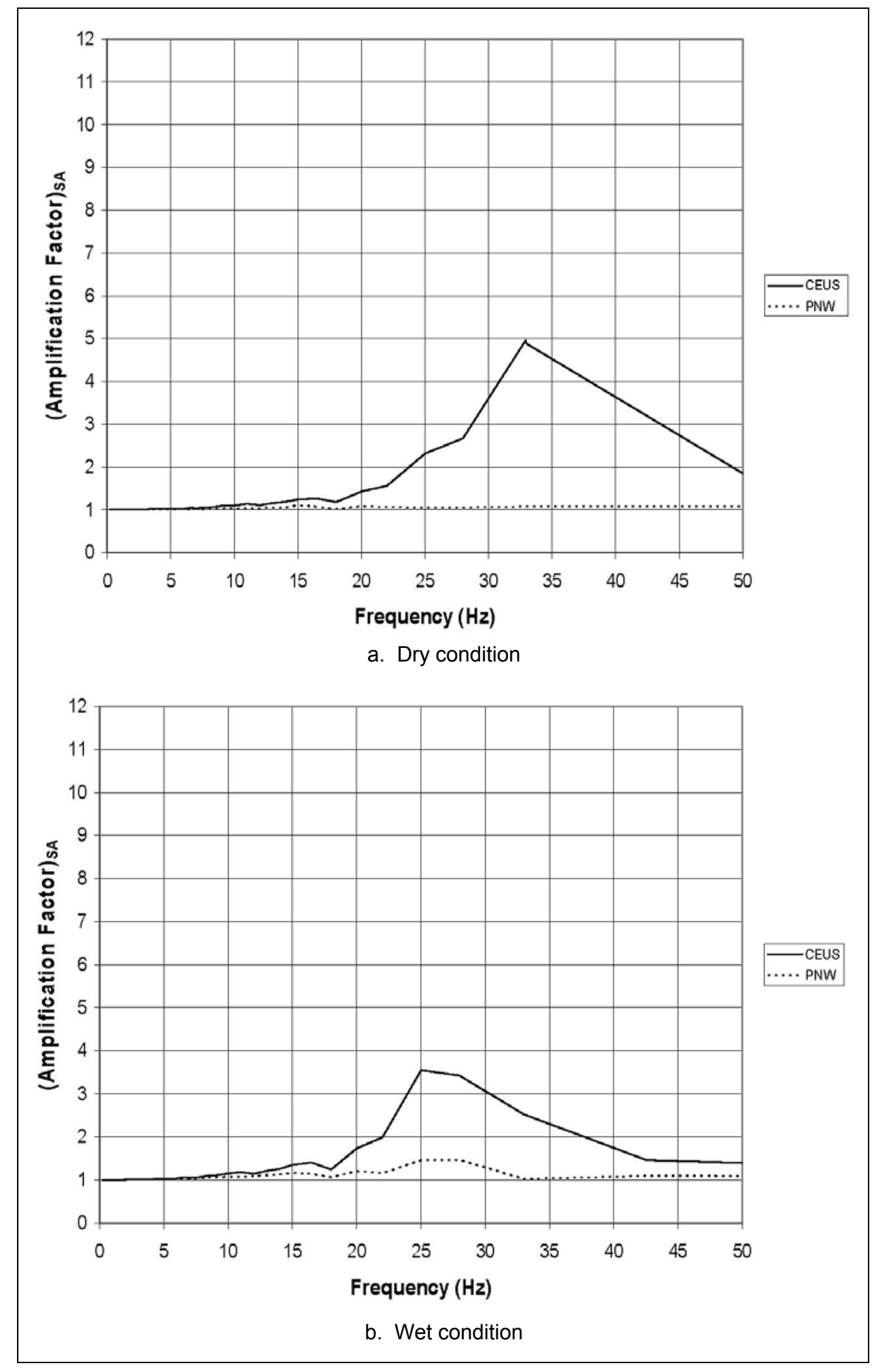

Figure 5-8. AF versus frequency curves, erection/service bay, block model, 45-ft height with 5 percent damping 


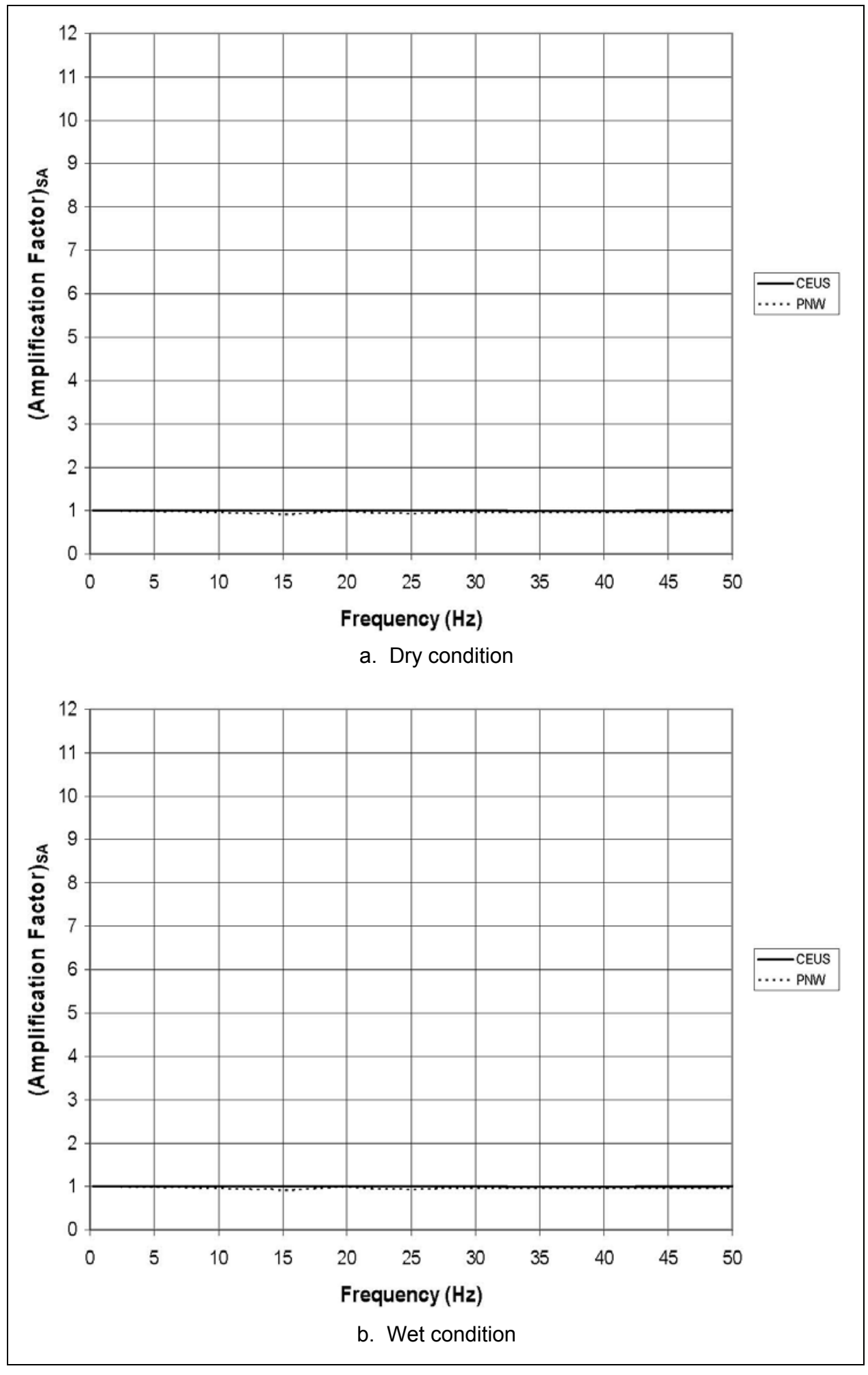

Figure 5-9. AF versus frequency curves, erection/service bay, block model, 20-ft height with 5 percent damping 


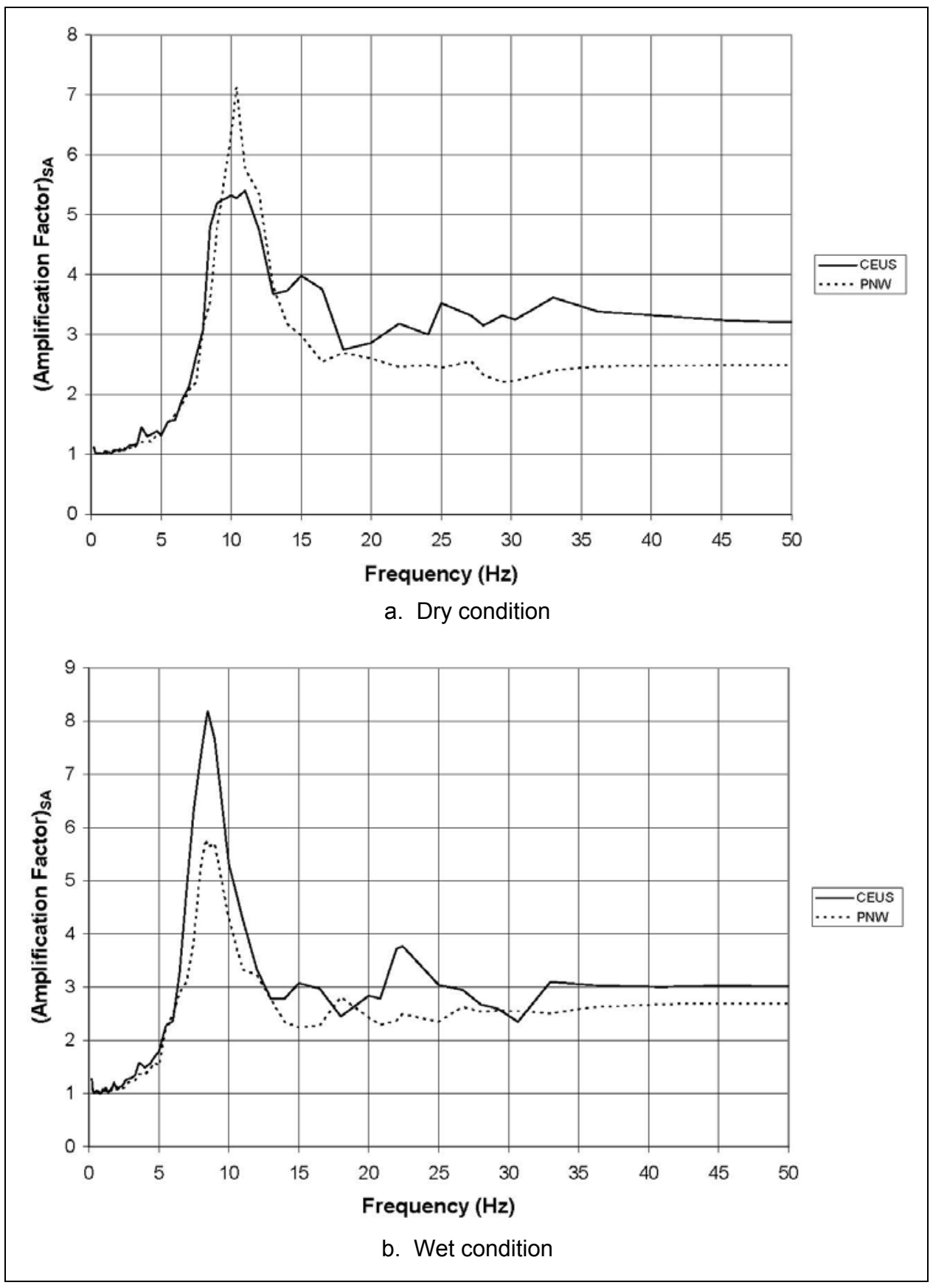

Figure 5-10. AF versus frequency curves, erection/service bay, block-frameshear wall model, 110-ft height with 5 percent damping 


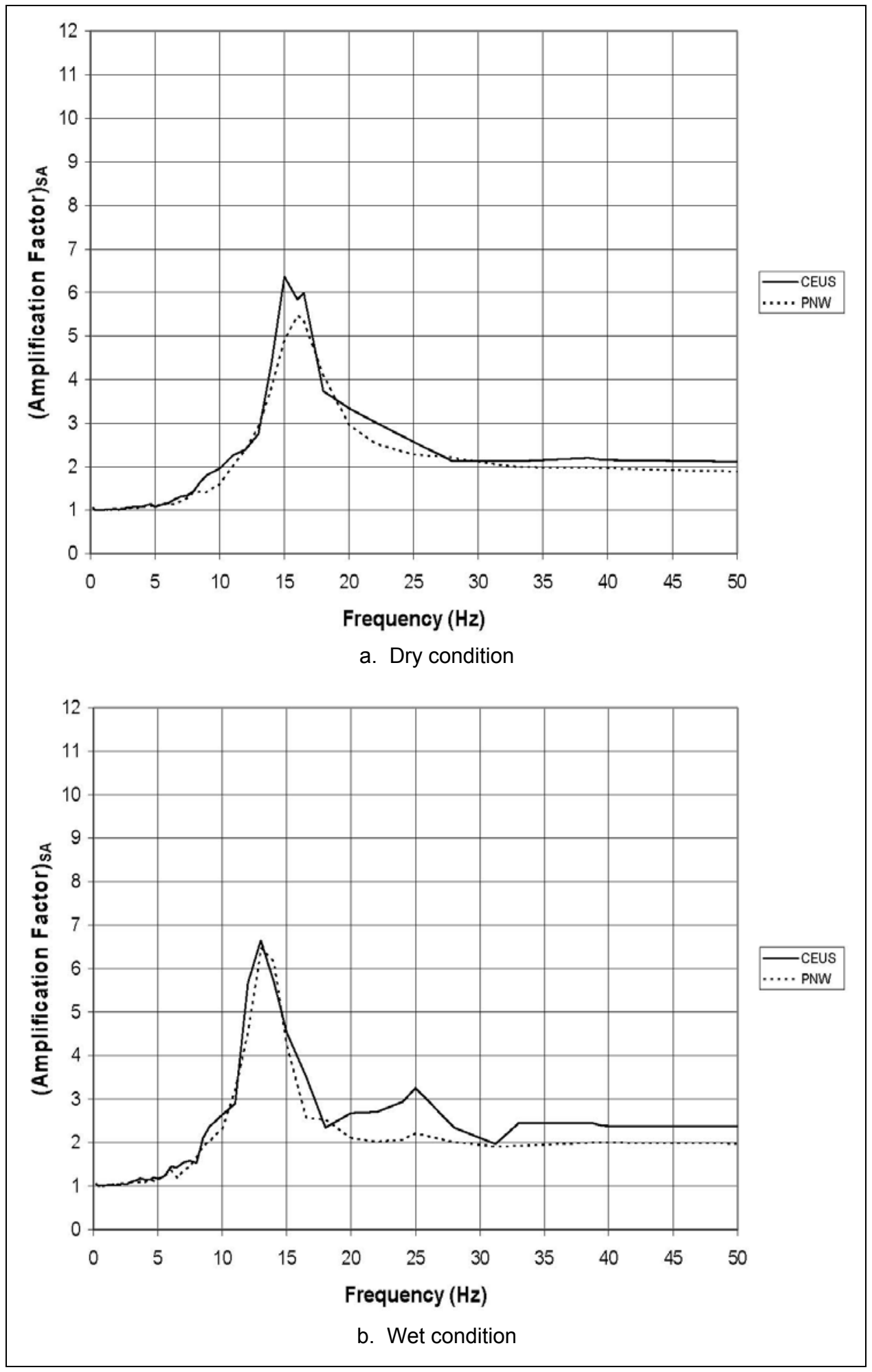

Figure 5-11. AF versus frequency curves, erection/service bay, block-frameshear wall model, $75-\mathrm{ft}$ height with 5 percent damping 


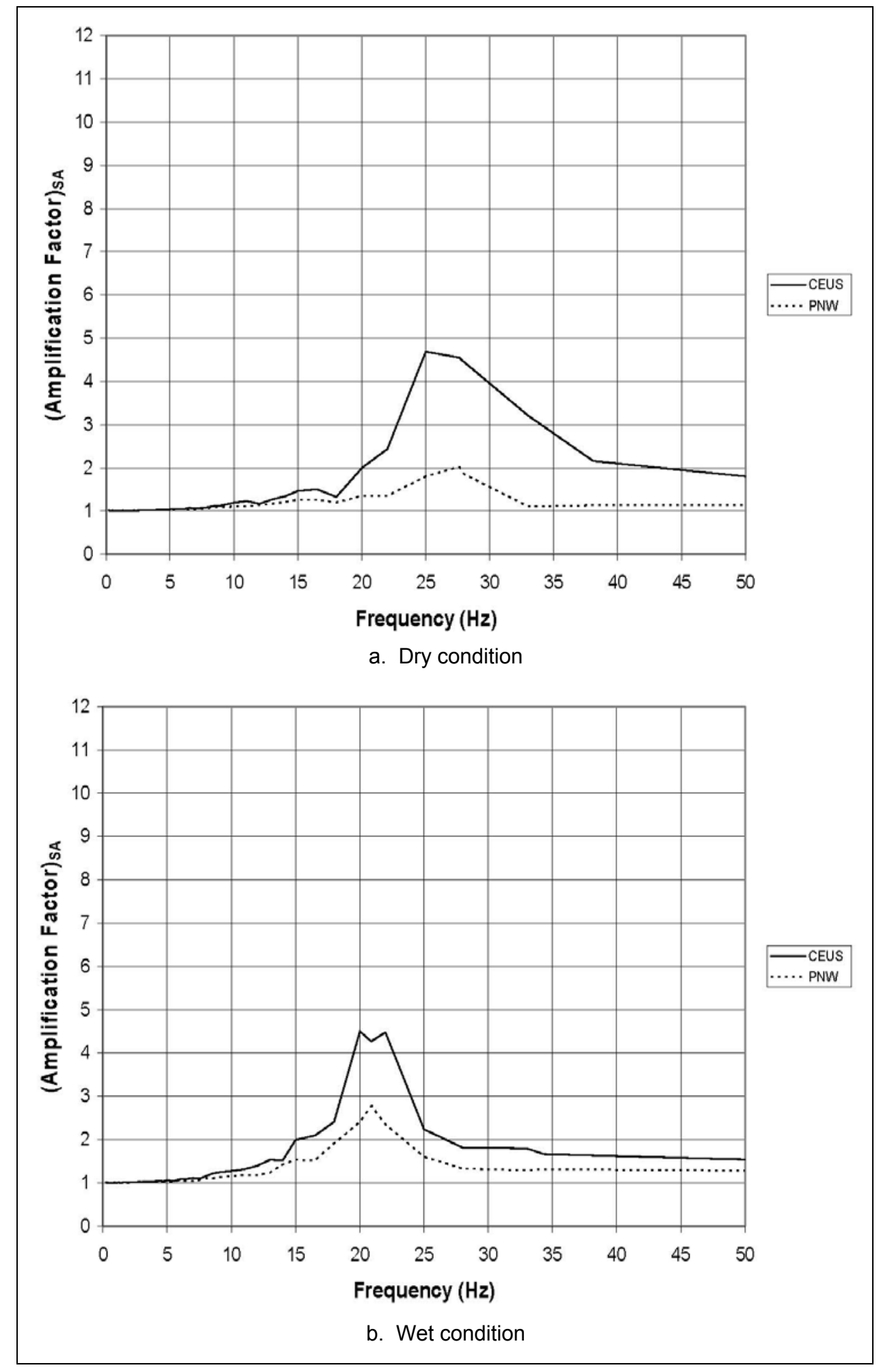

Figure 5-12. AF versus frequency curves, erection/service bay, block-frameshear wall model, $45-\mathrm{ft}$ height with 5 percent damping 


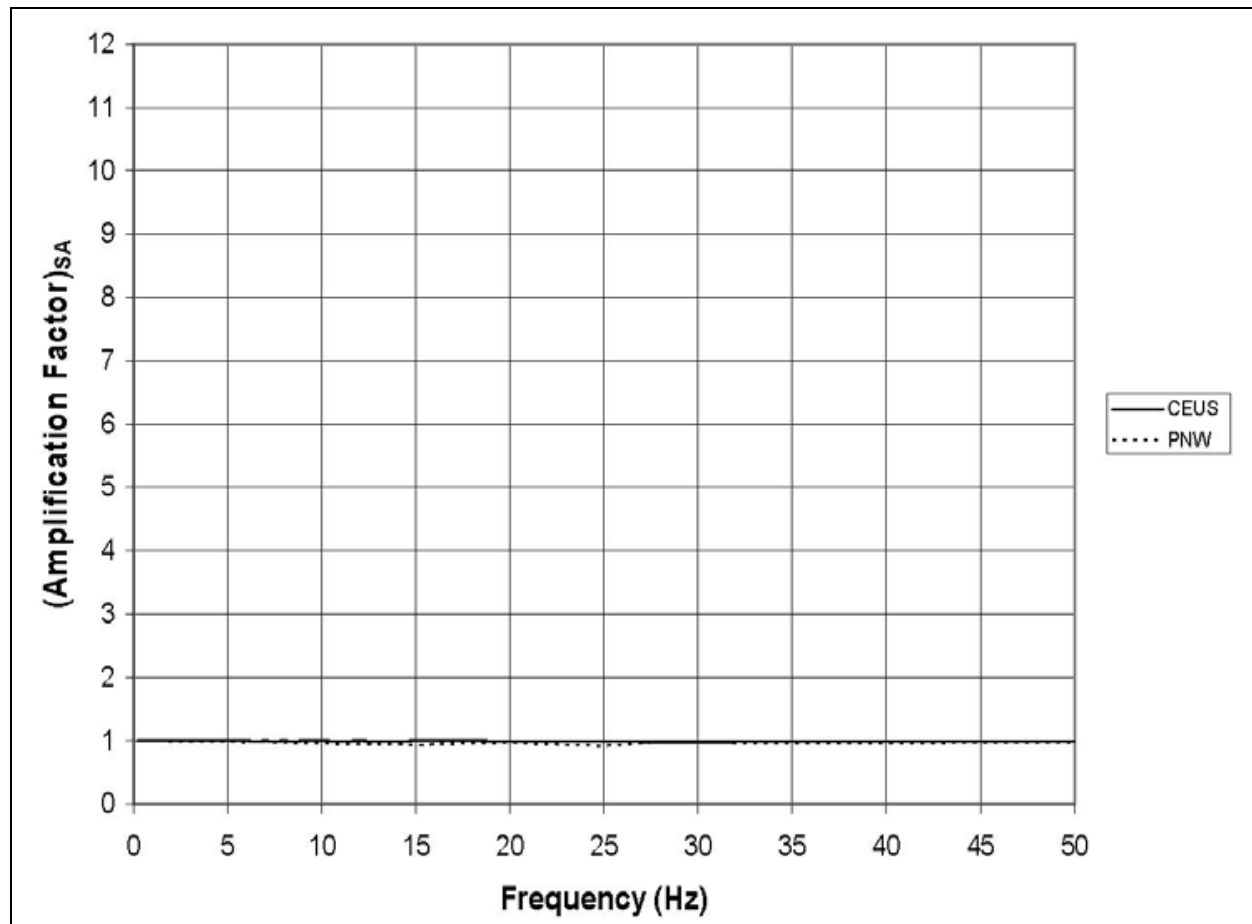

a. Dry condition

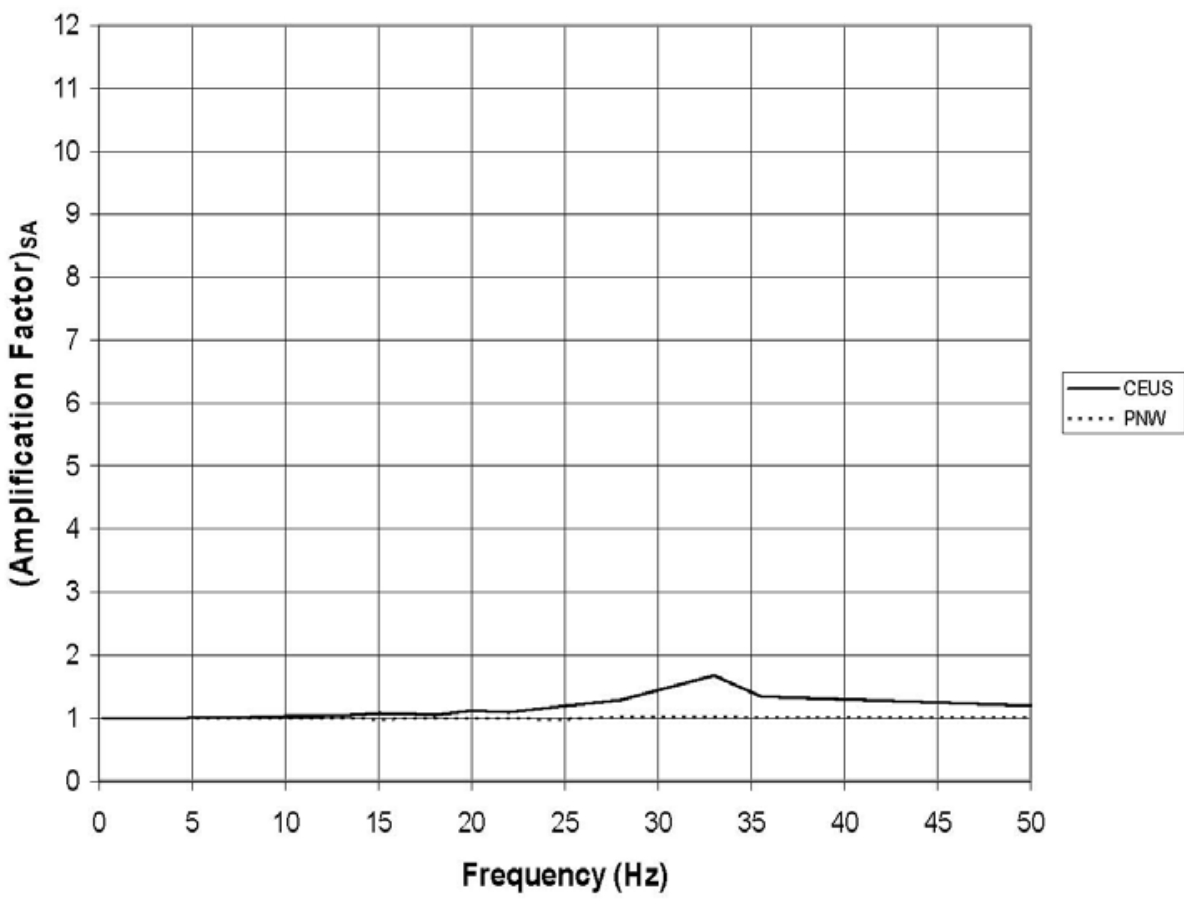

b. Wet condition

Figure 5-13. AF versus frequency curves, erection/service bay, block-frameshear wall model, 20 -ft height with 5 percent damping 
for the properties of the frame superstructure. The second model is identified as the decoupled frame model. It consists of only the frame that represents the superstructure. The structure material properties assumed for this example was mass concrete and reinforced concrete with the properties listed in Table 5-1 for the mass of concrete and Table 5-2 for the frames. Note that the type of finite elements and their material properties were previously presented in Table 4-2 for the block model. Table 5-3 lists the idealized geometry of the elements used in SAP2000.

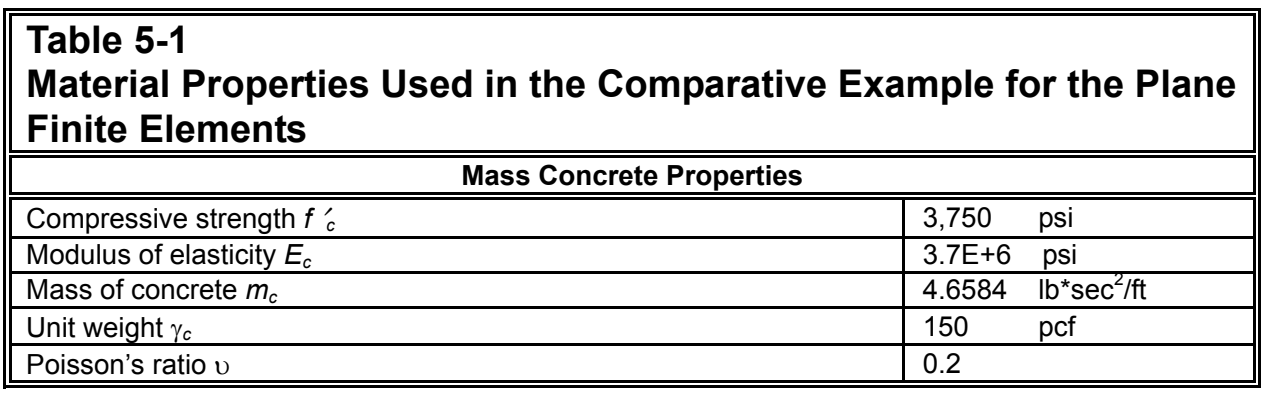

\begin{tabular}{|c|c|}
\hline \multicolumn{2}{|c|}{$\begin{array}{l}\text { Table 5-2 } \\
\text { Material Properties Used in the Frame Elements }\end{array}$} \\
\hline \multicolumn{2}{|c|}{$\begin{array}{ll} & \text { Mass Concrete Properties }\end{array}$} \\
\hline 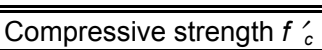 & $\begin{array}{ll}4,500 \quad \mathrm{psi} \\
\end{array}$ \\
\hline Modulus of elasticity $E_{c}$ & $4.1 \mathrm{E}+6 \quad \mathrm{psi}$ \\
\hline Mass of concrete $m_{c}$ & $\begin{array}{ll}4.6584 \quad \mathrm{lb}^{*} \mathrm{sec}^{2} / \mathrm{ft} \\
\end{array}$ \\
\hline Unit weight $\gamma_{c}$ & 150 pcf \\
\hline Poisson's ratio $v$ & 0.2 \\
\hline
\end{tabular}

\begin{tabular}{||l|l||}
\hline \hline \multicolumn{2}{|l||}{\begin{tabular}{l|} 
Table $\mathbf{5 - 3}$ \\
Geometry of Comparative Example SAP2000 Model
\end{tabular}} \\
\hline \hline Element & $\begin{array}{l}\text { Dimensions } \\
\mathrm{ft}\end{array}$ \\
\hline \hline 9-node plane stress elements, thickness & 43 \\
\hline Substructure vertical frame elements & 1.5 by 43 \\
\hline Substructure horizontal frame elements & 1 by 43 \\
\hline Superstructure horizontal frame element & 0.10 by 43 \\
\hline Superstructure top vertical frame element & 2.5 by 43 \\
\hline Superstructure bottom vertical frame element & 5 by 43 \\
\hline
\end{tabular}

The "complete" finite element model is shown in Figure 5-14. The response spectrum and time-history at rock used in the two complete analyses are also shown in this figure. The earthquake used in the analysis is the CEUS ground motion for the development of the AF curves in this study. Figure 5-15a shows the decoupled frame model. It consists of a single bay frame structure modeled with 9 nodes, each containing lumped masses in each vertical element. The decoupled frame model was subjected to the amplified response spectrum shown in Figure 5-15b that was constructed using the AFs obtained from the 75-ftheight block model assuming wet conditions. The response spectrum in Figure $5-19 \mathrm{~b}$ was developed by multiplying the in-rock CEUS SA value at each frequency by the AF for the same frequency. 


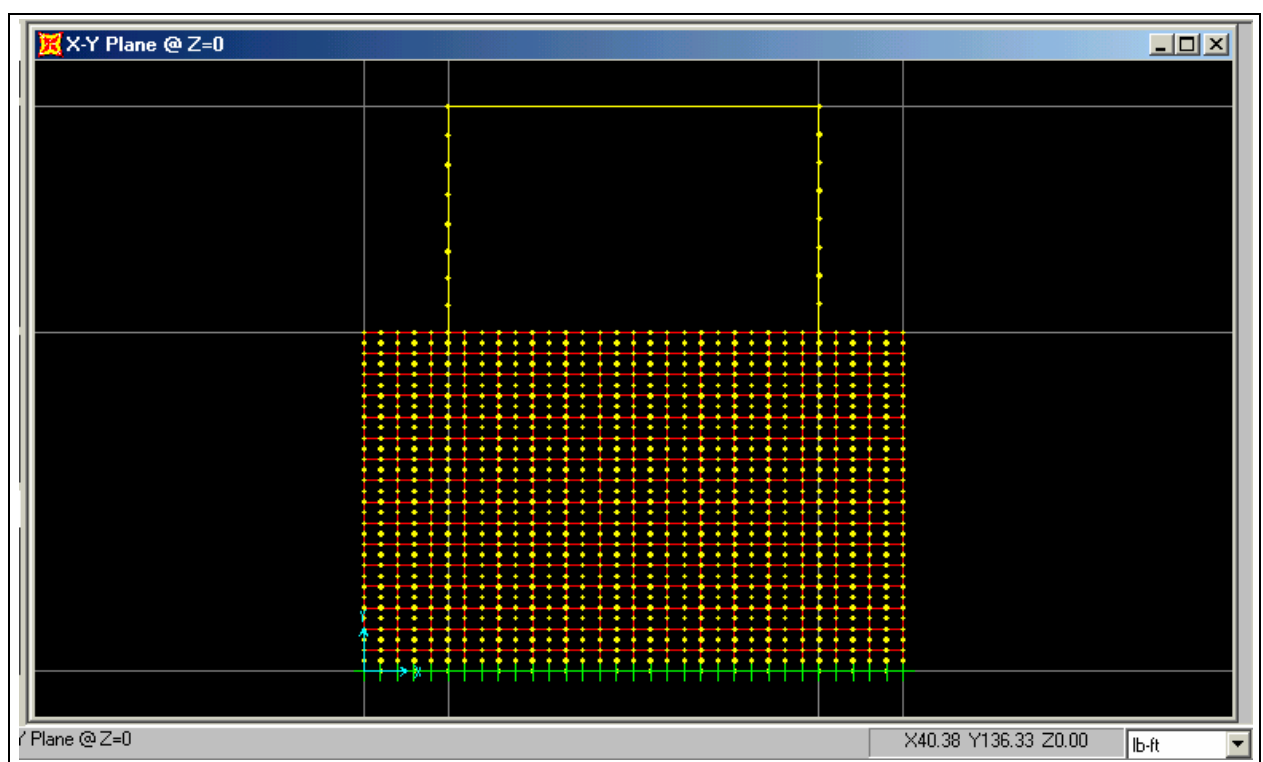

a. SAP2000 finite element model-complete analysis

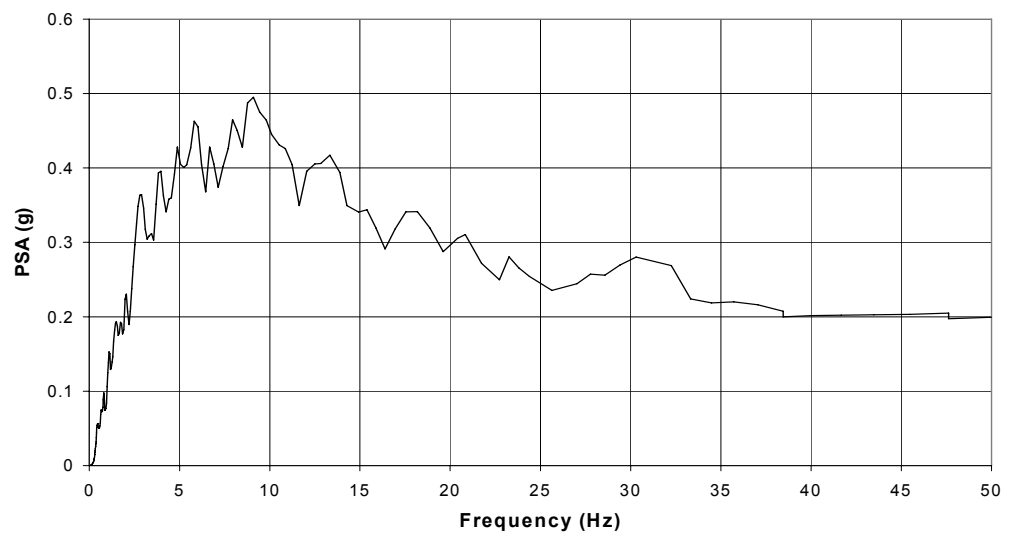

b. Rock response spectra for complete analysis (CEUS ground motion - 5 percent damping)

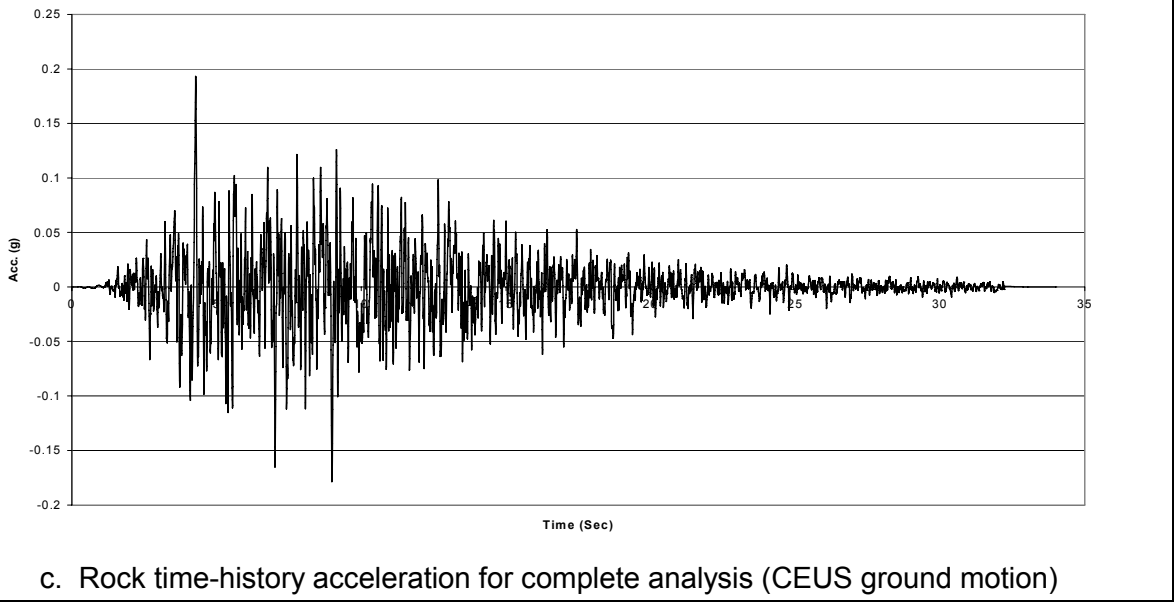

Figure 5-14. SAP2000 complete response spectra and time-history analysis of Cordell Hull erection/service bay cross section for comparison example 


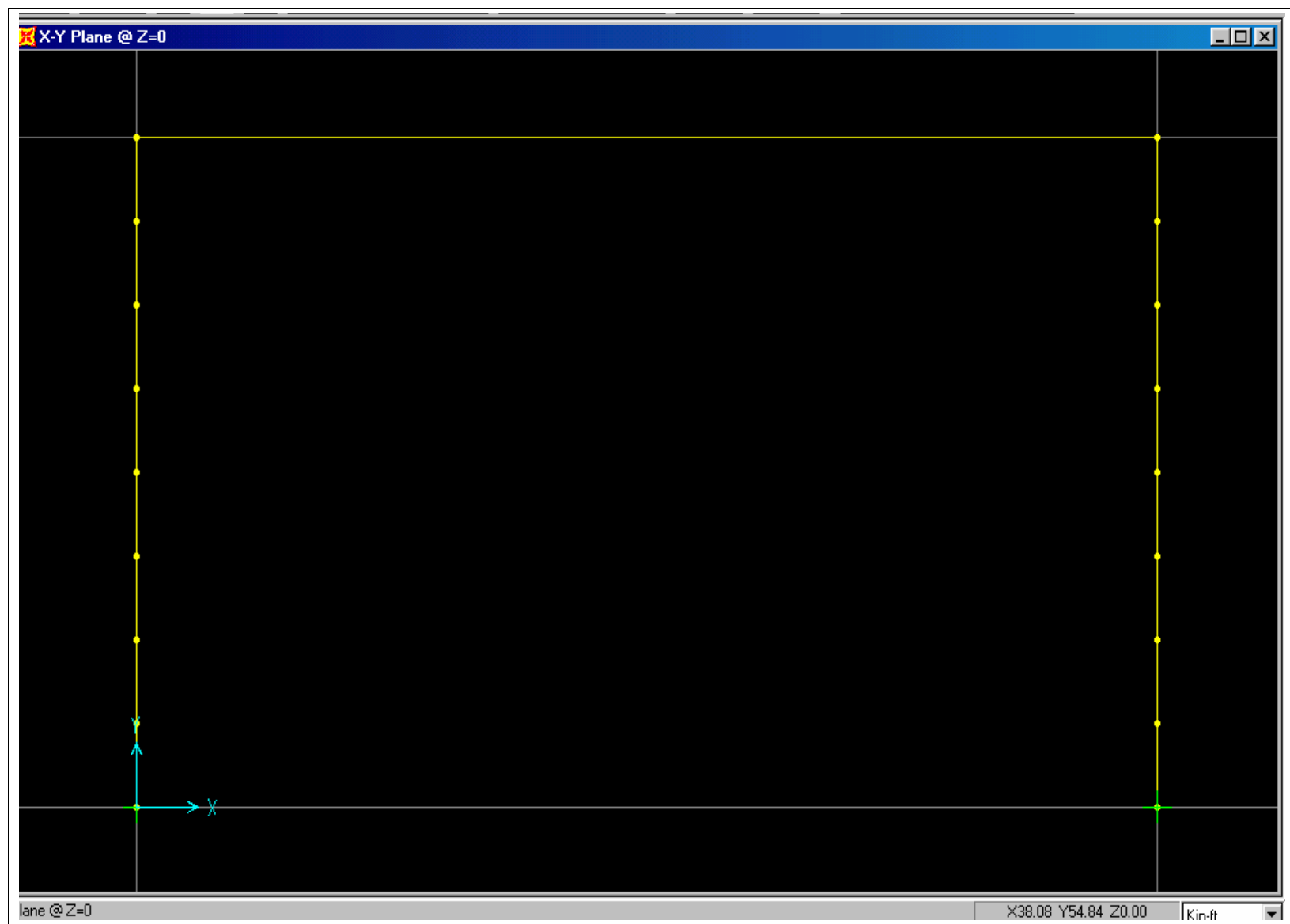

a. SAP2000 frame superstructure for decoupled analysis

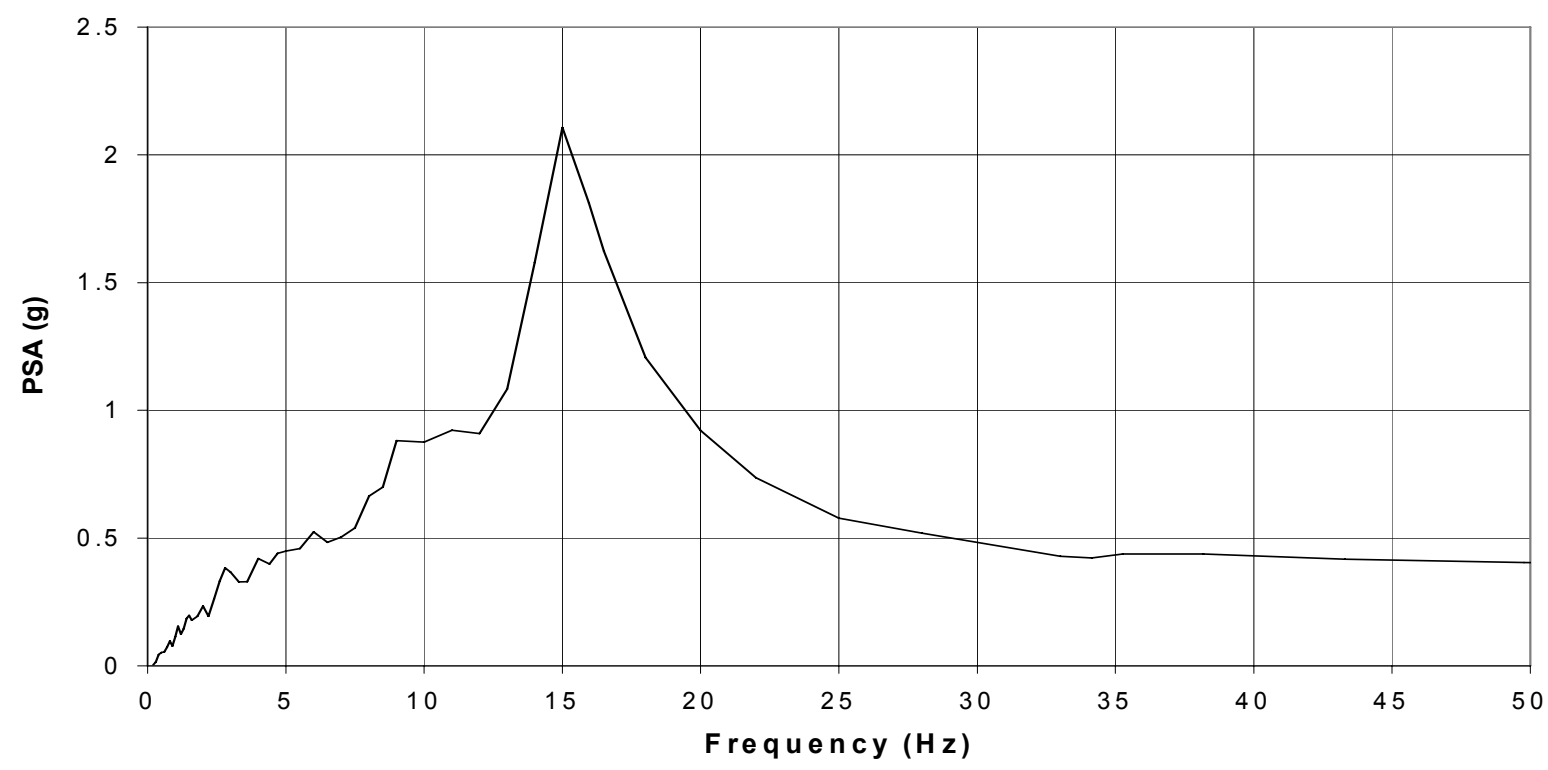

b. CEUS amplified pseudo-response spectrum (top-of-substructure) using the 75-ft-height block model AFs, wet condition

Figure 5-15. SAP2000 decoupled analysis of Cordell Hull Powerhouse for comparative example 
Table 5-4 lists the maximum displacements computed at the top of the frame superstructure. There is not a significant difference in maximum displacement between the results of the three analyses. Tables 5-5 and 5-6 present the internal forces calculated at different points in the frame superstructure. The locations of the points in Tables 5-5 and 5-6 are shown in Figure 5-16. In these tables also are listed the percent of difference between the response spectra analysis of the complete model and the decoupled frame model with the amplified response spectra. The maximum difference in shear forces was 17.6 percent. It was found in the left side of the crane at support point 2. A maximum difference of 17.1 percent in moment forces was calculated at the right side in the crane (point 4).

\begin{tabular}{||l|l|l|l||}
\hline \hline \multicolumn{4}{|l||}{$\begin{array}{l}\text { Table 5-4 } \\
\text { Maximum Displacement at Top of Frame Superstructure }\end{array}$} \\
\hline \hline Model ID & Description & $\begin{array}{l}\text { CEUS } \\
\mathrm{ft}\end{array}$ & $\begin{array}{l}\text { PNW } \\
\mathrm{ft}\end{array}$ \\
\hline \hline CordellHullW-Complete_TH & $\begin{array}{l}\text { Complete Model } \\
\text { Time-History Analysis }\end{array}$ & 0.04 & 0.05 \\
\hline CordellHullW-Complete_RS & $\begin{array}{l}\text { Complete Model } \\
\text { Response Spectra Analysis }\end{array}$ & 0.044 & 0.053 \\
\hline CordellHullWW-Frame_RS & $\begin{array}{l}\text { Decoupled Frame Model } \\
\text { Block Response Spectrum }\end{array}$ & 0.0419 & 0.0511 \\
\hline
\end{tabular}

\begin{tabular}{|c|c|c|c|c|}
\hline \multicolumn{5}{|c|}{$\begin{array}{l}\text { Table 5-5 } \\
\text { Shear Forces Within Frame Superstructure for CEUS Earthquake }\end{array}$} \\
\hline \multirow[b]{3}{*}{ Point } & \multicolumn{4}{|c|}{\begin{tabular}{|c|} 
Model \\
\end{tabular}} \\
\hline & \multirow[b]{2}{*}{$\begin{array}{l}\text { Complete_RS } \\
\text { kip }\end{array}$} & \multicolumn{2}{|c|}{ Decoupled Frame_RS } & \multirow[b]{2}{*}{$\begin{array}{l}\text { Complete_TH } \\
\text { kip }\end{array}$} \\
\hline & & kip & $\%$ Difference & \\
\hline 1 (LHS-Base) & 439 & 385.5 & 12.2 & -445 \\
\hline 2 (LHS-Crane) & 334.4 & 275.65 & 17.6 & -171.5 \\
\hline 3 (RHS-Base) & 501.3 & 456.2 & 9.0 & -576.8 \\
\hline 4 (RHS-Crane) & 313 & 290.4 & 7.2 & -167.8 \\
\hline
\end{tabular}

\begin{tabular}{|c|c|c|c|c|}
\hline \multicolumn{5}{|c|}{$\begin{array}{l}\text { Table 5-6 } \\
\text { Moment Forces Within Frame Superstructure for CEUS Earthquake }\end{array}$} \\
\hline \multirow[b]{3}{*}{ Point } & \multicolumn{4}{|c|}{ Model } \\
\hline & \multirow[b]{2}{*}{$\begin{array}{l}\text { Complete_RS } \\
\text { kip-ft }\end{array}$} & \multicolumn{2}{|c|}{ Decoupled Frame_RS } & \multirow[b]{2}{*}{$\begin{array}{l}\text { Complete_TH } \\
\text { kip-ft }\end{array}$} \\
\hline & & kip-ft & $\%$ Difference & \\
\hline 1 (LHS-Base) & 10,042 & $9,351.9$ & 6.9 & 9,993 \\
\hline 2 (LHS-Crane) & $3,614.03$ & $3,029.9$ & 16.2 & 3,983 \\
\hline 3 (RHS-Base) & 10,689 & $10,155.4$ & 5.0 & 8,733 \\
\hline 4 (RHS-Crane) & $3,770.64$ & $3,124.09$ & 17.1 & 3,423 \\
\hline
\end{tabular}




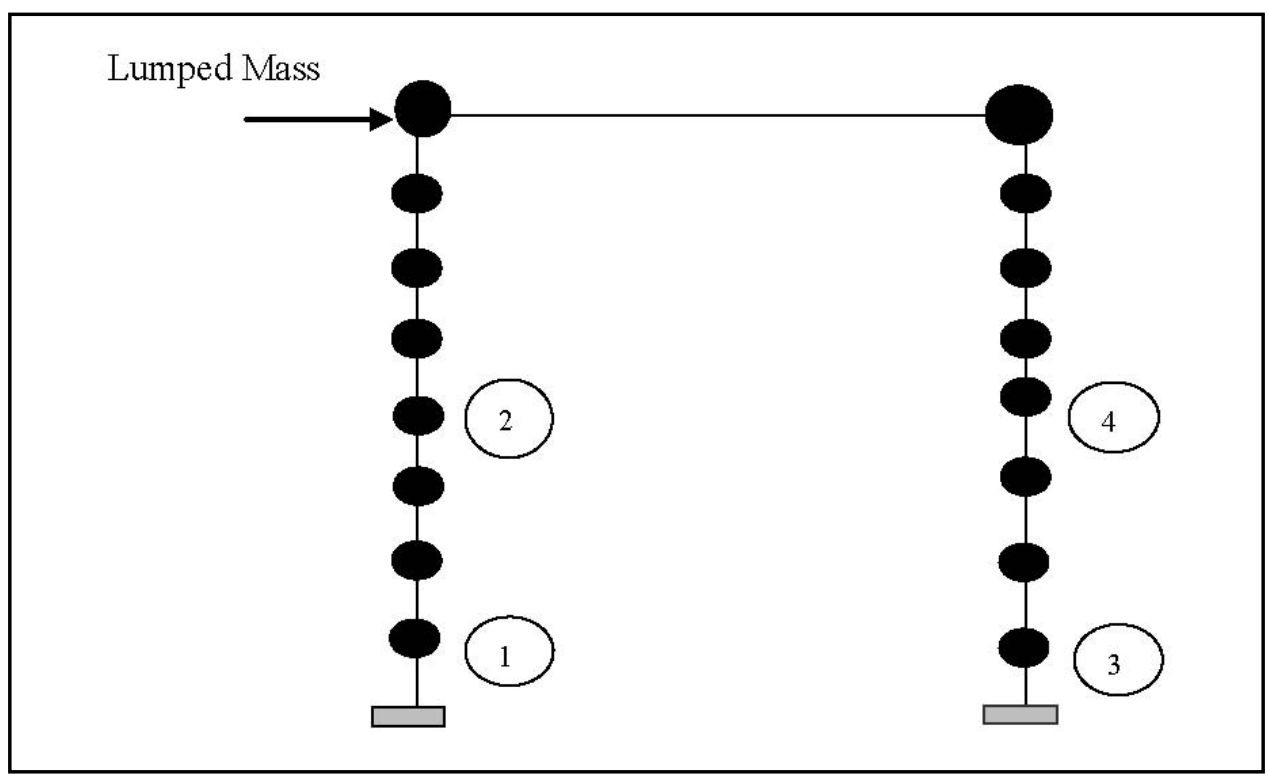

Figure 5-16. Frame lumped mass model

\subsection{Demonstration Example: Decoupled Analysis of an Erection/Service Bay Using NEHRP Maps}

In this section, the procedure for a decoupled dynamic analysis is outlined. A superstructure, represented by a frame structure, is analyzed by a response spectra/modal analysis procedure using a design response spectrum developed by following the NEHRP procedure (FEMA 2001). The in-rock, design response spectrum was amplified by the AF developed in this study to obtain the approximate top-of-substructure response spectrum for the frame superstructure. The computed maximum displacements at top of the frame, shear forces, and moment forces are reported.

A frame structure located at the top of an erection/service bay substructure was analyzed for earthquake loadings. The powerhouse is located at latitude of 36.29 and longitude of -85.9416 in the central-eastern part of the United States. It was assumed that the frame structure was constructed with reinforced concrete. Its properties are listed in Table 5-2. From construction drawings, an estimation of the dimensions of the structural elements was made, resulting in the simplified/idealized dimensions listed in Table 5-7. Figure 5-17 shows a schematic of the frame that was analyzed. The superstructure horizontal element is identified as $\mathrm{SH}$, the superstructure top vertical element is identified as STV, and the superstructure bottom vertical element as SBV.

The in-rock, design response spectrum used in this analysis corresponds to a 2,475-year return period and was developed for the powerhouse site according to the information obtained at http://earthquake.usgs.gov/research/hazmaps/design/. From this map the peak ground acceleration at rock $\left(\mathrm{PGA}_{\text {rock }}\right)$ is $0.11 \mathrm{~g}$, the PSA at a period of $0.2 \mathrm{sec}\left(\mathrm{PSA}_{0.2}\right)$ is $0.27 \mathrm{~g}$, and the PSA at a period of $1.0 \mathrm{sec}\left(\mathrm{PSA}_{1}\right)$ is $0.1118 \mathrm{~g}$. Figure 5-18 shows the resulting in-rock design response spectrum. 


\begin{tabular}{|c|c|c|}
\hline \multicolumn{3}{|c|}{$\begin{array}{l}\text { Table 5-7 } \\
\text { Geometry of the Frame Structural Elements for Demonstration } \\
\text { Example }\end{array}$} \\
\hline Element & Description & $\begin{array}{l}\text { Dimensions } \\
\mathrm{ft}\end{array}$ \\
\hline $\mathrm{SH}$ & Superstructure horizontal frame element & 0.10 by 43 \\
\hline STV & Superstructure top vertical frame element & 2.5 by 43 \\
\hline SBV & Superstructure bottom vertical frame element & 5 by 43 \\
\hline
\end{tabular}

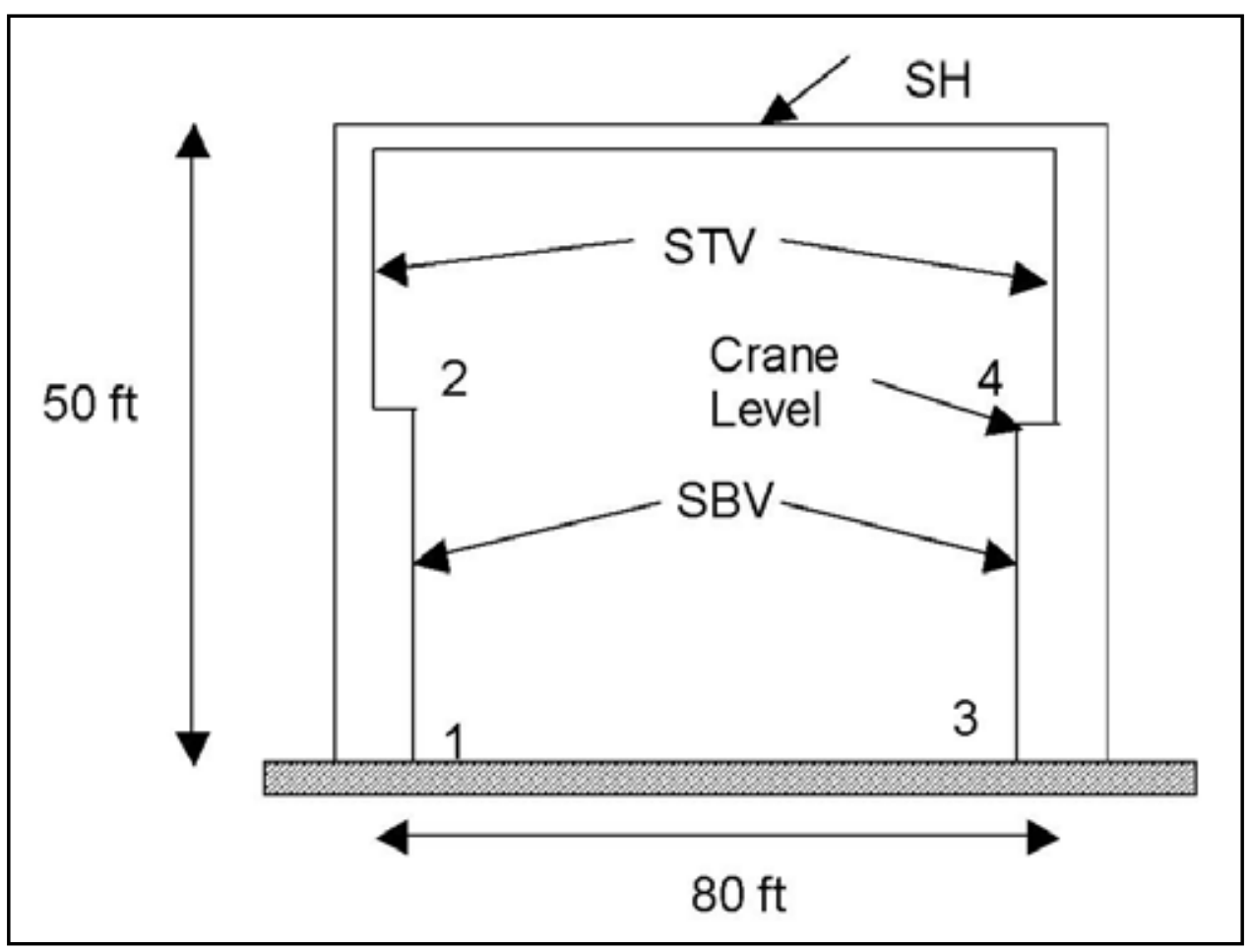

Figure 5.17. Frame superstructure for demonstration example

The design response spectrum at rock, determined by NEHRP procedure, is transferred to the top of the substructure for the decoupled dynamic analysis. Assuming a wet condition, the AF curve for the 75-ft block model of the erection/service bay substructure (Group 2) is used. The PSA at rock at each frequency is multiplied by the AF at that same frequency. The resulting top-ofsubstructure amplified design response spectrum is shown in Figure 5-19.

The structural analysis software SAP2000 was then used for creating a simplified/idealized finite element model and for the dynamic analysis of the superstructure only. The model consists of frame elements with three degrees at each node (two translations and one rotation) with nine lumped masses specified along its vertical elements. A response spectrum/modal analysis was then performed to calculate the maximum displacement at the top of the frame superstructure and the shear and moment forces at the base and at the crane levels. Figure 5-20 shows the SAP2000 model used in this example. 


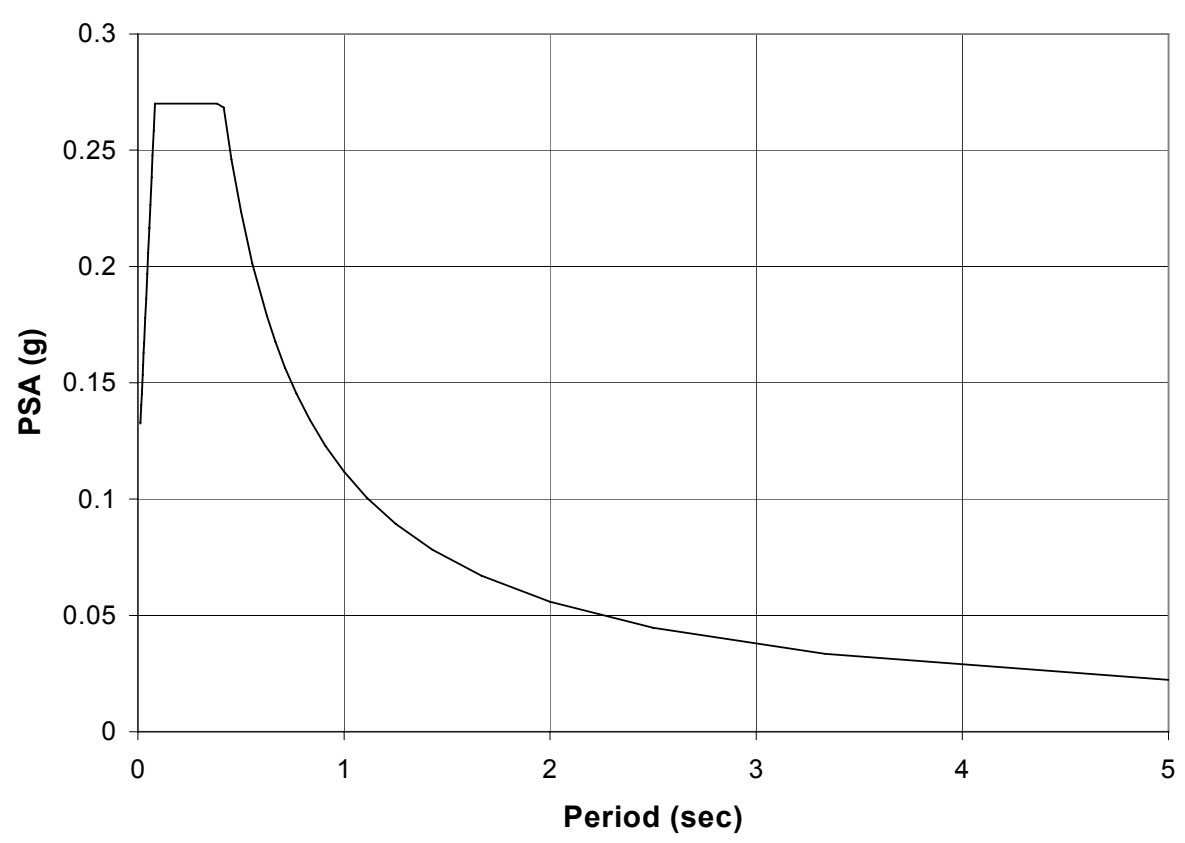

Return Period $=2475$ years

$\mathrm{PGA}=0.1116 \mathrm{~g}$

$\mathrm{PSA}_{0.2}=0.27 \mathrm{~g}$

$\mathrm{PSA}_{1}=0.1118 \mathrm{~g}$

a. PSA versus period - rock (2,475-year return period)

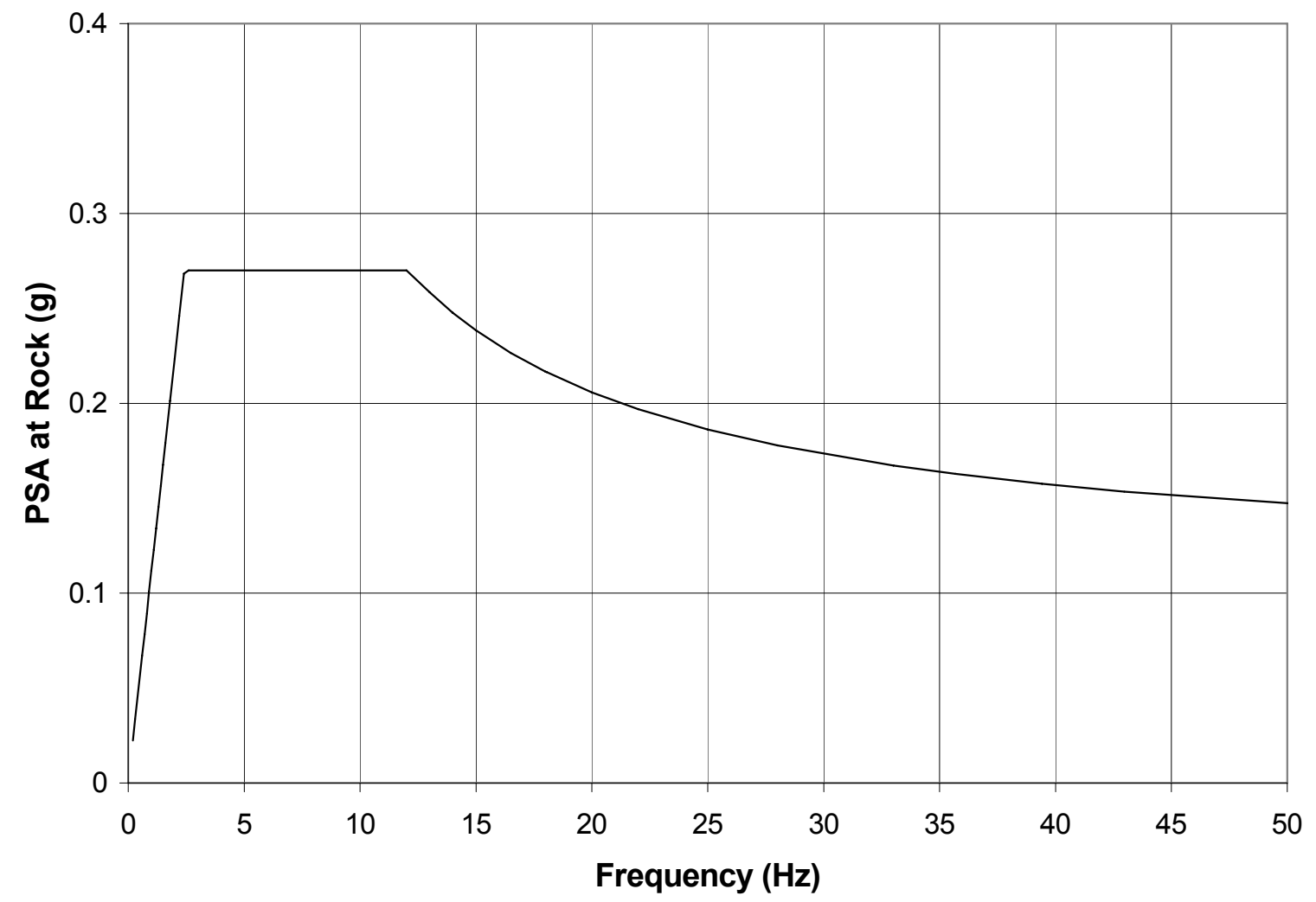

b. PSA versus frequency - rock (2,472-year return period)

Figure 5-18. Design rock response spectrum constructed using the NEHRP procedure with PGA anchor from USGS map for demonstration example site 


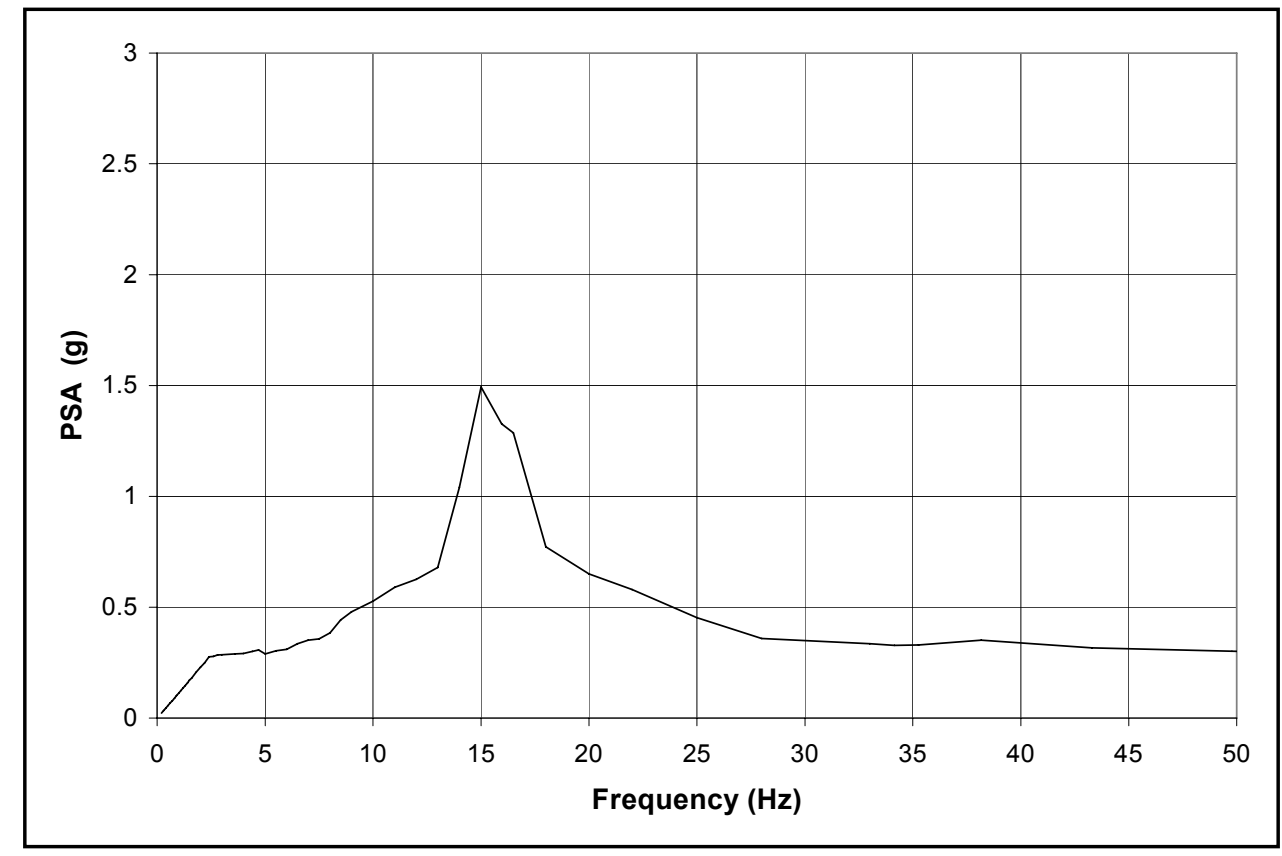

Figure 5-19. Amplified USGS/NEHRP response spectrum at top-of-substructure constructed using the 75 -ft block model AF curve for the wet condition

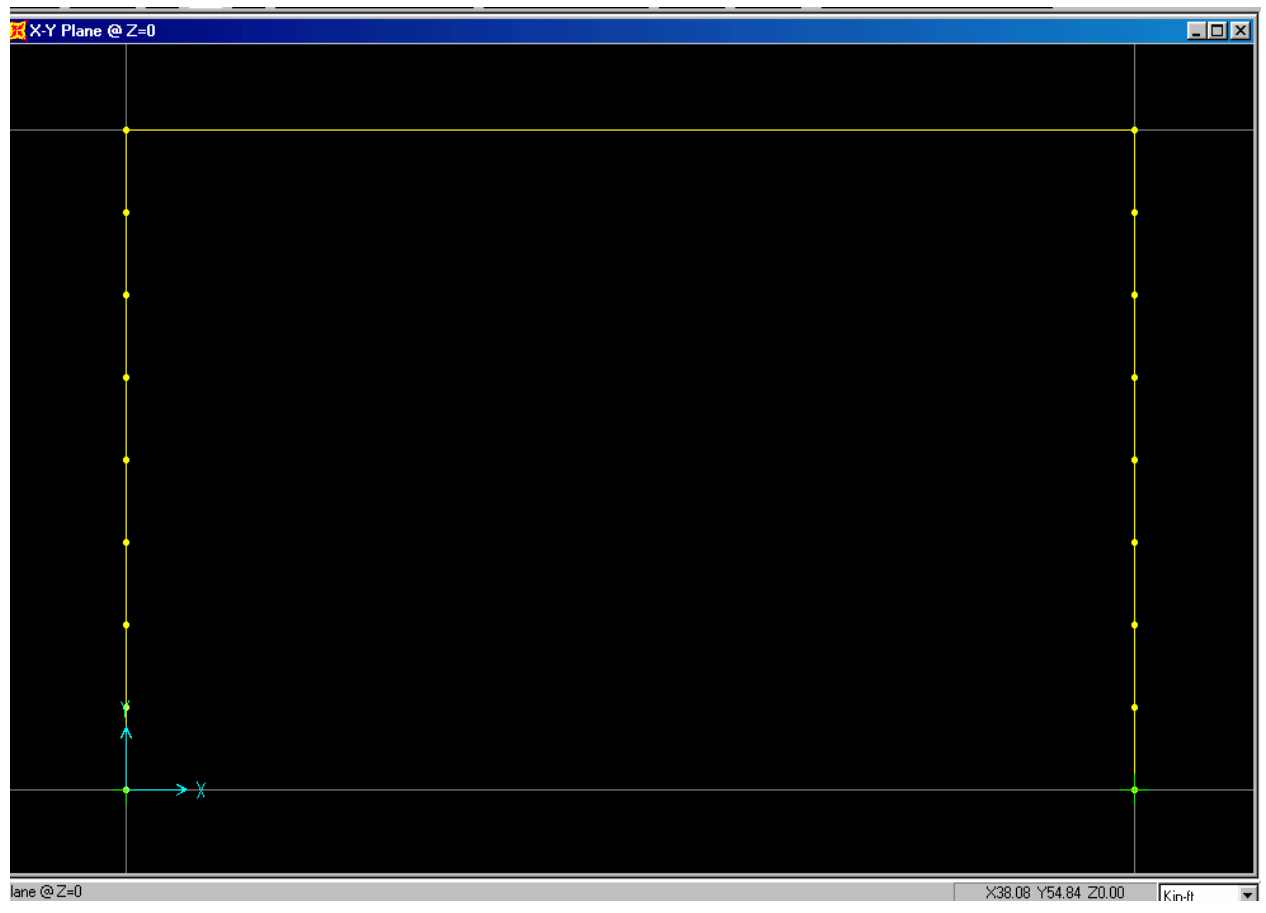

Figure 5-20. SAP2000 frame superstructure lumped mass model 
The analysis results are summarized in Table 5-8. A maximum displacement of $0.0366 \mathrm{ft}$ at top of the frame was calculated using the NEHRP procedure with the 75-ft block AF. The maximum shear force calculated for the right-side column at the base point 3 was 316.37 kips with a maximum moment of 7,926 kip-ft.

\begin{tabular}{|c|c|c|}
\hline \multicolumn{3}{|c|}{$\begin{array}{l}\text { Table 5-8 } \\
\text { Shear Forces and Moments within Frame from an NEHRP-Based, } \\
\text { Amplified Design Response Spectrum }\end{array}$} \\
\hline Point & $\begin{array}{l}\text { Shear } \\
\text { NEHRP } \\
\text { Block AF } \\
\text { kip } \\
\end{array}$ & $\begin{array}{l}\text { Moments } \\
\text { NEHRP } \\
\text { Block AF } \\
\text { kip-ft } \\
\end{array}$ \\
\hline 1 (LHS-Base) & 282.48 & 7,677 \\
\hline 2 (LHS-Crane) & 214.47 & $2,455.99$ \\
\hline 3 (RHS-Base) & 316.37 & $7,926.14$ \\
\hline 4 (RHS-Crane) & 219.42 & $2,938.64$ \\
\hline
\end{tabular}




\section{Summary and Conclusions}

This report summarizes the results of a series time-history analysis of powerhouse substructures conducted in order to develop amplification factor (AF) curves (i.e., AF versus frequency) at the top of the substructure to facilitate a decoupled response spectrum/modal analysis of the superstructure (or equipment). The massive size of the substructure allows for this decoupled dynamic analysis of the superstructure and/or equipment. In this simplified procedure of modal analysis, AF curves are used to transfer the rock response spectra to the top of the substructure for use in the decoupled analysis.

The construction of the amplification curves used in the decoupled response spectra/modal analysis of a superstructure or equipment consisted of three steps:

- For a specified in-rock acceleration time-history, construct a pseudoresponse spectra.

- Construct a finite element model of the substructure only and using SAP2000 compute the top-of-substructure acceleration time-history response.

- Construct the AF versus frequency curve by computing the ratio of the top-of-substructure value for absolute acceleration divided by the in-rock value absolute acceleration for each frequency up to $50 \mathrm{~Hz}$.

Two acceleration time-histories and their corresponding response spectra were developed representing an earthquake event in the central-eastern part of the United States (CEUS) and an event in the Pacific Northwest of the United States (PNW). They were developed synthetically for a seismic hazard exposure period of 1,000 years. The peak ground acceleration at rock for the CEUS earthquake was $0.19 \mathrm{~g}$ with a maximum pseudo-spectral acceleration of $0.49 \mathrm{~g}$ at frequency of $9 \mathrm{~Hz}$ ( 5 percent damping). For the PNW earthquake the maximum acceleration was $0.16 \mathrm{~g}$ with maximum pseudo-spectral acceleration of $0.46 \mathrm{~g}$ at 4 $\mathrm{Hz}$ (5 percent damping).

A "box" model consisting of five structural members idealized the generator bay substructure monoliths. Two shear walls along the upstream/downstream direction, two flexural walls, and a base slab constituted the idealized geometry. Corps generator bay substructures were tabulated, evaluated, and generalized into four groups according to their heights. Four finite element models were created and analyzed using the capabilities of the structural analysis software SAP2000. The analyses were performed considering the normal pool and tailrace water elevations (wet condition) and for the dry condition. 
Two models were created to idealize the erection/service bay substructure. One model consisted of a block finite element model, and the second a blockframe-shear wall model. A block model represents a stiff substructure, and the block-frame-shear wall model represents a more flexible substructure where the inside frames influence the structural system response to earthquake loadings. The erection/service bays were also categorized into four groups according to their heights.

The AF curves at top-of-substructure for each model were calculated using the results from time-history analysis as previously described. For the generator bay models, the wet conditions result in greater AFs than the dry cases for the 125 -ft- and 40 -ft-height models using the CEUS ground motion. The generator bay of group 4 (40-ft height) did not show a significant amplification for the PNW earthquake assuming dry conditions. The maximum AF for the wet condition was found for group 1 (125-ft height) to be a value of 7.3 at a frequency of $8 \mathrm{~Hz}$.

The AF curves were also developed for the block and block-frame-shear wall models of the erection/service bay. The maximum AF for the wet condition of the block models is 6.95 at a frequency of $9.63 \mathrm{~Hz}$ for the PNW ground motion. For the block-frame-shear wall models, the maximum AF is 8.18 at a frequency of $8.5 \mathrm{~Hz}$ for the CEUS ground motion. 


\section{References}

Abrahamson, N. A. (1998). "Non-stationary spectral matching program RSPMATCH," Internal Report, Pacific Gas and Electric, San Francisco, CA.

American Society of Civil Engineers. (2002). "Minimum design loads for buildings and other structures," ASCE 7-02, Reston, VA.

Boore, D. (2000). "SMSIM - FORTRAN programs for simulating ground motions from earthquakes: Version 2.0 - A revision of OFR 96-80-A," U.S. Geological Survey Open-File Report OF 00-509, U.S. Geological Survey, Denver, CO, 55 p. http://geopubs.wr.usgs.gov/open-file/ of00-509/index.html

Chopra, A. K. (1995). Dynamic of structures: Theory and applications to earthquake engineering. Prentice-Hall, Englewood Cliffs, NJ.

Computers and Structures, Inc. (1997). SAP2000: Integrated finite element analysis and design of structures. Volume 1, Berkeley, CA.

Cook, R. D., Malkus, D. S., Plesha, M. E., and Witt, R. J. (2002). Concepts and application of finite element analysis. John Wiley, New York.

Ebeling, R. M. (1992). "Introduction to the computation of response spectrum for earthquake loading," Technical Report ITL-92-4, U.S. Army Engineer Waterways Experiment Station, Vicksburg, MS.

Ebeling, R. M., and Morrison, E. E. (1992). "The seismic design of waterfront retaining structures," Technical Report ITL-92-11, NCEL TR-939, U.S. Army Engineer Waterways Experiment Station, Vicksburg, MS.

Ebeling, R. M., Hall, R. L., Strom, R. W., Yule, D. E., and Chowdhury, M. (2002). "Seismic stability of St. Stephen Hydropower Plant, South Carolina," Letter Report ERDC LR-02-1, U.S. Army Engineer Research and Development Center, Vicksburg, MS.

Federal Emergency Management Agency. (1997). "NEHRP recommended provisions for seismic regulations for new buildings and other structures; Part 1-Provisions (FEMA 302)," 1997 ed., Prepared for the Federal Emergency Management Agency by the Building Seismic Safety Council, Washington, D.C. 
Federal Emergency Management Agency. (2000). "Prestandard and commentary for the seismic rehabilitation of buildings," FEMA 356-357, prepared by American Society of Civil Engineers, Reston, VA, for Federal Emergency Management Agency, Washington, D.C.

. (2001). "NEHRP recommended provisions for seismic regulations for new buildings and other structures; Part 1-Provisions (FEMA 368)," 2000 ed., Prepared for the Federal Emergency Management Agency by the Building Seismic Safety Council, Washington, D.C.

Frankel, A., Mueller, D., Barnhard, T., Perkins, D., Leyendecker, E., Dickman, N., Hanson, S., and Hopper, M. (1996). "National seismic-hazard maps: documentation June 1996," U.S. Geological Survey, Open-file Report 96532, U.S. Geological Survey, Denver, CO, 110 pp. http://earthquake.usgs.gov/hazmaps/

Frankel, A. D., Mueller, C. S., Barnhard, T. P., Leyendecker, E. V., Wesson, R. L., Harmsen, S. C., Klein, F. W., Perkins, D. M., Dickman, N. C., Hanson, S. L., and Hopper, M. G. (2000). "Earthquake spectra," Professional Journal of the Earthquake Engineering Research Institute, 16(1).

Frankel, A. D., Petersen, M. D., Mueller, C. S., Haller, K. M., Wheeler, R. L., Leyendecker, E. V., Wesson, R. L., Harmsen, S. C., Cramer, C. H., Perkin, D. M., and Rukstales, K. S. (2002). "Documentation for the 2002 Update of the National Seismic Hazard Maps," U.S. Geological Survey, Open-file Report 02-420; U.S. Geological Survey, Denver, CO. http://pubs.usgs.gov/of/2002/ofr-02-420/

Headquarters, U.S. Army Corps of Engineers. (1993). "Seismic design provisions for RCC dams," Engineer Technical Letter 1110-2-8025, Washington, DC.

Headquarters, U.S. Army Corps of Engineers. (1995a). "Seismic analysis and design of reinforced concrete locks," Engineer Technical Letter 1110-2-342, Washington, DC. Rescinded by EC 25-1-273, 15 December 1998.

Headquarters, U.S. Army Corps of Engineers. (1995b). "Seismic design provisions for roller compacted concrete dams," Engineer Pamphlet 1110-212, Washington, DC.

Headquarters, U.S. Army Corps of Engineers. (2003). "Time-history dynamic analysis of concrete hydraulic structures," Engineer Manual No. 1110-26051, Washington, DC.

Lilhanand, K., and Tseng, W. S. (1988). "Development and application of realistic earthquake time histories compatible with multiple damping design spectra." Proceedings of Ninth World Conference on Earthquake Engineering, August [2-9], 1988, Tokyo-Kyoto, Japan. Vol. II, 819-824.

U.S. Geological Survey. (2002). "Interpolated probabilistic ground motion for the conterminus 48 states by latitude-longitude," http://earthquake.usgs.gov/research/hazmaps/design/ 
Waterloo Maple Inc. (2002). “Maple 7 Learning Guide,” Waterloo, Ontario, Canada.

Westergaard, H. M. (1993). "Water pressures on dams during earthquakes," Transactions of ASCE, 98, 418-472. 


\section{Appendix A}

\section{Summary of Generator and Erection/Service Bay Monolith Geometry}

Fifty-four Corps powerhouse plants were reviewed in this study. The generator bay and erection bay monolith cross sections were evaluated and categorized into one of four groups according to height of substructure. Table A-1 lists a summary of the heights considered and the height assigned to each of the four generator and four erection/service bay groups. Table A-2 presents a list sorted by height of the generator bay substructures and their respective widths. Table A-3 presents a list sorted by height of the erection/service bay substructure and their dimensions.

\begin{tabular}{|c|c|c|c|c|}
\hline \multicolumn{5}{|c|}{$\begin{array}{l}\text { Table A-1 } \\
\text { Summary of Heights Considered for Each Generator and } \\
\text { Erection/Service Bay Group }\end{array}$} \\
\hline \multirow[b]{3}{*}{ Group Number } & \multicolumn{4}{|c|}{ Generator Bay } \\
\hline & \multicolumn{3}{|c|}{ Height $H$} & \multirow{2}{*}{$\begin{array}{l}\text { Number of } \\
\text { Hydropower } \\
\text { Plants }\end{array}$} \\
\hline & $\begin{array}{l}\text { Maximum } \\
\mathrm{ft}\end{array}$ & $\begin{array}{l}\text { Minimum } \\
\mathrm{ft}\end{array}$ & $\begin{array}{l}\text { Assigned } \\
\mathrm{ft}\end{array}$ & \\
\hline 1 & 135 & 115 & $\overline{125}$ & 20 \\
\hline 2 & 115 & 85 & 100 & 19 \\
\hline 3 & 85 & 55 & 70 & 19 \\
\hline \multirow[t]{4}{*}{4} & 55 & & 40 & 11 \\
\hline & \multicolumn{4}{|c|}{ Erection/Service Bay } \\
\hline & \multicolumn{3}{|c|}{ Height $H$} & \multirow{2}{*}{$\begin{array}{l}\text { Number of } \\
\text { Hydropower } \\
\text { Plants }^{1}\end{array}$} \\
\hline & $\begin{array}{l}\text { Maximum } \\
\mathrm{ft}\end{array}$ & $\begin{array}{l}\text { Minimum } \\
\mathrm{ft}\end{array}$ & $\begin{array}{l}\text { Assigned } \\
\mathrm{ft}\end{array}$ & \\
\hline 1 & $\overline{c 135}$ & 91 & $\overline{1110}$ & 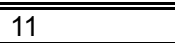 \\
\hline 2 & 90 & 60 & 75 & 13 \\
\hline 3 & 55 & 30 & 45 & 19 \\
\hline 4 & 29 & - & 20 & 7 \\
\hline
\end{tabular}




\begin{tabular}{|c|c|c|c|c|}
\hline \multicolumn{5}{|c|}{$\begin{array}{l}\text { Table A-2 } \\
\text { Powerhouses Sorted by Generator Bay Heights }\end{array}$} \\
\hline \multirow[b]{2}{*}{$\begin{array}{l}\text { Group } \\
\text { Number }\end{array}$} & \multicolumn{4}{|c|}{$\begin{array}{ll} & \text { Generator Bay } \\
\end{array}$} \\
\hline & Project & $\begin{array}{l}\text { Height } \\
H \\
\mathrm{ft}\end{array}$ & $\begin{array}{l}\text { Upstream/Downstream } \\
\text { Width } W \\
\text { ft }\end{array}$ & $\begin{array}{l}\text { Plan Width } \\
\text { B } \\
\text { ft }\end{array}$ \\
\hline \multirow{5}{*}{$\begin{array}{l}\text { 음 } \\
\text { ở }\end{array}$} & John Day & 135 & 145 & 90 \\
\hline & Bonneville II & 130 & 130 & 94 \\
\hline & Millers Ferry & 120 & 164 & 80 \\
\hline & Big Bend & 120 & 140 & 86 \\
\hline & Gavins Point & 118 & 120 & 80 \\
\hline \multirow{19}{*}{$\begin{array}{l}\text { N } \\
\text { o } \\
\text { ơ } \\
\text { Uे }\end{array}$} & Bonneville I & 113 & 134 & 62 \\
\hline & Dardanelle & 110 & 123 & 80 \\
\hline & Carters & 108 & 115 & 63 \\
\hline & Barkley & 108 & 150 & 86 \\
\hline & Cordell Hull & 106 & 184 & 86 \\
\hline & The Dalles & 106 & 124 & 86 \\
\hline & Ice Harbor & 105 & 138 & 86 \\
\hline & Richard B. Russell & 100 & 115 & 71 \\
\hline & Walter F. George & 100 & 118 & 67 \\
\hline & Robert F. Henry & 100 & 146 & 73 \\
\hline & Cheatham & 100 & 169 & 82 \\
\hline & Garrison & 96 & 111 & 75 \\
\hline & Harry S. Truman & 96 & 156 & 55 \\
\hline & Fort Randall & 95 & 102 & 70 \\
\hline & West Point & 90 & 117 & 77 \\
\hline & Jim Woodruff & 90 & 124 & 67 \\
\hline & Chief Joseph & 90 & 102 & 70 \\
\hline & Oahe & 90 & 122 & 76 \\
\hline & Sam Rayburn & 90 & 123 & 55 \\
\hline \multirow{19}{*}{ 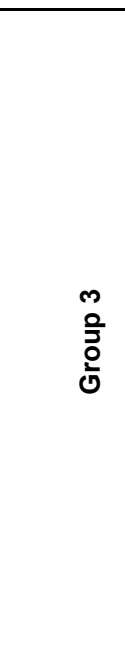 } & Allatoona & 75 & 124 & 54 \\
\hline & J. Strom Thurmond & 70 & 93 & 62 \\
\hline & Big Cliff & 70 & 72 & 40 \\
\hline & Laurel & 70 & 128 & 78 \\
\hline & Center Hill & 70 & 137 & 58 \\
\hline & Greers Ferry & 70 & 90 & 56 \\
\hline & Table Rock & 70 & 131 & 54 \\
\hline & Ozark & 69 & 206 & 65 \\
\hline & Lookout Point & 68 & 95 & 60 \\
\hline & Webbers Falls & 67 & 206 & 70 \\
\hline & Fort Peck & 65 & 85 & 60 \\
\hline & Wolf Creek & 65 & 137 & 58 \\
\hline & J. Percy Priest & 65 & 107 & 80 \\
\hline & John S. Kerr & 63 & 73 & 70 \\
\hline & Dale Hollow & 62 & 115 & 42 \\
\hline & Dexter & 60 & 93 & 90 \\
\hline & Sault Ste. Marie & 60 & 74 & 54 \\
\hline & Beaver & 60 & 94 & 61 \\
\hline & Blakely Mountain & 60 & 66 & 56 \\
\hline \multirow{11}{*}{$\begin{array}{l}+ \\
\text { 음 } \\
\text { ํํ }\end{array}$} & Buford & $54 / 64$ & 110 & 62 \\
\hline & Fort Gibson & 55 & 80 & 53 \\
\hline & Whitney & 55 & 90 & 46 \\
\hline & Bull Shoals & 53 & 79 & 54 \\
\hline & Broken Bow & 52 & 104 & 53 \\
\hline & Norfork & 47 & 58 & 54 \\
\hline & Hills Creek & 45 & 55 & 42.52 \\
\hline & Sault Ste. Marie (old) & 40 & 50 & 49 \\
\hline & Foster & 35 & 43 & 40 \\
\hline & Philpott & 25 & 40 & 38 \\
\hline & Cougar & 25 & 47 & 34 \\
\hline
\end{tabular}




\begin{tabular}{|c|c|c|c|c|}
\hline \multicolumn{5}{|c|}{$\begin{array}{l}\text { Table A-3 } \\
\text { Powerhouses Sorted by Erection/Service Bay Heights }\end{array}$} \\
\hline \multirow[b]{2}{*}{$\begin{array}{l}\text { Group } \\
\text { Number }\end{array}$} & \multicolumn{4}{|c|}{\begin{tabular}{|l} 
Erection or Service Bay \\
\end{tabular}} \\
\hline & Project & \begin{tabular}{|l|} 
Height \\
$\mathrm{ft}$
\end{tabular} & $\begin{array}{l}\text { Upstream/Downstream } \\
\text { Width, ft }\end{array}$ & $\begin{array}{l}\text { Plan Width } \\
\mathrm{ft}\end{array}$ \\
\hline \multirow{11}{*}{$\begin{array}{l}\overline{0} \\
\text { 음 } \\
\text { ò }\end{array}$} & Ozark & - & -4 & 65 \\
\hline & Sault Ste. Marie & - & 74 & 54 \\
\hline & Beaver & - & 68 & 65 \\
\hline & Fort Gibson & - & - & 57 \\
\hline & Bonneville II & 135 & 150 & 149 \\
\hline & Millers Ferry & 120 & 164 & 80 \\
\hline & Bonneville I & 113 & 134 & 45 \\
\hline & Barkley & 108 & 150 & 86 \\
\hline & John Day & 100 & 145 & $79 / 90$ \\
\hline & The Dalles & 100 & 124 & 86 \\
\hline & Garrison & 91 & 111 & 75 \\
\hline \multirow{13}{*}{ 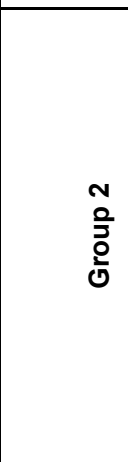 } & West Point & 90 & 117 & 90 \\
\hline & \begin{tabular}{|l} 
Jim Woodruff \\
\end{tabular} & 90 & 119 & 42 \\
\hline & Sam Rayburn & 90 & 123 & 45 \\
\hline & Robert F. Henry & 85 & 146 & 50 \\
\hline & Cordell Hull & 80 & 163 & 43 \\
\hline & Big Bend & 75 & 140 & 86 \\
\hline & Carters & 65 & 115 & 75 \\
\hline & Fort Peck & 65 & 85 & 60 \\
\hline & Dardanelle & 64 & 125 & 74 \\
\hline & Walter F. George & 63 & 118 & 55 \\
\hline & Cheatham & 62 & 147 & 60 \\
\hline & Greers Ferry & 60 & 90 & 63 \\
\hline & John S. Kerr & 60 & 73 & 69 \\
\hline \multirow{19}{*}{ 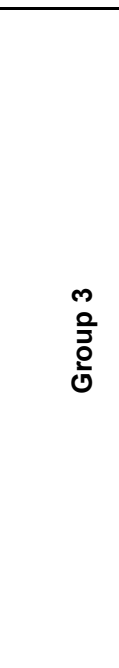 } & Richard B. Russell & 55 & 128 & 100 \\
\hline & Chief Joseph & 55 & 148 & 73 \\
\hline & Allatoona & 50 & 110 & 54 \\
\hline & Center Hill & 50 & 137 & 64 \\
\hline & Oahe & 47 & 97 & 76 \\
\hline & \begin{tabular}{|l|} 
Norfork \\
\end{tabular} & 47 & 58 & 54 \\
\hline & Table Rock & 46 & 114 & 68 \\
\hline & Buford & 45 & 110 & 43 \\
\hline & Wolf Creek & 45 & 137 & 66 \\
\hline & Dale Hollow & 45 & 115 & 68 \\
\hline & Bull Shoals & 45 & 79 & 48 \\
\hline & Ice Harbor & 44 & 146 & 83 \\
\hline & Whitney & 44 & 90 & 48 \\
\hline & Gavins Point & 42 & 120 & 92 \\
\hline & \begin{tabular}{|l} 
Lookout Point \\
\end{tabular} & 41 & 102 & 60 \\
\hline & Sault Ste. Marie (old) & 40 & 50 & 49 \\
\hline & Blakely Mountain & 36 & 66 & 56 \\
\hline & Fort Randall & 34 & 102 & 70 \\
\hline & Harry S. Truman & 30 & 156 & 77 \\
\hline \multirow{11}{*}{$\begin{array}{l}+ \\
\stackrel{0}{3} \\
\text { ò } \\
\text { U̦ }\end{array}$} & Broken Bow & 29 & 94 & 49 \\
\hline & Big Cliff & 25(approx) & 72 & 40 \\
\hline & Philpott & 25 & 40 & 20 \\
\hline & Hills Creek & 20 & 55 & 39 \\
\hline & Foster & 0 & 39 & 40 \\
\hline & Cougar & 0 & 47 & 47 \\
\hline & \begin{tabular}{|l|} 
J. Strom Thurmond \\
\end{tabular} & & None & \\
\hline & Laurel & & None & \\
\hline & Webbers Falls & & None & \\
\hline & \begin{tabular}{|l} 
J. Percy Priest \\
\end{tabular} & & None & \\
\hline & Dexter & & None & \\
\hline
\end{tabular}




\section{Appendix B Equivalent Flexural Wall in Generator Bay Idealized Geometry}

The model to idealize the generator bay substructure consisted of a composite model in two dimensions of five structural features that form a box as shown in Figure B-1a. Figure B-1b shows a three-dimensional view of the construction of the two-dimensional composite model used in the finite element analyses. Shear Wall 2 was superimposed on shear Wall 1 to have both in the same plane. The open space in the center of the box (Figure B-1a) represents the location of the turbine.

The flexural walls are identified by Wall 4 facing the upstream side and Wall 5 facing the downstream side. The real generator bay substructure upstream walls have the geometry shown in the left side of Figure B-2. To simplify the model, the two walls that form the channel to the water intake at the upstream face were converted to an equivalent rectangular flexural wall (Wall 4). Applying the Parallel Axis Theorem, the inertia of the real geometry was calculated at the center of the generator bay, and an equivalent flexural wall area was calculated using the actual (real) wall inertia. Table B-1 lists a summary of the structural features dimensions for the generator bay substructure model for Groups 1 and 2 . In this appendix, the equivalent inertia calculations are presented as written in Maple 6 code. 


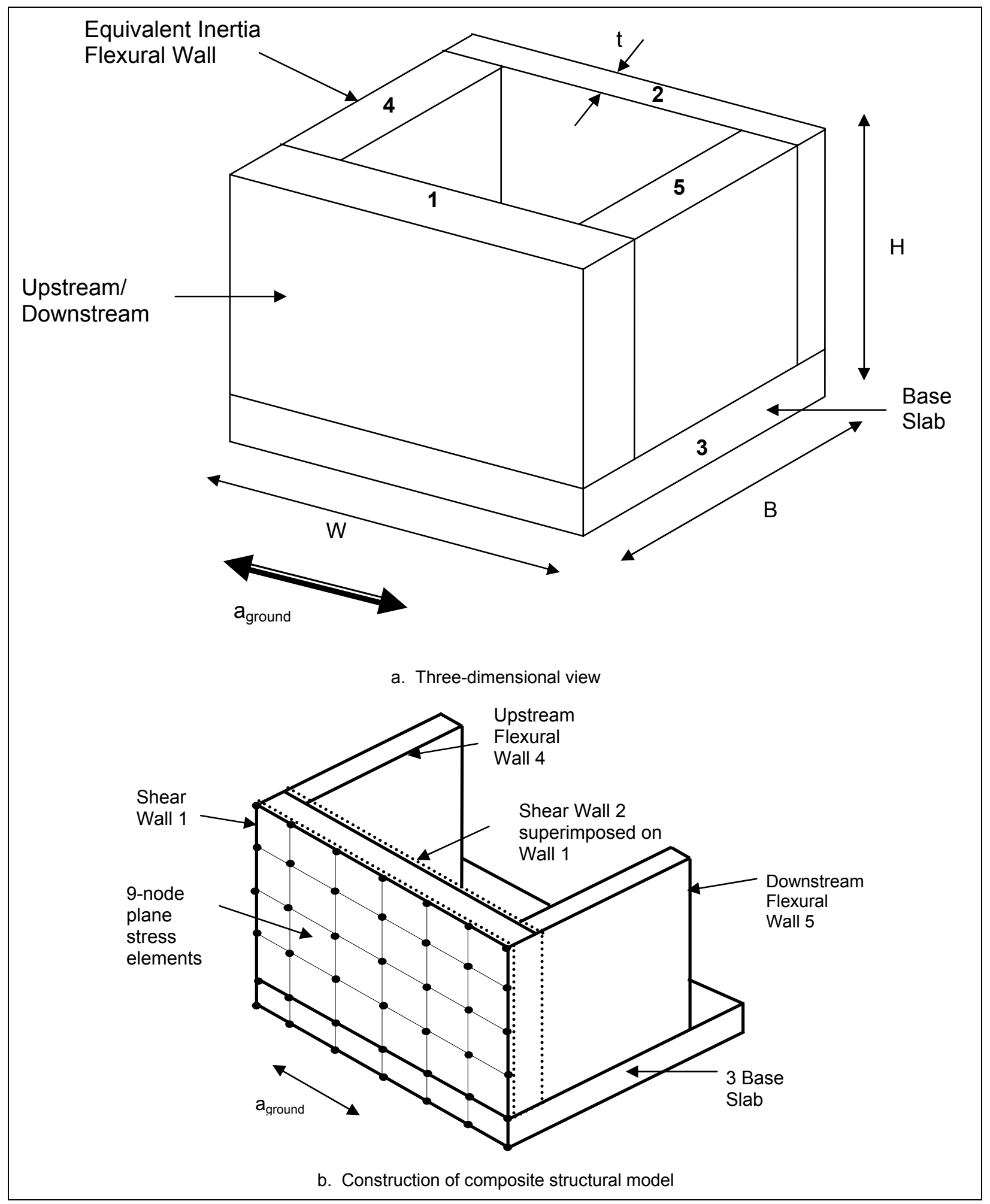

Figure B-1. Three-dimensional view of the idealized composite structural model for generator bay substructure idealization 


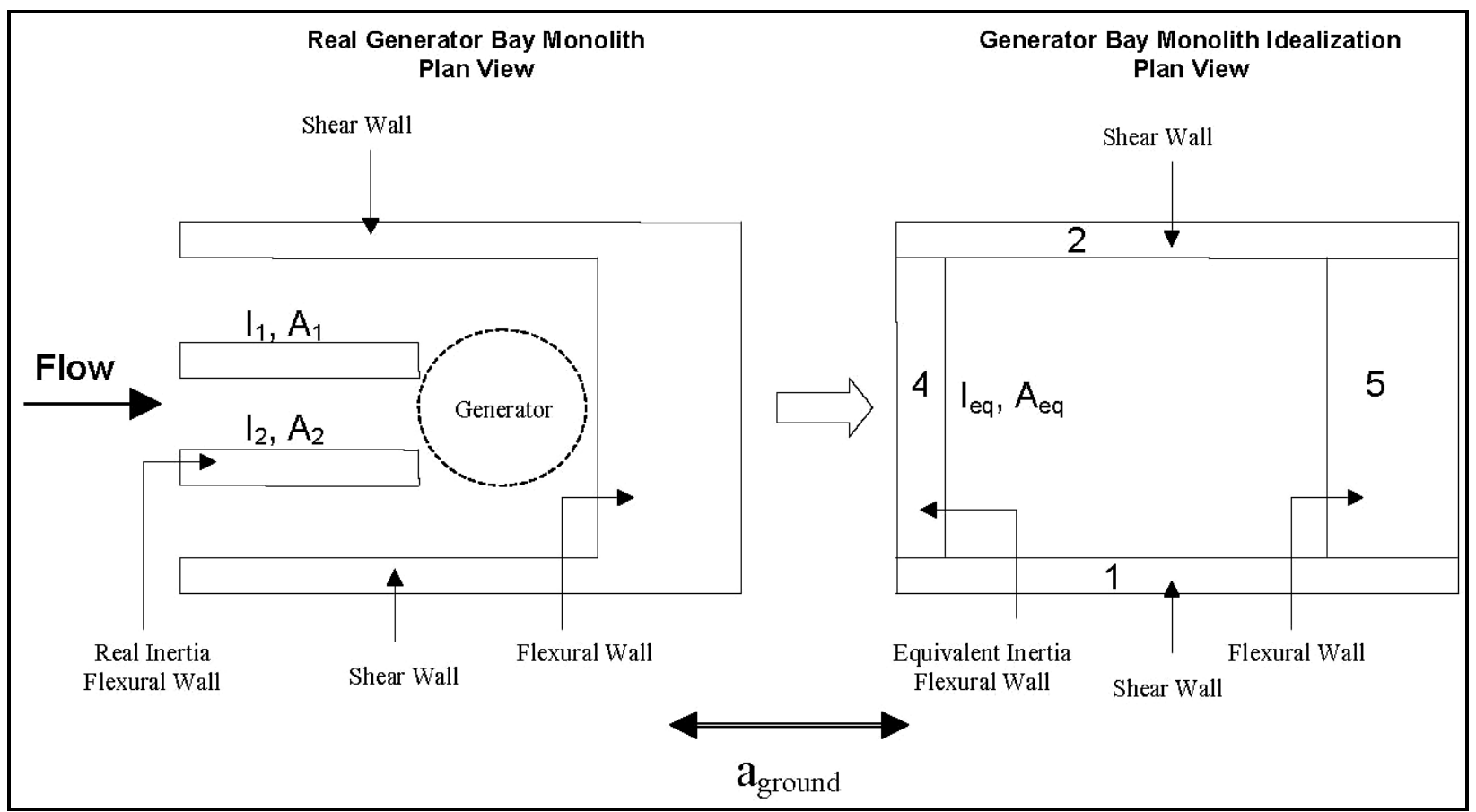

Figure B-2. Plan view of the real generator bay channel walls and its conversion to equivalent inertia flexural wall 


\begin{tabular}{|c|c|c|c|c|c|c|c|c|c|}
\hline \multicolumn{10}{|l|}{$\begin{array}{l}\text { Table B-1 } \\
\text { Summary }\end{array}$} \\
\hline Powerhouse & $\begin{array}{l}\text { Wall } 1 \\
\mathrm{ft}\end{array}$ & $\begin{array}{l}\text { Wall } 2 \\
\mathrm{ft}\end{array}$ & $\begin{array}{l}\text { Base } 3 \\
\mathrm{ft}\end{array}$ & \begin{tabular}{|l|} 
Wall 4 \\
Real \\
$\mathrm{ft}$
\end{tabular} & $\begin{array}{l}\text { Wall } 4 \\
\text { Ideal } \\
\mathrm{ft}\end{array}$ & \begin{tabular}{|l|} 
Wall 5 \\
Real \\
$\mathrm{ft}$
\end{tabular} & \begin{tabular}{|l|} 
Wall 5 \\
Ideal \\
$\mathrm{ft}$
\end{tabular} & $\begin{array}{l}\text { Pool } \Delta \mathrm{H}^{1} \\
\mathrm{ft}\end{array}$ & $\underset{\mathrm{ft}}{\text { Tail } \Delta \mathrm{H}^{1}}$ \\
\hline \multicolumn{10}{|c|}{ Group 1 (Height = $125 \mathrm{ft}$, Width = $135 \mathrm{ft}$, Plan Width = $85 \mathrm{ft}$ ) } \\
\hline \multicolumn{10}{|l|}{ John Day } \\
\hline \multicolumn{10}{|l|}{ Bonneville II } \\
\hline Millers Ferry & 15 & 15 & 10 & (2) $7 \times 53$ & 6 & (2) $6 \times 57$ & 7 & 2 & -35 \\
\hline Big Bend & 12 & 15 & 17 & (2) $7 \times 72$ & 14 & (2) $5 \times 57$ & 8 & 37 & -32 \\
\hline Gavins Point & 13 & 12 & 10 & (2) $7 \times 60$ & 10 & (2) $7 \times 55$ & 8 & 13 & -33.6 \\
\hline \multicolumn{10}{|c|}{ Group 2 (Height = $100 \mathrm{ft}$, Width = $130 \mathrm{ft}$, Plan Width = $75 \mathrm{ft}$ ) } \\
\hline Bonneville I & 25 & 8 & 16 & & & & & 17 & -15 \\
\hline Dardanelle & 12 & 12 & 10 & (2) $8 \times 50$ & 8 & (2) $8 \times 48$ & 7 & 9 & -20 \\
\hline \multicolumn{10}{|l|}{ Carters } \\
\hline Barkley & 12 & 12 & 9 & (2) $7 \times 52$ & 7 & (2) $6 \times 50$ & 5 & & \\
\hline Cordell Hull & 15 & 12 & 10 & (2) $7 \times 50$ & 9 & (2) $7 \times 54$ & 8 & 13 & -34 \\
\hline \multicolumn{10}{|l|}{ The Dalles } \\
\hline Ice Harbor & & & & & & & & 80.75 & -14.25 \\
\hline \multicolumn{10}{|l|}{ Richard B. Russell } \\
\hline Walter F. George & 13 & 12 & 9 & & & & & 45.5 & 19 \\
\hline Robert F. Henry & 10 & 13 & 16 & & & & & 4 & \\
\hline Cheatham & 15 & 12 & 10 & (2) $7 \times 50$ & 9 & (2) $6 \times 57$ & 7 & -12 & -36 \\
\hline Garrison & 10 & 15 & 15 & & & (2) $6 \times 45$ & 5 & & \\
\hline \multicolumn{10}{|l|}{ Harry S. Truman } \\
\hline Fort Randall & 15 & 17 & 10 & & & & & & \\
\hline West Point & 14 & 12 & 14 & (2) $5 \times 58$ & 7 & (2) $5 \times 58$ & 7 & 38 & -25 \\
\hline Jim Woodruff & 12 & 12 & 6 & (1) $6 \times 36$ & 2 & (1) $5 \times 50$ & 1 & -3 & -36 \\
\hline \multicolumn{10}{|l|}{ Chief Joseph } \\
\hline Oahe & 15 & 15 & 11 & & & & & & \\
\hline Sam Rayburn & & & & & & & & & \\
\hline
\end{tabular}

Maple 6 Example of Calculations

$>$ restart:

************************************************************

Calculation of equivalent moment of inertia of flexural Wall 4 for generator idealization.

*******************June $30,2004 * * * * * * * * * * * * * * * * * * * * * * * * *$

Inertia for actual geometry

Input

bact : $=8$ :

hact : $=48$ :

dact: $=55$ :

Actual moment of inertia

Iact $:=2 *\left(\left(\left(\right.\right.\right.$ bact*hact^3) /12) $+($ bact*hact $\left.) * \operatorname{dact}^{\wedge} 2\right)$; 
Inertia for flexural wall idealization

Input

$\mathrm{W}:=135$ :

bw: $=85:$

Ifw: $=\left(\left(b w^{\star} h w^{\wedge} 3\right) / 3\right)-$

$\left(\left(w^{\star} b w^{\star} h w^{\wedge} 2\right) / 2\right)+\left(\left(b w^{*} h w^{*} W^{\wedge} 2\right) / 4\right)=$ Iact:

Solve for hw:

$h w:=$ solve ( Ifw, hw) ;

$$
\mathrm{hw}:=7.1000
$$




\section{Appendix C Investigation of Plane Stress and Plane Strain Modal Time- History Analyses of a Monolith Using SAP2000 Linear Elastic Finite Elements}

A dynamic time-history structural analysis was performed of the generator bay and erection/service bay substructure finite element models in order to calculate the top-of-substructure acceleration time-history and then the pseudospectral acceleration curve. The analytical model and the dynamic earthquake analyses were performed using the structural analysis software SAP2000 (Computers and Structures, Inc., $1997^{1}$ ). The analytical model represents the geometry and material properties of the idealized powerhouse substructures. Parametric analyses were carried out to determine the type of finite elements to be used in the study.

The response of elements to applied loads or displacements will depend on the material constitutive properties. The constitutive properties relate the stresses to strains as shown in Equation C-1:

$$
\{\sigma\}=[C]\{\varepsilon\}
$$

where $\{\sigma\}$ is the stresses vector, $\{\varepsilon\}$ is the strains vector, and $[C]$ is the constitutive matrix. Equations $\mathrm{C}-2$ and $\mathrm{C}-3$ list the constitutive matrix for twodimensional (2-D) plane stress elements and for 2-D plane strain elements, respectively. For linear elastic structural analysis, it is typically assumed that the material constitutive matrix $[C]$ doesn't change with load.

\footnotetext{
1 References cited in this appendix are included in the References section at the end of the main
} text. 


$$
\begin{aligned}
& {[C]=\frac{E}{1-v^{2}}\left[\begin{array}{ccc}
1 & v & 0 \\
v & 1 & 0 \\
0 & 0 & \frac{(1-v)}{2}
\end{array}\right]} \\
& {[C]=\frac{E}{(1+v)(1-2 v)}\left[\begin{array}{ccc}
1-v & v & 0 \\
v & 1-v & 0 \\
0 & 0 & \frac{(1-2 v)}{2}
\end{array}\right]}
\end{aligned}
$$

where $E$ is the elastic modulus and $v$ is Poisson's ratio.

Two types of plane elements are available in SAP2000 to conduct a planar analysis: plane stress elements or plane strain elements. When plane stress elements are used, it is assumed that the stresses out of plane to the element are zero $\left(\sigma_{z}=0\right)$; but out-of-plane deformations will occur. With the plane strain elements, the out-of-plane deformations are zero $\left(\varepsilon_{\mathrm{z}}=0\right)$, and out-of-plane stresses are nonzero.

Monoliths of concrete gravity dams are constructed with construction joints between them, allowing out-of-plane deformations. Plane stress elements are recommended in this situation (HQUSACE 2003). A similar construction process is applied to powerhouse monoliths, so it is logical to make a similar modeling assumption.

In SAP2000 structural analysis software, different numbers of nodes can be assigned to planar finite elements. The number of nodes will define the total degrees of freedom for an element. In this parametric study, plane stress and plane strain elements with four and nine nodes and shell elements were compared. The 110-ft-height erection/service bay block model was used. The first mode period, the number of modes that must be included based on participating mass ratio (PMR) considerations, and the peak acceleration at top of the substructure were all compared. The investigation was performed using the centraleastern United States (CEUS) and the Pacific Northwest of the United States (PNW) acceleration time-histories.

Table C-1 lists the first mode periods and frequencies, highest periods and frequencies, the number of modes included, and the resulting PMR for the different elements considered in this study for the 110-ft-height erection/service bay block model. Significant differences in the model dynamic properties were not found between the types of elements. The first mode period for the stress and shell elements were $0.091 \mathrm{sec}$ and for the strain elements $0.090 \mathrm{sec}$ for a percent difference of 1.09. There was no significant difference in the first mode periods for the four-node and nine-node elements for the same type of planar element (i.e., stress or strain). Tables C-2 and C-3 list the top-of-substructure total and relative peak acceleration for the CEUS and PNW ground motions, respectively. No significant differences were found between the plane strain and plane stress elements given the same number of nodes. In addition, no significant difference 
was observed between plane stress (or plane strain) when the number of nodes was increased for each element. Note that these observations will be dependent on the discretization of the fine mesh, as reflected by a large number of vertical layers of elements in the mesh.

\begin{tabular}{|c|c|c|c|c|c|c|c|c|}
\hline \multicolumn{9}{|c|}{$\begin{array}{l}\text { Table C-1 } \\
\text { Periods and Frequencies Found for Different Types of Elements for 110-ft-Height } \\
\text { Erection/Service Substructure Model }\end{array}$} \\
\hline \multirow[b]{2}{*}{ Model ID } & \multirow{2}{*}{\begin{tabular}{|l|} 
Vertical No. \\
of Layers \\
of \\
Elements in \\
Mesh \\
\end{tabular}} & \multirow{2}{*}{$\begin{array}{l}\text { Element } \\
\text { Type }\end{array}$} & \multirow[b]{2}{*}{ Modes $i$} & \multirow[b]{2}{*}{ PMR, \% } & \multicolumn{2}{|c|}{\begin{tabular}{|c|} 
Period, sec \\
\end{tabular}} & \multicolumn{2}{|c|}{ Frequency, $\mathrm{Hz}$} \\
\hline & & & & & $T_{1}$ & $T_{i}$ & $f_{1}$ & $f_{i}$ \\
\hline 4ShErD110B5 & 4 & Shell & 4 & 93.2 & 0.0917 & 0.0298 & 10.91 & 33.47 \\
\hline 8ShErD110B5 & 8 & Shell & 6 & 92.2 & 0.0914 & 0.0216 & 10.94 & 46.22 \\
\hline 4S4ErD110B5 & 4 & Q4 Stress & 4 & 93.3 & 0.0910 & 0.0289 & 10.98 & 34.6 \\
\hline 8S4ErD110B5 & 8 & Q4 Stress & 6 & 92.4 & 0.0912 & 0.0216 & 10.96 & 46.30 \\
\hline 16S4ErD110B5 & 16 & Q4 Stress & 6 & 90.3 & 0.0914 & 0.0215 & 10.94 & 46.59 \\
\hline 4S9ErD110B5 & 4 & Q9 Stress & 6 & 93.2 & 0.0914 & 0.0214 & 10.94 & 46.75 \\
\hline 8S9ErD110B5 & 8 & Q9 Stress & 8 & 93.3 & 0.0915 & 0.0155 & 10.93 & 64.43 \\
\hline 4N4ErD110B5 & 4 & Q4 Strain & 4 & 93.4 & 0.0898 & 0.0284 & 11.13 & 35.22 \\
\hline 8N4ErD110B5 & 8 & Q4 Strain & 6 & 92.5 & 0.0901 & 0.0215 & 11.10 & 46.49 \\
\hline 16N4ErD110B5 & 16 & Q4 Strain & 6 & 90.5 & 0.0903 & 0.0214 & 11.08 & 46.77 \\
\hline 4N9ErD110B5 & 4 & Q9 Strain & 6 & 91.8 & 0.0903 & 0.0213 & 11.08 & 46.77 \\
\hline 8N9ErD110B5 & 8 & Q9 Strain & 8 & 93.4 & 0.0904 & 0.0153 & 11.07 & 65.12 \\
\hline
\end{tabular}




\begin{tabular}{|c|c|c|c|c|c|c|}
\hline $\begin{array}{l}\text { Table C-2 } \\
\text { Absolute an } \\
\text { Erection/Se } \\
\text { Ground Mot }\end{array}$ & $\begin{array}{l}\text { Relative Pea } \\
\text { :e Bay Bloc }\end{array}$ & $\begin{array}{l}\text { Acceleratio } \\
\text { Model Usin }\end{array}$ & $\begin{array}{l}\text { at Tr } \\
\text { Diffe }\end{array}$ & $\begin{array}{l}\text { Ibstructu } \\
\text { pes of Fir }\end{array}$ & $\begin{array}{l}\text { for } 1 \\
\text { Ele }\end{array}$ & $\begin{array}{l}\text { ight } \\
\text { or CEUS }\end{array}$ \\
\hline & $\begin{array}{l}\begin{array}{l}\text { Vertical No. of } \\
\text { Layers of }\end{array} \\
\end{array}$ & & & $\begin{array}{l}\text { Acceleration } \\
\mathrm{g}\end{array}$ & & $\begin{array}{l}\text { k Acceleration } \\
\mathrm{g}\end{array}$ \\
\hline Model ID & $\begin{array}{l}\text { Elements in } \\
\text { Mesh }\end{array}$ & Element Type & $(+)$ & $(-)$ & $(+)$ & $(-)$ \\
\hline 4ShErD110B5 & 4 & Shell & 0.44 & -0.54 & 0.44 & -0.52 \\
\hline 8ShErD110B5 & 8 & Shell & 0.46 & -0.56 & 0.46 & -0.53 \\
\hline 4S4ErD110B5 & 4 & Q4 Stress & 0.44 & -0.54 & 0.44 & -0.51 \\
\hline 8S4ErD110B5 & 8 & Q4 Stress & 0.46 & -0.55 & 0.45 & -0.53 \\
\hline 16S4ErD110B5 & 16 & Q4 Stress & 0.46 & -0.56 & 0.46 & -0.54 \\
\hline 4S9ErD110B5 & 4 & Q9 Stress & 0.46 & -0.56 & 0.46 & -0.54 \\
\hline 8S9ErD110B5 & 8 & Q9 Stress & 0.46 & -0.56 & 0.46 & -0.54 \\
\hline 4N4ErD110B5 & 4 & Q4 Strain & 0.44 & -0.52 & 0.45 & -0.50 \\
\hline 8N4ErD110B5 & 8 & Q4 Strain & 0.46 & -0.54 & 0.46 & -0.52 \\
\hline 16N4ErD110B5 & 16 & Q4 Strain & 0.46 & -0.55 & 0.47 & -0.53 \\
\hline 4N9ErD110B5 & 4 & Q9 Strain & 0.46 & -0.55 & 0.47 & -0.53 \\
\hline 8N9ErD110B5 & 8 & Q9 Strain & 0.46 & -0.55 & 0.46 & -0.54 \\
\hline
\end{tabular}

\begin{tabular}{|c|c|c|c|c|c|c|}
\hline $\begin{array}{l}\text { Table C-3 } \\
\text { Absolute a } \\
\text { Erection/Se } \\
\text { Ground Mo }\end{array}$ & $\begin{array}{l}\text { Relative Pea } \\
\text { ce Bay Bloc } \\
\text { n }\end{array}$ & $\begin{array}{l}\text { Acceleratic } \\
\text { Model Usin }\end{array}$ & $\begin{array}{l}\text { at To } \\
\text { Diffe }\end{array}$ & $\begin{array}{l}\text { ubstructu } \\
\text { pes of Fir }\end{array}$ & $\begin{array}{l}\text { for } \\
\text { e Ele }\end{array}$ & $\begin{array}{l}\text { ight } \\
\text { or PNW }\end{array}$ \\
\hline & $\begin{array}{l}\text { Vertical No. of } \\
\text { Layers of }\end{array}$ & & & $\begin{array}{l}\text { Acceleration } \\
\mathrm{g}\end{array}$ & & $\begin{array}{l}\text { Acceleration } \\
\text { g }\end{array}$ \\
\hline Model ID & \begin{tabular}{|l} 
Elements in \\
Mesh
\end{tabular} & Element Type & $(+)$ & $(-)$ & $(+)$ & $(-)$ \\
\hline 4ShErD110B5 & 4 & Shell & 0.40 & -0.35 & 0.34 & -0.33 \\
\hline 8ShErD110B5 & 8 & Shell & 0.41 & -0.36 & 0.36 & -0.35 \\
\hline 4S4ErD110B5 & 4 & Q4 Stress & 0.40 & -0.35 & 0.35 & -0.34 \\
\hline 8S4ErD110B5 & 8 & Q4 Stress & 0.41 & -0.36 & 0.36 & -0.35 \\
\hline 16S4ErD110B5 & 16 & Q4 Stress & 0.41 & -0.37 & 0.36 & -0.35 \\
\hline 4S9ErD110B5 & 4 & Q9 Stress & 0.41 & $\mid-0.37$ & 0.36 & 0.35 \\
\hline 8S9ErD110B5 & 8 & Q9 Stress & 0.41 & -0.37 & 0.36 & 0.35 \\
\hline 4N4ErD110B5 & 4 & Q4 Strain & 0.41 & -0.37 & 0.35 & -0.35 \\
\hline 8N4ErD110B5 & 8 & Q4 Strain & 0.41 & -0.37 & 0.36 & -0.36 \\
\hline 16N4ErD110B5 & 16 & Q4 Strain & 0.42 & -0.37 & 0.36 & 0.36 \\
\hline 4N9ErD110B5 & 4 & Q9 Strain & 0.41 & $\mid-0.37$ & 0.36 & $\mid-0.36$ \\
\hline 8N9ErD110B5 & 8 & Q9 Strain & 0.42 & 0.37 & 0.36 & -0.35 \\
\hline
\end{tabular}




\section{Appendix D Hydrodynamic Added Mass}

\section{D.1. Introduction}

Hydrodynamic added mass was added to the upstream and downstream faces of the finite element models to account for the pool and tailrace water elevations, respectively, of the powerhouse monoliths. Specifically, the mass was added to the upstream and downstream nodes. For the computations of the water-added mass, a simplified procedure of the Westergaard's Solution (1993) ${ }^{1}$ found in HQUSACE (1995a) was adapted for this study.

The simplified procedure assumes a parabolic mass distribution along the upstream and downstream faces of the powerhouse substructure model as shown in Figure D-1. In order to calculate the added mass, the effective width of water parallel to the monolith at the point of interest at level (y) is calculated. The effective width can be approximated by Equation D-1:

$$
b(y)=\frac{7}{8} \sqrt{H_{w} y}
$$

where $H_{w}$ is the total depth of water and $y$ the distance below the free surface of the water to the point of interest. This "width" times the surface area associated with the node estimates the volume of water and consequently the mass to be added to the node. This calculation is repeated for all nodes along the upstream and downstream faces of the substructure. The total added weight is calculated by Equation D-2:

$$
W_{\text {total }}=\frac{7}{12} \gamma_{w} w H_{w}^{2}
$$

per Ebeling and Morrison (1992) where $\gamma_{w}$ is the unit weight of water and $w$ is the plan width (i.e., along the axis of the powerhouse substructure) of the idealized substructure monolith. The weight is then divided by the gravitational constant of acceleration $g$ to get the total added mass for the model.

1 References cited in this appendix are included in the References section at the end of the main text. 


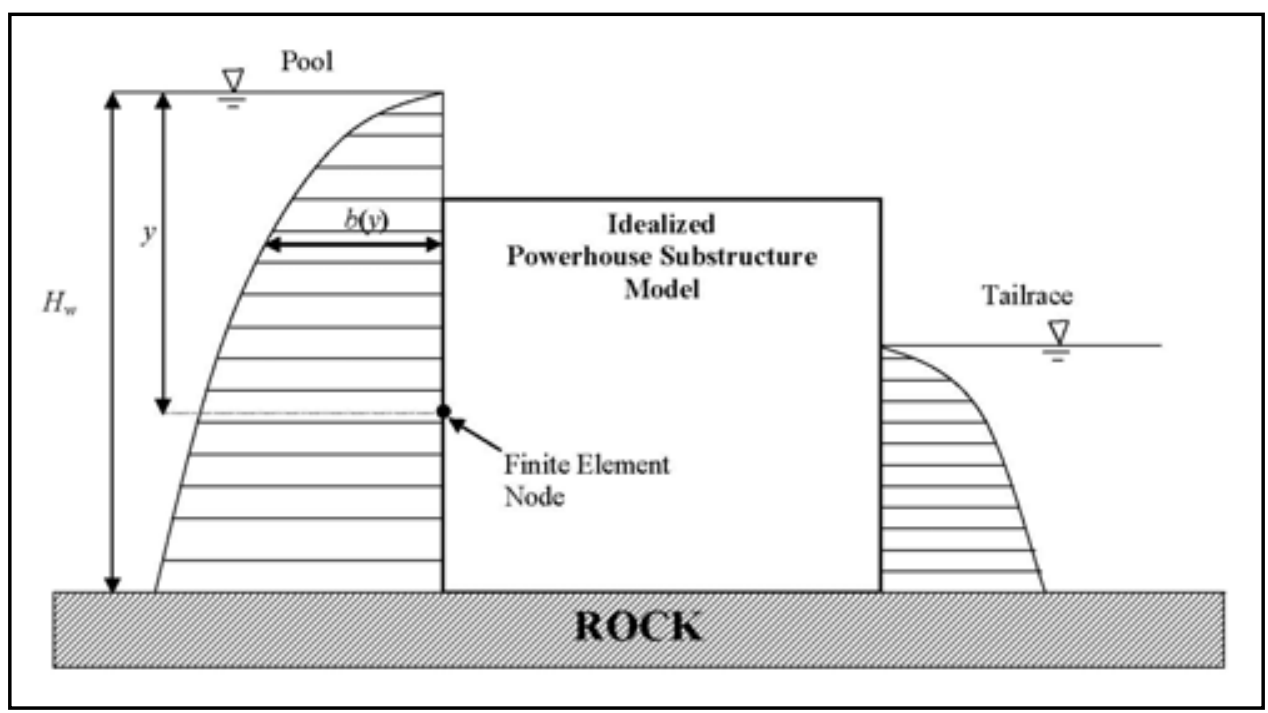

Figure D-1. Hydrodynamic added mass distribution on the idealized powerhouse substructure model

\section{D.2. Example Computation}

The following is an example of the calculations for the 110-ft-height block model of the erection/service bay idealized substructure (Figure D-2). The finite element model has a height of $110 \mathrm{ft}$ and includes 33 nodes along the upstream face and 23 nodes along the downstream face. The nodes are spaced at intervals of $3.4375 \mathrm{ft}$. The model has a plan width of $75 \mathrm{ft}$ (along the axis of the powerhouse substructure), the upstream pool water elevation is assigned $20 \mathrm{ft}$ above the top of the idealized substructure, and the tailrace water elevation is $34.4 \mathrm{ft}$ below the top of the idealized substructure model. The unit weight of water was taken as $62.4 \mathrm{lb} / \mathrm{ft}^{3}$.

Table D-1 summarizes the calculations for the pool added mass in spreadsheet form. In the first column the node numbers are identified and in Column 2 the distance below the water table of each node is calculated. The effective width $b(y)$ is calculated in Column 3 using Equation D-1. The added weight at each node is calculated by multiplying the effective width $b(y)$ by the tributary area of each node times the water unit weight as presented in Column 4 . For the node at top of the model, the $20 \mathrm{ft}$ of water weight above the top-of-substructure was added. The weight is divided by the gravitational acceleration constant $32.2 \mathrm{ft} / \mathrm{sec}^{2}$ in Column 5 to obtain the added hydrodynamic mass at each node. Table D-2 lists the results for the tailrace water added mass for each downstream face node.

The total weight is calculated by summing the weight for each of the nodes. This value is compared to the exact value calculated by Equation D-2. Acceptable errors of 1.52 percent were found for the pool side and 1.02 percent for the tailrace side (this error results from the linearization of the Figure D-1 curve between nodes). 


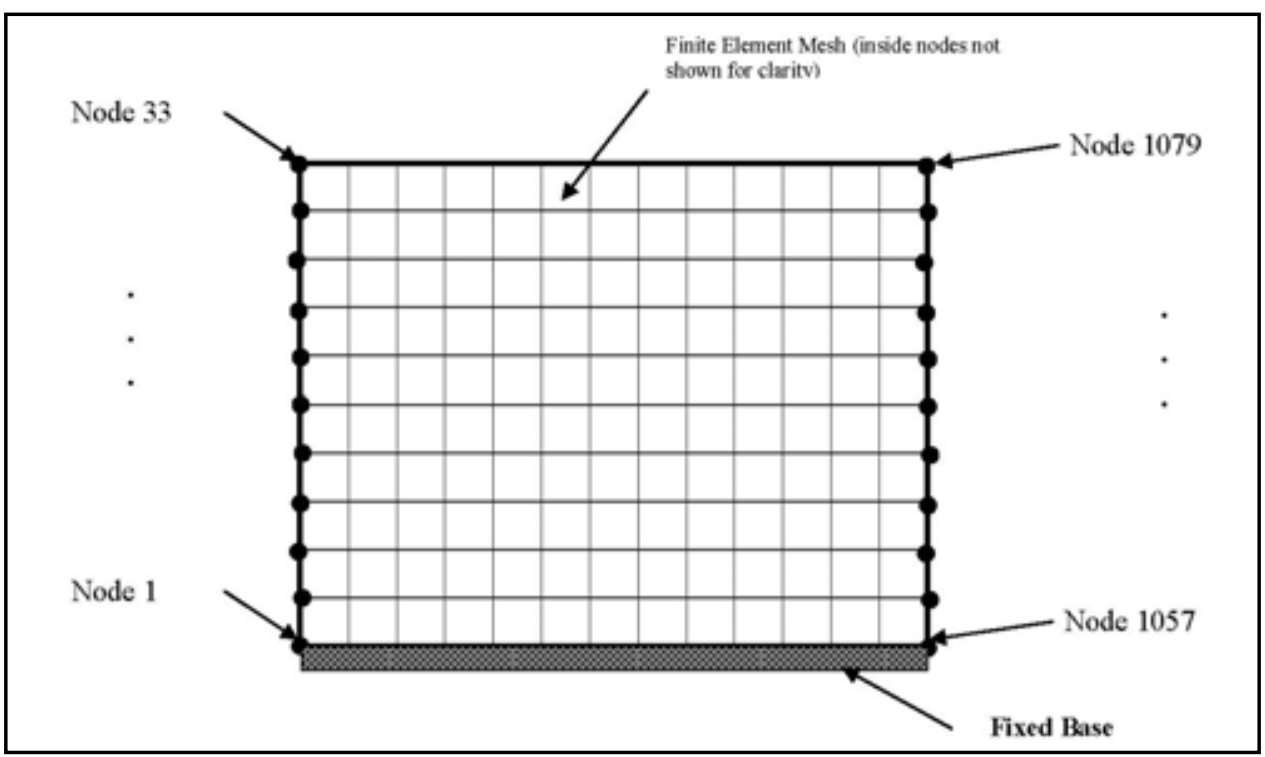

Figure D-2. Finite element block model for 110 -ft-height erection/service bay idealization

Table D-3 lists the percent contribution of the added mass to the model mass. For this example 28.2 percent of the total mass in the block finite element model is attributed to the hydrodynamic added mass. 


\begin{tabular}{|c|c|c|c|c|}
\hline \multicolumn{5}{|c|}{$\begin{array}{l}\text { Table D-1 } \\
\text { Calculated Hydrodynamic Mass Added to Each Node along the } \\
\text { Upstream Pool Face }\end{array}$} \\
\hline 1 & 2 & 3 & 4 & 5 \\
\hline Node & $\begin{array}{l}y \\
\mathrm{ft}\end{array}$ & $\begin{array}{l}b \\
\mathrm{ft}\end{array}$ & $\begin{array}{l}\text { Weight } \\
\text { lb }\end{array}$ & $\begin{array}{l}\text { Mass } \\
\left(\text { lb-sec }^{2}\right) / \mathrm{ft}\end{array}$ \\
\hline 33 & 20 & 44.61642074 & 2446932 & 75991.67159 \\
\hline 32 & 23.4375 & 48.29869224 & 777005.2 & 24130.59663 \\
\hline 31 & 26.875 & 51.71945808 & 832036.8 & 25839.65161 \\
\hline 30 & 30.3125 & 54.92759794 & 883647.7 & 27442.47615 \\
\hline 29 & 33.75 & 57.95843069 & 932406.3 & 28956.71595 \\
\hline 28 & 37.1875 & 60.83846119 & 978738.7 & 30395.61318 \\
\hline 27 & 40.625 & 63.58818311 & 1022975 & 31769.4067 \\
\hline 26 & 44.0625 & 66.22383033 & 1065376 & 33086.20715 \\
\hline 25 & 47.5 & 68.7585222 & 1106153 & 34352.56913 \\
\hline 24 & 50.9375 & 71.20304099 & 1145479 & 35573.87957 \\
\hline 23 & 54.375 & 73.56637628 & 1183499 & 36754.62976 \\
\hline 22 & 57.8125 & 75.85611637 & 1220335 & 37898.61093 \\
\hline 21 & 61.25 & 78.0787363 & 1256092 & 39009.05808 \\
\hline 20 & 64.6875 & 80.2398139 & 1290858 & 40088.75795 \\
\hline 19 & 68.125 & 82.34419473 & 1324712 & 41140.13145 \\
\hline 18 & 71.5625 & 84.39612004 & 1357723 & 42165.29755 \\
\hline 17 & 75 & 86.39932725 & 1389949 & 43166.12352 \\
\hline 16 & 78.4375 & 88.35713 & 1421445 & 44144.26487 \\
\hline 15 & 81.875 & 90.27248248 & 1452259 & 45101.19758 \\
\hline 14 & 85.3125 & 92.14803181 & 1482431 & 46038.24415 \\
\hline 13 & 88.75 & 93.98616088 & 1512002 & 46956.59513 \\
\hline 12 & 92.1875 & 95.78902395 & 1541006 & 47857.3268 \\
\hline 11 & 95.625 & 97.55857615 & 1569474 & 48741.41596 \\
\hline 10 & 99.0625 & 99.2965984 & 1597434 & 49609.75238 \\
\hline 9 & 102.5 & 101.0047183 & 1624913 & 50463.14926 \\
\hline 8 & 105.9375 & 102.6844282 & 1651936 & 51302.35214 \\
\hline 7 & 109.375 & 104.3371002 & 1678523 & 52128.04654 \\
\hline 6 & 112.8125 & 105.9639993 & 1704696 & 52940.86454 \\
\hline 5 & 116.25 & 107.566295 & 1730473 & 53741.39038 \\
\hline 4 & 119.6875 & 109.1450708 & 1755871 & 54530.16543 \\
\hline 3 & 123.125 & 110.7013331 & 1780908 & 55307.69244 \\
\hline 2 & 126.5625 & 112.2360184 & 1805597 & 56074.43932 \\
\hline \multirow[t]{4}{*}{1} & 130 & 113.75 & 914976.6 & 28415.4212 \\
\hline & & Total & 45437862 & 1411113.715 \\
\hline & & Exact Value & 46137000 & 1432826.087 \\
\hline & & $\%$ Error $=$ & 1.52 & 1.52 \\
\hline
\end{tabular}




\begin{tabular}{|c|c|c|c|c|}
\hline \multicolumn{5}{|c|}{$\begin{array}{l}\text { Table D-2 } \\
\text { Calculated Hydrodynamic Mass Added to Each Node along the } \\
\text { Downstream Tailrace Face }\end{array}$} \\
\hline 1 & 2 & 3 & 4 & 5 \\
\hline Node & $\begin{array}{l}y \\
\mathrm{ft}\end{array}$ & $\begin{array}{l}b \\
\mathrm{ft}\end{array}$ & $\begin{array}{l}\text { Weight } \\
\text { Ib }\end{array}$ & $\begin{array}{l}\text { Mass } \\
\left(\mathrm{lb}-\sec ^{2}\right) / \mathrm{ft}\end{array}$ \\
\hline 1079 & 0 & 0 & 0 & 0 \\
\hline 1078 & 3.436364 & 14.10322739 & 113405.3 & 3521.904768 \\
\hline 1077 & 6.872727 & 19.94497544 & 320758.7 & 9961.450977 \\
\hline 1076 & 10.30909 & 24.42750638 & 392847.6 & 12200.236 \\
\hline 1075 & 13.74545 & 28.20645477 & 453621.3 & 14087.61907 \\
\hline 1074 & 17.18182 & 31.53577514 & 507164.1 & 15750.43694 \\
\hline 1073 & 20.61818 & 34.54571082 & 555570.4 & 17253.73921 \\
\hline 1072 & 24.05455 & 37.31363235 & 600084.6 & 18636.16831 \\
\hline 1071 & 27.49091 & 39.88995089 & 641517.4 & 19922.90195 \\
\hline 1070 & 30.92727 & 42.30968216 & 680432 & 21131.42861 \\
\hline 1069 & 34.36364 & 44.5983209 & 717238.3 & 22274.48154 \\
\hline 1068 & 37.8 & 46.77511358 & 752245.9 & 23361.67333 \\
\hline 1067 & 41.23636 & 48.85501277 & 785695.2 & 24400.47199 \\
\hline 1066 & 44.67273 & 50.84990949 & 817777.5 & 25396.81646 \\
\hline 1065 & 48.10909 & 52.76944493 & 848647.8 & 26355.52198 \\
\hline 1064 & 51.54545 & 54.6215648 & 878433.9 & 27280.55703 \\
\hline 1063 & 54.98182 & 56.41290955 & 907242.7 & 28175.23814 \\
\hline 1062 & 58.41818 & 58.14909618 & 935164.3 & 29042.37072 \\
\hline 1061 & 61.85455 & 59.83492633 & 962276.2 & 29884.35293 \\
\hline 1060 & 65.29091 & 61.47454296 & 988644.8 & 30703.25395 \\
\hline 1059 & 68.72727 & 63.07155028 & 1014328 & 31500.87389 \\
\hline 1058 & 72.16364 & 64.62910704 & 1039377 & 32278.79038 \\
\hline \multirow[t]{4}{*}{1057} & 75.6 & 66.15 & 531918.2 & 16519.19763 \\
\hline & & Total & 15444391 & 479639.4858 \\
\hline & & Exact Value & 15602933 & 484563.1304 \\
\hline & & $\%$ Error $=$ & 1.02 & 1.02 \\
\hline
\end{tabular}

\begin{tabular}{|c|c|c|c|c|c|}
\hline \multicolumn{6}{|c|}{$\begin{array}{l}\text { Table D-3 } \\
\text { Summary of Hydrodynamic Mass Added to the Idealized Model }\end{array}$} \\
\hline $\begin{array}{l}\text { Hydrodynamic } \\
\text { Added Mass }\end{array}$ & $\begin{array}{l}\text { Block } \\
\left(\text { k-sec }{ }^{2}\right) / f t\end{array}$ & $\begin{array}{l}\text { Pool } \\
\left(k-\sec ^{2}\right) / f t\end{array}$ & $\begin{array}{l}\text { Tail } \\
\left(k-\sec ^{2}\right) / f t\end{array}$ & $\begin{array}{l}\text { Total Added } \\
\text { Mass } \\
\left(\mathrm{k}-\sec ^{2}\right) / \mathrm{ft}\end{array}$ & $\begin{array}{l}\text { Total } \\
\left(\mathrm{k}-\sec ^{2}\right) / \mathrm{ft}\end{array}$ \\
\hline Mass & 4803.97 & 1411.1 & 479.6 & 1890.7 & 6694.67 \\
\hline$\%$ of Added Mass & & $74.6 \%$ & $25.4 \%$ & & $100.0 \%$ \\
\hline$\%$ of Block Mass & & $29.4 \%$ & $10.0 \%$ & $39.4 \%$ & \\
\hline$\%$ of Total Mass & & $21.1 \%$ & $7.2 \%$ & $28.2 \%$ & \\
\hline
\end{tabular}




\section{Appendix E Absolute Acceleration versus Pseudo-Spectral Acceleration (PSA)}

This appendix compares amplification factor curves developed using absolute acceleration (SA) curves and pseudo-spectral acceleration (PSA) curves. The 110 -ft-height block model of the erection/service bay substructure is used in this example.

A response spectrum is a graph of maximum values of acceleration, velocity, or displacement response of an infinite series of damped elastic single-degree-offreedom (SDOF) systems subjected to an acceleration time-history (Ebeling 1992). ${ }^{1}$ When referring to absolute acceleration, SA (also known as spectral acceleration response spectrum), the ground acceleration time-history is added to the relative response values of the computed time-history (refer to SA equation given in box in Figure 1-3). For the PSA, the computed relative time-history acceleration is used to construct the response spectrum curve.

Figure E-1 shows the calculated top-of-substructure response spectra with 5 percent damping using SA and PSA for the 110-ft-height block model. The structural analysis software SAP2000 (Computers and Structures, Inc., 1997) was used for the calculation of the response spectra, and the central-eastern United States ground motion (CEUS) as the earthquake. Figure E-2 shows the resulting amplification factor curves constructed using the SA and the PSA curves for 5 percent damping.

The difference between the two spectra and amplification factor curves is small because a short-period structure with low percent damping was being evaluated. The PSA considers only elastic forces and SA considers elastic and damping forces (Appendix A, Ebeling 1992). With low percent damping, the contribution of damping forces considered in SA is not significant to the analysis. For long-period structures and a high percent damping, the difference between the two spectra will be increased.

1 References cited in this appendix are included in the References section at the end of the main text. 


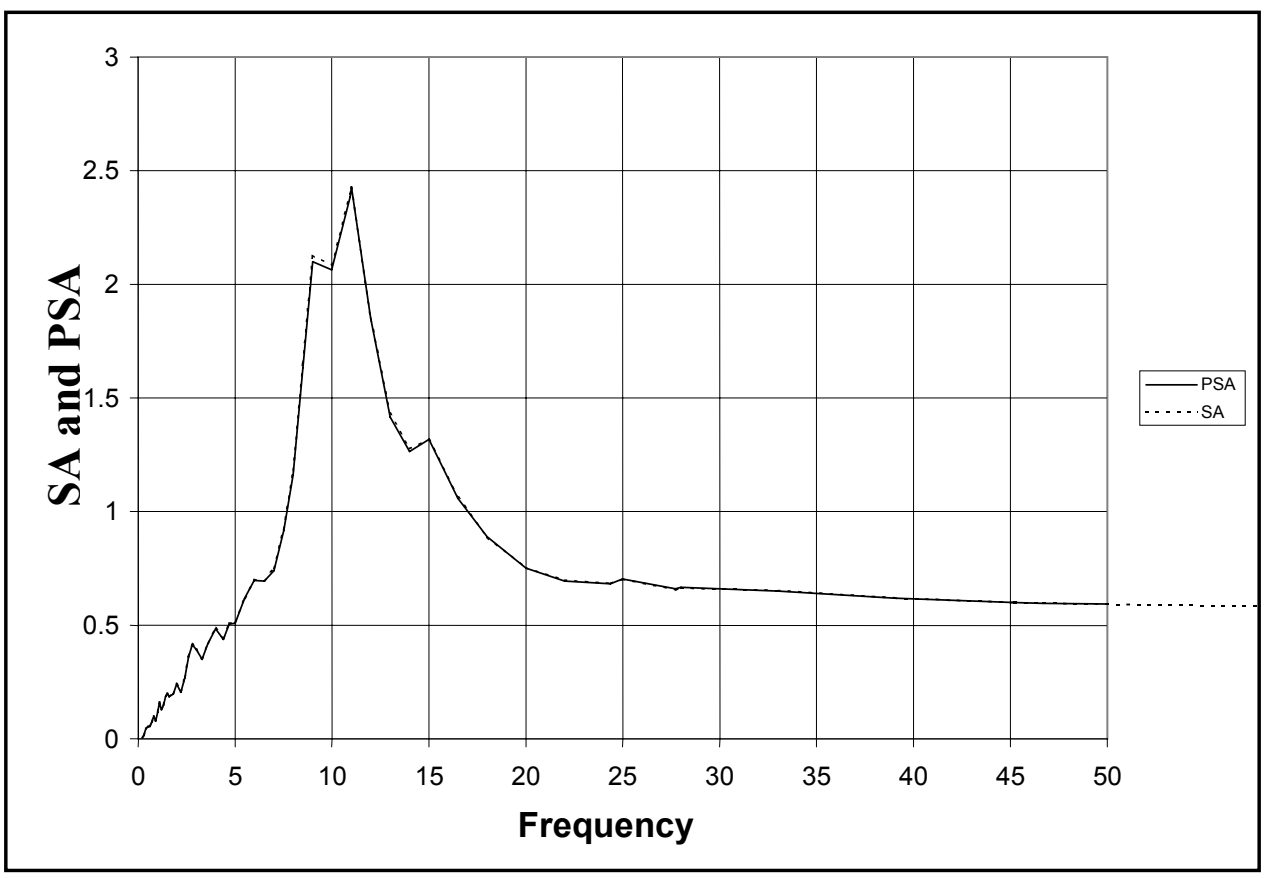

Figure E-1. SA and PSA response spectrum curves at top-of-substructure for the 110-ft-height block model using the CEUS ground motion for 5 percent damping

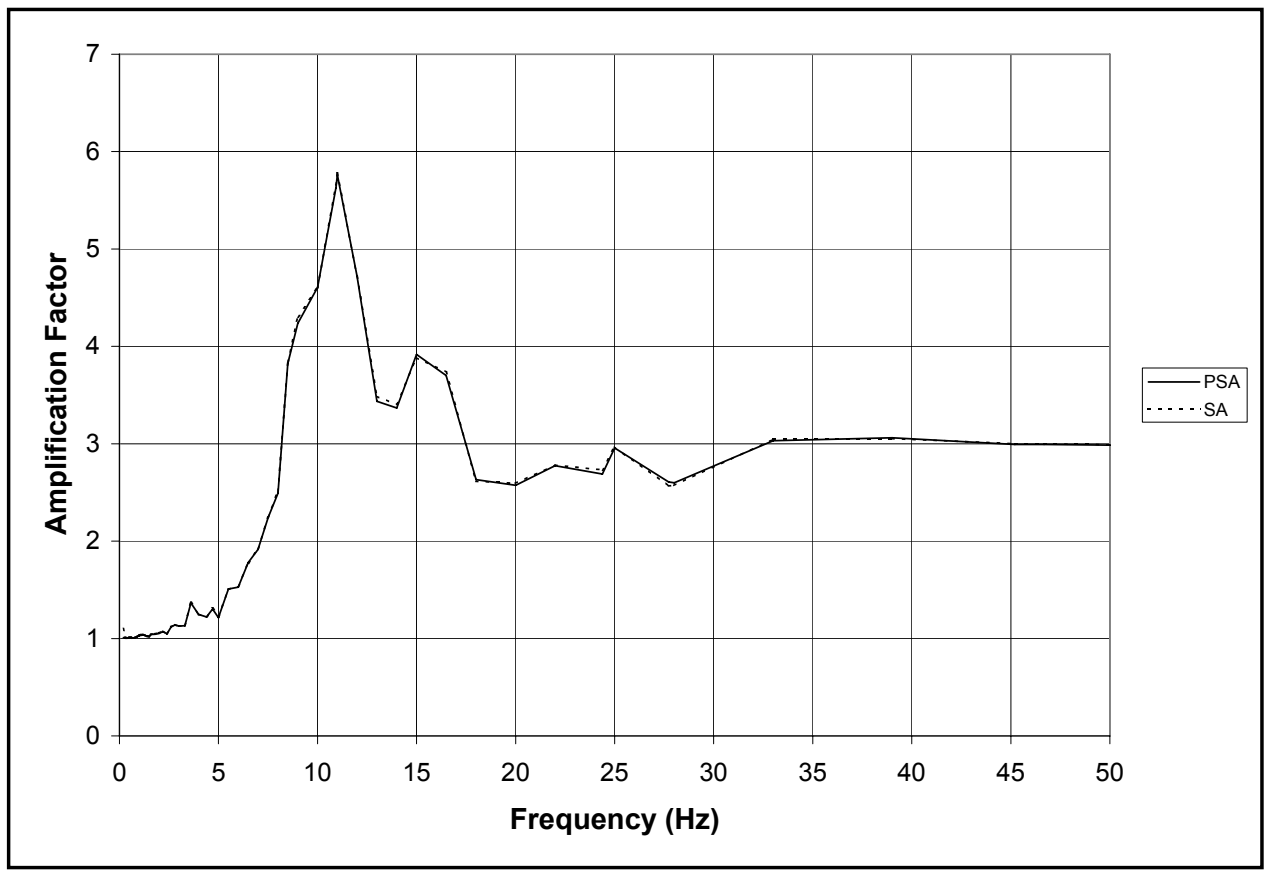

Figure E-2. AF using SA and PSA at top-of-substructure for the 110-ft-height block model using the CEUS ground motion 


\section{Appendix F Amplification Factor Curves for 2 Percent Damping}

\section{F.1. Introduction}

In this appendix, amplification factor (AF) curves for 2 percent damping are shown for the composite model of the idealized generator bay substructure. The results for the block model and block-frame-shear wall model of the erection/ service bay substructure are also presented. Lower values of damping are used to compute response spectra for analyzing the equipment on top of the substructure than are used for analyzing the superstructure.

The AF curves were calculated using the same procedure as explained in Chapter 1. The superstructure was decoupled from the substructure, and a timehistory analysis was performed of the four idealized substructure finite element models. The top-of-substructure 2 percent damping response spectrum was then calculated. The percent damping for the substructure finite element model was kept at 5 percent for all analyses. To calculate the AF curve, the top-ofsubstructure spectral acceleration for 2 percent damping was divided by the pseudo-spectral acceleration in rock for 2 percent damping for each frequency. The time-histories of the ground motions for the central-eastern United States (CEUS) and the Pacific Northwest of the United States (PNW) were used in the analyses. The AF curves presented in this appendix are plotted up to $50 \mathrm{~Hz}$. However, the ground motions used in this study have frequency content up to $33 \mathrm{~Hz}$. The use of AF curves above $33 \mathrm{~Hz}$ is not recommended.

Figure F-1 shows the process used to develop the AF curve and its application when doing response spectrum analysis for equipment resting on the powerhouse substructure. 


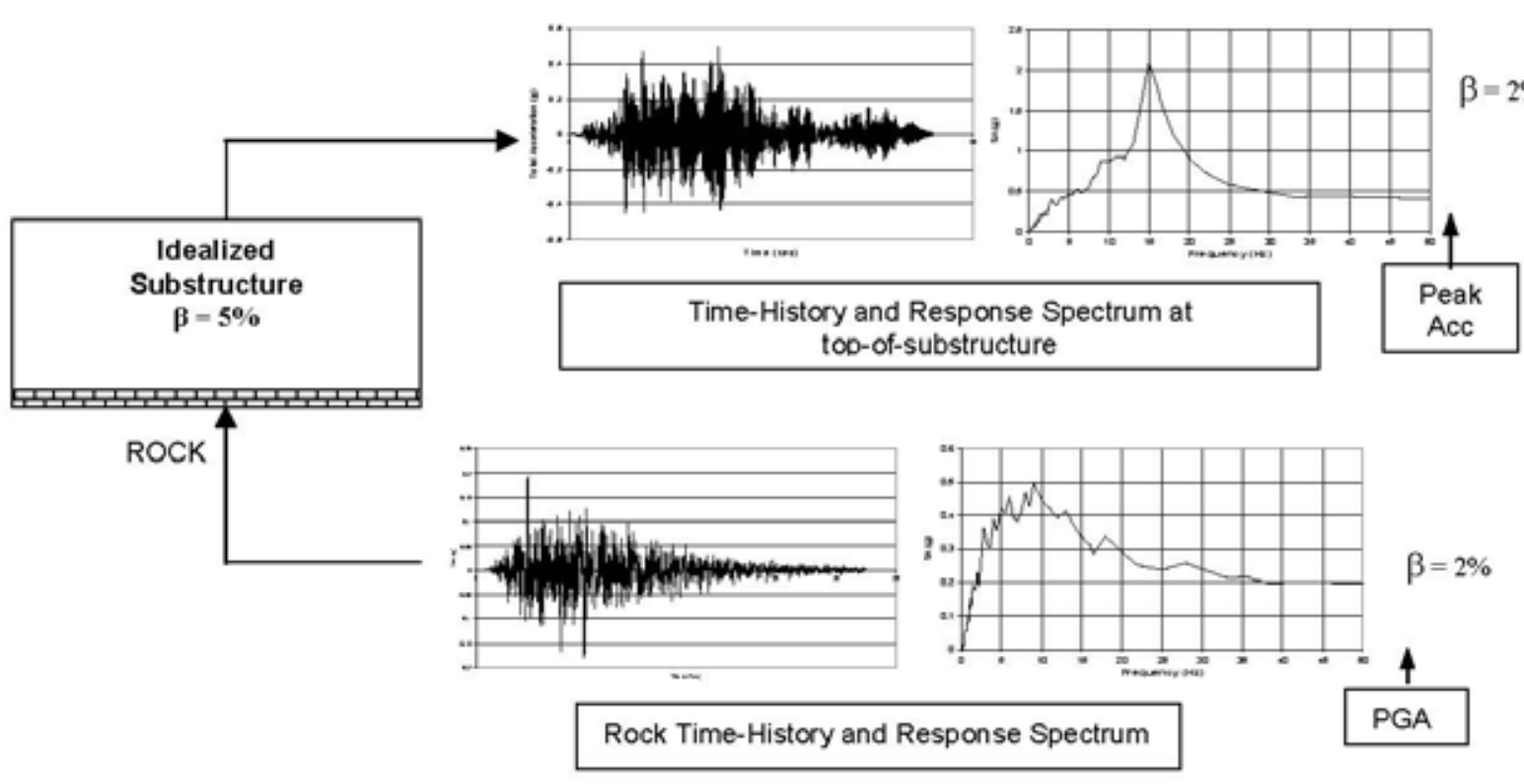

a. Top-of-substructure 2 percent damping response spectrum calculation
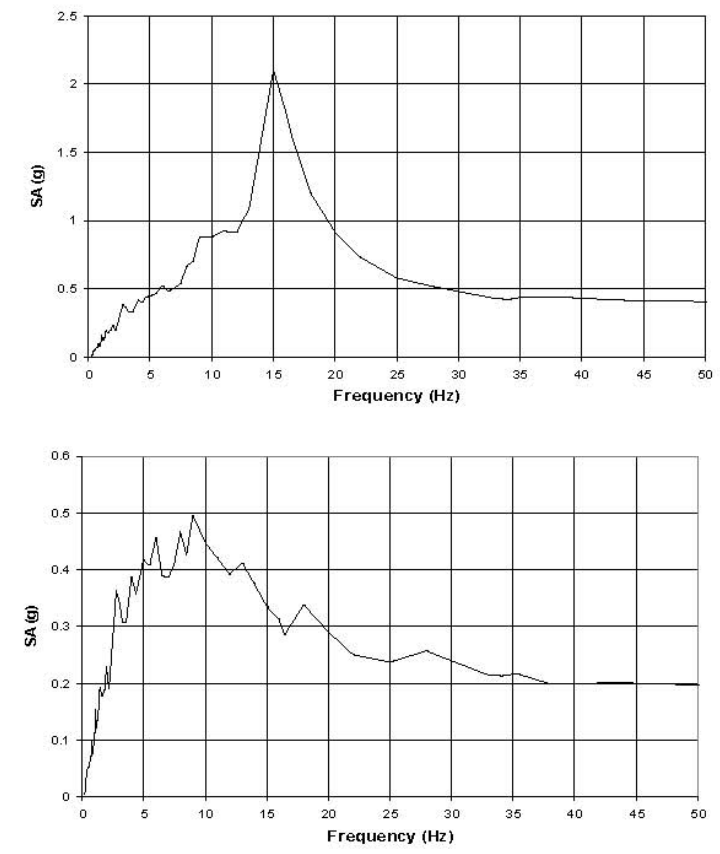

Response Spectrum at topof-substructure $\beta=2 \%$

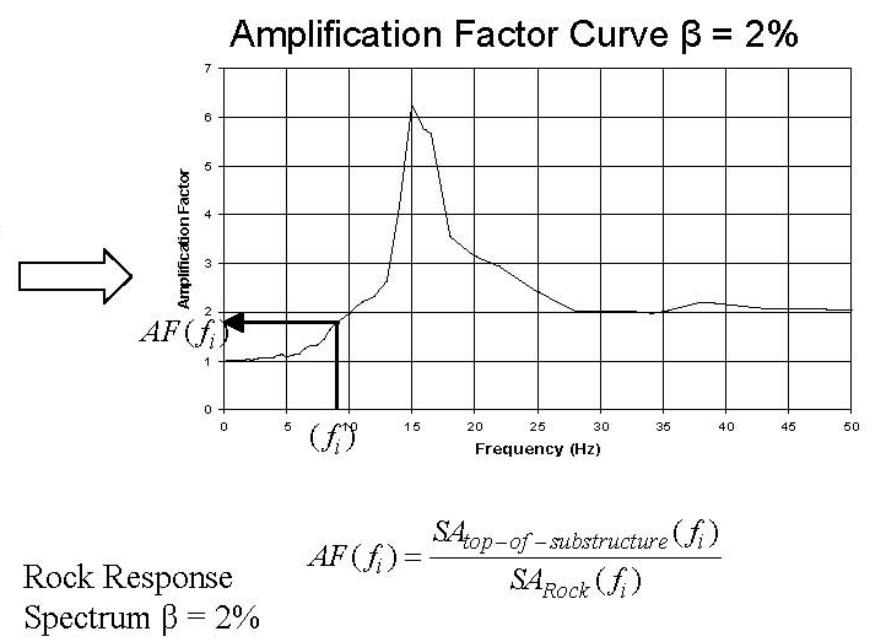

b. Construction of the AF curve for 2 percent damping

Figure F-1. AF curve development for 2 percent damping and its application to equipment analysis (Continued) 


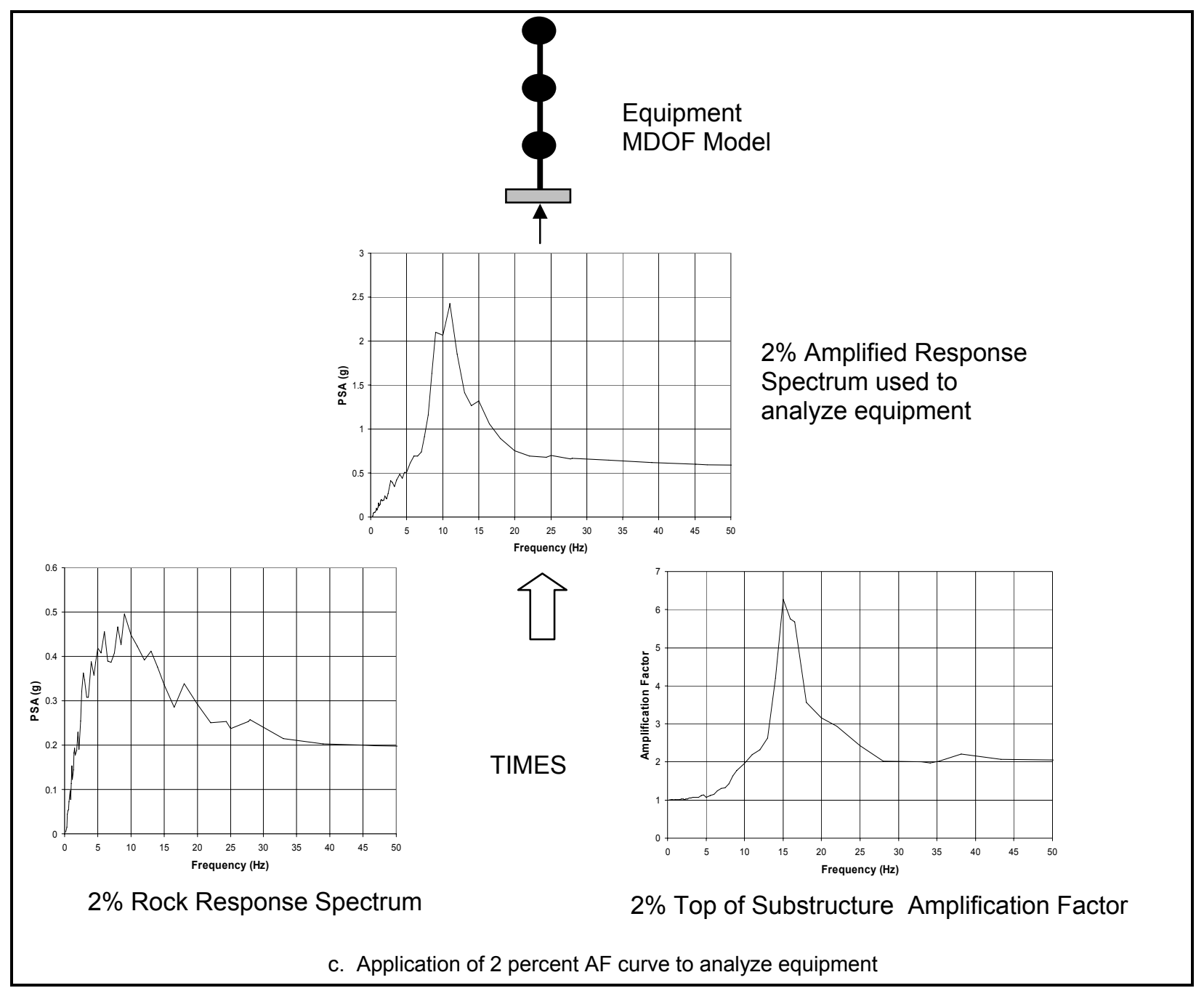

Figure F-1. (Concluded)

\section{F.2. Generator Bay Substructure Amplification Factor for 2 Percent Damping}

Table F-1 lists the AF curves and response spectrum figures obtained for the composite structural model of the idealized generator bay substructure. As expected, when the percent damping value is decreased, the response increases for each of the four group models. Tables F-2 and F-3 list the SA and PGA ratio at $50 \mathrm{~Hz}$ for dry and wet conditions, respectively.

\begin{tabular}{|l|l|l|l||}
\hline \hline \multicolumn{4}{||}{$\begin{array}{l}\text { Table F-1 } \\
\text { List of Figures for Generator Bay Substructure AF Curves }\end{array}$} \\
\hline \hline Group & Height, ft & CEUS & PNW \\
\hline \hline 1 & 125 & Figure F-2 & Figure F-6 \\
\hline 2 & 100 & Figure F-3 & Figure F-7 \\
\hline 3 & 70 & Figure F-4 & Figure F-8 \\
\hline 4 & 40 & Figure F-5 & Figure F-9 \\
\hline
\end{tabular}




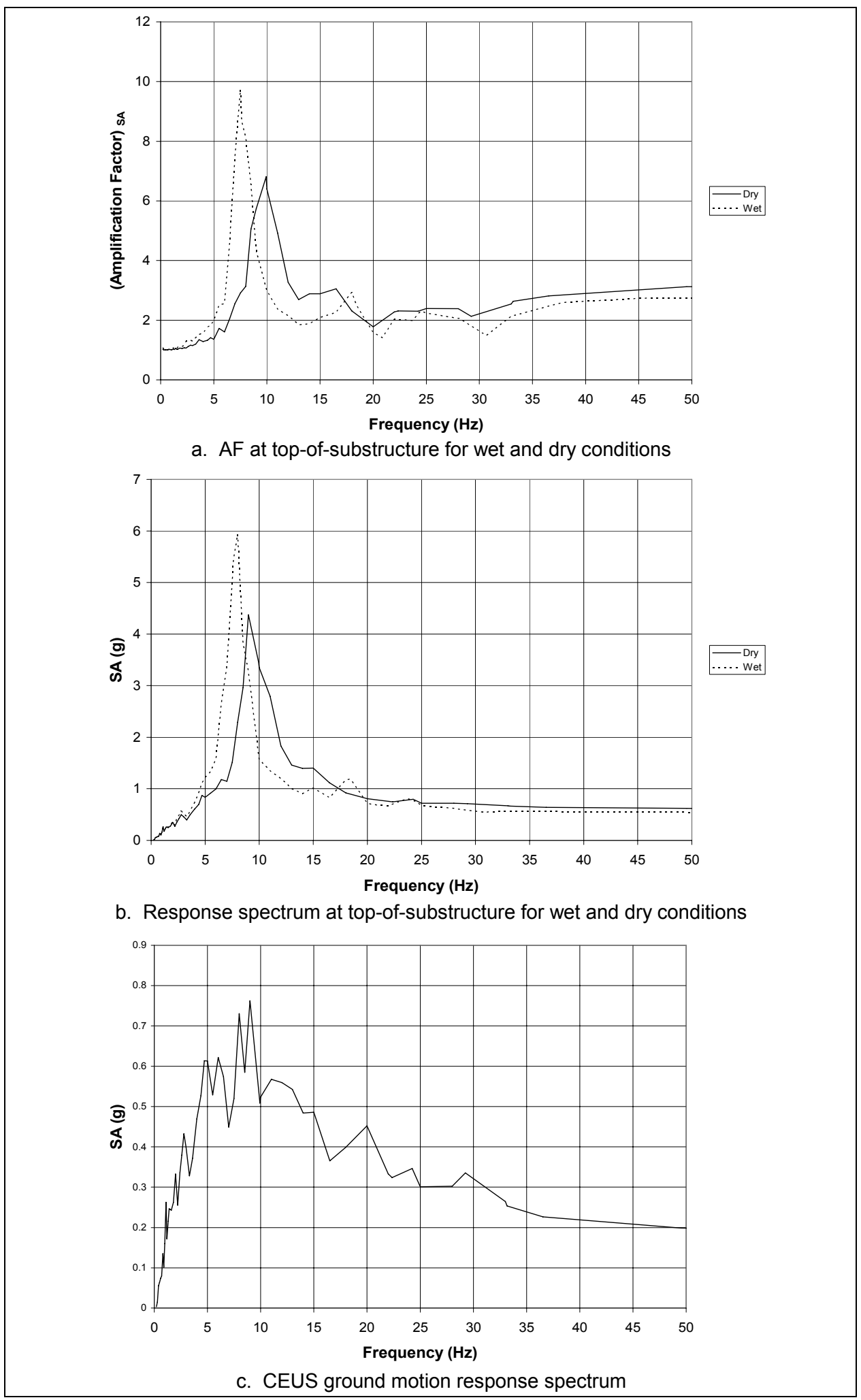

Figure F-2. Response spectra and AF curves, generator bay, composite model, 125-ft height (Dry Model ID: 25S9GeD125C5, Wet Model ID:

25S9GeW125C5), for CEUS ground motion with 2 percent damping 


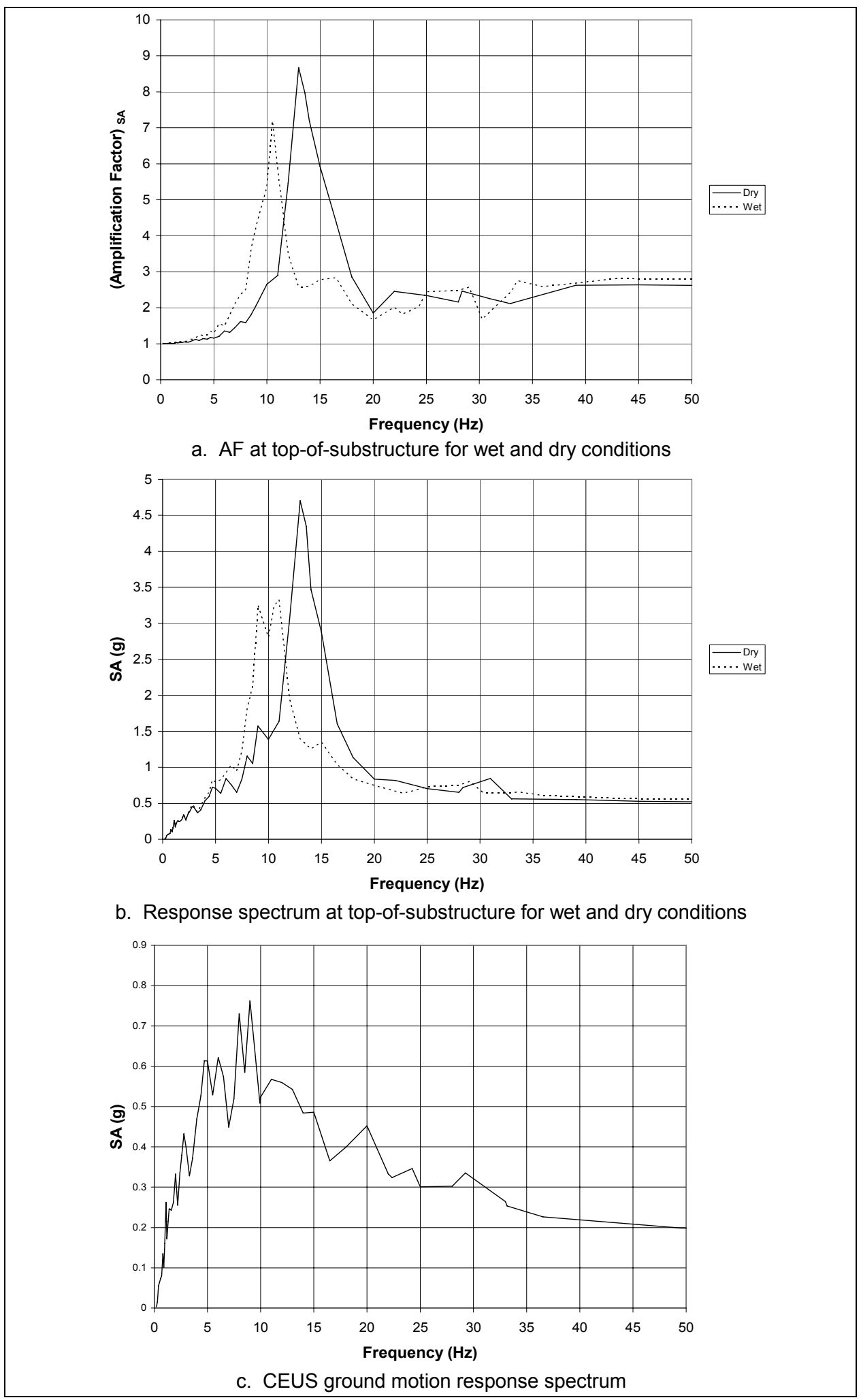

Figure F-3. Response spectra and AF curves, generator bay, composite model, 100-ft height (Dry Model ID: 50S9GeD100C5, Wet Model ID:

$50 S 9 \mathrm{GeW} 100 \mathrm{C} 5)$, for CEUS ground motion with 2 percent damping 


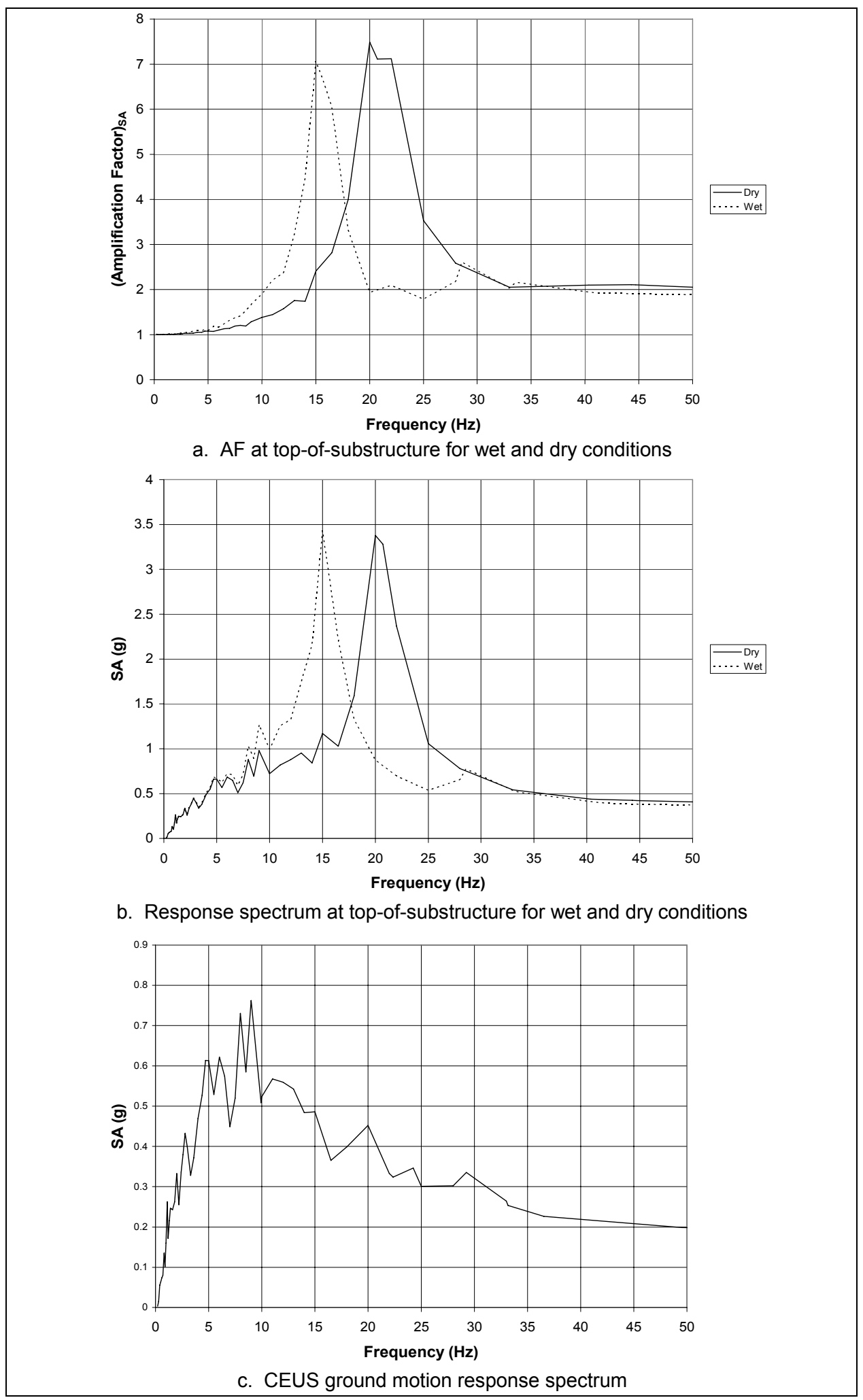

Figure F-4. Response spectra and AF curves, generator bay, composite model, 70-ft height (Dry Model ID: 35S9GeD70C5, Wet Model ID: 35S9GeW70C5), for CEUS ground motion with 2 percent damping 


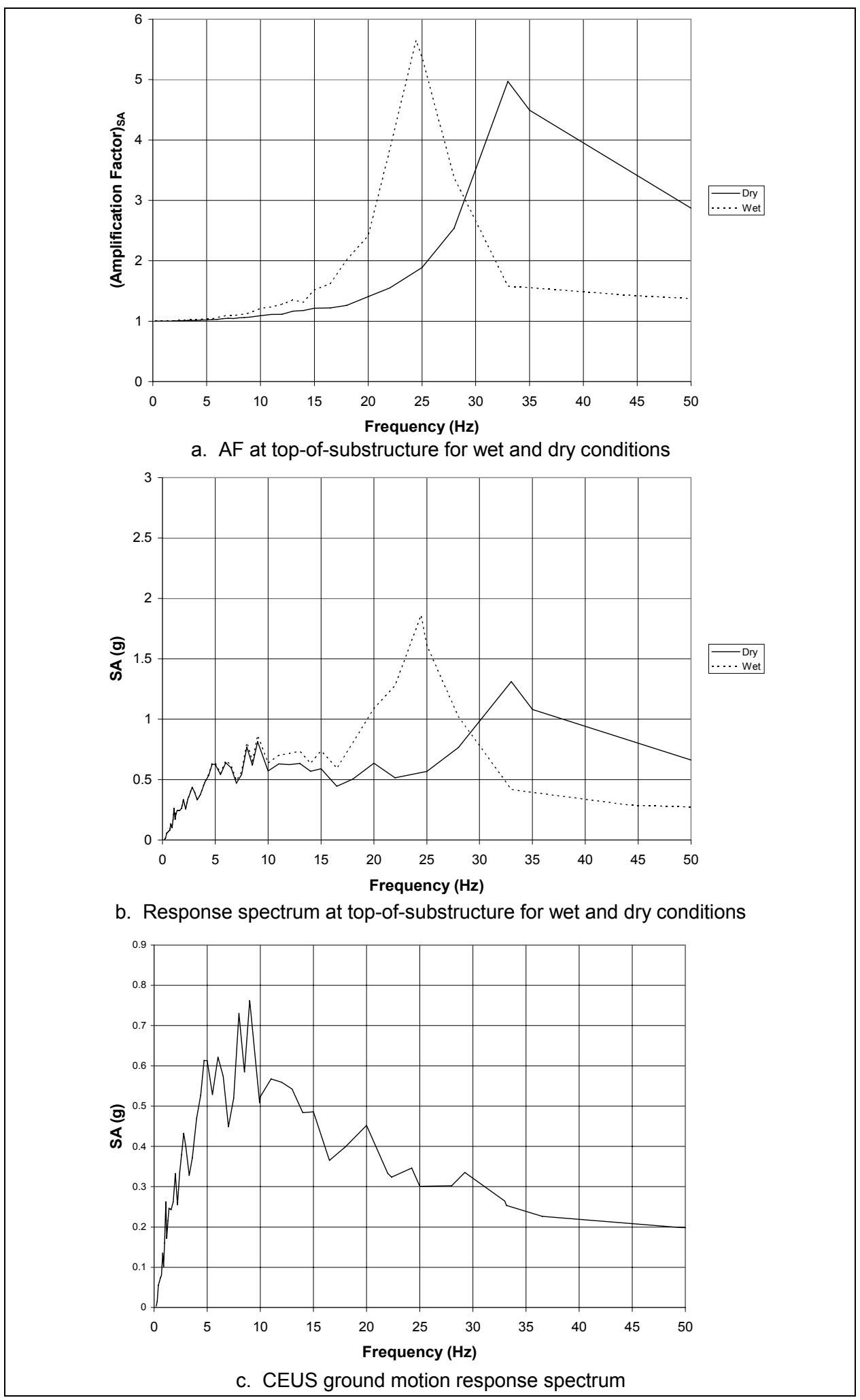

Figure F-5. Response spectra and AF curves, generator bay, composite model, 40-ft height (Dry Model ID: 8S9GeD40C5, Wet Model ID:

$8 S 9 \mathrm{GeW} 40 \mathrm{C} 5)$, for CEUS ground motion with 2 percent damping 


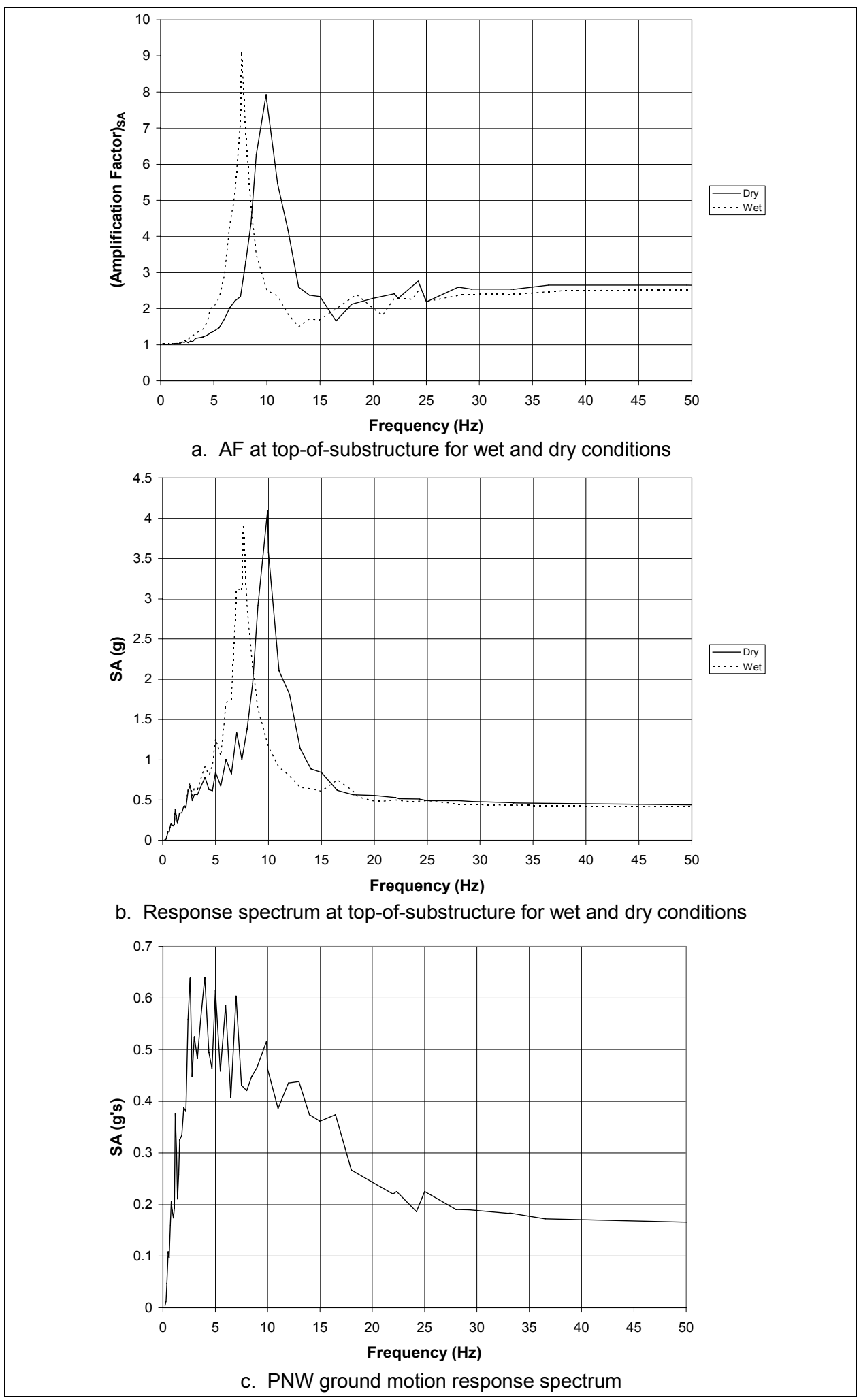

Figure F-6. Response spectra and AF curves, generator bay, composite model, 125-ft height (Dry Model ID: 25S9GeD125C5, Wet Model ID:

25S9GeW125C5), for PNW ground motion with 2 percent damping 


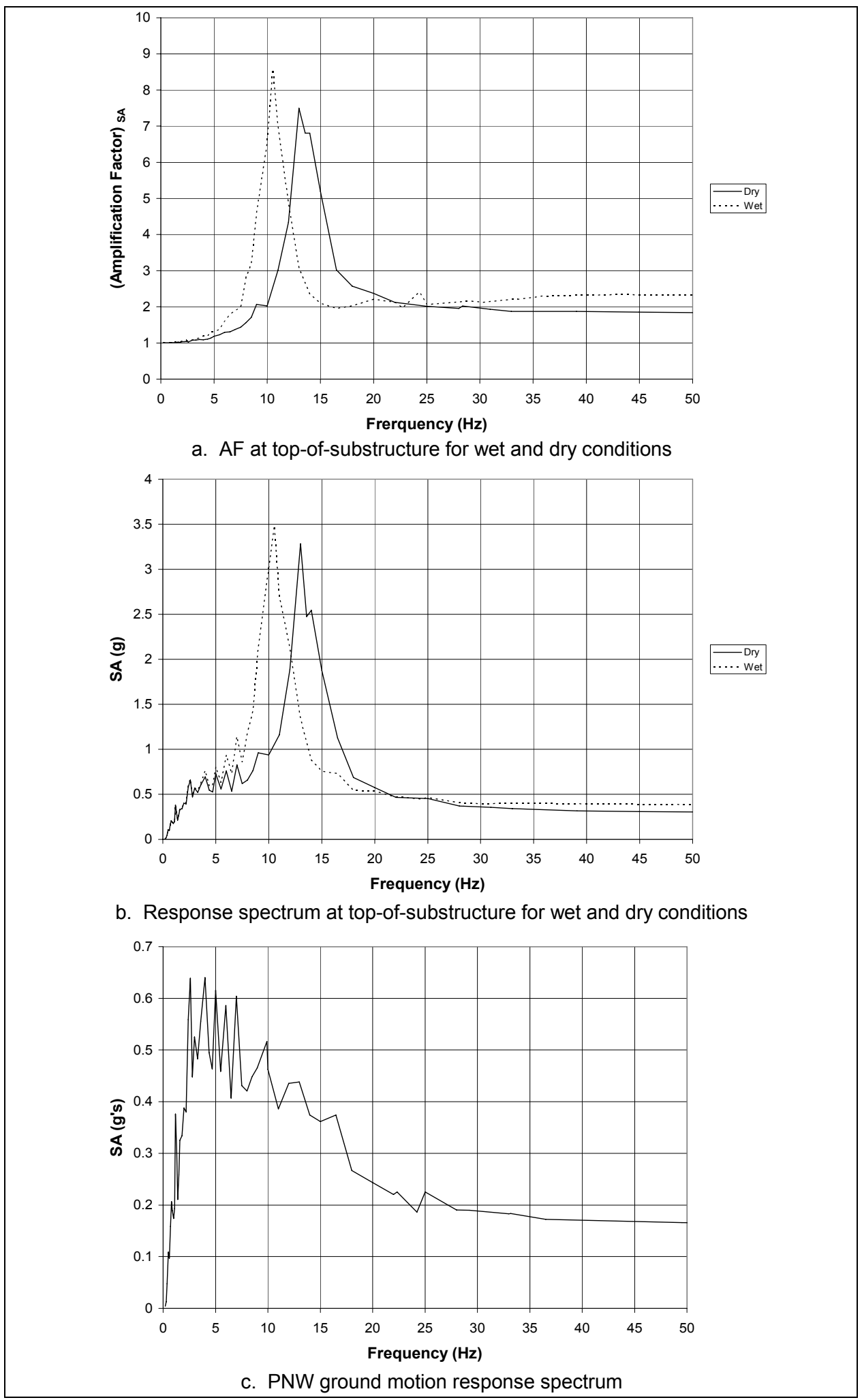

Figure F-7. Response spectra and AF curves, generator bay, composite model, 100 -ft height (Dry Model ID: 50S9GeD100C5, Wet Model ID:

$50 S 9 \mathrm{GeW} 100 \mathrm{C} 5)$, for PNW ground motion with 2 percent damping 


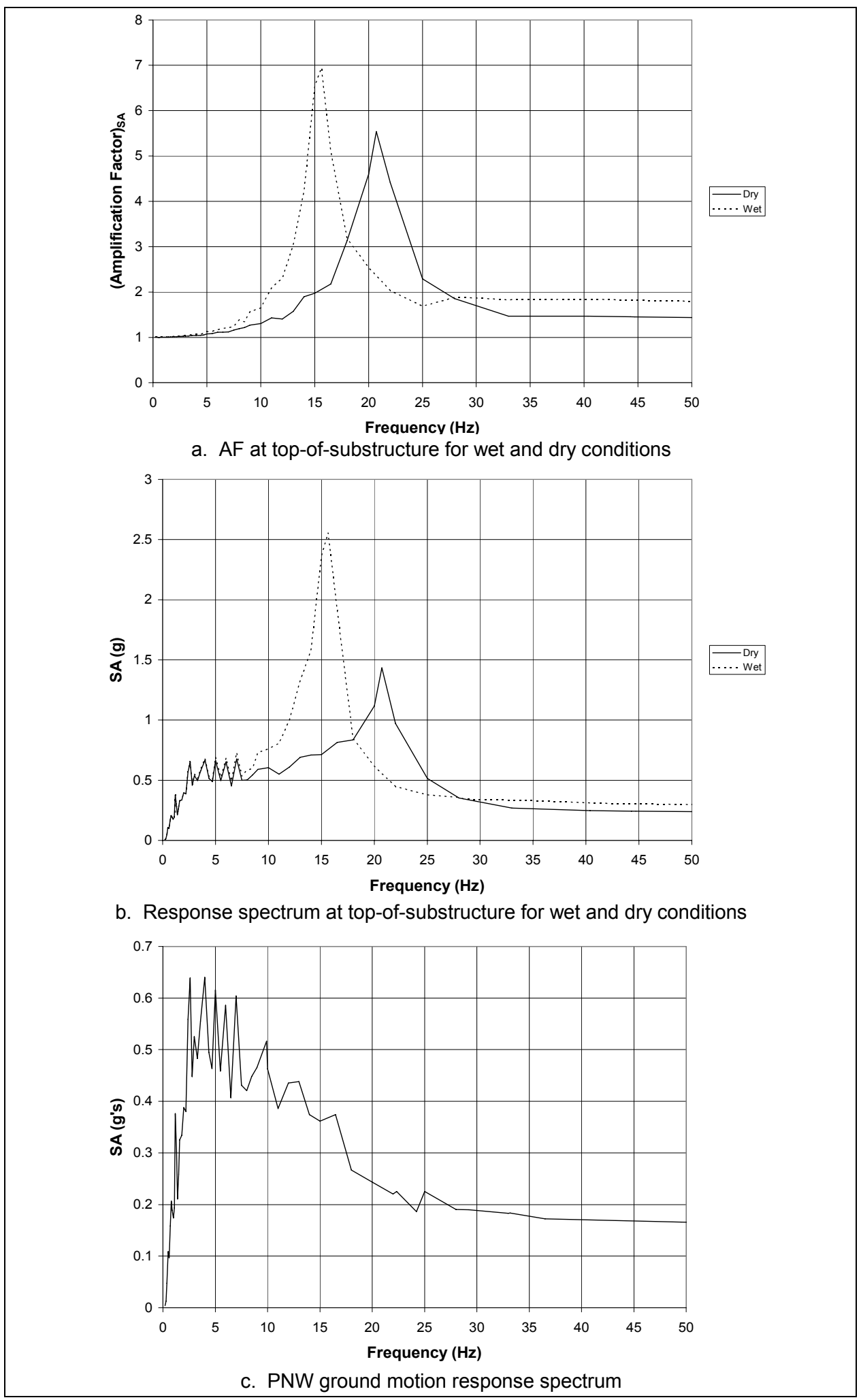

Figure F-8. Response spectra and AF curves, generator bay, composite model, 70-ft height (Dry Model ID: 35S9GeD70C5, Wet Model ID: 35S9GeW70C5), for PNW ground motion with 2 percent damping 


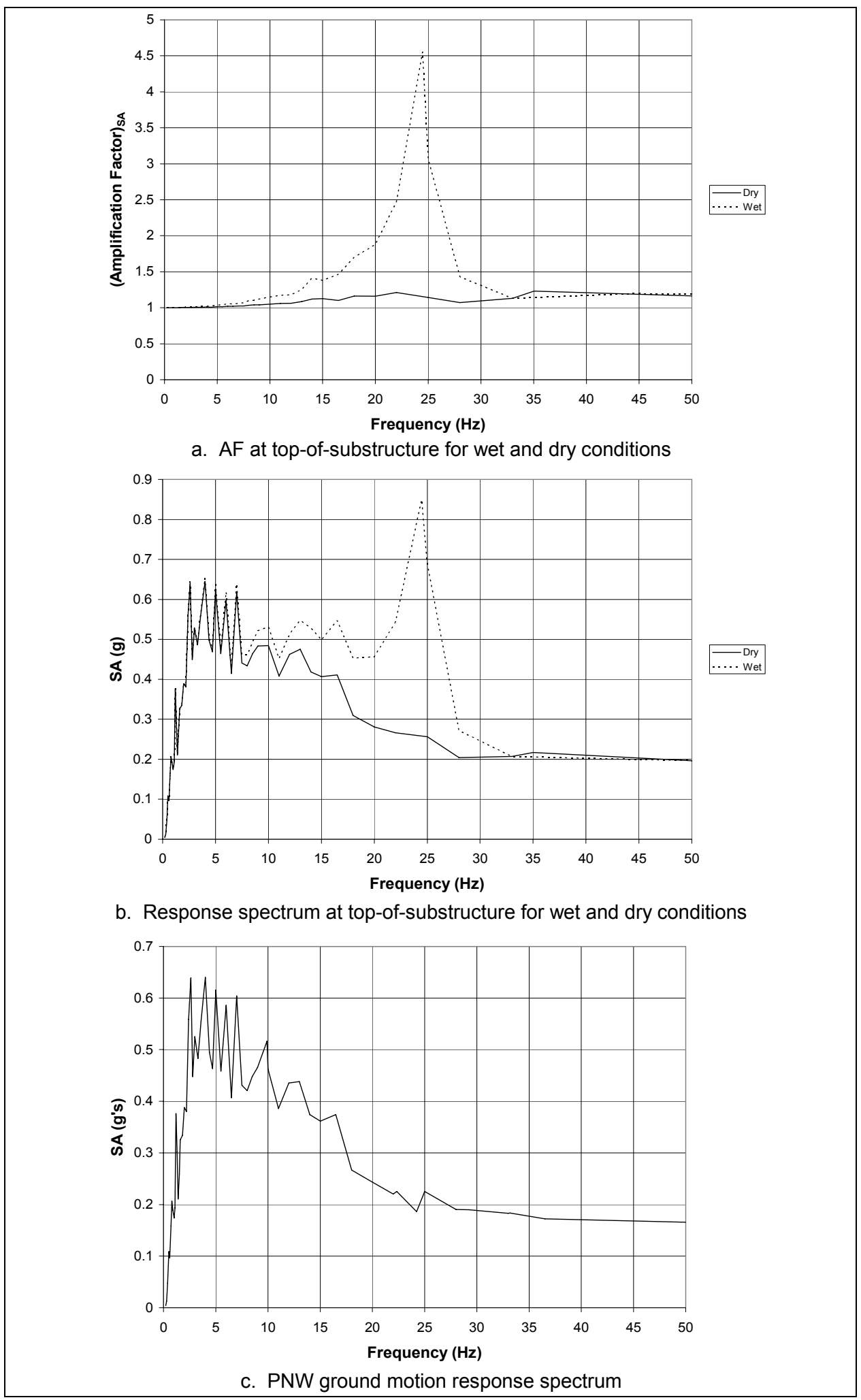

Figure F-9. Response spectra and AF curves, generator bay, composite model, 40-ft height (Dry Model ID: 8S9GeD40C5, Wet Model ID: $859 \mathrm{GeW} 40 \mathrm{C5}$ ), for PNW ground motion with 2 percent damping 


\begin{tabular}{|c|c|c|c|c|c|}
\hline \multicolumn{6}{|c|}{$\begin{array}{l}\text { Table F-2 } \\
\text { SA at Frequency of } 50 \mathrm{~Hz} \text { for Generator Bay Composite Models for } \\
2 \text { Percent Damping, Dry Condition }\end{array}$} \\
\hline \multirow[b]{2}{*}{ Model ID } & \multirow[b]{2}{*}{$\begin{array}{l}\text { Height } \\
\mathrm{ft}\end{array}$} & \multicolumn{2}{|c|}{ CEUS } & \multicolumn{2}{|c|}{ PNW } \\
\hline & & $\begin{array}{l}\mathrm{SA}_{50 \mathrm{~Hz}} \\
\mathrm{~g}\end{array}$ & $\begin{array}{l}\mathrm{SA}_{50 \mathrm{~Hz}} / \mathrm{PGA} \\
\mathrm{g}\end{array}$ & $\begin{array}{l}\mathrm{SA}_{50 \mathrm{~Hz}} \\
\mathrm{~g}\end{array}$ & $\begin{array}{l}\mathrm{SA}_{50 \mathrm{~Hz}} / \mathrm{PGA} \\
\mathrm{g}\end{array}$ \\
\hline 25S9GeD125C5 & 125 & 0.62 & (3.26 & 0.44 & 2.75 \\
\hline 50S9GeD100C5 & 100 & 0.51 & 2.68 & 0.30 & 1.88 \\
\hline 35S9GeD70C5 & 70 & 0.4 & 2.11 & 0.23 & 1.44 \\
\hline 8S9GeD40C5 & 40 & 0.3 & 1.58 & 0.18 & 1.13 \\
\hline
\end{tabular}

\begin{tabular}{|c|c|c|c|c|c|}
\hline \multicolumn{6}{|c|}{$\begin{array}{l}\text { Table F-3 } \\
\text { SA at Frequency of } 50 \mathrm{~Hz} \text { for Generator Bay Composite Models for } \\
2 \text { Percent Damping, Wet Condition }\end{array}$} \\
\hline \multirow[b]{2}{*}{ Model ID } & \multirow[b]{2}{*}{$\begin{array}{l}\text { Height } \\
\mathrm{ft}\end{array}$} & \multicolumn{2}{|c|}{ CEUS } & \multicolumn{2}{|c|}{ PNW } \\
\hline & & $\begin{array}{l}\mathbf{S A}_{50 \mathrm{~Hz}} \\
\mathrm{~g}\end{array}$ & $\begin{array}{l}\mathrm{SA}_{50 \mathrm{~Hz}} / \mathrm{PGA} \\
\mathrm{g}\end{array}$ & $\begin{array}{l}\mathrm{SA}_{50 \mathrm{~Hz}} \\
\mathrm{~g}\end{array}$ & $\begin{array}{l}\mathrm{SA}_{50 \mathrm{~Hz}} / \mathrm{PGA} \\
\mathrm{g}\end{array}$ \\
\hline 25S9GeW125C5 & 125 & 0.54 & 2.84 & 0.42 & 2.63 \\
\hline $50 S 9 G e W 100 C 5$ & 100 & 0.55 & 2.89 & 0.38 & 2.38 \\
\hline 35S9GeW70C5 & 70 & 0.37 & 1.95 & 0.29 & 1.81 \\
\hline 8S9GeW40C5 & 40 & 0.26 & 1.37 & 0.19 & 1.1875 \\
\hline
\end{tabular}

\section{F.3. Block Model of Idealized Erection/Service Bay Substructure AF Curves for 2 Percent Damping}

The AF curves for the block model with 5 percent damping were shown in Chapter 3. In this section, the AF and response spectrum curves are shown for 2 percent damping. As for 5 percent damping, wet and dry conditions were considered and two earthquakes were used to analyze the idealized models: CEUS ground motion and PNW ground motion. Table F-4 lists the figures for each group and ground motion used in the analysis. The AFs obtained with 2 percent damping were higher than the results with 5 percent damping, as expected. Tables F-5 and F-6 list that SA and PGA ratio for dry and wet conditions, respectively.

\begin{tabular}{||l|l|l|l||}
\hline \hline \multicolumn{4}{|l||}{$\begin{array}{l}\text { Table F-4 } \\
\text { List of Figures for Substructure Block Model AF Curves }\end{array}$} \\
\hline \hline Group & $\begin{array}{l}\text { Height } \\
\mathrm{ft}\end{array}$ & CEUS & PNW \\
\hline \hline 1 & 110 & Figure F-10 & Figure F-14 \\
\hline 2 & 75 & Figure F-11 & Figure F-15 \\
\hline 3 & 45 & Figure F-12 & Figure F-16 \\
\hline 4 & 20 & Figure F-13 & Figure F-17 \\
\hline \hline
\end{tabular}




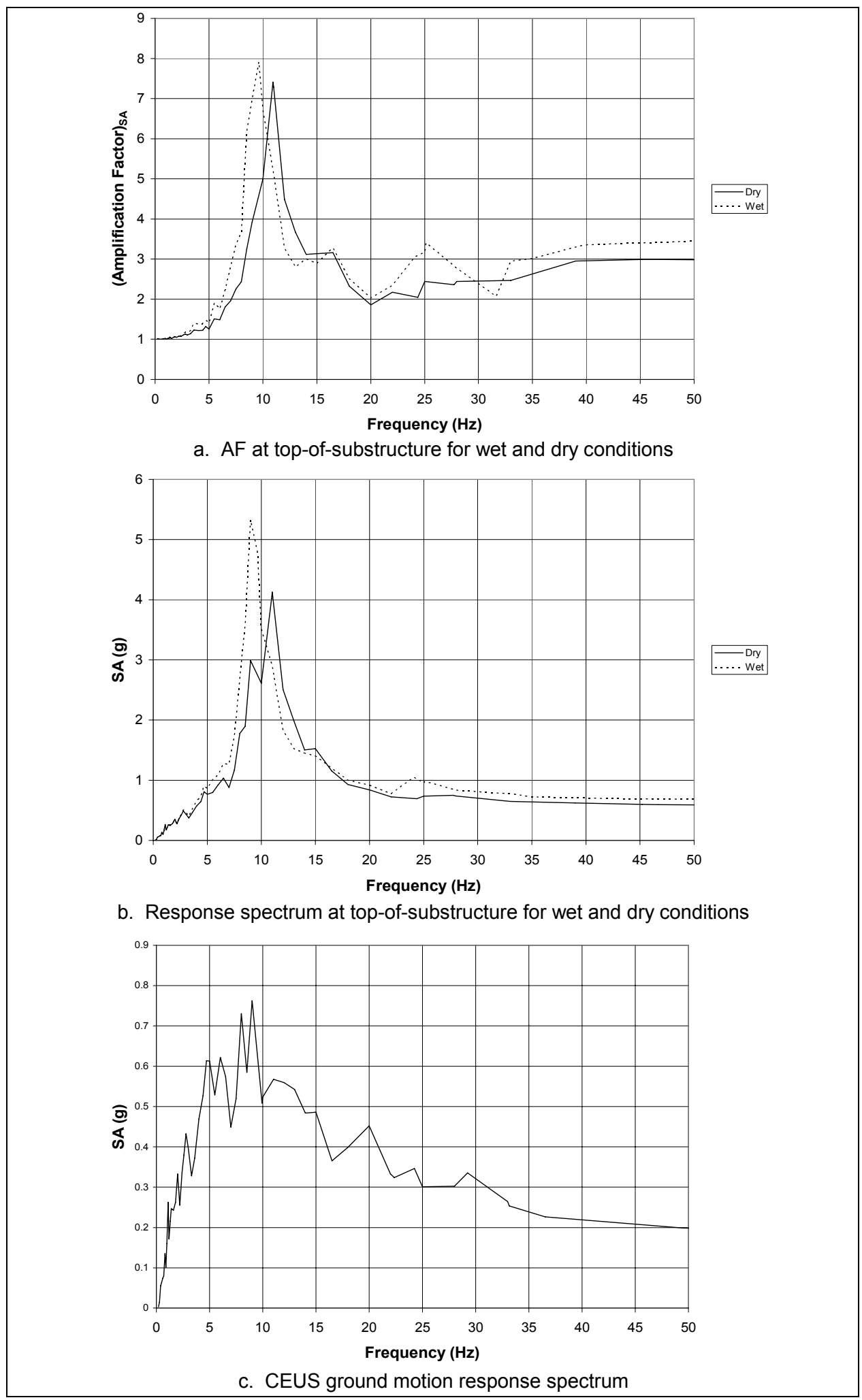

Figure F-10. Response spectra and AF curves, erection/service bay, block model, 110-ft height (Dry Model ID: 16S9ErD110B5, Wet Model ID: 16S9ErW110B5), for CEUS ground motion with 2 percent damping 


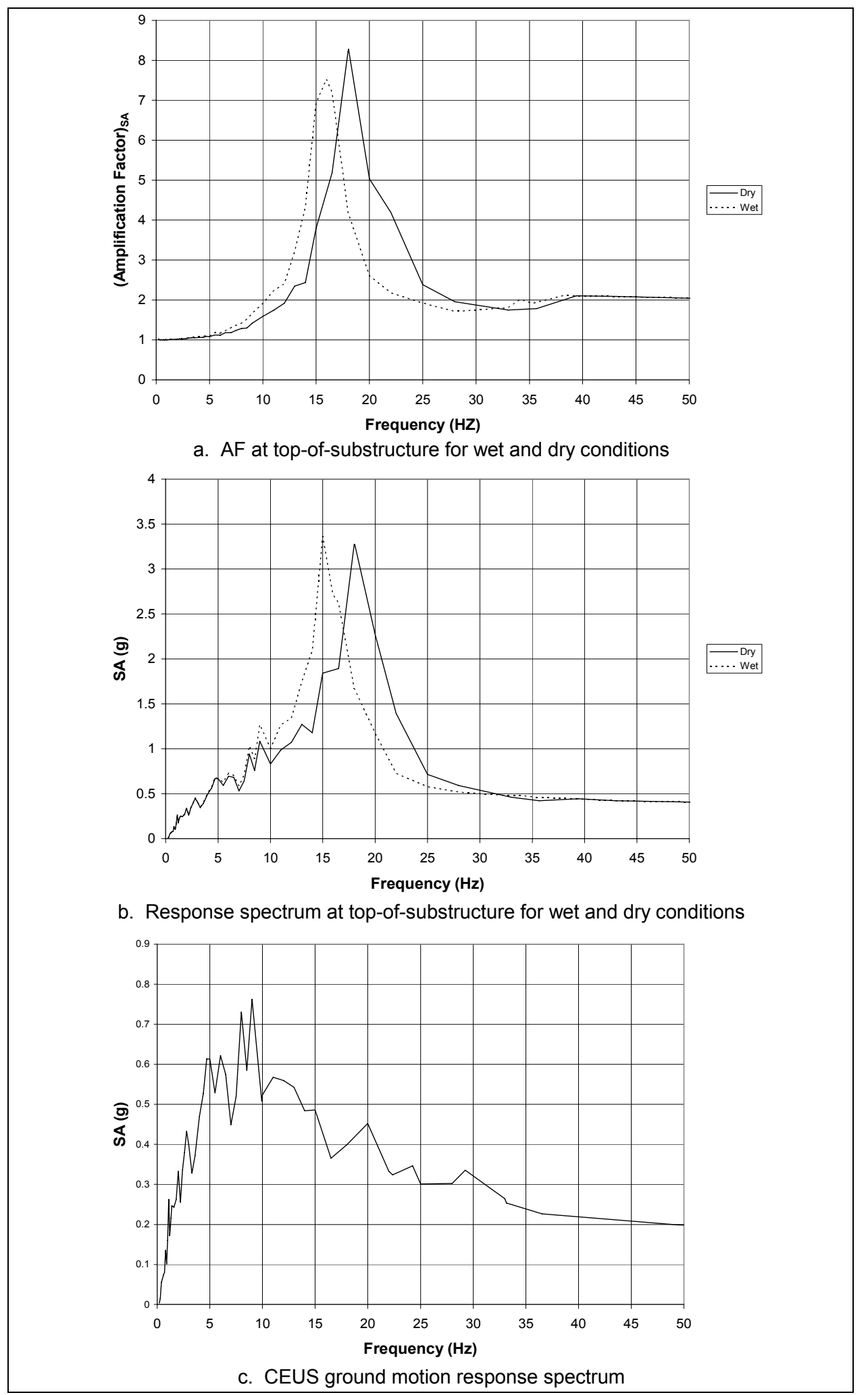

Figure F-11. Response spectra and AF curves, erection/service bay, block model, 75-ft height (Dry Model ID: 16S9ErD75B5, Wet Model ID: 16S9ErW75B5), for CEUS ground motion with 2 percent damping 


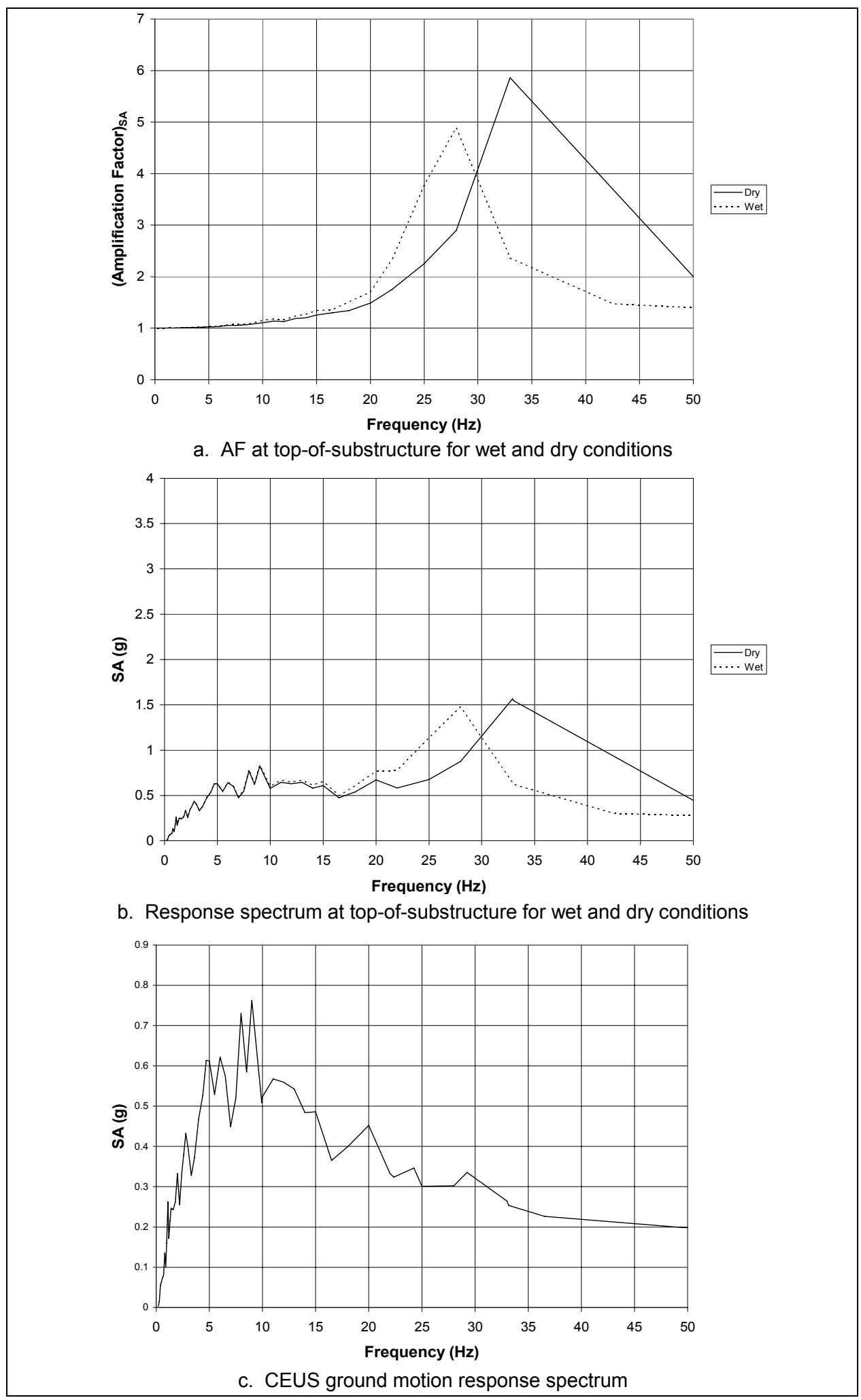

Figure F-12. Response spectra and AF curves, erection/service bay, block model, 45-ft height (Dry Model ID: 16S9ErD45B5, Wet Model ID: 16S9ErW45B5), for CEUS ground motion with 2 percent damping 


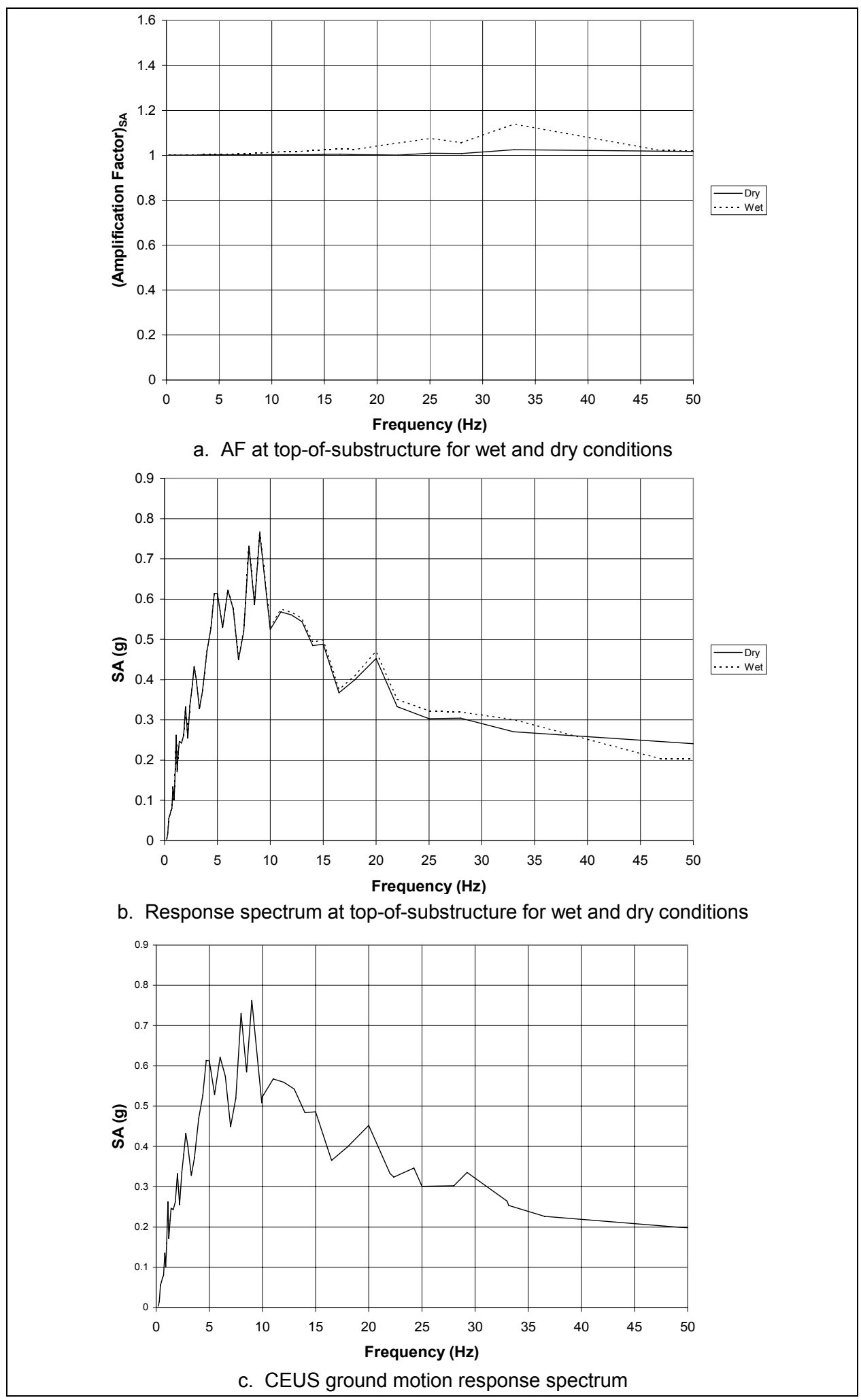

Figure F-13. Response spectra and AF curves, erection/service bay, block model, 20-ft height (Dry Model ID: 8S9ErD20B5, Wet Model ID: 8S9ErW20B5), for CEUS ground motion with 2 percent damping 


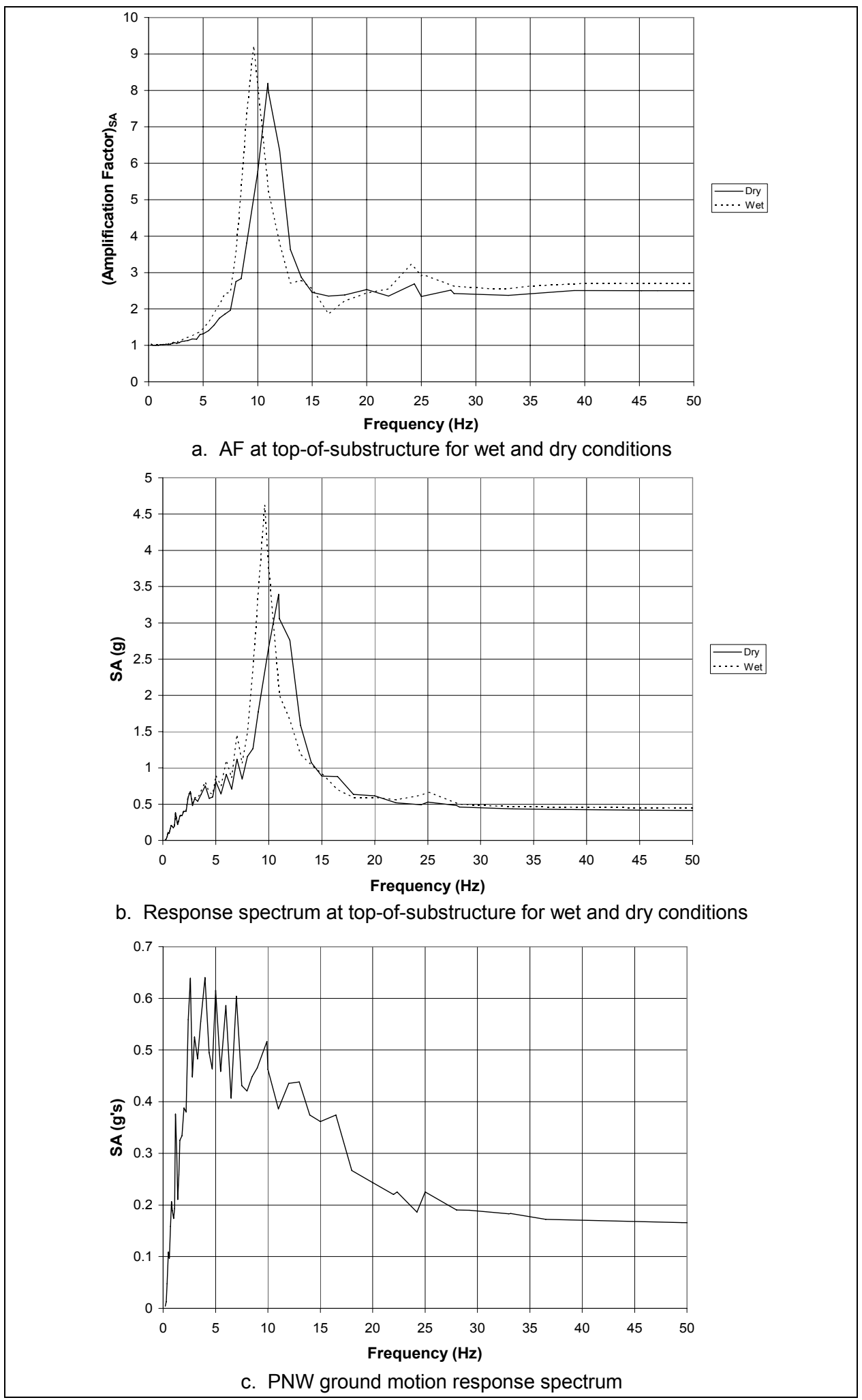

Figure F-14. Response spectra and AF curves, erection/service bay, block model, 110-ft height (Dry Model ID: 16S9ErD110B5, Wet Model ID: 16S9ErW110B5), for PNW ground motion with 2 percent damping 


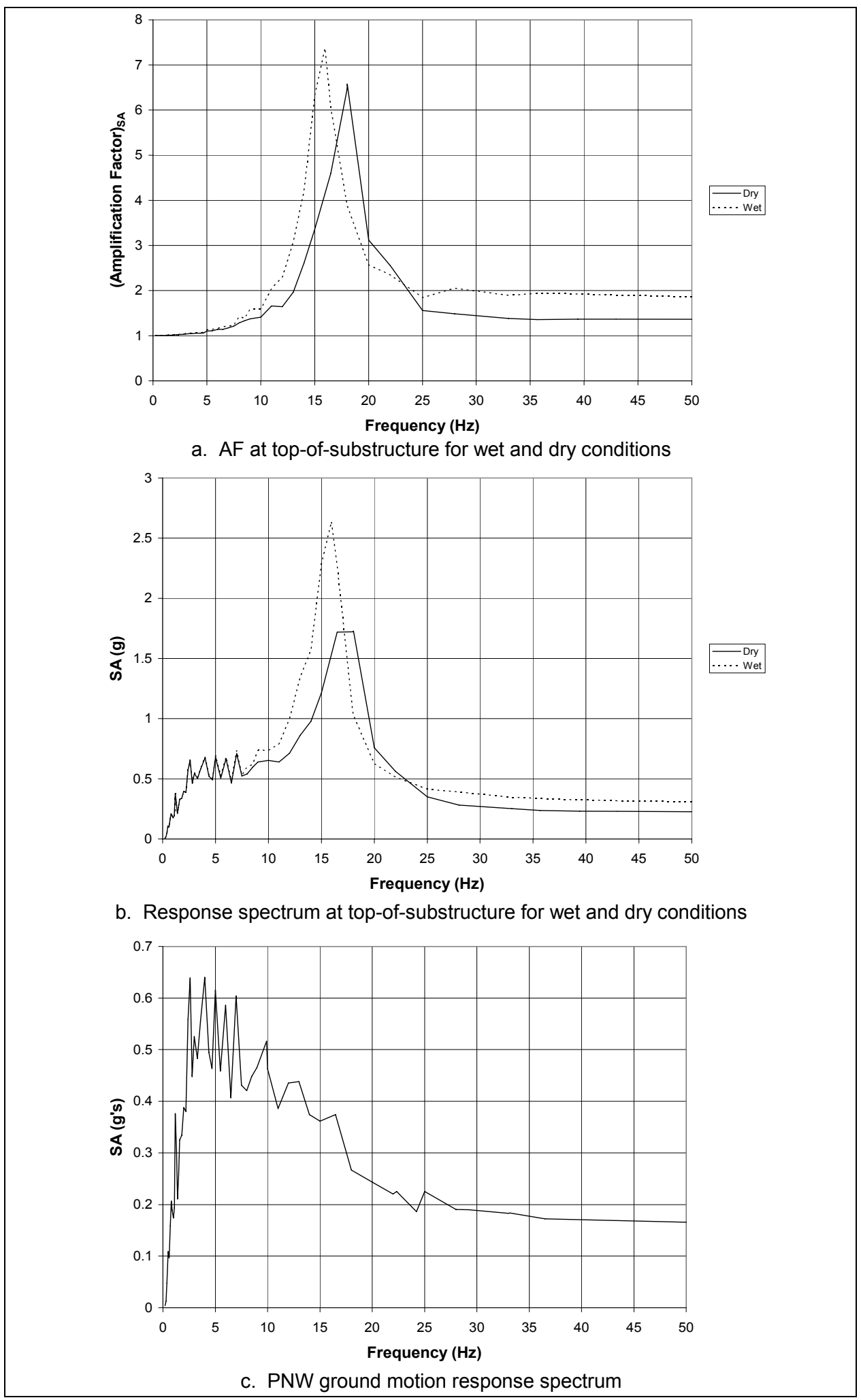

Figure F-15. Response spectra and AF curves, erection/service bay, block model, 75-ft height (Dry Model ID: 16S9ErD75B5, Wet Model ID: 16S9ErW75B5), for PNW ground motion with 2 percent damping 


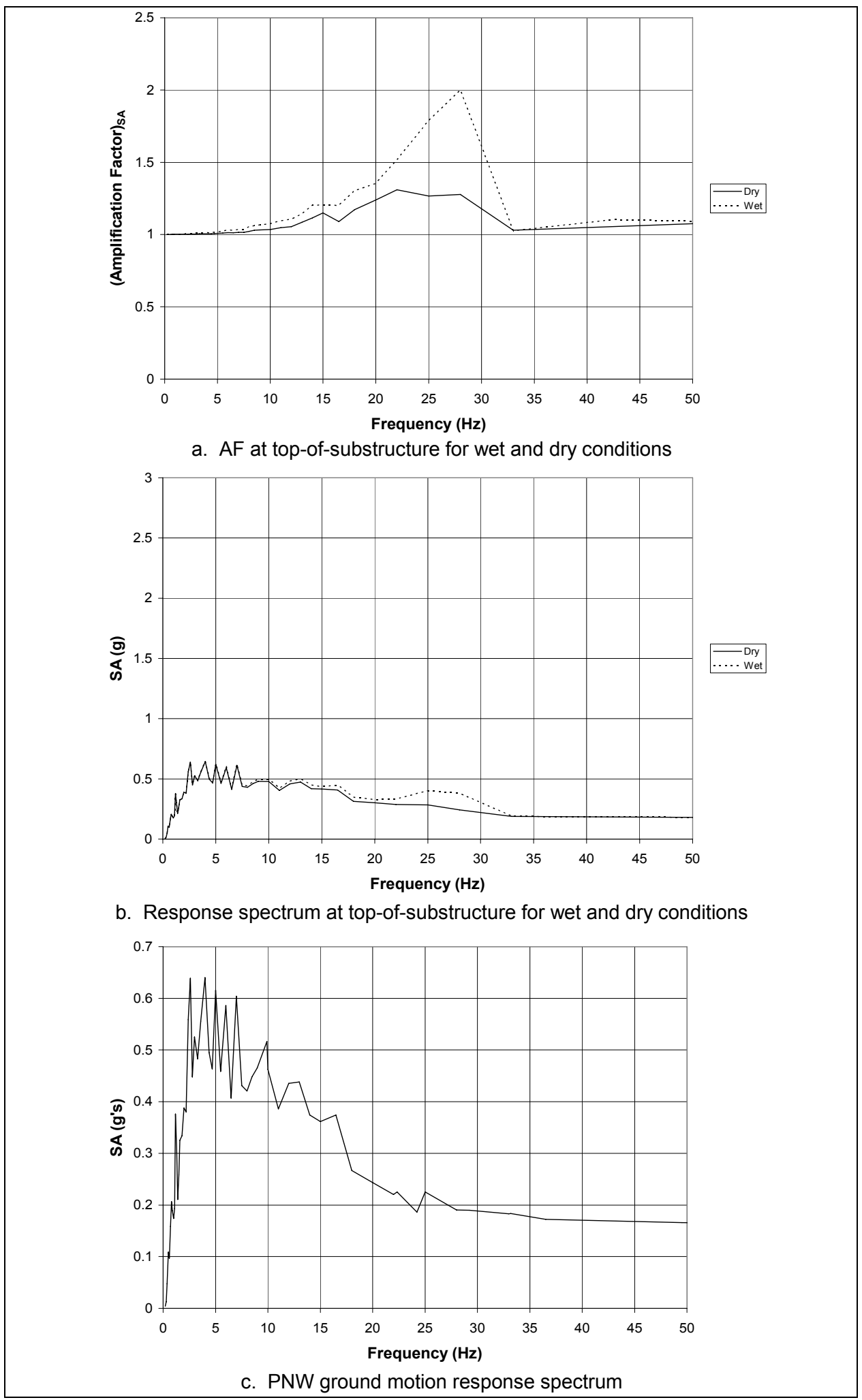

Figure F-16. Response spectra and AF curves, erection/service bay, block model, 45-ft height (Dry Model ID: 16S9ErD45B5, Wet Model ID: 16S9ErW45B5), for PNW ground motion with 2 percent damping 


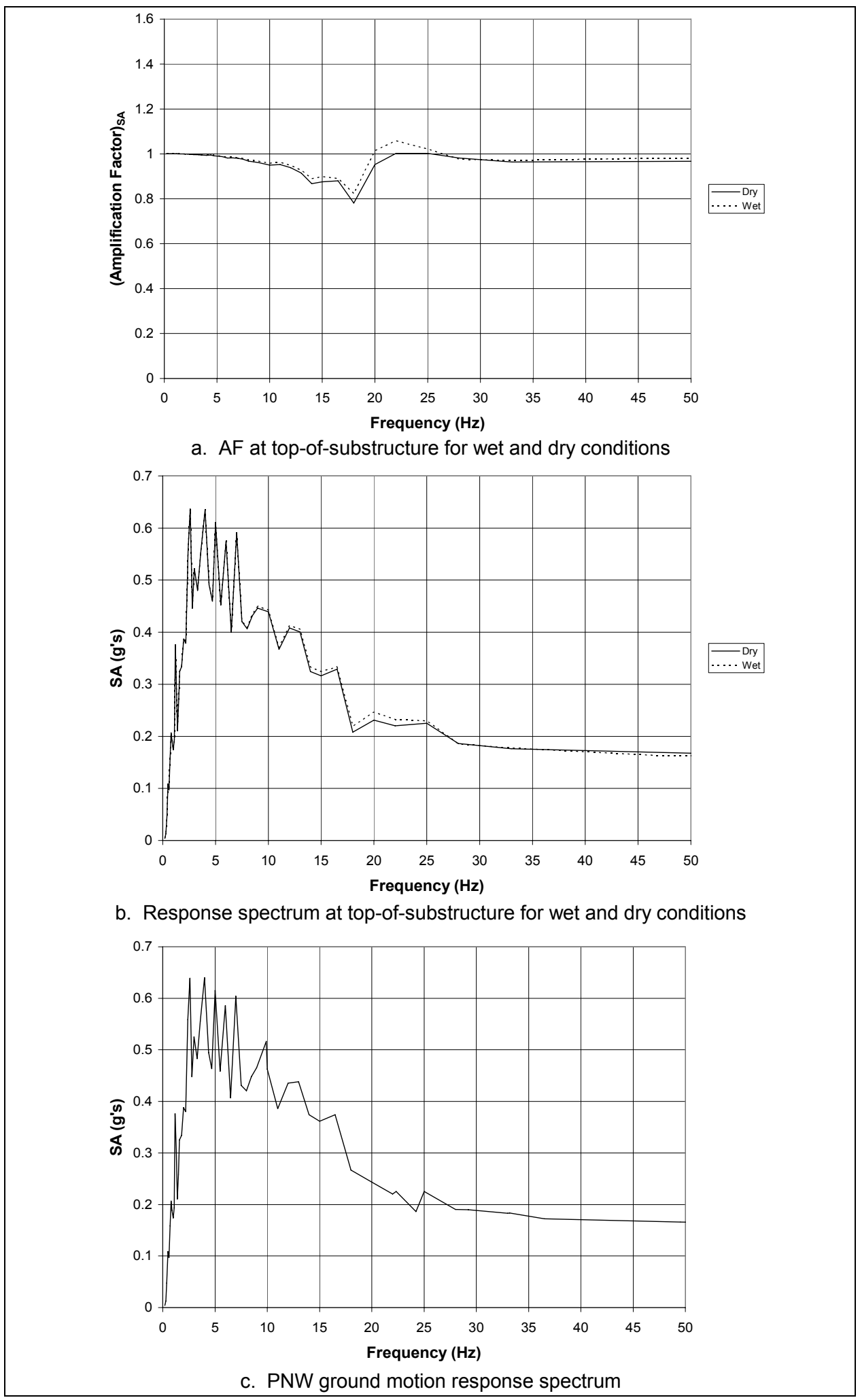

Figure F-17. Response spectra and AF curves, erection/service bay, block model, 20-ft height (Dry Model ID: 8S9ErD20B5, Wet Model ID: 8S9ErW20B5), for PNW ground motion with 2 percent damping 


\begin{tabular}{|c|c|c|c|c|c|}
\hline \multicolumn{6}{|c|}{$\begin{array}{l}\text { Table F-5 } \\
\text { SA at Frequency of } 50 \mathrm{~Hz} \text { for Generator Bay Composite Models for } \\
2 \text { Percent Damping, Dry Condition }\end{array}$} \\
\hline \multirow[b]{2}{*}{ Model ID } & \multirow[b]{2}{*}{$\begin{array}{l}\text { Height } \\
\mathrm{ft}\end{array}$} & \multicolumn{2}{|c|}{$\begin{array}{ll}\text { CEUS } \\
\end{array}$} & \multicolumn{2}{|c|}{ PNW } \\
\hline & & $\begin{array}{l}\mathrm{SA}_{50 \mathrm{~Hz}} \\
\mathrm{~g}\end{array}$ & $\begin{array}{l}\mathrm{SA}_{50 \mathrm{~Hz}} / \mathrm{PGA} \\
\mathrm{g}\end{array}$ & $\begin{array}{l}\mathrm{SA}_{50 \mathrm{~Hz}} \\
\mathrm{~g}\end{array}$ & $\begin{array}{l}\mathrm{SA}_{50 \mathrm{~Hz}} / \mathrm{PGA} \\
\mathrm{g}\end{array}$ \\
\hline 16S9ErD110B5 & 110 & 0.58 & 3.05 & 0.41 & 2.56 \\
\hline 16S9ErD75B5 & 75 & 0.4 & 2.11 & 0.23 & 1.44 \\
\hline 16S9ErD45B5 & 45 & 0.28 & 1.47 & 0.17 & 1.06 \\
\hline 8S9ErD20B5 & 20 & 0.24 & 1.26 & 0.16 & 1.00 \\
\hline
\end{tabular}

\begin{tabular}{|c|c|c|c|c|c|}
\hline \multicolumn{6}{|c|}{$\begin{array}{l}\text { Table F-6 } \\
\text { SA at Frequency of } 50 \mathrm{~Hz} \text { for Generator Bay Composite Models for } \\
2 \text { Percent Damping, Wet Condition }\end{array}$} \\
\hline \multirow[b]{2}{*}{ Model ID } & \multirow[b]{2}{*}{$\begin{array}{l}\text { Height } \\
\mathrm{ft}\end{array}$} & \multicolumn{2}{|c|}{ CEUS } & \multicolumn{2}{|c|}{ PNW } \\
\hline & & $\begin{array}{l}\mathbf{S A}_{50 \mathrm{~Hz}} \\
\mathbf{g}\end{array}$ & $\begin{array}{l}\mathrm{SA}_{50 \mathrm{~Hz}} / \mathrm{PGA} \\
\mathrm{g}\end{array}$ & $\begin{array}{l}\mathbf{S A}_{50 \mathrm{~Hz}} \\
\mathrm{~g}\end{array}$ & $\begin{array}{l}\mathrm{SA}_{50 \mathrm{H}} / \mathrm{PGA} \\
\mathrm{g}\end{array}$ \\
\hline 16S9ErW110B5 & 110 & 0.68 & 3.58 & 0.44 & 2.75 \\
\hline 16S9ErW75B5 & 75 & 0.4 & 2.11 & 0.31 & 1.94 \\
\hline 16S9ErW45B5 & 45 & 0.26 & 1.37 & 0.17 & 1.06 \\
\hline 8S9ErW20B5 & 20 & 0.2 & 1.05 & 0.16 & 1.00 \\
\hline
\end{tabular}

\section{F.4. Block-Frame-Shear Wall Model of Idealized Erection/Service Bay Substructure Amplification Factor Curves for 2 Percent Damping}

In Section F.2, the AF curves were shown for the composite structural model of the generator bay substructure. For the erection/service bay substructure two models were analyzed: block model and block-frame-shear wall model. The AF curves for the block model were shown in the previous section. In this section the $\mathrm{AF}$ and response spectrum curves for 2 percent damping are presented for the block-frame-shear wall model. Table F-7 lists the figures shown in this section for the two ground motions considered in this section. The models were analyzed assuming dry and wet conditions. Tables F-8 and F-9 list the SA and PGA ratios at $50 \mathrm{~Hz}$ for dry and wet conditions, respectively.

\begin{tabular}{|l|l|l|l||}
\hline \hline \multicolumn{4}{||l||}{$\begin{array}{l}\text { Table F-7 } \\
\text { List of Figures for Substructure Block Model AF Curves }\end{array}$} \\
\hline \hline Group & $\begin{array}{l}\text { Height } \\
\mathbf{f t}\end{array}$ & CEUS & PNW \\
\hline \hline 1 & 110 & Figure F-18 & Figure F-22 \\
\hline 2 & 75 & Figure F-19 & Figure F-23 \\
\hline 3 & 45 & Figure F-20 & Figure F-24 \\
\hline 4 & 20 & Figure F-21 & Figure F-25 \\
\hline \hline
\end{tabular}




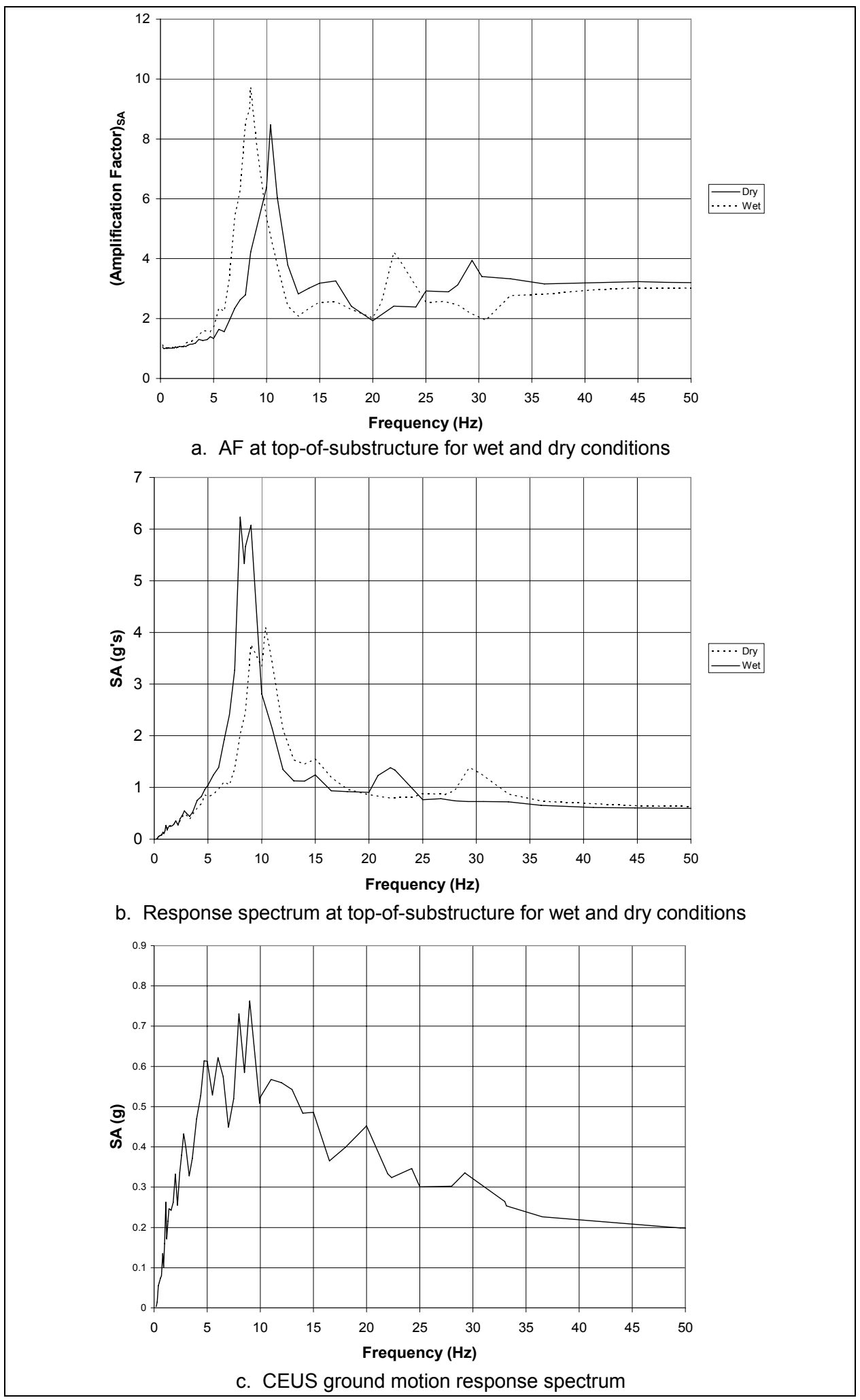

Figure F-18. Response spectra and AF curves, erection/service bay, block-frameshear wall model, 110-ft height (Dry Model ID: 14S9ErD110FW5, Wet Model ID: 14S9ErW110FW5), for CEUS ground motion with 2 percent damping 


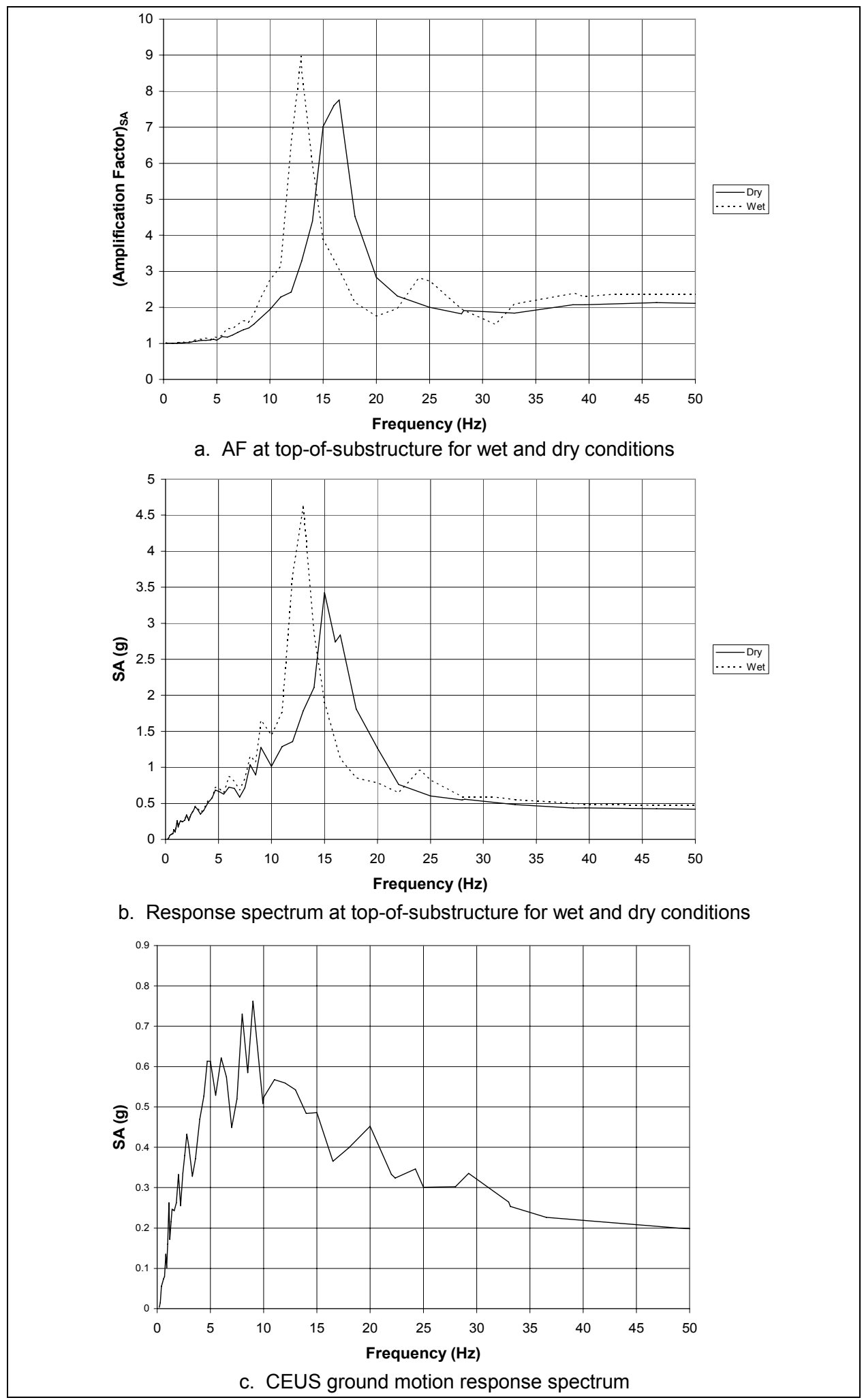

Figure F-19. Response spectra and AF curves, erection/service bay, block-frameshear wall model, 75-ft height (Dry Model ID: 20S9ErD75FW5, Wet Model ID: 20S9ErW75FW5), for CEUS ground motion with 2 percent damping 


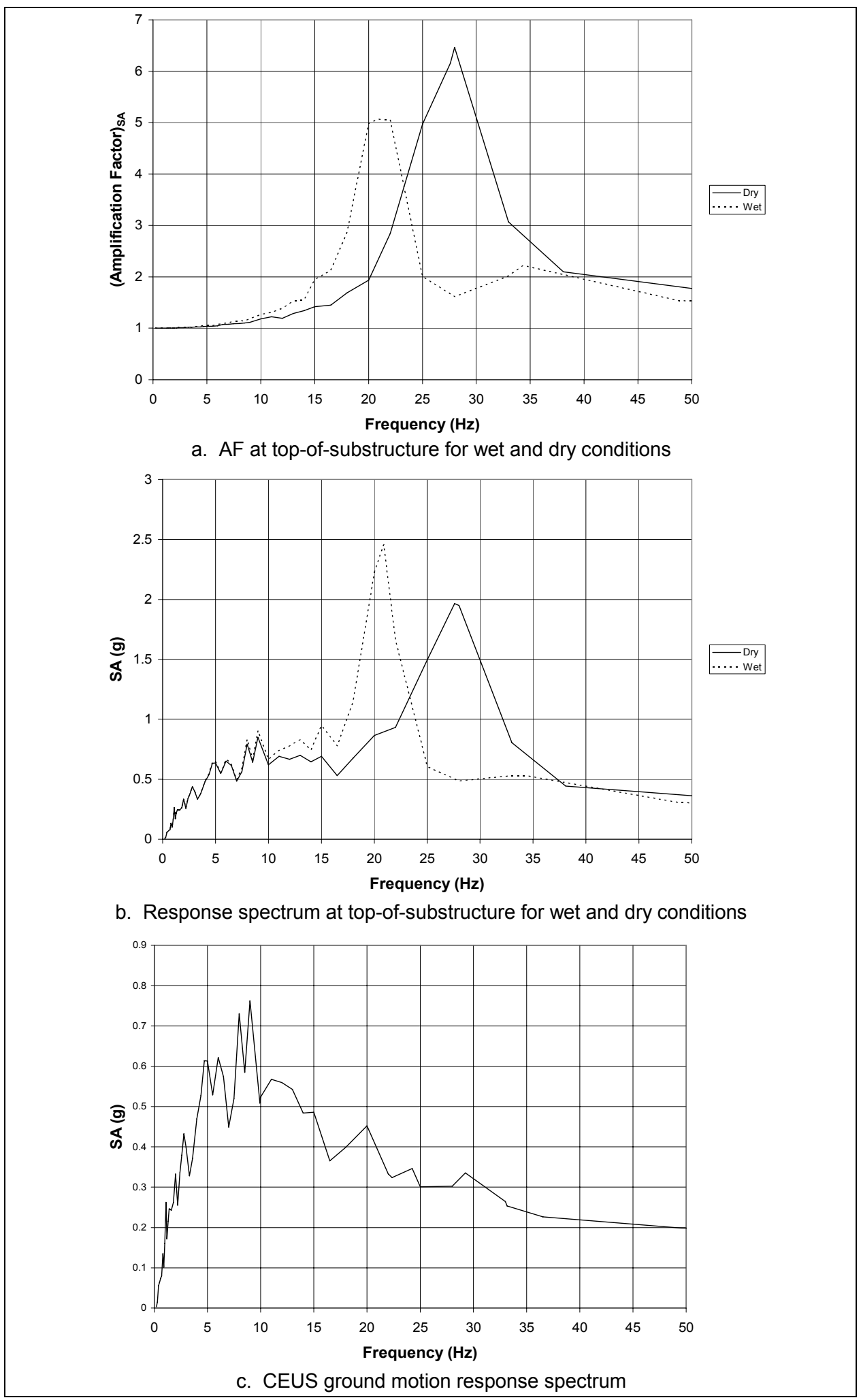

Figure F-20. Response spectra and AF curves, erection/service bay, block-frameshear wall model, 45-ft height (Dry Model ID: 12S9ErD45FW5, Wet Model ID: 12S9ErW45FW5), for CEUS ground motion with 2 percent damping 


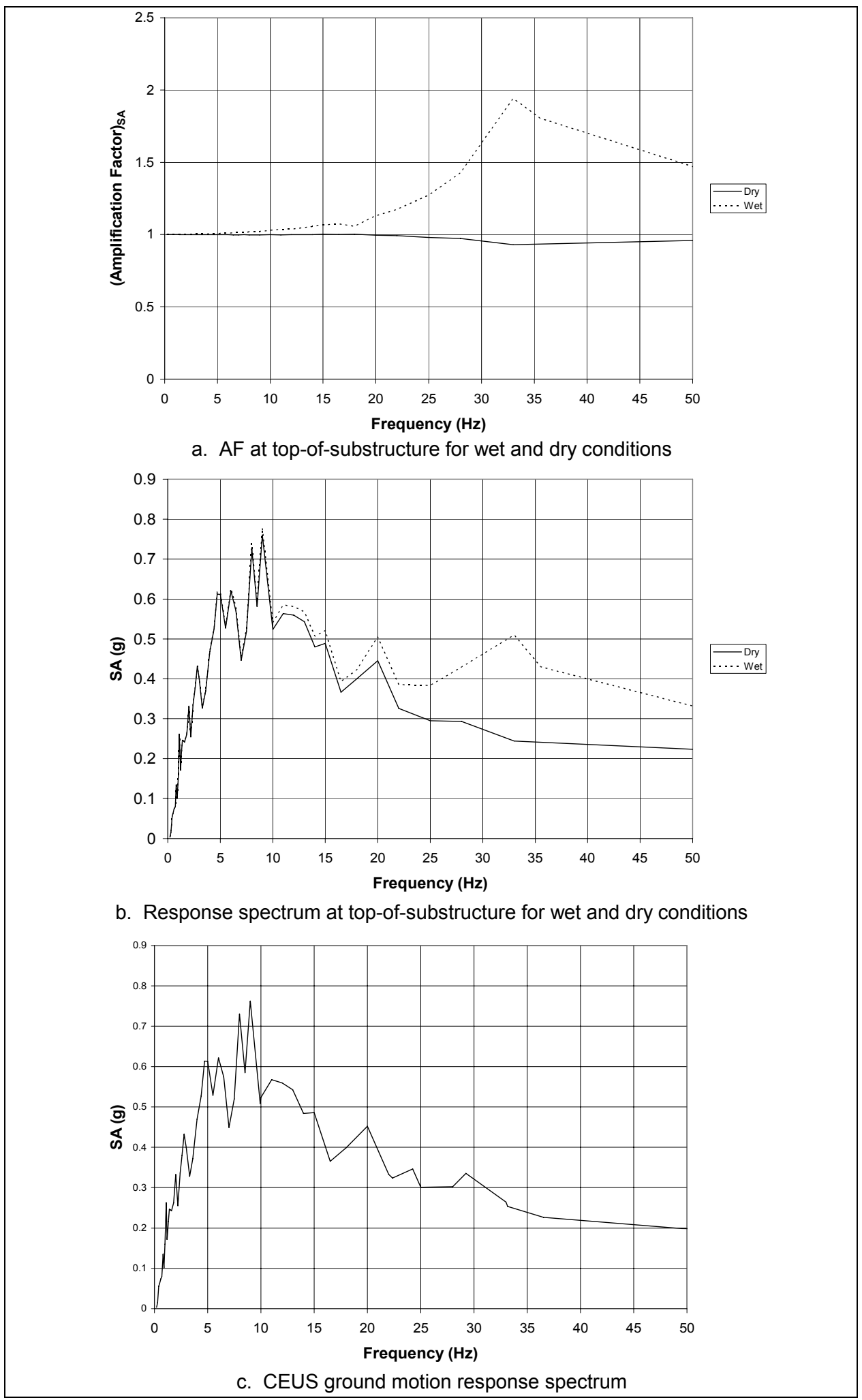

Figure F-21. Response spectra and AF curves, erection/service bay, block-frameshear wall model, 20-ft height (Dry Model ID: 8S9ErD20FW5, Wet Model ID: 8S9ErW20FW5), for CEUS ground motion with 2 percent damping 


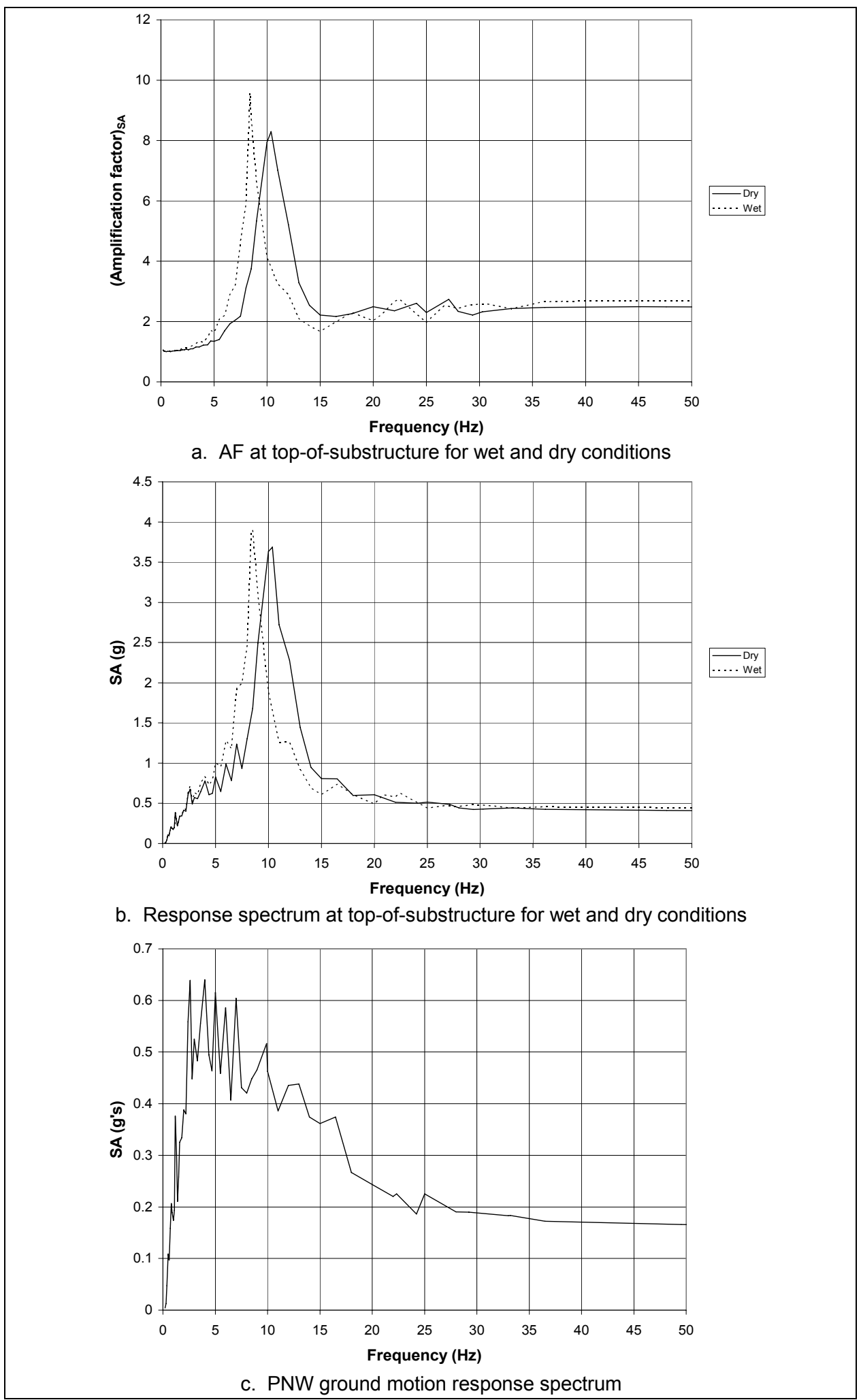

Figure F-22. Response spectra and AF curves, erection/service bay, block-frameshear wall model, 110-ft height (Dry Model ID: 14S9ErD110FW5, Wet Model ID: 14S9ErW110FW5), for PNW ground motion with 2 percent damping 


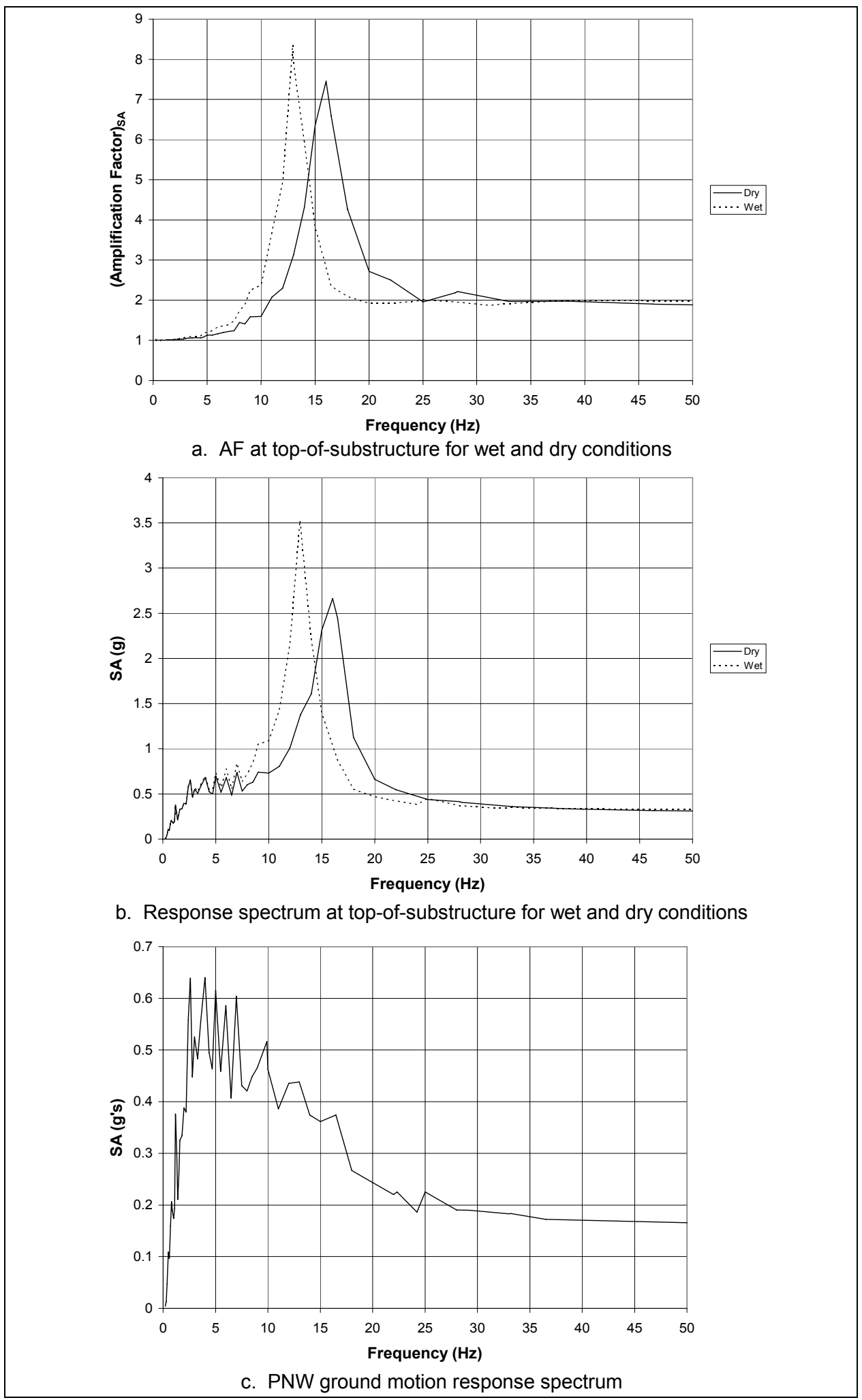

Figure F-23. Response spectra and AF curves, erection/service bay, block-frameshear wall model, 75-ft height (Dry Model ID: 20S9ErD75FW5, Wet Model ID: 20S9ErW75FW5), for PNW ground motion with 2 percent damping 


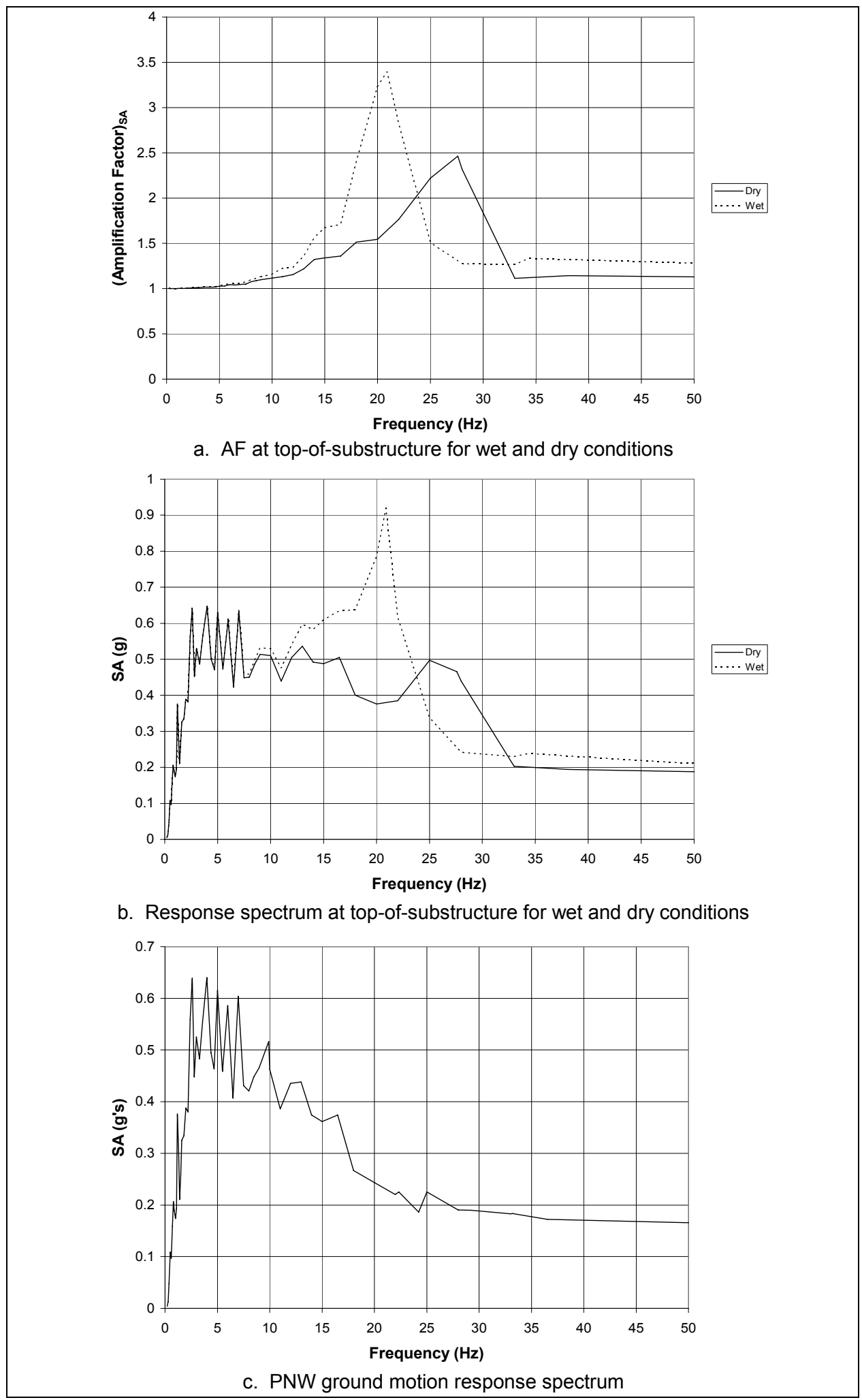

Figure F-24. Response spectra and AF curves, erection/service bay, block-frameshear wall model, 45-ft height (Dry Model ID: 12S9ErD45FW5, Wet Model ID: 12S9ErW45FW5), for PNW ground motion with 2 percent damping 


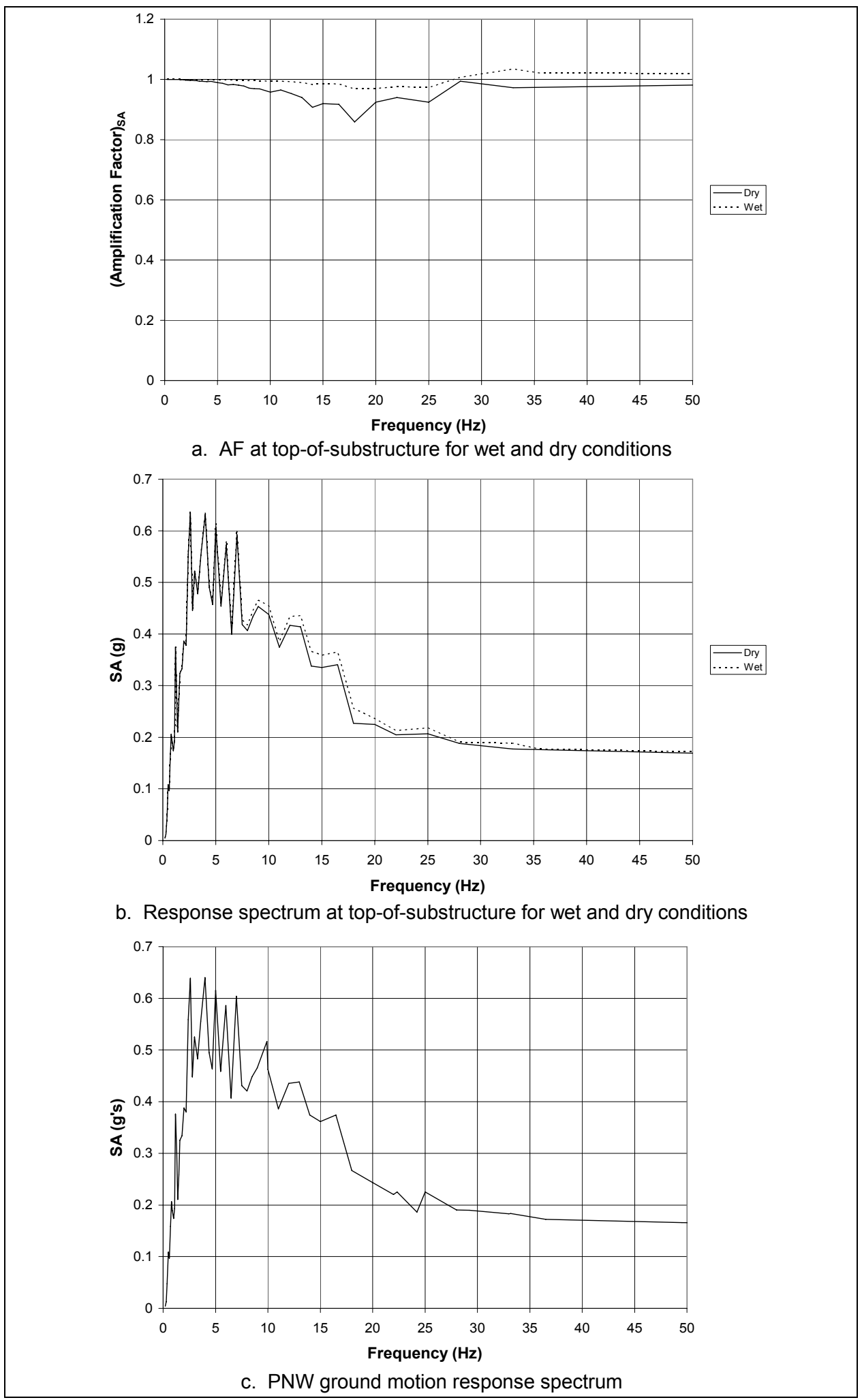

Figure F-25. Response spectra and AF curves, erection/service bay, block-frameshear wall model, 20-ft height (Dry Model ID: 8S9ErD20FW5, Wet Model ID: 8S9ErW20FW5), for PNW ground motion with 2 percent damping 


\begin{tabular}{|c|c|c|c|c|c|}
\hline \multicolumn{6}{|c|}{$\begin{array}{l}\text { Table F-8 } \\
\text { SA at Frequency of } 50 \mathrm{~Hz} \text { for Generator Bay Composite Models for } \\
2 \text { Percent Damping, Dry Condition }\end{array}$} \\
\hline \multirow[b]{2}{*}{ Model ID } & \multirow[b]{2}{*}{$\begin{array}{l}\text { Height } \\
\mathrm{ft}\end{array}$} & \multicolumn{2}{|c|}{ CEUS } & \multicolumn{2}{|c|}{$\begin{array}{ll}\text { PNW } \\
\end{array}$} \\
\hline & & $\begin{array}{l}\mathrm{SA}_{50 \mathrm{~Hz}} \\
\mathrm{~g}\end{array}$ & $\begin{array}{l}\mathrm{SA}_{50 \mathrm{~Hz}} / \mathrm{PGA} \\
\mathrm{g}\end{array}$ & $\begin{array}{l}\mathrm{SA}_{50 \mathrm{~Hz}} \\
\mathrm{~g}\end{array}$ & $\begin{array}{l}\mathrm{SA}_{50 \mathrm{~Hz}} / \mathrm{PGA} \\
\mathrm{g}\end{array}$ \\
\hline 14S9ErD110FW5 & 110 & 0.63 & 3.32 & 0.41 & 2.56 \\
\hline 20S9ErD75FW5 & 75 & 0.41 & 2.16 & 0.31 & 1.94 \\
\hline 12S9ErD45FW5 & 45 & 0.36 & 1.89 & 0.18 & 1.13 \\
\hline 8S9ErD20FW5 & 20 & 0.22 & 1.16 & 0.17 & 1.0625 \\
\hline
\end{tabular}

\section{Table F-9}

SA at Frequency of $50 \mathrm{~Hz}$ for Generator Bay Composite Models for 2 Percent Damping, Wet Condition

\begin{tabular}{|c|c|c|c|c|c|}
\hline \multirow[b]{2}{*}{ Model ID } & \multirow[b]{2}{*}{$\begin{array}{l}\text { Height } \\
\mathrm{ft}\end{array}$} & \multicolumn{2}{|c|}{ CEUS } & \multicolumn{2}{|c|}{ PNW } \\
\hline & & $\begin{array}{l}\mathrm{SA}_{50 \mathrm{~Hz}} \\
\mathbf{g}\end{array}$ & $\begin{array}{l}\mathrm{SA}_{50 \mathrm{~Hz}} / \mathrm{PGA} \\
\mathrm{g}\end{array}$ & $\begin{array}{l}\mathrm{SA}_{50 \mathrm{~Hz}} \\
\mathrm{~g}\end{array}$ & $\begin{array}{l}\mathrm{SA}_{50 \mathrm{~Hz}} / \mathrm{PGA} \\
\mathrm{g}\end{array}$ \\
\hline 14S9ErW110FW5 & 110 & 0.6 & 3.16 & 0.44 & 2.75 \\
\hline 20S9ErW75FW5 & 75 & 0.47 & 2.47 & 0.32 & 2.00 \\
\hline 12S9ErW45FW5 & 45 & 0.3 & 1.58 & 0.21 & 1.31 \\
\hline 8S9ErD20FW5 & 20 & 0.33 & 1.74 & 0.17 & 1.0625 \\
\hline
\end{tabular}




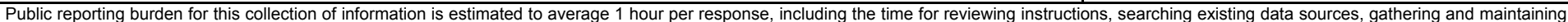

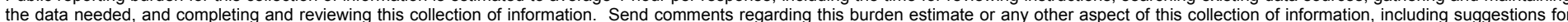

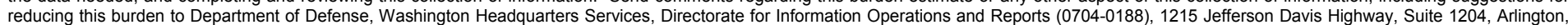

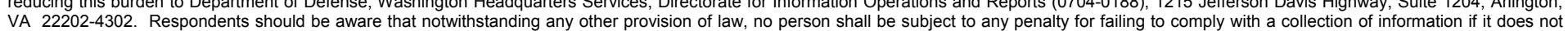
VA 22202-4302. Respondents should be aware that notwithstanding any other provision of law, no person shall be sube
display a currently valid OMB control number. PLEASE DO NOT RETURN YOUR FORM TO THE ABOVE ADDRESS.

\begin{tabular}{l|c}
$\begin{array}{l}\text { 1. REPORT DATE }(D D-M M-Y Y Y Y) \\
\text { June } 2006\end{array}$ & $\begin{array}{c}\text { 2. REPORT TYPE } \\
\text { Final report }\end{array}$ \\
\hline
\end{tabular}

\section{TITLE AND SUBTITLE}

Response Amplification of Idealized Powerhouse Substructures to Earthquake Ground Motions

3. DATES COVERED (From - To)

5a. CONTRACT NUMBER

5b. GRANT NUMBER

5c. PROGRAM ELEMENT NUMBER

5d. PROJECT NUMBER

5e. TASK NUMBER

5f. WORK UNIT NUMBER

8. PERFORMING ORGANIZATION REPORT NUMBER

U.S. Army Engineer Research and Development Center

Information Technology Laboratory and Geotechnical and Structures Laboratory

3909 Halls Ferry Road, Vicksburg, MS 39180-6199;

ERDC TR-06-3

CMA Architects and Engineers, LLP

1509 F.D. Roosevelt Avenue, Guaynabo, Puerto Rico 00968

\section{SPONSORING / MONITORING AGENCY NAME(S) AND ADDRESS(ES)}

U.S. Army Corps of Engineers

Washington, DC 20314-1000
10. SPONSOR/MONITOR'S ACRONYM(S)

11. SPONSOR/MONITOR'S REPORT NUMBER(S)

\section{DISTRIBUTION / AVAILABILITY STATEMENT}

Approved for public release; distribution is unlimited.

\section{SUPPLEMENTARY NOTES}

\section{ABSTRACT}

This report summarizes an investigation of the seismic response of Corps powerhouse structures. Research results include (1) the characterization and organization of the range in geometry of Corps powerhouse substructures for generator bays and service/erection bays; (2) development of representative, idealized substructure geometries for these types of structures; (3) construction of a series of finite element models of the substructures and subjecting these substructures to earthquake acceleration time-histories representing central/eastern United States ground motions and ground motions of the Pacific Northwest of the United States; (4) development of a database of first-mode periods of the typical powerhouse substructures; (5) computation of top-of-substructure acceleration timehistories and conversion of these time-histories into response spectra; (6) development of amplification factor curves (as a function of frequency) that quantify the magnitude of the amplification of ground shaking by the substructures; (7) development of a methodology for performing a simplified seismic analysis of the superstructure (or of the equipment on top of the substructure) that takes into account, in an approximate sense, the effect of the substructure on the response of the superstructures in the decoupled seismic structural analysis.

\section{SUBJECT TERMS}

Decoupled dynamic analysis

Powerhouses

Ground motions

16. SECURITY CLASSIFICATION OF:

\begin{tabular}{|l|l|}
\hline $\begin{array}{l}\text { a. REPORT } \\
\text { UNCLASSIFIED }\end{array}$ & $\begin{array}{l}\text { b. ABSTRACT } \\
\text { UNCLASSIFIED }\end{array}$ \\
\hline
\end{tabular}

Response spectrum

c. THIS PAGE
UNCLASSIFIED

Seismic amplification

Time-history analysis

\begin{tabular}{c|l}
$\begin{array}{c}\text { 18. NUMBER } \\
\text { OF PAGES }\end{array}$ & $\begin{array}{l}\text { 19a. NAME OF RESPONSIBLE } \\
\text { PERSON }\end{array}$ \\
\cline { 2 - 2 } 201 & $\begin{array}{l}\text { 19b. TELEPHONE NUMBER (include } \\
\text { area code) }\end{array}$ \\
&
\end{tabular}

